UNIVERSIDADE DE SÃO PAULO

ESCOLA DE EDUCAÇÃO FÍSICA E ESPORTE

\title{
EFEITO DA DISPONIBILIDADE DE CARBOIDRATO SOBRE RESPOSTAS PERCEPTIVAS E FISIOLÓGICAS EM EXERCÍCIOS DE ALTA INTENSIDADE
}

Adriano Eduardo Lima da Silva

\author{
SÃO PAULO
}

2009 


\title{
EFEITO DA DISPONIBILIDADE DE CARBOIDRATO SOBRE RESPOSTAS PERCEPTIVAS E FISIOLÓGICAS EM EXERCÍCIOS DE ALTA INTENSIDADE
}

\author{
ADRIANO EDUARDO LIMA DA SILVA
}

Tese apresentada à Escola de Educação Física e Esporte da Universidade de São Paulo, como requisito parcial para obtenção do grau de Doutor em Educação Física. 


\section{AGRADECIMENTOS}

Ao término desse trabalho, me lembro das pessoas que me ajudaram e contribuíram para o meu crescimento pessoal e profissional. Aqui, fica meu agradecimento para cada um que, de uma forma ou de outra, doou parte do seu tempo na minha formação. Em especial:

A José Eduardo da Silva e Maria Santina Lima da Silva, meu pais, que não mediram esforços na minha formação e, o mais importante, me serviram de exemplo do que é viver decentemente.

Ao meu irmão Alessandro E. Lima Silva, que além de me ensinar muitas coisas da vida, me ajudou imensamente com as tarefas burocráticas da tese.

A Najoua Adriana Salomão, que pacientemente e com muito carinho suportou todas as viagens, finais de semanas "perdidos" e o mau humor derivado dos momentos mais críticos desse trabalho.

A minha orientadora, professora Maria Augusta Peduti Dal Molin Kiss por ter me dado a liberdade necessária para a construção desse trabalho. Aprendi muito nesses anos que convivi ao seu lado.

Aos amigos do laboratório, bar e bilhar, Flávio Pires e Rômulo Bertuzzi, pela parceria leal, discussões acadêmicas acirradas e, principalmente, pelas risadas e piadas mesmo nos momentos mais difíceis.

Aos demais amigos do laboratório, Nilo Okuno e Eduardo Rumenig, que apesar de ter convivido pouco tempo com eles, aprendi muito.

Aos eternos professores Fernando Oliveira e João Fernando Gagliardi, que me ensinaram a dar os primeiros passos na profissão e, o mais importante, sempre serviram de referência na minha trajetória acadêmica.

A Fábio Lira e Nelo Zanchi pelo auxilio nas dosagens de pH, insulina e cortisol. As professoras Marie Doki Nogueira e Dulce Elena Casarini pelo auxilio nas dosagens de catecolaminas. Ao Instituto Veterinário de Imagem (IVI) pela dosagem de potássio 
plasmático. Ao professor Carlos Ugrinowitsch pelo empréstimo do analisador de gases. Aos professores Antonio Herbert Lancha Júnior e Patrícia Chakur Brum por disponibilizar seus laboratórios durante a coleta de dados.

A todos os sujeitos que fizeram parte da amostra do estudo, pois sem eles não teria sido possível a conclusão desse estudo.

Tese dedicada a

Valdeci Eduardo da Silva (em memória). 
Mesmo quando tudo pede Um pouco mais de calma Até quando o corpo pede Um pouco mais de alma A vida não pára...

Enquanto o tempo Acelera e pede pressa Eu me recuso faço hora Vou na valsa A vida é tão rara...

Enquanto todo mundo Espera a cura do mal E a loucura finge Que isso tudo é normal Eu finjo ter paciência...

O mundo vai girando Cada vez mais veloz A gente espera do mundo

E o mundo espera de nós Um pouco mais de paciência...

Será que é tempo Que lhe falta prá perceber? Será que temos esse tempo Prá perder?

E quem quer saber? A vida é tão rara Tão rara...

Lenine e Dudu Falcão 
SUMÁRIO

Página

LISTA DE TABELAS................................................................... iv

LISTA DE FIGURAS......................................................................... vii

LISTA DE SIGLAS, ABREVIAÇÕES E SÍMBOLOS............................. viii

LISTA DE ANEXOS......................................................................... ix

LISTA DE APÊNDICES................................................................. xii

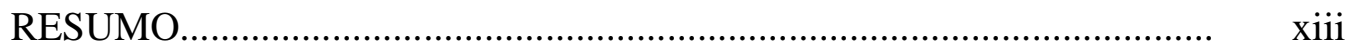

ABSTRACT ....................................................................................... xiv

$1 \quad$ INTRODUÇÃO

2. OBJETIVO

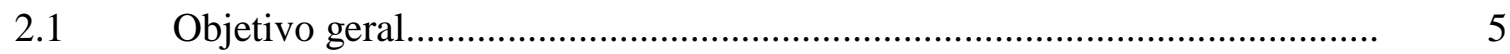

$2.2 \quad$ Objetivos específicos........................................................................... 5

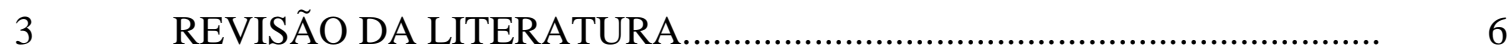

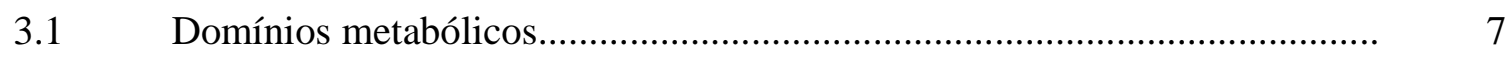

3.2 Metabolismo dos carboidratos................................................................. 12

3.2.1 Efeito da insulina e do exercício no transporte celular de glicose..... 18

3.2.2 Estrutura funcional do glicogênio muscular...................................... 19

3.2.3 Efeito da intensidade do esforço no metabolismo de glicogênio muscular e alterações bioquímicas intracelulares........................................ 23

3.2.4 Metabolismo do glicogênio hepático................................................. 26

3.3 Mecanismos de fadiga durante o exercício................................................. 30

3.3.1 Possíveis sítios de fadiga................................................................ 31

3.3.2 Modelo integrativo-complexo de fadiga............................................. 42 
3.4 Percepção Subjetiva de Esforço...................................................................... 46

$4 \quad$ MATERIAIS E MÉTODOS................................................................ 49

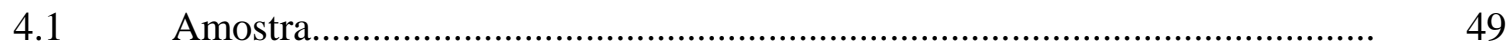

4.2 Desenho experimental............................................................................ 50

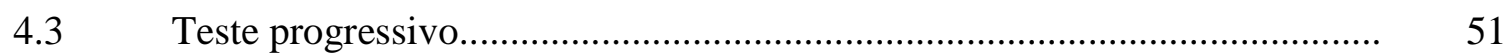

$4.4 \quad$ Teste controle....................................................................................... 52

4.5 Protocolo para depleção das reservas de CHO…………………………..... 52

4.6 Controle dietético.......................................................................................... 53

$4.7 \quad$ Testes experimentais............................................................................ 54

4.8 Análises bioquímicas............................................................................. 54

4.9 Mensuração de variáveis respiratórias, frequiência cardíaca e percepção

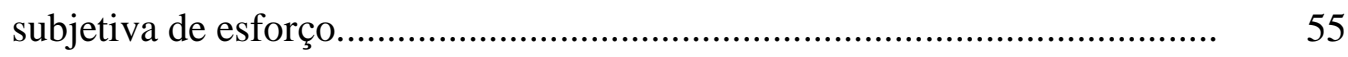

4.10 Análise dos dados............................................................................

4.10.1 Teste progressivo...................................................................... 55

4.10.1 Testes controle e experimentais................................................... 56

4.11 Análise estatística....................................................................................... 57

$5 \quad$ RESULTADOS

5.1 Características dos sujeitos......................................................................... 58

5.2 Protocolo de depleção do glicogênio muscular.............................................. 59

$5.3 \quad$ Controle dietético......................................................................................... 60

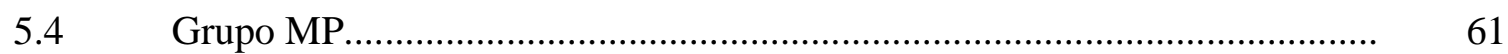

5.4.1 Tempo de exaustão............................................................................. 61

5.4.2 Resposta da percepção subjetiva de esforço......................................... 62

5.4.3 Respostas cardiorrespiratórias............................................................ 65

5.4.4 Respostas metabólicas e hormonais................................................. 72

5.4.5 Relações entre taxa de aumento na PSE e respostas metabólicas, hormonais e cardiorrespiratórias.................................................................

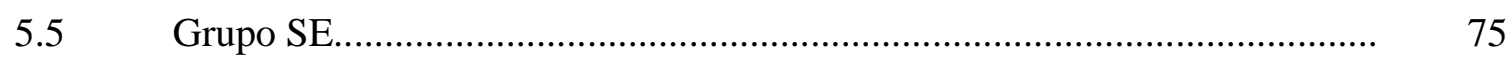

5.5.1 Tempo de exaustão.......................................................................

5.5.2 Resposta da percepção subjetiva de esforço.......................................... 77

5.5.3 Respostas cardiorrespiratórias............................................................. 
5.5.4 Respostas metabólicas e hormonais................................................ 86

5.5.5 Relações entre taxa de aumento na PSE e respostas metabólicas, hormonais e cardiorrespiratórias................................................................. 88

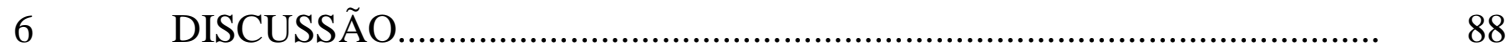

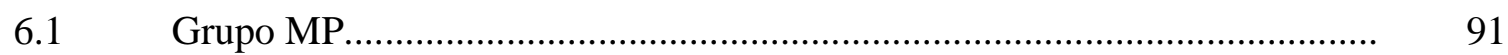

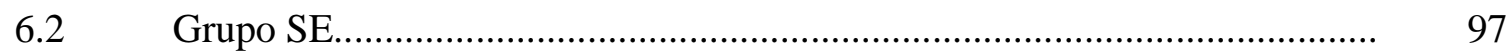

6.3 Comparação entre os domínios metabólicos................................................... 100

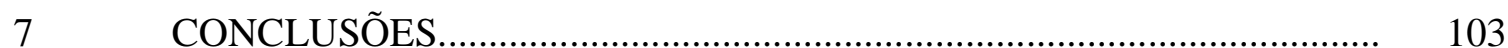

$8 \quad$ REFERÊNCIAS ……………………………............................. 104

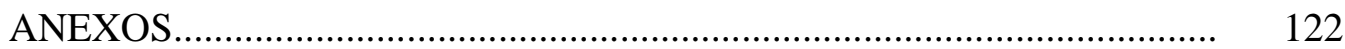

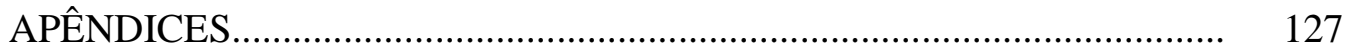




\section{LISTA DE TABELAS}

Página

TABELA 1 - Principais estudos sobre depleção de glicogênio muscular e fadiga.

TABELA 2 - Utilização do glicogênio muscular, gordura e glicose durante 145 minutos de cicloergometro a $70 \%$ do consumo máximo de oxigênio em três diferentes situações.

TABELA 3 - Características morfofisiológicas dos indivíduos do grupo de esforço muito pesado (MP) e severo (SE).

TABELA 4 - Tabela 4 - Conteúdo dietético das dietas consumidas nos dois dias anteriores as situações controle, alto e baixo carboidrato

TABELA 5 - Valores (média \pm desvio padrão) das variáveis cardio-respiratórias ao final do exercício muito pesado (média dos últimos $30 \mathrm{~s}$ ) nas três situações (controle, alto e baixo $\mathrm{CHO}$ ).

TABELA 6 - Valores (média \pm desvio padrão) dos parâmetros cinéticos da frequência respiratória (FR), ventilação (VE), consumo de oxigênio $\left(\mathrm{VO}_{2}\right)$, dióxido de carbono produzido $\left(\mathrm{VCO}_{2}\right)$ e frequência cardíaca (FC) durante o exercício muito pesado (MP), nas três situações (controle, alto e baixo $\mathrm{CHO}$ )

TABELA 7 - Valores (média \pm desvio padrão) das variáveis bioquímicas e hormonais no repouso e ao final do exercício muito pesado nas três situações (controle, alto e baixo $\mathrm{CHO}$ )

TABELA 8 - Valores (média \pm desvio padrão) das variáveis cardio-respiratórias ao final do exercício severo (média dos últimos $30 \mathrm{~s}$ ) nas três situações (controle, alto e baixo $\mathrm{CHO}$ )

TABELA 9 - Valores (média \pm desvio padrão) dos parâmetros cinéticos da frequência respiratória (FR), ventilação (VE), consumo de oxigênio $\left(\mathrm{VO}_{2}\right)$, dióxido de carbono produzido $\left(\mathrm{VCO}_{2}\right)$ e frequência cardíaca 
(FC) durante o exercício severo (SE), nas três situações (controle, alto e baixo $\mathrm{CHO}$ )

TABELA 10 - Valores (média \pm desvio padrão) das variáveis bioquímicas e hormonais no repouso e ao final do exercício severo nas três situações (controle, alto e baixo $\mathrm{CHO}$ ) 


\section{LISTA DE FIGURAS}

Página

FIGURA 1 - Comportamento hipotético do lactato sangüíneo (linha contínua) e do consumo de oxigênio (linha tracejada) em função da intensidade (painel superior). A partir da curva lactato intensidade é possível identificar o primeiro (LL1) e o segundo (LL2) limiar de lactato, separando os domínios moderado, pesado e severo. No painel inferior está representada a curva potência-tempo, com identificação do valor assintótico chamado de potência crítica (CP). Teoricamente, $\mathrm{CP}$ corresponde ao LL2 no painel superior.

FIGURA 2 - Modelo ilustrativo da resposta do consumo de oxigênio $\left(\mathrm{VO}_{2}\right)$ durante exercício de carga constante no domínio moderado, pesado e severo. Observa-se que no domínio moderado, o $\mathrm{VO}_{2}$ aumenta exponencialmente e estabiliza em valores similares ao estimado pela relação intensidade- $\mathrm{VO}_{2}$ em cargas abaixo do primeiro limiar de lactato. No domínio pesado o $\mathrm{VO}_{2}$ estabiliza em valores superiores ao estimado por essa relação. No domínio severo, os valores de $\mathrm{VO}_{2}$ não estabilizam e tendem a atingir o $\mathrm{VO}_{2 \max }$ identificado em um teste incremental máximo.....

FIGURA 3 - Relação entre a concentração inicial de glicogênio muscular e tempo de performance a $70 \%$ do $\mathrm{VO}_{2 \max } . \square$ após dieta baixa em carboidrato, após dieta balanceada e $\bullet$ após dieta alta em carboidrato. Adaptado de Bergstrom et al. (1967).

FIGURA 4 - Taxa de glicogenólise (unidades de glicose em mmol/kg de músculo seco/minuto) do macroglicogênio (MG), proglicogênio (PG) e glicogênio total (Gt) no início (0-15 $\mathrm{min}$ ou 0-10 $\mathrm{min}$ ) e no final (15-45 $\mathrm{min}$ ou 10 min-exaustão) de exercício a 70\% e 85\% do VO2max. De Graham et al. (2001). Letras iguais entre os dois intervalos de tempo, na mesma intensidade e para a mesma forma de glicogênio, representam igualdade de valores.o asterisco representa diferenças entre MG e PG no mesmo intervalo de tempo. Utilizado com permissão (ANEXO 1)

FIGURA 5 - Modelo esquemático da ligação actina e miosina. Na primeira etapa, a 
molécula de ATP está ligada a cabeça da miosina, impedindo a o contato com a actina. Na segunda etapa, ATP dissocia-se a ADP + Pi, mudando a conformação da cabeça da miosina. Na terceira etapa, Pi é liberado e a união entre actina e miosina passa do estágio de baixa energia para 0 estágio de alta energia. Na quarta e última etapa, ADP é liberado causando o encurtamento do sarcômero (Esquema adaptado de FITTS, 1994).

FIGURA 6 - Modelo ilustrativo de como a PSE pode ser regulada a partir do modelo de proto-self. A parte "A" demonstra como uma perturbação pode gerar um proto-self de segunda ordem. A diferença entre o proto-self de primeira e segunda ordem representa a magnitude do estímulo. Na parte "B" é ilustrado como múltiplos proto-self de segunda ordem podem ser gerados ao longo do exercício de carga constante e como a PSE responde a esses novos proto-self. Cada proto-self de segunda ordem é influenciado pelas vias aferentes, estado emocional e motivacional naquele momento. O esforço máximo corresponde ao máximo seguro, onde acima dele existiria apenas uma reserva quase nunca utilizada em situações normais.

FIGURA 7 - Painel A: Desenho experimental para o grupo de esforço muito pesado (MP). Painel B: desenho experimental para o grupo de esforço severo (SE). $\Delta 75 \%$ : carga correspondente a $75 \%$ da diferença entre o segundo limiar de lactato e a carga máxima. $\Delta 50 \%$ : carga correspondente a $55 \%$ da diferença entre o primeiro e o segundo limiar de lactato.

115\% VO2max: carga correspondente a $115 \%$ do consumo máximo de oxigênio. CHO: carboidratos. Os números 1 e 2 indicam as duas situações experimentais possíveis para ambos os grupos. Essas duas sequências foram realizadas de forma contrabalanceada entre os sujeitos e separadas por sete dias para washout....

FIGURA 8 - Tempo de exaustão do grupo que realizou esforço no domínio muito pesado (MP) em três situações distintas (controle, alto ou baixo carboidrato na dieta). O painel superior representa os valores médios e o desvio padrão do tempo de exaustão do grupo em cada situação. O painel inferior representa os valores individuais do tempo de exaustão para cada individuo avaliado em cada uma das situações.

FIGURA 9 - Percepção subjetiva de esforço (PSE) de um sujeito do grupo de esforço muito pesado (MP) nas três situações (controle, alto ou baixo carboidrato na dieta). Os dados do painel superior são referentes a PSE geral. O painel inferior representa os valores da PSE local.

FIGURA 10 Consumo de oxigênio (painel superior) e produção de dióxido de carbono (painel inferior) no grupo de esforço muito pesado (MP) nas três situações (controle, alto ou baixo carboidrato na dieta). Os dados são expressos como média e desvio padrão. $\mathrm{O}$ desvio padrão da situação 
controle foi omitido para melhor visualização do gráfico. * Efeito significativo do tempo de exercício $(\mathrm{P}<0,05)$; ** Efeito significativo da situação $(\mathrm{P}<0,05)$..

FIGURA 11 Razão de trocas respiratórias (R) no grupo de esforço muito pesado (MP) nas três situações (controle, alto ou baixo carboidrato na dieta). Os dados são expressos como média e desvio padrão. O desvio padrão da situação controle foi omitido para melhor visualização do gráfico. * Efeito significativo do tempo de exercício $(\mathrm{P}<0,05)$; ** Efeito significativo da situação $(\mathrm{P}<0,05)$

FIGURA 12 - Frequência respiratória (painel superior) e ventilação (painel inferior) no grupo de esforço muito pesado (MP) nas três situações (controle, alto ou baixo carboidrato na dieta). Os dados são expressos como média e desvio padrão. O desvio padrão da situação controle foi omitido para melhor visualização do gráfico. * Efeito significativo do tempo de exercício $(\mathrm{P}<$ $0,05)$; ** Efeito significativo da situação $(\mathrm{P}<0,05)$.

FIGURA 13 - Frequência cardíaca (FC) no grupo de esforço muito pesado (MP) nas três situações (controle, alto ou baixo carboidrato na dieta). Os dados são expressos como média e desvio padrão. $\mathrm{O}$ desvio padrão da situação controle foi omitido para melhor visualização do gráfico. * Efeito significativo do tempo de exercício $(\mathrm{P}<0,05)$; ${ }^{*}$ Efeito significativo da situação $(\mathrm{P}<0,05)$

FIGURA 14 - Concentração de lactato no sangue venoso (painel superior) e arterializado (painel inferior) no grupo de esforço muito pesado (MP) nas três situações (controle, alto ou baixo carboidrato na dieta). Os dados são expressos como média e desvio padrão. O desvio padrão da situação de alto $\mathrm{CHO}$ foi omitido para melhor visualização do gráfico. * Efeito significativo do tempo de exercício $(\mathrm{P}<0,05)$; ** Efeito significativo da situação $(\mathrm{P}<0,05)$

FIGURA 15 - Tempo de exaustão do grupo que realizou esforço no domínio severo (SE) em três situações distintas (controle, alto ou baixo carboidrato na dieta). O painel superior representa os valores médios e o desvio padrão do tempo de exaustão do grupo em cada situação. O painel inferior representa os valores individuais do tempo de exaustão para cada individuo avaliado em cada uma das situações. * Significativamente menor do que a situação controle e de alto carboidrato $(\mathrm{P}<0,05)$.

FIGURA 16 - Percepção subjetiva de esforço (PSE) de um sujeito do grupo de esforço severo (SE) nas três situações (controle, alto ou baixo carboidrato na dieta). Os dados do painel superior são referentes a PSE geral. O painel inferior representa os valores da PSE local.

FIGURA 17 - Consumo de oxigênio (painel superior) e produção de dióxido de 
carbono (painel inferior) no grupo de esforço severo (SE) nas três situações (controle, alto ou baixo carboidrato na dieta). Os dados são expressos como média e desvio padrão. O desvio padrão da situação controle foi omitido para melhor visualização do gráfico. * Efeito significativo do tempo de exercício $(\mathrm{P}<0,05)$.

FIGURA 18 - Razão de trocas respiratórias (R) no grupo de esforço severo (SE) nas três situações (controle, alto ou baixo carboidrato na dieta). Os dados são expressos como média e desvio padrão. O desvio padrão da situação controle foi omitido para melhor visualização do gráfico. * Efeito significativo do tempo de exercício $(\mathrm{P}<0,05)$.

FIGURA 19 - Frequência respiratória (painel superior) e ventilação (painel inferior) no grupo de esforço severo (SE) nas três situações (controle, alto ou baixo carboidrato na dieta). Os dados são expressos como média e desvio padrão. O desvio padrão da situação controle foi omitido para melhor visualização do gráfico. * Efeito significativo do tempo de exercício $(\mathrm{P}<$ $0,05)$;** Efeito significativo da situação $(\mathrm{P}<0,05)$; $\uparrow$ Interação entre os fatores tempo de exercício e situação $(\mathrm{P}<0,05)$.

FIGURA 20 - Frequência cardíaca (FC) no grupo de esforço severo (SE) nas três situações (controle, alto ou baixo carboidrato na dieta). Os dados são expressos como média e desvio padrão. $O$ desvio padrão da situação controle foi omitido para melhor visualização do gráfico. * Efeito significativo do tempo de exercício $(\mathrm{P}<0,05)$; ** Efeito significativo da situação $(P<0,05)$

FIGURA 21 - Concentração de lactato no sangue venoso (painel superior) e arterializado (painel inferior) no grupo de esforço severo (SE) nas três situações (controle, alto ou baixo carboidrato na dieta). Os dados são expressos como média e desvio padrão. $\mathrm{O}$ desvio padrão da situação controle foi omitido para melhor visualização do gráfico. * Efeito significativo do tempo de exercício $(\mathrm{P}<0,05) ; * *$ Efeito significativo da situação $(\mathrm{P}<0,05)$ 
LISTA DE ANEXOS

Página

ANEXO I ～- Permissão de reimpressão da figura 4..................................................... 122

ANEXO II $\quad$ - Termo de consentimento informado.................................................. 123 


\section{LISTA DE APÊNDICES}

Página

APÊNDICE 1 - Percepção subjetiva de esforço (PSE) geral de cada sujeito do grupo que realizou o esforço no domínio muito pesado (MP) nas três situações (controle, alto e baixo carboidrato na dieta).

APÊNDICE 2 - Percepção subjetiva de esforço (PSE) local de cada sujeito do grupo que realizou o esforço no domínio muito pesado (MP) nas três situações (controle, alto e baixo carboidrato na dieta).

APÊNDICE 3 - Percepção subjetiva de esforço (PSE) geral de cada sujeito do grupo que realizou o esforço no domínio severo (SE) nas três situações (controle, alto e baixo carboidrato na dieta)

APÊNDICE 4 - Percepção subjetiva de esforço (PSE) local de cada sujeito do grupo que realizou o esforço no domínio severo (SE) nas três situações (controle, alto e baixo carboidrato na dieta). 


\section{LISTA DE SIGLAS, ABREVIAÇÕES E SÍMBOLOS}

\begin{tabular}{ll} 
A & Amplitude \\
AGL & Ácidos graxos livres \\
ADP & Adenosina Difosfato \\
AMP & Adenosina Monofosfato \\
AMPc & Adenosina Monofosfato cíclico \\
ATP & Adenosina Trifosfato \\
bpm & Batimentos por minuto \\
bpm.s ${ }^{-1}$ & Batimentos por minuto por segundo \\
Ca & Cálcio \\
CaHPO 4 & Fosfato de cálcio \\
CHO & Carboidrato \\
Ciclos.min ${ }^{-1}$ & Ciclos por minuto \\
Ciclos.min ${ }^{-1} . s^{-1}$ & Ciclos por minuto por segundo \\
CP & Fosfocreatina \\
Cr & Creatina \\
Da & Daltons \\
$\Delta L L 50 \%$ & 50\% da diferença entre o primeiro e segundo limiar de lactato \\
$\Delta L W 75 \%$ & 75\% da diferença entre a carga máxima e o segundo limiar de lactato \\
EDTA & Anticoagulante \\
FC & Frequência cardíaca \\
FC max $_{\text {FR }}$ & Frequência cardíaca máxima \\
& Frequência respiratória \\
\hline
\end{tabular}




\begin{tabular}{|c|c|}
\hline GF & Glicogênio fosforilase \\
\hline GM & Glicogênio muscular \\
\hline GS & Glicogênio sintetase \\
\hline $\mathrm{H}^{+}$ & Prótons \\
\hline HPLC & Cromatografia líquida de alta performance \\
\hline $\mathrm{HPO}^{4--}$ & Fosfato monoprotonado \\
\hline $\mathrm{H}_{2} \mathrm{PO}^{4-}$ & Fosfato diprotonado \\
\hline IMP & Inosinamonofosfato \\
\hline IRS-1 & Receptor primário da insulina \\
\hline $\mathrm{K}^{+}$ & Potássio \\
\hline kcal & Quilocalorias \\
\hline $\mathrm{kDa}$ & Quilodaltons \\
\hline $\mathrm{kg}$ & Quilogramas \\
\hline $\mathrm{kJ}$ & Quilo joules \\
\hline $\mathrm{kJ} / \mathrm{L}$ & Quilo joules por litro \\
\hline $\mathrm{km}$ & Quilômetros \\
\hline $\mathrm{K}_{\mathrm{m}}$ & Constante de Michaelis-Menten \\
\hline $\mathrm{L}$ & Litros \\
\hline$[\mathrm{La}]$ & Concentração de lactato \\
\hline lactato art & Lactato arterializado \\
\hline lactato ven & Lactato venoso \\
\hline LL1 & Primeiro limiar de lactato \\
\hline LL2 & Segundo limiar de lactato \\
\hline L.min ${ }^{-1}$ & Litros por minuto \\
\hline L. $\min ^{-1} \cdot \mathrm{s}^{-1}$ & Litros por minuto por segundo \\
\hline MG & Macroglicogênio \\
\hline MP & Domínio muito pesado \\
\hline mmol. $1^{-1}$ & Milimoles por litro \\
\hline $\mathrm{ml} \cdot \mathrm{kg}^{-1} \cdot \min ^{-1}$ & Mililitros por quilo de peso corporal por minuto \\
\hline $\operatorname{ml} . \min ^{-1}$ & Mililitros por minuto \\
\hline $\mathrm{ml} \cdot \mathrm{min}^{-1} \cdot \mathrm{s}^{-1}$ & Mililitros por minuto por segundo \\
\hline
\end{tabular}




\begin{tabular}{|c|c|}
\hline $\mathrm{Na}^{+}$ & Sódio \\
\hline NAD & Nicotinamida adenina dinucleotídeo \\
\hline NADH & Nicotinamida adenina dinucleotídeo reduzida \\
\hline $\mathrm{NH}_{3}$ & Amônia \\
\hline nmol. $1^{-1}$ & Nanomoles por litro \\
\hline $\mathrm{P}$ & Probabilidade \\
\hline PAS & Reação periódica do ácido-Schiff \\
\hline PC & Potência Crítica \\
\hline PG & Proglicogênio \\
\hline PKF & Fosfofrutoquinase \\
\hline$P_{i}$ & Fosfato inorgânico \\
\hline PI3-quinase & Subunidade de fosfatidilinositol 3-quinase \\
\hline PKA & Proteína quinase \\
\hline $\mathrm{PO}_{2}$ & Pressão parcial de oxigênio \\
\hline PSE & Percepção subjetiva de esforço \\
\hline $\mathrm{PSE}_{\mathrm{Geral}}$ & Percepção subjetiva de esforço geral \\
\hline $\mathrm{PSE}_{\text {Local }}$ & Percepção subjetiva de esforço local \\
\hline $\mathrm{r}$ & Coeficiente de correlação \\
\hline $\mathrm{R}^{2}$ & Coeficiente de determinação \\
\hline $\mathrm{Rd}$ & Taxa de desaparecimento \\
\hline rpm & Rotações por minuto \\
\hline SE & Domínio severo \\
\hline $\mathrm{SNC}$ & Sistema nervoso central \\
\hline TAN & Total de adenina nucleotídeo \\
\hline TMB & Taxa metabólica basal \\
\hline $\mathrm{T}_{\mathrm{UEI}}$ & Tempo do último estágio incompleto \\
\hline Unidades.min ${ }^{-1}$ & Unidades por minuto \\
\hline Unidades. $\%^{-1}$ & Unidades por porcentagem \\
\hline VE & Ventilação \\
\hline $\mathrm{VC}$ & Volume corrente \\
\hline $\mathrm{VCO}_{2}$ & Volume de dióxido de carbono produzido \\
\hline
\end{tabular}




$\begin{array}{ll}\mathrm{VO}_{2} & \text { Consumo de oxigênio } \\ \mathrm{VO}_{2 \max } & \text { Consumo máximo de oxigênio } \\ \mathrm{W} & \text { Watts } \\ \mathrm{W}_{\max } & \text { Carga máxima obtida no teste progressivo } \\ \mathrm{W}_{\mathrm{UEC}} & \text { Carga do último estágio completo } \\ \text { y0 } & \text { Linha de base } \\ \tau & \text { Constante de tempo } \\ \delta & \text { Tempo de atraso }\end{array}$


RESUMO

\title{
EFEITO DA DISPONIBILIDADE DE CARBOIDRATO SOBRE O DESEMPENHO, RESPOSTAS PERCEPTIVAS E FISIOLÓGICAS EM EXERCÍCIOS DE ALTA INTENSIDADE
}

\author{
Autor: ADRIANO EDUARDO LIMA DA SILVA \\ Orientador: PROF ${ }^{\mathrm{a}}$.DR ${ }^{\mathrm{a}}$. MARIA AUGUSTA PEDUTI DAL MOLIN KISS
}

O objetivo desse estudo foi avaliar o efeito da disponibilidade de carboidratos (CHO) sobre a taxa de incremento da percepção subjetiva de esforço (PSE), respostas cardio-respiratórias, metabólicas e hormonais em exercícios de domínio muito pesado (MP) e severo (SE). Doze sujeitos foram designados aleatoriamente para um de dois grupos (MP ou SE). Os indivíduos realizaram: 1) um teste progressivo máximo; 2) um teste de carga constante até a exaustão (controle); 3) um protocolo de depleção de CHO com exercício, seguido por 48 horas de dieta com baixo (10\%) ou alto $(80 \%) \mathrm{CHO}$; 4) um teste experimental, igual ao controle, até a exaustão. Após sete dias, os procedimentos 3 e 4 foram realizados novamente, mas invertendo a dieta (ordem contrabalanceada). Para MP, o tempo de exaustão não foi diferente entre as situações, mas a taxa de incremento da PSE geral foi maior para a situação de baixo $\mathrm{CHO}$ do que para controle ou alto $\mathrm{CHO}$. $\mathrm{O} \mathrm{VO}_{2}$, FC, ventilação (VE), frequência respiratória (FR) e lactato foram menores na situação de 
baixo CHO. A insulina foi maior para baixo e alto $\mathrm{CHO}$ do que para controle. A taxa de aumento da PSE geral foi associada a amplitude de incremento do $\mathrm{VO}_{2}$. Para SE, o tempo de exaustão foi menor com baixo CHO. A taxa de incremento da PSE geral não foi diferente entre as situações, mas a da PSE local (específica do músculo ativo) foi maior para baixo CHO. A FR e a VE foram maiores para baixo $\mathrm{CHO}$, enquanto o volume corrente, a FC e o lactato foram menores. A PSE geral foi associada a PSE local. Esses resultados sugerem que a disponibilidade de $\mathrm{CHO}$ afeta diversas variáveis fisiológicas de maneira dependente da intensidade. Por conseqüência, afetam a PSE também de modo dependente da intensidade.

Palavras-chave: percepção subjetiva de esforço, domínio metabólico, dieta, desempenho, fadiga. 


\begin{abstract}
EFFECT OF CARBOHYDRATE AVAILABILITY ON PERCEPTUAL AND PHYSIOLOGICAL RESPONSES DURING HIGH INTENSITY EXERCISES
\end{abstract}

\author{
Author: ADRIANO EDUARDO LIMA DA SILVA
}

Adviser: PROF.DR. MARIA AUGUSTA PEDUTI DAL MOLIN KISS

The aim of the present study was to examine the effect of carbohydrate (CHO) availability on the rate of increase in rating perceived exertion (RPE), cardio-respiratory, metabolic and hormonal responses during exercise at very heavy (VH) or severe (SE) domains. Twelve subjects were randomly allocated at VH or SE groups. The subjects performed: 1) a maximal incremental test; 2) a constant workload test until exhaustion (control); 3) an exercise protocol to depletion of CHO stores, followed for 48 hours of low $(10 \%)$ or high $(80 \%) \mathrm{CHO}$ diet; 4) an experimental test, mirrored the control, until the exhaustion. Seven days apart, the procedures 3 and 4 were performed again, but using opposite diet (counterbalanced order). In the $\mathrm{VH}$ group, the time to exhaustion was not significantly different among the conditions, but the rate of increase in global RPE was higher to low $\mathrm{CHO}$ diet than control or high $\mathrm{CHO}$ diet. The $\mathrm{VO}_{2}$, heart rate (HR), ventilation (VE), breathing rate (BR) and lactate were lower in low $\mathrm{CHO}$ diet. The insulin was higher in low and high $\mathrm{CHO}$ diet than in control. The rate of increase in global RPE was associated with the $\mathrm{VO}_{2}$ amplitude. For SE, the time to exhaustion was lower in low CHO diet. The rate of increase in global RPE was not different among conditions, but the 
local RPE (pain in the active muscle) was greater in low CHO diet. The BR and VE were greater in low $\mathrm{CHO}$ diet, while tidal volume, HR and lactate were lesser. The global RPE was associated with local RPE. These results could suggest that $\mathrm{CHO}$ availability can affect several physiological variables for a way what has to be dependent of the exercise intensity. For consequence, its affect RPE also for a way that is dependent of the intensity.

Keywords: rating of perceived exertion, metabolic domain, diet, performance, fatigue. 


\section{INTRODUÇÃO}

A fadiga durante um determinado exercício pode ser definida como a incapacidade para manter a produção de força em níveis pré-estipulados, levando a redução no desempenho da tarefa (EDWARDS, 1983; FITTS, 1994). De maneira mais abrangente, Fitts (1994) sugeriu que a fadiga poderia ser considerada uma redução em dois importantes parâmetros, a capacidade de aplicação de força e a velocidade do movimento, reduzindo por conseqüência, a potência gerada. Operacionalmente, durante exercícios dinâmicos em cicloergômetro e com intensidades constantes, a fadiga pode ser definida como a incapacidade da manutenção na rotação de pedal estabelecida a priori. Os eventos fisiológicos associados à fadiga têm sido motivo de grande debate na literatura (ENOKA; STUART, 1992; FITTS, 1994; DAVIS; BAILEY, 1997; ST CLAIR GIBSON; NOAKES, 2004; NOAKES; ST CLAIR GIBSON; LAMBERT, 2004; MCKENNA; HARGREAVES, 2008).

Existem três principais teorias destinadas a explicar os possíveis mecanismos psicofisiológicos que causariam a fadiga. No primeiro modelo, o considerado clássico, a fadiga pode ser explicada por alterações metabólicas ou elétricas em áreas específicas do sistema neuromuscular. As principais áreas afetadas pelo exercício e que teriam relação com a fadiga muscular seriam: a redução na excitabilidade do sarcolema devido ao extravasamento dos íons de potássio $\left(\mathrm{K}^{+}\right)$(GREEN, 1997; McKENNA; BANGSBO; RENAUD, 2008), a redução na liberação e re-captação dos íons de cálcio (WESTERBLAD, ALLEN; LANNERGREN, 2002; ALLEN; LAMB; WESTERBLAD, 2008), o acúmulo de metabolitos devido à ineficiência no fornecimento de oxigênio ao músculo, como lactato, prótons $\left(\mathrm{H}^{+}\right)$e fosfato $\left(\mathrm{P}_{\mathrm{i}}\right)$, dos quais todos poderiam interferir na ligação actina-miosina (FITTS, 1994; McLESTER Jr., 1997) e a depleção de substratos, como fosfocreatina e glicogênio muscular (KARLSSON; SALTIN, 1970; AHLBORG et al., 1967; BERGSTROM et al., 1967). Nesse modelo é previsto que, caso ocorra uma modificação em um ou mais desses fatores, atingindo um determinado nível crítico, a continuidade ou a manutenção na aplicação de "força" seria prejudicada, caracterizando estado de fadiga (AMENT; VERKERKE, 2009). Essa teoria foi classificada como "fadiga periférica" (NOAKES, 1997; 2000; AMENT; VERKERKE, 2009). O ponto fundamental desse modelo é que a fadiga pode ser dependente exclusivamente de alterações bioquímicas e metabólicas, sendo que o fator principal causador de fadiga muda de acordo 
com a tarefa, como por exemplo, acúmulo de metabolitos para exercício intenso e depleção de substratos para exercício mais prolongado.

Com o avanço do conhecimento, novos pontos de alteração foram identificados, sendo muitos deles externo ao músculo esquelético. Por exemplo, uma redução na estimulação cortical, e consequentemente na excitabilidade do motoneurônio, poderiam diminuir o desempenho em uma tarefa, independentemente de alterações significativas no meio intracelular (TAYLOR; BUTLER; GANDEVIA, 2000). Alguns produtos metabólicos e eventos físicos derivados da contração muscular podem ter seu ponto de atuação em outros locais que não o próprio músculo. Nesse caso, alguns estudos mostraram que, durante o exercício prolongado, a quantidade de ácidos graxos livres (AGL) circulantes no plasma aumenta (DAVIS; BAILEY, 1997; BERTUZZI; FRANCHINI; KISS, 2004). Esse aumento de AGL resulta em aumento de triptofano livre no plasma, pois os dois competem pelo mesmo sítio de ligação de uma proteína transportadora, a albumina. O aumento do triptofano poderia aumentar a produção de serotonina no sistema nervoso central (SNC), o que causaria indisposição e falta de atenção, reduzindo o desempenho. Outras alterações como a redução no fluxo sanguíneo cerebral, aumento da concentração de citocinas no plasma com consequente atuação no SNC e aumento da temperatura central também poderiam levar à fadiga de maneira paralela as alterações intramusculares. Essa teoria pode ser classificada como fadiga central e é considerada uma extensão da fadiga periférica, pois as duas apresentam as mesmas características conceituais, em que a fadiga é dependente de um fator isolado em um dado momento do esforço, de modo dependente do tipo de atividade. A combinação dos dois pode ser chamada de modelo catastrófico, pois prevê que a fadiga só acontece quando níveis críticos de alterações metabólicas são atingidos (EDWARDS, 1983).

O problema central desses dois modelos de fadiga (periférica e central) é que ambos assumem que a ocorrência de fadiga está ligada a um ou mais fatores fisiológicos, mas de maneira independente um do outro. Em outras palavras, a simples modificação de um dado fator ou conjunto de fatores seria a causa direta da fadiga naquele momento, mas não existiria integração entre eles. A dificuldade em se sustentar um modelo com característica linear como esses aumenta à medida que novos possíveis sítios de fadiga vão sendo descobertos. Pensando nisso, uma hipótese alternativa para explicar a fadiga foi sugerida recentemente, na qual um suposto "governador central", localizado no SNC, controlaria o tempo total de exercício que poderia ser realizado de maneira segura, sem causar distúrbios metabólicos danosos ao 
organismo, preservando a integridade das fibras musculares e de outros órgãos (NOAKES; ST CLAIR GIBSON, 2004; ST CLAIR GIBSON; NOAKES, 2004; LAMBERT; ST CLAIR GIBSON; NOAKES, 2005, 2004; NOAKES, ST CLAIR GIBSON; LAMBERT, 2004). Nesse modelo, o tempo total de esforço considerado seguro é "escolhido" antecipadamente (feedforward) por esse "governador", baseada em experiências prévias com o esforço (memória motora), sendo constantemente refinado ao longo do exercício por múltiplos sinais aferentes (feedback) vindo de diferentes regiões do organismo, que informam as condições metabólicas e fisiológicas ao centro de controle (TUCKER, 2009). Desse modo, as alterações metabólicas e fisiológicas passam de causadores da fadiga, como dito no modelo de fadiga catastrófico, para sinalizadores, no modelo do governador central.

Esses múltiplos sinais aferentes, além de informarem o sistema central de controle sobre as condições metabólicas periféricas, também servem de base para a construção da percepção consciente do esforço realizado, isto é, a percepção subjetiva de esforço (PSE) (NOAKES; ST CLAIR GIBSON, 2004; ST CLAIR GIBSON; NOAKES, 2004; LAMBERT; ST CLAIR GIBSON; NOAKES, 2005; NOAKES, ST CLAIR GIBSON; LAMBERT, 2004). Como durante o exercício de intensidade constante não é possível alterar a carga imposta pelo exercício, tanto as alterações metabólicas quanto a PSE, teriam natureza escalar com o tempo, ou seja, aumentariam em função do tempo transcorrido ou do tempo restante. Realmente, alguns estudos têm dado suporte ao conceito de que a PSE possui natureza escalar com o tempo de exercício de intensidade constante (NOAKES, 2004; ESTON et al., 2007; CREWE; TUCKER, NOAKES, 2008). Noakes (2004) observou que a taxa de aumento na PSE em função do tempo era maior quando os indivíduos realizavam um exercício de intensidade constante $\left(70 \%\right.$ do $\left.\mathrm{VO}_{2 \max }\right)$ com depleção prévia de glicogênio muscular (GM), quando comparada a uma situação de reserva aumentada. Eston et al. (2007) demonstraram que a taxa de aumento na PSE era maior quando os indivíduos pedalavam em uma intensidade fixa $(75 \%$ do $\mathrm{VO}_{2 \max }$ ) em condições de fadiga prévia do que em condições normais. Crewe, Tucker e Noakes (2008) observaram uma maior taxa de PSE em exercícios de maiores intensidades ou temperatura ambiente mais alta. Porém, em todos esses estudos, quando a PSE foi plotada em função do tempo restante para o término do esforço, ficou demonstrado que a taxa de incremento era similar entre as condições. Isso sugere que, independentemente da condição, a PSE aumenta proporcionalmente ao tempo final calculado, ou ao tempo de exercício já transcorrido. O que se altera então é o tempo final calculado, provavelmente em decorrência 
da modificação na sinalização aferente causada pelas diferentes intervenções (reserva de GM, acúmulo de metabólitos, temperatura, etc.). Essas diferenças entre as situações talvez seja gerada pela comparação entre um construto formado a partir dos sinais aferentes e de uma condição esperada, baseada nas sensações obtidas em experiências motoras anteriores durante exercícios similares (MAUGER, JONES, WILLIAMS, 2009). Contudo, quais seriam os principais sinalizadores aferentes e como eles se combinam para alterar a PSE não foi totalmente explorado na literatura.

Diversos possíveis sinalizadores aferentes fisiológicos, classificados como centrais e periféricos, foram listados em um estudo de revisão de Hampson et al. (2001). Dentre os possíveis sinalizadores centrais, os fatores cardiorrespiratórios (HAMPSON et al., 2001) e hormonais (HAVEMANN et al., 2006) teriam importância destacada na modulação da PSE. Dentre os periféricos, o lactato sanguíneo, $\mathrm{pH}$ plasmático, $\mathrm{pH}$ muscular, dano e dor muscular (como a percepção da dor localizada no músculo ativo), potássio plasmático, temperatura corporal e disponibilidade de carboidratos $(\mathrm{CHO})$ seriam também fatores chaves (HAMPSON et al., 2001). Acredita-se que a importância desses sinalizadores para a elaboração da PSE pode variar de acordo com a intensidade e condição metabólica prévia ao exercício. Por exemplo, fatores como a dor muscular, lactato, potássio e $\mathrm{pH}$ plasmáticos poderiam exercer maior influência sobre a PSE durante o exercício de maior intensidade, como os realizados no domínio muito pesado (MP) e severo (SE) (ÖZYENER et al., 2001). Nesses dois domínios existe um grande acúmulo de lactato, com consequente redução do $\mathrm{pH}$, o que poderia ser um fator determinante para a elaboração da PSE (NETHERY, 2002). Do mesmo modo, a redução das reservas de $\mathrm{CHO}$ aumenta consideravelmente a ventilação, a frequência respiratória (HEIGENHAUSER; SUTTON, JONES, 1983; PERREY et al., 2003), a frequência cardíaca (PERREY et al., 2003), altera parâmetros cinéticos do $\mathrm{VO}_{2}$ (KRUSTRUP et al., 2004; CARTER et al., 2004; BOUCKAERT; JONES; KOPPO, 2004; OSBORNE; SCHNEIDER, 2005), a concentração de potássio extracelular (BUSSE et al., 1991) e a atividade da bomba de sódio e potássio (GREEN et al., 2007; STEWART et al., 2007). Assim, a combinação dessas duas variáveis (intensidade e reserva de $\mathrm{CHO}$ ), seria uma alternativa para induzir alterações nos principais sinalizadores (centrais e periféricos) e investigar se essas alterações se relacionam ou não com a natureza escalar da PSE em função do tempo. 
Contudo, o grau de importância de cada um desses sinalizadores na determinação da taxa de aumento da PSE ainda não foi descrita na literatura. Além disso, como esses sinalizadores se combinam para alterar a PSE é pouco compreendido.

Baseado no exposto anteriormente, no presente estudo foi investigado o efeito da manipulação das reservas de CHO (controle, alta e baixa disponibilidade), sobre a taxa de aumento da PSE em função do tempo, respostas cardiorrespiratórias, metabólicas e hormonais em exercícios de alta intensidade, isto é, em exercício de domínio MP e SE. A ideia de utilizar esses domínios baseia-se na expectativa de que os dois poderiam gerar distúrbios acentuados em muitos dos sinalizadores, mas de magnitude diferente entre eles. Assim, espera-se que caso um determinado sinalizador seja importante na elaboração da PSE em um domínio, não necessariamente deverá ser para o outro. Do mesmo modo, espera-se que se um determinado sinalizador for afetado pela manipulação na disponibilidade de $\mathrm{CHO}$, e for importante para a elaboração da PSE, esse efeito deveria estar associado às modificações na taxa de incremento da PSE em função do tempo.

\section{OBJETIVO}

\subsection{Objetivo geral}

Analisar o efeito da disponibilidade de CHO sobre a taxa de aumento da PSE durante exercícios de alta intensidade e a sua relação com as respostas cardiorrespiratórias, metabólicas e hormonais.

\subsection{Objetivos específicos}

- Comparar o tempo de exaustão de exercício realizado no domínio MP entre três situações distintas de disponibilidade de $\mathrm{CHO}$ (controle, alto e baixo $\mathrm{CHO}$ );

- Comparar o tempo de exaustão de exercício realizado no domínio SE entre três situações distintas de disponibilidade de $\mathrm{CHO}$ (controle, alto e baixo $\mathrm{CHO}$ );

- Comparar a resposta e a taxa de incremento na PSE geral e local em função do tempo absoluto (minutos) e relativo (\% do tempo final) nas três situações distintas e em ambos os domínios; 
- Comparar a resposta da ventilação (VE), frequência respiratória (FR), consumo de oxigênio $\left(\mathrm{VO}_{2}\right)$, dióxido de carbono $\left(\mathrm{VCO}_{2}\right)$ e frequência cardíaca $(\mathrm{FC})$ em função do tempo nas três situações e em ambos os domínios;

- Comparar a resposta das variáveis metabólicas (lactato venoso, lactato arterializado, glicose, potássio e pH plasmático) e hormonais (epinefrina, norepinefrina, dopamina, insulina e cortisol) entre as situações, tanto para o domínio muito pesado, quanto para o severo;

- Verificar se existe relação dos sinalizadores centrais e periféricos com a taxa de incremento da PSE geral e local em ambos os domínios.

- Verificar se existe relação dos sinalizadores (centrais e periféricos) e da taxa de incremento da PSE geral e local com o tempo de exaustão.

\section{REVISÃO DA LITERATURA}

O objetivo dessa revisão de literatura é apresentar e discutir o estado da arte dos principais aspectos teóricos envolvidos na construção do problema de estudo aqui levantado. Além disso, alguns tópicos têm caráter didático, pois visa esclarecer ao leitor conceitos e pressupostos que serão importantes na compreensão e discussão de resultados.

Na primeira parte será abordada a idéia de domínios metabólicos, dando um enfoque aos métodos de identificação dos domínios e as suposições fisiológicas que permitem assumir a subdivisão da intensidade de exercício de acordo com suas características. Na etapa seguinte será abordado um dos fatores que foi manipulado no presente estudo, as reservas endógenas de $\mathrm{CHO}$, dando ênfase a aspectos funcionais, como o seu metabolismo durante o exercício. Os modelos de fadiga citados na introdução serão abordados mais detalhadamente nessa revisão. A parte inicial de fadiga será apresentada de modo segmentado por sitio de fadiga, como sugerido no modelo catastrófico. Após essa apresentação, a fadiga será discutida de um ponto de vista mais amplo, de acordo com o modelo integrativo-complexo. Para finalizar, uma pequena revisão sobre PSE, começando com aspectos metodológicos de validação e partindo para a sua representação no modelo integrativo-complexo, será abordado. 


\subsection{Domínios metabólicos}

A ideia de domínio metabólico deriva-se de duas medidas fisiológicas, que são $\mathrm{VO}_{2} \mathrm{e}$ lactato, e da relação hiperbólica entre potência-tempo. A identificação dos domínios metabólicos surge a partir da resposta dessas variáveis fisiológicas frente a um teste incremental máximo ou a um teste de carga constante com duração fixa ou realizado até a exaustão. O modelo de resposta dessas variáveis depende do domínio metabólico em que se está realizando o esforço. Portanto, é a partir das diferenças de resposta dessas variáveis que se identifica um domínio metabólico.

Durante um teste incremental máximo escalonado ou de rampa, o $\mathrm{VO}_{2}$ aumenta linearmente com a intensidade do esforço até atingir o $\mathrm{VO}_{2 \max }($ GAESSER; POOLE, 1996). A concentração de lactato no sangue aumenta de maneira trifásica, demarcando dois pontos de transição metabólica. O primeiro ponto de aceleração na curva lactato-intensidade é chamado de limiar de lactato (LL), mas para evitar confusão de terminologia, no presente estudo ele pode ser caracterizado com o primeiro limiar lactato (LL1) (RIBEIRO, 1995). O segundo ponto de aceleração na curva lactato-intensidade pode ser chamado então de segundo limiar de lactato (LL2). Teoricamente, esse segundo limiar de lactato corresponde ao valor assintótico da relação potência-tempo, chamado de potência crítica (PC) (figura 1). A identificação desses pontos em um teste incremental máximo (LL1 e LL2), ou do valor assintótico da relação potência-tempo (PC), demarca os domínios metabólicos moderado, pesado e severo (WHIPP, 1994; GAESSER; POOLE, 1996).

Utilizando a identificação dos domínios metabólicos é possível investigar os modelos de resposta do $\mathrm{VO}_{2}$ e lactato em cada um desses domínios. No caso específico do $\mathrm{VO}_{2}$, a sua resposta em todos os domínios é caracterizada por um aumento acentuado no início do esforço, seguido de um aumento mais gradativo posteriormente (figura 2). 

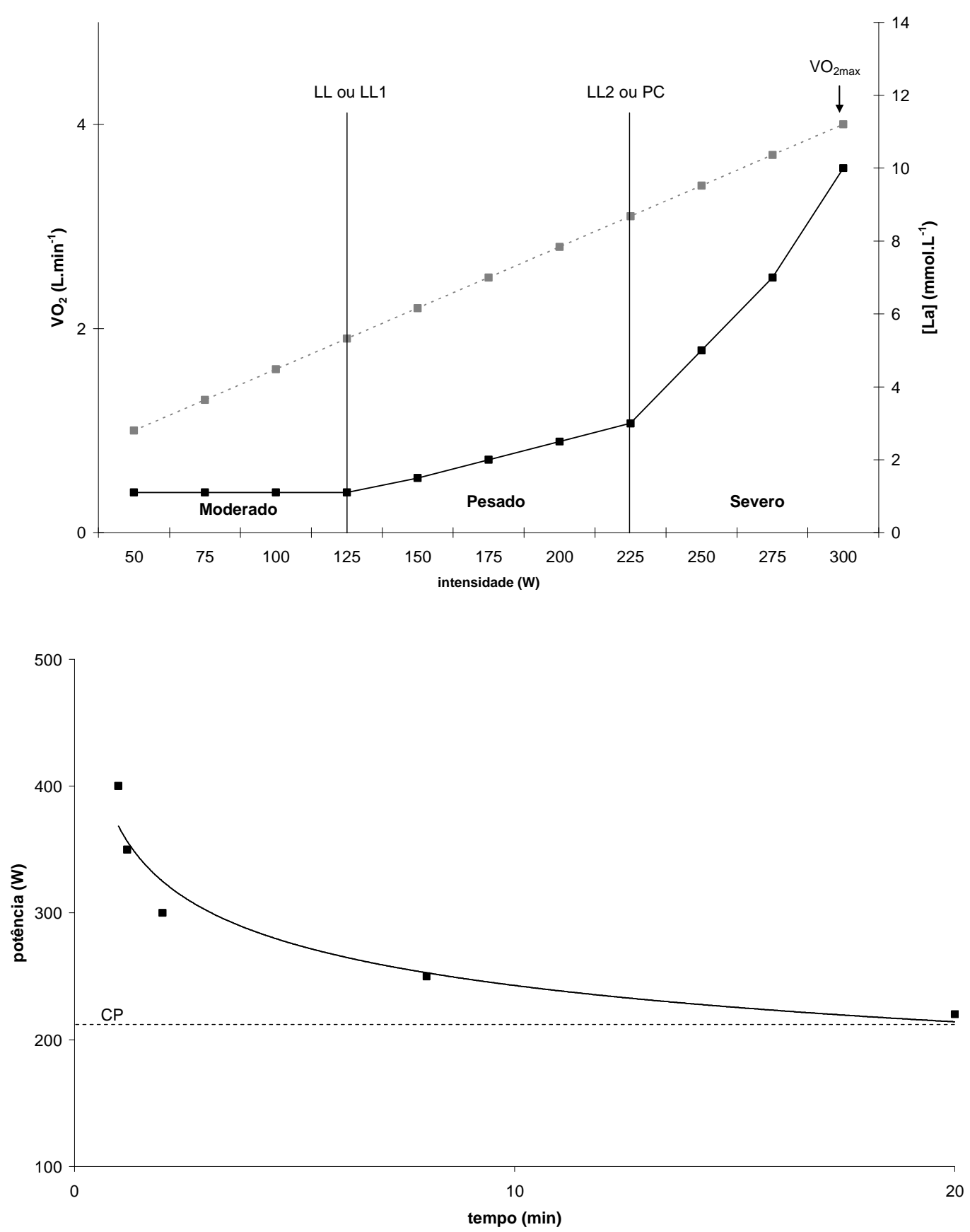

Figura 1. Comportamento hipotético do lactato sangüíneo (linha contínua) e do consumo de oxigênio (linha tracejada) em função da intensidade (painel superior). A partir da curva lactato intensidade é possível identificar o primeiro (LL1) e o segundo (LL2) limiar de lactato, separando os domínios moderado, pesado e severo. No painel inferior está representada a curva potência-tempo, com identificação do valor assintótico chamado de potência crítica (CP). Teoricamente, CP corresponde ao LL2 no painel superior. 
Apesar de apresentar um padrão de resposta parecido em todos os domínios, a característica da curva $\mathrm{VO}_{2}$-tempo é dependente do domínio metabólico em que se está investigando. Classicamente, podem ser identificadas três fases fisiológicas distintas (I, II e III) no ajuste da relação $\mathrm{VO}_{2}$-tempo de carga, segundo Whipp (1994):

Fase I - Os primeiros segundos do exercício, denominada "fase I da resposta do consumo de oxigênio $\left(\mathrm{VO}_{2}\right)$ )", com uma trajetória ascendente (fase on), é caracterizado por um atraso temporário na resposta do $\mathrm{VO}_{2}$, ocasionado pela dissociação entre o oxigênio absorvido no pulmão e o consumido na musculatura esquelética, especialmente nos músculos responsáveis pela contração muscular. A fase I pode ser ajustada com uma equação monoexponencial e deve ser incluída na equação monoexponencial da fase II como uma constante (tempo de atraso), tendo duração aproximada de 15 a 20 segundos (figura 2).

Fase II - Após esses 15 - 20 primeiros segundos existe a fase II, ou componente primário, da resposta on, apresentando um aumento contínuo no $\mathrm{VO}_{2}$, podendo ou não resultar em uma fase de equilíbrio, dependendo da intensidade do exercício (figura 2). A fase II caracteriza-se, principalmente, pela utilização dos estoques de oxigênio pelos músculos esqueléticos, ocasionando uma redução no conteúdo de oxigênio do sangue venoso misto, uma redução da pressão parcial de oxigênio $\left(\mathrm{PO}_{2}\right)$ nas unidades contráteis e possivelmente, uma menor contribuição da desaturação do complexo oxigênio - mioglobina nas fibras musculares. Como conseqüência, ocorre um aumento na diferença do conteúdo de oxigênio arteriovenoso.

Fase III - A terceira fase da resposta on, descrita por Whipp (1994), nem sempre é atingida (BARSTOW; MOLE, 1991; WHIPP; WASSERMAN, 1972). Quando o exercício é realizado no domínio moderado (abaixo do LL1), o $\mathrm{VO}_{2}$ estabiliza e permanece com pouca variação até o final, representando um aparente equilíbrio metabólico. Porém, quando os exercícios são realizados no domínio pesado e severo (acima de LL1, mas abaixo do $\mathrm{VO}_{2 \max }$ ), o $\mathrm{VO}_{2}$ correspondente à carga encontra-se acima do predito pela relação $\mathrm{VO}_{2}$-carga obtida no domínio moderado. Esse oxigênio "extra" consumido é denominado componente lento do consumo de oxigênio (figura 2).

A amplitude e a estabilização ou não do componente lento depende do domínio metabólico. Em exercícios realizados no domínio pesado, existe uma tendência à estabilização do $\mathrm{VO}_{2}$, mas como dito anteriormente, em valores superiores ao predito pela relação $\mathrm{VO}_{2}$ carga obtida no domínio moderado. No domínio severo, existe uma tendência ao $\mathrm{VO}_{2}$ aumentar progressivamente, atingindo o $\mathrm{VO}_{2 \max }$ identificado em teste incremental 
(GAESSER; POOLE, 1996). Assim, a amplitude do componente lento é proporcional a intensidade do esforço, ou seja, será maior no domínio severo do que no domínio pesado.

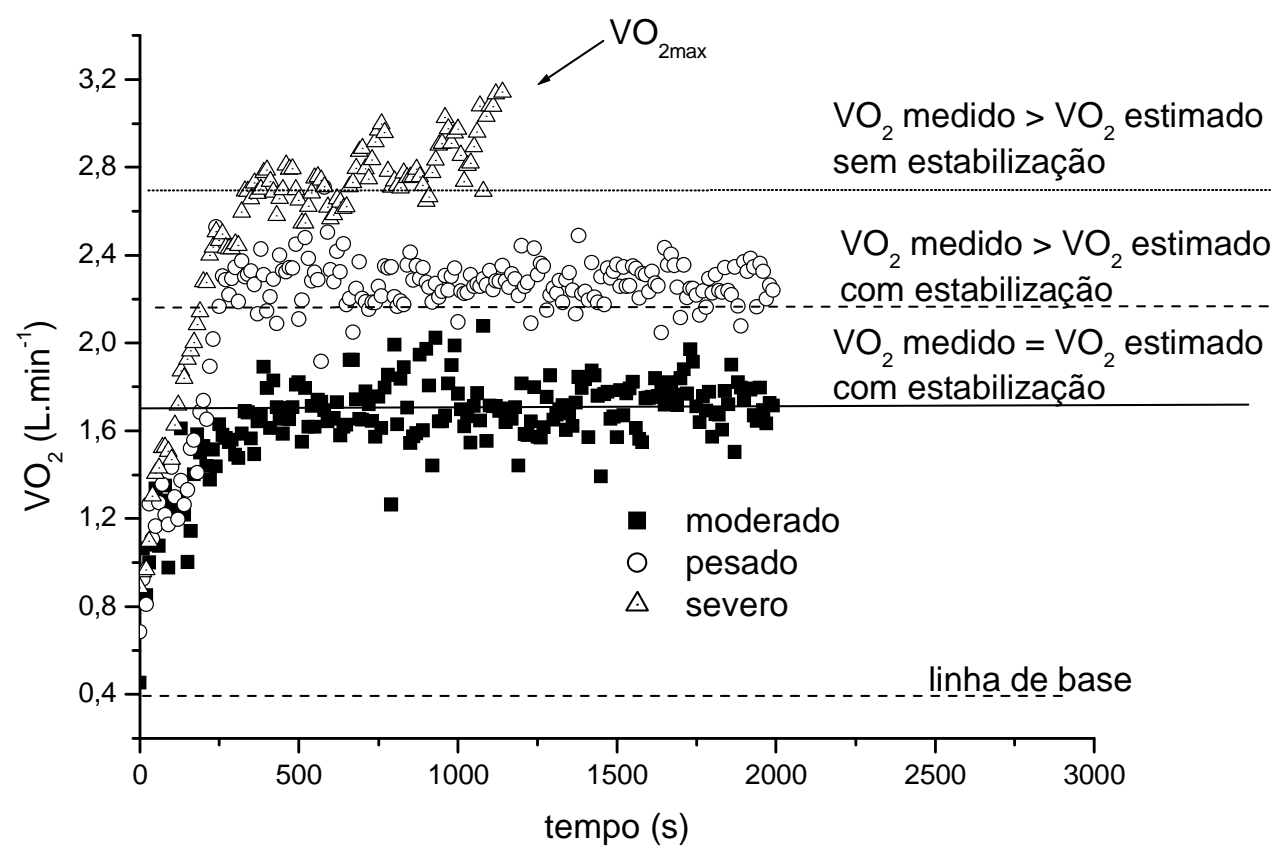

Figura 2. Modelo ilustrativo da resposta do consumo de oxigênio $\left(\mathrm{VO}_{2}\right)$ durante exercício de carga constante no domínio moderado, pesado e severo. Observa-se que no domínio

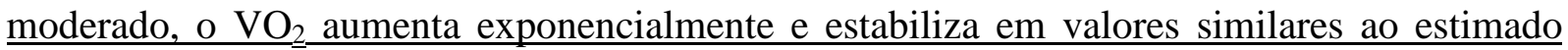
pela relação intensidade- $\mathrm{VO}_{2}$ em cargas abaixo do primeiro limiar de lactato. No domínio pesado o $\mathrm{VO}_{2}$ estabiliza em valores superiores ao estimado por essa relação. No domínio

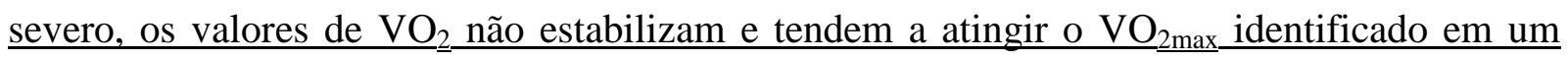
teste incremental máximo.

A partir do apresentado, fica evidente que, o que determina um domínio metabólico é o modelo de resposta do $\mathrm{VO}_{2}$ no tempo. Contudo, na proposta descrita anteriormente, não foi incluída a resposta do $\mathrm{VO}_{2}$ em exercícios supramáximo, isto é, em intensidades acima do $\mathrm{VO}_{2 \max }$. Özyener et al. (2001) caracterizou a amplitude e o tempo de resposta do componente primário (fase II) e do componente lento (fase III) em quatro diferentes intensidades. Cada uma das intensidades representou um domínio metabólico. Assim, uma pequena alteração de nomenclatura foi proposta no estudo de Özyener et al. (2001), sendo que, no presente estudo, essa nova nomenclatura foi acatada e utilizada nas sessões posteriores do trabalho. Esses 
domínios foram chamados de moderado (90\% do LL), pesado ( $L L+40 \%$ da diferença entre o $\mathrm{VO}_{2 \max }$ e LL), muito pesado ( $\mathrm{LL}+80 \%$ da diferença entre o $\mathrm{VO}_{2 \max }$ e $\mathrm{LL}$ ) e severo $(110 \%$ do $\mathrm{VO}_{2 \max }$ ). Observa-se aqui que, o domínio muito pesado substitui o antigo domínio severo, enquanto o novo domínio severo descreve a intensidade de esforço supra $\mathrm{VO}_{2 \max }$. Nesse estudo, os autores observaram que o modelo monoexponencial descreve melhor o comportamento do $\mathrm{VO}_{2}$ nos domínios moderado e severo (supra $\mathrm{VO}_{2 \max }$ ), enquanto, o modelo biexponencial descreve melhor o comportamento dos domínios pesado e muito pesado (ÖZYENER et al., 2001). Nesse caso, a descrição dos melhores modelos sugere a presença de componente lento apenas nos domínios pesado e muito pesado. Nos esforços do domínio severo, a intensidade é tão elevada que reduz o tempo possível de sustentar o esforço, e por consequência, não é suficiente para permitir o aparecimento do componente lento. Realmente, nesse estudo o tempo médio para início da segunda exponencial, isto é, início do componente lento, foi de aproximadamente 154 e 137 segundos para o domínio pesado e muito pesado, respectivamente, sugerindo que o componente lento só poderia ser identificado em intensidades nas quais fosse possível suportar um tempo superior a esse. O tempo de sustentação no domínio severo foi de 150 segundos, justificando a ausência de componente lento.

Ainda sobre a divisão dos domínios, Hill, Poole e Smith (2002) não têm o mesmo entendimento que Özyener et al. (2001) e, utilizam como domínio severo, qualquer intensidade de esforço que esteja entre a $\mathrm{PC}$ e a maior intensidade capaz de atingir o $\mathrm{VO}_{2 \max }$. Esse ponto superior então seria a maior intensidade na qual a duração do esforço fosse longa o suficiente para permitir que o $\mathrm{VO}_{2 \max }$ pudesse ser atingido. No estudo de Hill, Poole e Smith (2002), esse limite superior correspondeu a $136 \%$ da potência máxima aeróbia, com duração mínima de 136 segundos. Apesar de interessante, do ponto de vista prático, essa proposta inviabiliza a utilização dessa nomenclatura, pois seriam necessários muitos testes para identificar o limite superior desse domínio. Assim, como dito anteriormente, a nomenclatura "severo" será reservada a esforços supra $\mathrm{VO}_{2 \max }$, enquanto a "muito pesado" para esforços entre o LL2 ou PC e o VO $\mathrm{V}_{2 \max }$, segundo a sugestão de Özyener et al. (2001).

Para finalizar, o modelo de resposta da concentração de lactato sanguíneo no tempo para cada um dos domínios segue, basicamente, o mesmo do $\mathrm{VO}_{2}$, porém sem a possibilidade de ajustes matemáticos complexos, devido à baixa resolução da medida (enquanto $\mathrm{VO}_{2}$ pode 
ser medido a cada respiração, lactato só pode ser medido em janelas maiores de tempo, como 30 segundos ou 1 minuto).

\subsection{Metabolismo dos carboidratos}

A musculatura esquelética e o fígado são os principais órgãos de armazenamento de glicogênio. Embora encontremos no fígado uma maior concentração desse composto (até 6\%), as reservas são maiores em termos absolutos na musculatura esquelética (MAYES, 1994).

O metabolismo do GM durante o exercício passou a ser mais bem compreendido a partir de uma série de estudos clássicos publicados pelo grupo do Instituto da Karolinska de Estocolmo (ALBORG et al. 1967, BERGSTROM et al., 1967, BERGSTROM; HULTMAN, 1967). Esses estudos constituíram a base do conhecimento sobre o metabolismo do GM durante o exercício (COYLE et al., 1986; CONLEE, 1987; ADAMO; TARNOPOLSKY; GRAHAM, 1998; FEBBRAIO; DANCEY, 1999). Dentre os principais achados deste grupo estão: a correlação linear entre o tempo de fadiga em uma determinada intensidade $\left(\% \mathrm{VO}_{2 \max }\right)$ e as concentrações iniciais de glicogênio no músculo (figura 3), bem como, a redução dos estoques de glicogênio ( $\mathrm{g} / 100 \mathrm{~g}$ músculo seco) de forma semi-logarítmica em função do tempo, tendendo a aproximar-se de zero no mesmo instante em que passa a ser difícil a manutenção da intensidade do exercício.

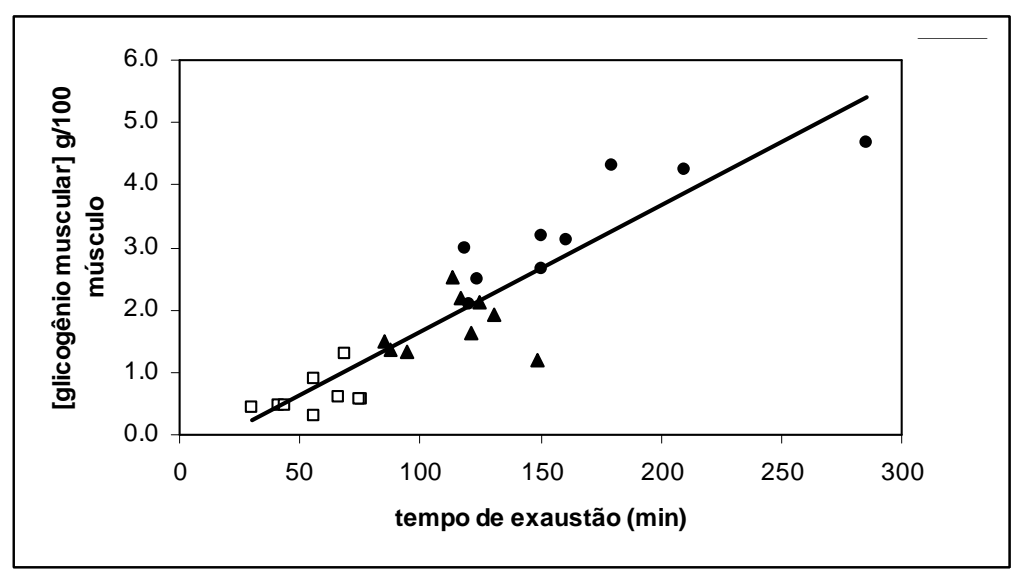

Figura 3. Relação entre a concentração inicial de glicogênio muscular e tempo de performance

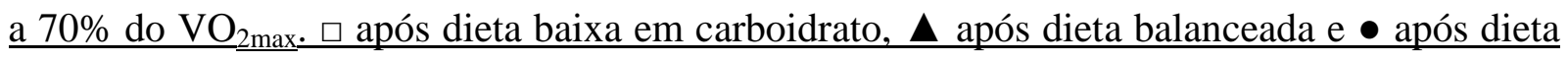
alta em carboidrato. Adaptado de Bergstrom et al. (1967). 
Estudos posteriores suportaram esse comportamento de redução do GM em função do tempo de exercício (COYLE et al., 1986; BOSCH; DENNIS; NOAKES, 1993). Entretanto, foi destacado que a curva glicogênio-tempo de exercício poderia apresentar comportamento trifásico, ou seja, possui um rápido declínio inicial, seguido por uma queda constante, e finalmente, uma degradação mais lenta nos minutos finais. Inicialmente, a explicação para esse comportamento baseou-se na existência de um estado de hipóxia relativa nos momentos iniciais do exercício, levando a uma rápida degradação do GM, com conseqüente formação de lactato sanguíneo. Na parte média da curva, a queda constante poderia ser derivada da estabilização nos processos metabólicos, com equilíbrio entre a utilização do GM de forma aeróbia e a produção de lactato. Na última parte da curva, os estoques reduzidos de GM levariam a uma lenta degradação, aumentando gradativamente a utilização de gordura e glicose sanguínea como fonte de energia (BERGSTROM; HULTMAN, 1967).

Contudo, a primeira explicação atualmente pode ser contestada, pois um estado de hipóxia nem sempre é encontrado nas células musculares a ponto de impossibilitar a utilização do metabolismo oxidativo (BROOKS, 1985). A degradação rápida do GM, tendo como produto final o lactato, pode ser decorrente da ineficiência dos sistemas de transporte de íons $\mathrm{H}^{+}$para dentro da mitocôndria pelas lançadeiras de glicerol-fosfato (STAINSBY, 1986), ou de uma inerente inércia das enzimas mitocondriais, responsáveis pelos processos oxidativos (GRASSI et al., 1998).

A ideia de que as reservas de GM aproximam-se de zero no instante em que iniciam os sintomas de fadiga foram falseadas (Tabela 1). Em todos os estudos subsequentes a 1967, observou-se resquício de $\mathrm{GM}(\cong 24 \%)$ ao final de exercícios prolongados $\left(\cong 70 \% \mathrm{VO}_{2 \max }\right)$, interrompidos pela exaustão do indivíduo (LOY et al., 1986; BOSCH; DENNIS; NOAKES, 1993; TSINTZAS et al., 1995). Embora na maior parte desses estudos a fadiga se apresentasse associada com a redução do GM, a pequena reserva restante seria suficiente para o prolongamento da atividade, o que leva à especulação de outros mecanismos envolvidos na interrupção de exercícios com essas características. 
Tabela 1. Principais estudos sobre depleção de glicogênio muscular e fadiga.

\begin{tabular}{|c|c|c|c|c|}
\hline Modo de exercício & Tempo de exaustão (min.) & Glicogênio inicial & Glicogênio final & Referência \\
\hline Ciclismo a $75 \% \mathrm{VO}_{2 \max }$ & $\begin{array}{l}166,5 \text { (dieta } \uparrow \mathrm{CHO}) \\
113,6 \text { (dieta mista) } \\
56,9 \text { (dieta } \downarrow \mathrm{CHO})\end{array}$ & $\begin{array}{l}3,31 \pm 0,30+t+ \\
1,75 \pm 0,15+t+ \\
0,63 \pm 0,10+t \neq\end{array}$ & $\begin{array}{l}0,43 \pm 0,06 \ddagger+\ddagger \\
0,17 \pm 0,05+4 \ddagger \\
0,13 \pm 0,05+4 \ddagger\end{array}$ & Bergstrom et al. (1967) \\
\hline Ciclismo a $62 \%$ de $\mathrm{W}_{170}$ & 126,9 & $1,53 \pm 0,41 \neq+\neq$ & $0,38 \pm 0,20 \ddagger+\ddagger$ & Ahlborg et al. (1967) \\
\hline Ciclismo a $86 \% \mathrm{VO}_{2 \max }$ & $\begin{array}{c}\text { Fadiga } 1 \#=42,0 \pm 6,2(24 \mathrm{~h} \text { de jejum }) \\
115,3 \pm 25,6(\text { dieta normal }) \\
\text { Fadiga } 2 \#=170,0 \pm 20,4(24 \text { jejum }) \\
201,0 \pm 14,8(\text { dieta normal })\end{array}$ & $\begin{array}{c}182,9 \pm 29,9 \ddagger(24 \text { jejum }) \\
168,0 \pm 17,1 \ddagger(\text { dieta } \\
\text { normal })\end{array}$ & $\begin{array}{c}\text { Fadiga } 2 \#=74,3 \pm 14,3 \ddagger(24 \\
\text { jejum) } \\
70,9 \pm 26,3 \ddagger(\text { dieta normal })\end{array}$ & Loy et al. (1986) \\
\hline Ciclismo a $79 \% \mathrm{VO}_{2 \max }$ & $\begin{array}{c}\text { Fadiga } 1 \#=142,0 \pm 19,6(24 \mathrm{~h} \text { de } \\
\text { jejum); } 167,5 \pm 10,5 \text { (dieta normal }) \\
\text { Fadiga } 2 \#=191,3 \pm 25,0(24 \text { jejum }) \\
214,3 \pm 18,9 \text { (dieta normal })\end{array}$ & $\begin{array}{c}143,7 \pm 22,0 \ddagger(24 \text { jejum }) \\
186,1 \pm 23,8 \ddagger(\text { dieta } \\
\text { normal })\end{array}$ & $\begin{array}{c}\text { Fadiga } 2 \#=50,3 \pm 10,7 \ddagger(24 \\
\text { jejum) } \\
78,1 \pm 35,5 \ddagger(\text { dieta normal })\end{array}$ & Loy et al. (1986) \\
\hline Ciclismo $71 \% \mathrm{VO}_{2 \max }$ & $\begin{array}{l}\cong 240^{*} \\
\cong 180 \dagger\end{array}$ & $\begin{array}{l}173 \pm 11 \$ \\
163 \pm 13 \$\end{array}$ & $\begin{array}{l}39 \pm 8 \$ \\
37 \pm 5 \$\end{array}$ & Coyle et al. (1986) \\
\hline Ciclismo a $70 \%$ da $\mathrm{W}_{\max }$ & Fadiga \#\# $<2$ horas & ------ & ------- & $\begin{array}{l}\text { Wagenmakers et al. } \\
\text { (1991) }\end{array}$ \\
\hline Ciclismo a $70 \% \mathrm{VO}_{2 \max }$ & $150(n=4)$ & $124 \pm 7 \ddagger(\mathrm{n}=8)$ & $22 \pm 4 \div(n=4)$ & Bosch et al. (1993) \\
\hline Ciclismocom uma perna@ & $195 \pm 13$ & $354 \pm 41 \$$ & $25 \pm 9 \$$ & Casey et al. (1996) \\
\hline Corrida a $70 \% \mathrm{VO}_{2 \max }$ & $\begin{array}{c}132,4 \pm 12,3 * \\
104,3 \pm 8,6 \dagger\end{array}$ & $\begin{array}{l}382,4 \pm 20,2 \ddagger \\
395,9 \pm 29,9 \ddagger\end{array}$ & $\begin{array}{c}59,8 \pm 7,9 \ddagger \\
76,4 \pm 14,2 \ddagger\end{array}$ & Tsintzas et al. (1996) \\
\hline Ciclismo a $70 \% \mathrm{VO}_{2 \max }$ & $\begin{array}{l}103 \pm 15(\phi) \\
155 \pm 9(\phi \phi)\end{array}$ & ------ & ------ & Baldwin et al. (2003) \\
\hline
\end{tabular}

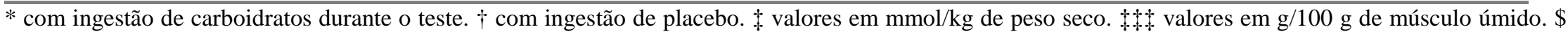
$\mathrm{mmol}$ de unidades de glicose $/ \mathrm{kg}$. \# fadiga 1 quando não conseguia manter a intensidade inicial exigida e fadiga 2 quando não conseguia manter $65 \%$ VO $\mathrm{O}_{2 \text { max }}$. \#\# quando não conseguia manter $50 \%$ da carga máxima. @ intensidade não apresentada. $\mathrm{VO}_{2 \max }$ consumo máximo de oxigênio. $\mathrm{W}_{\text {max }}$ carga máxima. $\mathrm{W}_{170}$ carga correspondente a uma frequiência cardíaca de 170 batimentos por minuto. $\phi$ glicogênio pré-exercício abaixo do normal. $\phi \phi$ glicogênio pré-exercício supercompensado. ------ Os valores de glicogênio não foram obtidos, porque nos artigos originais, são apresentados apenas graficamente. 
Outra série de estudos iniciada a partir da década de 1970 em Estocolmo, pelo grupo liderado por Gollnick, complementou o conhecimento sobre depleção de GM. Utilizando a técnica de histoquímica qualitativa, denominada "reação periódica do ácido-Schiff” (periodic acid-Schiff's reaction - PAS), Gollnick et al. (1972) verificaram que, após a redução do GM com manipulação exercício-dieta, seguida por três dias de dieta rica em carboidratos $(\cong 2.000$ kcal de carboidratos), as reservas de GM aumentavam aproximadamente $60 \%$ em relação a uma dieta mista. Ao final de trinta minutos de exercício na bicicleta ergométrica (74\% $\mathrm{VO}_{2 \max }$ ), a concentração de GM foi maior quando uma dieta rica em carboidratos precedia o teste. A novidade desse trabalho foi a apresentação dos resultados de depleção seletiva do GM, ou seja, a maior parte do glicogênio utilizado advinha das fibras de contração lenta. Resultados similares também foram encontrados após uma corrida de $30 \mathrm{~km}$, embora a influência da dieta anterior ao exercício não tenha sido estudada (COSTILL et al., 1973).

Em estudo posterior, Gollnick et al. (1973) observaram que o glicogênio das fibras de contração rápida era o primeiro a ser depletado após a realização de seis séries de um minuto de duração (150\% da potencia aeróbia máxima), intercalado por períodos de dez minutos de repouso entre as séries. Em publicação posterior, Gollnick, Piehl e Saltin (1974) finalizaram o modelo de depleção seletiva do GM, analisando diferentes intensidades de exercício na bicicleta ergométrica que variavam de 30 a $150 \%$ do $\mathrm{VO}_{2 \max }$. Os principais achados foram: 1) a depleção do GM foi 2,7 e 7,4 vezes maior, respectivamente, em 64 e $84 \%$ do $\mathrm{VO}_{2 \max }$, quando comparados a $31 \%$ do $\mathrm{VO}_{2 \max } ; 2$ ) as fibras de contração lenta foram as primeiras a diminuir as reservas de glicogênio em todas as intensidades abaixo do $\mathrm{VO}_{2 \max }$, mas com o passar do tempo, um progressivo decréscimo acontecia também em fibras de contração rápida; 3) nos exercícios de intensidade acima do $\mathrm{VO}_{2 \max }$, o glicogênio de ambas as fibras era depletado. Esses achados foram confirmados em estudos posteriores (VOLLESTAD; VAAGE; HERMANSEN, 1984).

Apesar do conhecimento obtido nas décadas de 1960 e 1970, os mecanismos fisiológicos e bioquímicos envolvidos na regulação da via de degradação do GM durante o exercício não foram totalmente esclarecidos. Atualmente, sabe-se que com o prolongamento da atividade a degradação (absoluta) do glicogênio diminui, enquanto os AGL circulantes no plasma e a glicose sanguínea aumentam sua participação na ressíntese do ATP. Entretanto, pouco se sabe sobre os mecanismos que controlam essas alterações. 
Em exercícios submáximos (entre $65-75 \% \quad \mathrm{VO}_{2 \mathrm{max}}$ ), o músculo ativo passa gradativamente a utilizar a glicose sanguínea e o AGL plasmático como fonte de energia, conforme mencionado acima. Isso parece mais evidente quando os níveis de GM pré-exercício encontram-se abaixo do normal (COSTILL et al., 1971). Uma questão inerente é: Qual desses dois substratos tem preferência na "substituição" do GM? Um trabalho de Weltan et al. (1998) permite levantar algumas especulações (tabela 2). Nesse estudo os indivíduos foram designados aleatoriamente para um de quatro grupos, sendo que em três grupos a glicemia foi mantida estável (euglicemia) através de infusão intravenosa de glicose. Desses três, um apresentava concentração inicial de GM normal, um depleção de glicogênio prévia e um depleção de glicogênio prévia mais infusão de insulina no exercício. No quarto grupo, também com depleção prévia, a taxa de infusão de glicose foi aumentada a fim de manter uma situação de hiperglicemia. Nos grupos com depleção, a utilização do GM foi significativamente reduzida. Mesmo mantendo a glicemia estável, a gordura foi o substrato energético preferencialmente utilizado na situação de depleção de glicogênio, exceto quando foi mantida uma hiperglicemia ou hiperinsulinemia. Nessas duas últimas situações, a glicose sangüínea foi utilizada predominantemente como fonte energética.

Tabela 2. Utilização do glicogênio muscular, gordura e glicose durante 145 minutos de exercício em cicloergometro a $70 \%$ do consumo máximo de oxigênio em três diferentes situações.

\begin{tabular}{lccc}
\hline & $\begin{array}{l}\text { Utilização de } \\
\text { glicogênio muscular }\end{array}$ & $\begin{array}{l}\text { Utilização de } \\
\text { Gordura }\end{array}$ & $\begin{array}{l}\text { Utilização de } \\
\text { glicose }\end{array}$ \\
\hline DG-euglicemia & $\downarrow$ & $\uparrow$ & $\uparrow$ \\
DG-euglicemia + insulina & $\downarrow$ & $=$ & $\uparrow$ \\
DG-hiperglicemia & $\downarrow$ & $=$ & $\uparrow$ \\
\hline
\end{tabular}

DG = depleção prévia de glicogênio muscular. Setas e símbolos descrevem a modificação no metabolismo em comparação com a situação de glicogênio muscular normal. Adaptado de Weltan et al. (1998).

Esses achados, embora se distanciem de situações fisiológicas normais, sugerem que em situações de depleção de GM, o músculo ativo utiliza preferencialmente os lipídios como 
substrato energético, provavelmente por controle hormonal. A norepinefrina exerce um papel importante, pois sua concentração no sangue aumenta significativamente com o exercício, aumentando as concentrações de AGL plasmáticos e auxiliando na manutenção da glicemia. Em contrapartida, a insulina em excesso (por infusão ou hiperglicemia) exerce efeitos antagônicos, estimulando o consumo de glicose pelo músculo, e inibindo a lipólise. A preferência por lipídios como fonte de energia na ausência de concentração adequada de GM tem sido sustentada na literatura (ROMIJN et al., 1993).

A partir dos dados experimentais apresentados na literatura, especula-se que, de forma defensiva e prioritária, o organismo privilegia a oferta de glicose ao sistema nervoso central (SNC), protegendo-o de possíveis "lesões" por deficiência de nutriente. Esse raciocínio corrobora com a hipótese de um "governador central" controlando os mecanismos de fadiga (NOAKES; PELTONEN; RUSKO, 2001). O mecanismo fisiológico de restrição no consumo de glicose plasmática em situações de depleção de GM não está totalmente esclarecido, mas a hipótese mais provável seria a limitação no transporte de glicose através da membrana da célula. Estudos de HESPEL e RICHTER (1990), com animais, demonstraram que ratos com depleção de glicogênio aumentavam o transporte de glicose pela membrana em 25\% durante 15 minutos de contração isométrica máxima, quando comparados a ratos com supercompensação (combinação de exercício e dieta). Mesmo assim, esse aumento não foi suficiente para restabelecer o metabolismo de carboidratos, sendo necessária a compensação através de um aumento no consumo de lipídios e aminoácidos, conforme já mensurado em humanos (COGGAN, 1991; BLOMSTRAND; SALTIN, 1999). Como discutido anteriormente, o aumento exógeno de insulina no exercício, em conjunto com uma hiperglicemia induzida, pode facilitar o transporte de glicose através da membrana plasmática e restabelecer o metabolismo de carboidrato nas situações de depleção de GM (WELTAN et al., 1998).

Se por um lado, a escolha da célula muscular em utilizar lipídios como fonte de energia proporciona uma "economia" de carboidratos, em especial de glicose sanguínea, por outro, constitui uma manobra que, inevitavelmente, prejudica a manutenção da intensidade do exercício e o desempenho (MANETTA et al., 2002). Isso porque os ácidos graxos necessitam de maior quantidade de oxigênio para serem oxidados. A quantidade de energia liberada por litro de oxigênio e a velocidade de degradação da molécula é maior quando metabolizada a

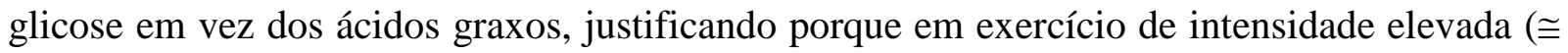


$85 \% \mathrm{VO}_{2 \max }$ ) os carboidratos são preferencialmente utilizados (ROMIJN et al., 1993; BROOKS; MERCIER, 1994). Como o importante para atletas em competições de longa duração é realizar a prova na maior intensidade possível, os carboidratos acabam constituindo a principal fonte de energia. Esse pensamento está de acordo com o conceito de "crossover" do metabolismo, que estabelece uma modificação da predominância de lipídios para carboidratos acontecendo próximo a $80 \%$ do $\mathrm{VO}_{2 \max }$, independente do nível de aptidão aeróbia (BROOKS; MERCIER, 1994; BROOKS; TRIMMER, 1996). Infelizmente, não existem estudos que tenham utilizados os limiares de lactato para identificar essa transição, apesar de Achten e Jeukendrup (2004) terem demonstrado que o LL1 corresponderia ao ponto de máxima utilização de gordura em termos absolutos, enquanto o LL2 o ponto de mínima utilização. Interessante que o ponto de mínima utilização acontece a aproximadamente $80 \%$ do $\mathrm{VO}_{2 \max }$, sugerindo que, a partir desse ponto, a energia é derivada quase que exclusivamente dos carboidratos.

\subsubsection{Efeito da insulina e do exercício no transporte celular de glicose}

Conforme discutido anteriormente, o excesso de insulina exógena em conjunto com uma elevação da glicemia sanguínea aumenta o catabolismo da glicose vinda do sangue (WELTAN et al., 1998). Tem sido documentado atualmente que, durante o exercício, a glicose entra na fibra muscular de forma independente da insulina, provavelmente por aumentar o número de transportadores de membrana ativos, chamados de GLUT-4 (JESSEN et al., 2003). Entretanto, apesar dessa ativação independente durante o exercício, o transporte pode permanecer parcialmente controlado pela insulina. Dados recentes de Christ-Roberts et al. (2003) suportam essa concepção, demonstrando que o exercício com duração de 30 minutos a $70 \% \mathrm{VO}_{2 \max }$, com infusão de insulina, aumenta o transporte de glicose pela membrana plasmática. Esse aumento no transporte foi devido a uma maior ligação entre o receptor primário da insulina (IRS-1) com a subunidade de fosfatidilinositol 3-quinase (PI3-quinase), desencadeando um potente efeito de cascata dentro do citoplasma, com subsequente fosforilação dos receptores serina/tireonina quinase e aumento na ação do GLUT-4.

Estudos com animais têm demonstrado que o exercício também estimula a ação do GLUT-4, independentemente da sinalização de PI3-quinase (JESSEN et al., 2003). O mecanismo envolvido não está totalmente esclarecido, mas uma possível via seria a produção da 5'-AMP-ativador da proteína quinase (PKA), o qual aumentaria a expressão gênica do 
GLUT-4 (NIELSEN et al., 2003). Aparentemente, a combinação insulina-exercício exerce um efeito amplificador, com maior consumo de glicose pela célula muscular. Provavelmente, apenas combinando exercício e infusão de insulina com manutenção exógena da glicose é que a predominância energética em exercícios prolongados passaria de lipídios para carboidratos.

Um estudo de Nielsen et al. (2003) demonstrou que, em exercício a $80 \% \mathrm{VO}_{2 \max }$, a fosforilação da subunidade catalítica a-PKA (Thr172) foi menor em um grupo de pessoas treinadas aerobiamente, quando comparados com um grupo de sedentários. Interessante que, com menor ativação de transportadores, a concentração de glicose plasmática foi aumentada $(5,9 \pm 0,5$ vs 4,7 $\pm 0,3 \mathrm{mM})$; similar aos dados reportados por Coggan et al. (1995) que observaram na mesma intensidade ( $\cong 80 \% \mathrm{VO}_{2 \max }$ ), uma menor taxa de desaparecimento $(\mathrm{Rd})$ da glicose do sangue em ciclistas bem treinados. Nielsen et al. (2003) mostraram também uma utilização de GM similar entre os grupos, mesmo com os treinados apresentando um maior estoque inicial. Isso corrobora em parte com o conceito de "crossover" (BROOKS; TRIMMER, 1996) e sugere um mecanismo poupador de glicose plasmática em indivíduos treinados aerobiamente.

Três importantes constatações podem ser destacadas quanto ao metabolismo de GM: 1) uma preferencial utilização de ácidos graxos em situações de depleção de glicogênio; 2) o consumo de glicose pelo músculo esquelético durante o exercício pode ser transporte-limitado e; 3) quando os estoques de glicogênio estão em níveis normais, principalmente nas intensidades mais elevadas, existe uma preferência por essa fonte de energia. A glicose vem a ser então um rico e precioso combustível, que deve ser utilizada predominantemente pelo músculo ativo apenas quando a concentração plasmática possa ser mantida de forma exógena (infusão ou ingestão).

\subsubsection{Estrutura funcional do glicogênio muscular}

Além do integrado controle apresentado na sessão anterior, envolvendo sinalizadores e receptores de membrana, a própria estrutura do glicogênio parece contribuir para esse controle. Uma proposta de auto-regulação, a partir da integração física e enzimática da molécula de glicogênio, foi apresentada por Shearer e Graham (2004). O modelo foi elaborado a partir do desenvolvimento de um método semi-quantitativo de determinação do GM, utilizando a técnica de microscopia de transmissão eletrônica, a qual permite conhecer o número, distribuição e área de cada grânulo de glicogênio. Inicialmente, o grânulo cresce em 
um formato linear, com aumento seqüencial de unidades de glicose, sendo a primeira ligação unida à glicogenin, uma proteína auto-glicosilante. A partir dessa primeira ligação, mais unidades de glicose podem ser adicionadas pela ação de duas enzimas-chave no processo de síntese, a glicogênio sintetase (GS) e a enzima ramificadora. O acréscimo sequencial e ramificado de glicose realizado por essas duas enzimas faz com que os estoques de carboidratos dentro da célula cresçam de forma exponencial. A molécula passa então a apresentar um formato esférico, com o seu crescimento sendo inibido quando atinge um diâmetro de aproximadamente 42 nanômetros.

Existem duas principais formas de armazenamento do glicogênio, as quais podem ser identificadas pela sua solubilidade em ácido perclórico, denominadas proglicogênio (PG) e macroglicogênio $(\mathrm{MG})$. A primeira constitui uma molécula menor ( $\cong 400$ quilodaltons - kDa) com maior razão proteína/carboidrato. A segunda, uma molécula maior (107 daltons - Da), com a mesma quantidade de proteína da PG, mas com mais carboidrato (menor razão proteína/carboidrato).

Um estudo de Graham et al. (2001) demonstrou que PG e MG apresentam dinâmicas de degradação diferentes, que podem ser dependentes da intensidade de esforço. Nesse estudo, os autores demonstraram que a taxa de degradação de MG e PG era similar em exercícios a $70 \% \mathrm{VO}_{2 \max }$, mas muito maior de $\mathrm{PG}$ quando o exercício era realizado a $85 \% \mathrm{VO}_{2 \max }$. Durante a primeira série de exercício intermitente ( 3 x 3 minutos a $100 \% \mathrm{VO}_{2 \max }$ ), as duas formas eram utilizadas em proporções similares, mas com tendência a manter a preferência pela PG. Na segunda série, um declínio no metabolismo de MG e manutenção de PG foram observados, apesar de não diferirem estatisticamente. Na última, as duas formas diminuíram a taxa de degradação. Os autores concluíram que a forma PG pode ser metabolicamente mais ativa e o metabolismo de MG pode ser rapidamente inibido com o passar do tempo, tanto em exercícios continuados, quanto repetidos. Esse fato não parece ser generalizável, uma vez que, analisando a figura 1 (figura 4 do presente texto) do trabalho de Graham et al. (2001), percebe-se que a $85 \% \mathrm{VO}_{2 \max }$, uma queda significativa na taxa de degradação do glicogênio com o tempo foi observada apenas para PG, com a de MG mantendo-se constante no tempo. Resta ainda, determinar a mudança na degradação de MG e PG em exercícios prolongados, em especial de exercícios realizados até a exaustão. 


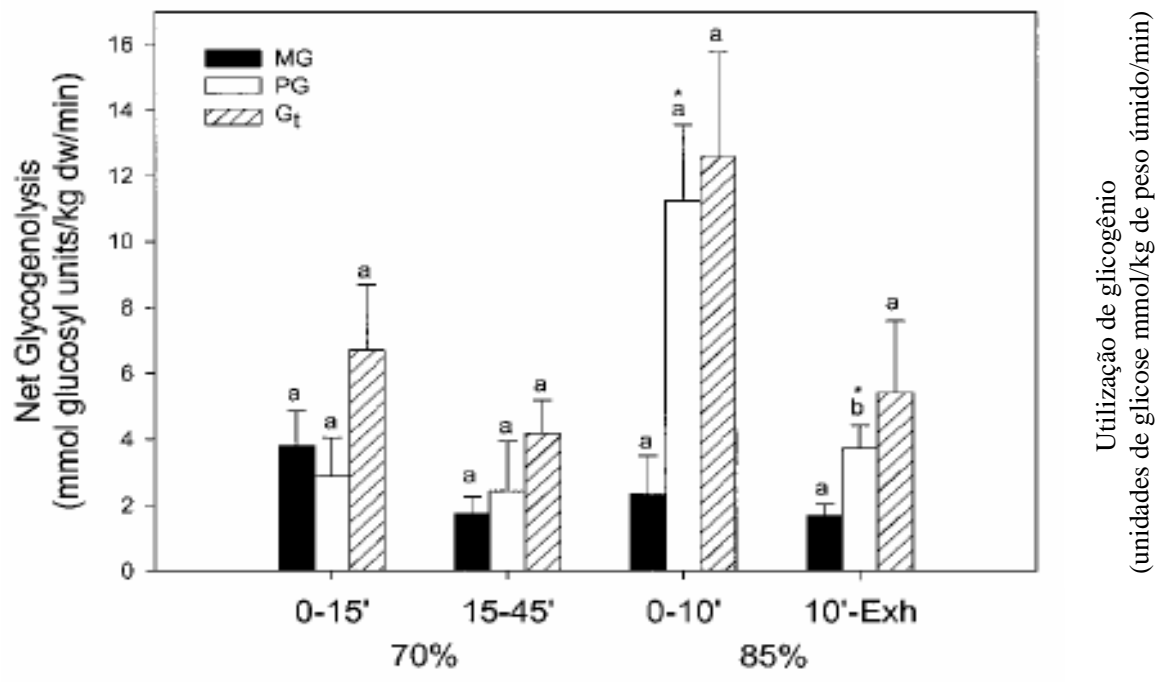

Figura 4. Taxa de glicogenólise (unidades de glicose em mmol/kg de músculo seco/minuto) do macroglicogênio (MG), proglicogênio (PG) e glicogênio total $\left(\mathrm{G}_{t}\right)$ no início (0-15 min ou 0-10

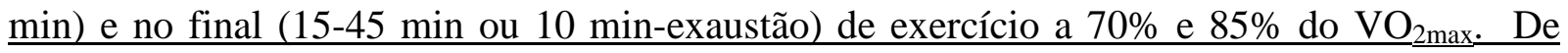
Graham et al. (2001). Letras iguais entre os dois intervalos de tempo, na mesma intensidade e para a mesma forma de glicogênio, representam igualdade de valores. o asterisco representa diferenças entre MG e PG no mesmo intervalo de tempo. Utilizado com permissão (ANEXO $\underline{1)}$.

Outro estudo anterior do mesmo grupo já havia mostrado que, após exercício a $70 \%$ $\mathrm{VO}_{2 \max }$ realizado até a exaustão, seguido por uma dieta composta por $75 \%$ de carboidrato durante dois dias, a forma MG aumenta somente nas 24 e 48 horas após o exercício. Outro dado interessante é que, apesar de aumentar a forma macro, a micro (PG) é mantida em valores próximos a $350 \mathrm{mmol}$ unidades de glicose $/ \mathrm{kg}$ de peso seco, muito semelhante à concentração total de glicogênio normal, sem supercompensação (ADAMO; TARNOPOLSKY; GRAHAM, 1998). Aparentemente, o glicogênio "extra" foi armazenado na forma MG, mas preservando a concentração fisiológica de PG. Os autores sugerem que esses resultados, junto com os obtidos no estudo de Graham et al. (2001), são fortes indicadores de que o PG é metabolicamente mais ativo. Entretanto, algumas lacunas deixadas em aberto merecem ser mais bem investigadas. Por que a supercompensação aumenta preferencialmente a forma $\mathrm{MG}$, se o aumento no tempo de exaustão causado pela supercompensação está 
associado à forma MG de glicogênio, e quais são os possíveis efeitos da depleção prévia de GM sobre o metabolismo de MG e PG, são questões que ainda precisam ser respondidas.

Conforme a "árvore" de glicogênio vai perdendo o conteúdo de glicose das extremidades, uma diminuição na atividade da enzima catalítica glicogênio fosforilase (GF) e aumento na atividade da enzima GS é observada (SHEARER; GRAHAM, 2004). O mecanismo exato dessa interferência física da molécula de glicogênio na ação enzimática não está muito bem explicado, mas assume-se que está relacionada a uma maior ativação da PKA em situações de diminuição na reserva de glicogênio, uma vez que essa enzima apresenta um sítio de ligação com a molécula de glicogênio e outro com a GS e GF. A PKA é uma importante proteína responsável pelo transporte de glicose e AGL para dentro da célula, o que poderia aumentar a oxidação e diminuir a síntese de substratos. Assim, a entrada de substrato na célula pode ser mediada parcialmente pelo conteúdo de GM.

Para a glicose 1-fosfato liberada do GM iniciar na via glicolítica, é necessário a conversão para glicose 6-fosfato, através da enzima fosfoglicomutase. Parece razoável imaginar que uma diminuição da atividade da GF acarretaria em uma menor formação de glicose 1-fosfato, e consequentemente, de glicose 6-fosfato. A diminuição na concentração de glicose 6-fosfato no músculo esquelético é um potente estimulador alostérico da hexoquinase, a enzima responsável pela fosforilação da glicose vinda do sangue. Como a reação glicose 6fosfato para frutose 6-fosfato apresenta-se em equilíbrio, a diminuição da glicose 6-fosfato leva a uma concomitante diminuição da frutose 6-fosfato. Como essa última enquadra-se como um regulador alostérico da fosfofrutoquinase (PFK), essa enzima pode diminuir sua atividade nas situações em que a concentração de frutose 6-fosfato decai. Uma predominância de glicose sanguínea entrando na via glicolítica pode ocasionar uma simultânea redução na velocidade de degradação, causada pela menor atividade da enzima PFK. Como consequência, a redução da glicose para piruvato aconteceria de forma mais lenta, facilitando a entrada dessa molécula na mitocôndria, o que evitaria a formação de lactato. Isso pode explicar porque alguns estudos apresentam uma menor concentração de lactato em exercício submáximo e máximo em situações de depleção de GM (PODOLIN et al., 1991; BLOMSTRAND. SALTIN, 1999). Realmente, existem evidências de que a formação de lactato a partir do GM é dez vezes maior do que a partir da glicose (NEWSHOLME; BLOMSTRAND; EKBLOM, 1992). 


\subsubsection{Efeito da intensidade do esforço no metabolismo de glicogênio muscular e alterações bioquímicas intracelulares}

Para uma determinada porcentagem do $\mathrm{VO}_{2 \max }$, a maioria dos estudos sobre depleção de GM demonstra que, nessa situação, ocorre uma diminuição significativa no tempo de manutenção do esforço (BERGSTROM et al., 1967; LOY et al., 1986; WAGENMAKERS et al., 1991). Além de todas as alterações metabólicas levantadas até aqui contribuírem para diminuição na performance, uma interessante hipótese seria a existência de um declínio nos intermediários do ciclo de Krebs, levando consequentemente, a uma menor ressíntese de ATP pela via aeróbia. Seguindo essa linha de raciocínio, isso aumentaria a concentração de ADP intramuscular, estimulando a reação da mioquinase e causando um acúmulo de IMP, com formação de amônia $\left(\mathrm{NH}_{3}\right)$. Entretanto, essa afirmação foi refutada recentemente em trabalho de Baldwin et al. (2003), que não conseguiram observar decréscimo na soma de quatro intermediários do ciclo (citrato, isocitrato, fumarato e malato) - os quais representam $70 \%$ do total - após $\cong 100$ minutos de exercício com depleção prévia de glicogênio ou $\cong 150$ minutos com supercompensação prévia de glicogênio, em uma intensidade referente a $70 \% \mathrm{VO}_{2 \max }$. Nesse mesmo estudo, a soma do total de adenina nucleotídeo (TAN = ATP + ADP + AMP) não foi alterada em nenhuma das situações.

Esse mecanismo continua intrigante porque existem resultados conflitantes na literatura. Por exemplo, Spencer e Katz (1991) observaram que, após um exercício de duração $\mathrm{de} \cong 5,5$ minutos na intensidade correspondente $\mathrm{a} \cong 95 \% \mathrm{VO}_{2 \max }$, o acúmulo de IMP foi maior em situações de depleção prévia de glicogênio, quando comparado com supercompensação prévia. Apesar do acúmulo de frutose 6-fosfato ter sido menor com depleção prévia (o que levaria a uma inibição da PFK), a glicólise não foi alterada devido à compensação exercida pelo acúmulo de ADP e AMP livre na célula, que funcionam como ativadores alostéricos da PFK. Resultados opostos foram encontrados por Febbraio e Dancey (1999), em que um exercício realizado $\mathrm{a} \cong 65 \% \mathrm{VO}_{2 \max }(93 \%$ do limiar de lactato) até a exaustão não causou um significativo aumento em IMP ou hipoxantinas, e também não reduziu o TAN. Apesar de uma significativa relação entre tempo de exaustão e uso de GM ter sido encontrada $(r=0,95 ; \mathrm{p}<$ $0,05)$, a associação entre IMP e GM no final do exercício não foi significativa $(r=0,73 ; \mathrm{p}>$ $0,05, \mathrm{n}=6)$. 
As diferenças entre os estudos podem ser devidas simplesmente à forma de controle da intensidade do exercício. Por exemplo, Broberg e Sahlin (1988) encontraram resultados diferentes de Febbraio e Dancey (1999), associando o acúmulo progressivo de $\mathrm{NH}_{3}$ com o baixo nível de GM ocasionado pelo exercício. A intensidade utilizada, entretanto, foi muito semelhante ( $\left.\cong 67 \% \mathrm{VO}_{2 \max }\right)$, mas a forma de determiná-la muito diferente. No estudo de Febbraio e Dancey (1999) a intensidade foi estabelecida a partir do limiar de lactato, o que de certa forma individualiza a intensidade de esforço, uma vez que, uma porcentagem fixa estabelecida unicamente a partir do $\mathrm{VO}_{2 \max }$, como utilizado no estudo de Broberg e Sahlin (1988), pode representar uma "carga interna" muito diferente entre os indivíduos (WELTMAN et al., 1989). Essas diferenças metodológicas podem submeter os indivíduos a diferentes domínios fisiológicos, sendo que os mecanismos de fadiga podem ser totalmente diferenciados quando comparadas intensidades referentes aos limiares de lactato (figura 1). Isso explica também porque, dependendo da intensidade estudada, a depleção de glicogênio pode ou não estar associada à fadiga (LOY et al., 1986).

Um estudo conduzido recentemente destacou o quanto a intensidade do esforço e o domínio fisiológico influência nos mecanismos de fadiga e no metabolismo energético (LIMA-SILVA et al., 2009). Nesse estudo, os indivíduos pedalavam até a exaustão em uma intensidade abaixo de LL2 e, em outro momento, acima do LL2. Em cada uma das intensidades foram utilizadas duas situações experimentais: 1) depleção de GM e 2) GM restaurado. O conteúdo de GM foi manipulado utilizando a metodologia clássica exercíciodieta. Nesse estudo foi observado que, quando o exercício era realizado abaixo de LL2, a depleção prévia de GM não interferia no tempo de exaustão ( $\cong 60$ minutos), além de não causar mudanças na concentração plasmática de lactato e glicose. Entretanto, um aumento na utilização de gordura como fonte de energia e uma diminuição no tempo de exaustão $(\cong 23$ vs 18 minutos) e na concentração de lactato foram observadas quando o exercício era realizado acima de LL2 com depleção prévia de GM, quando comparado a uma situação de não

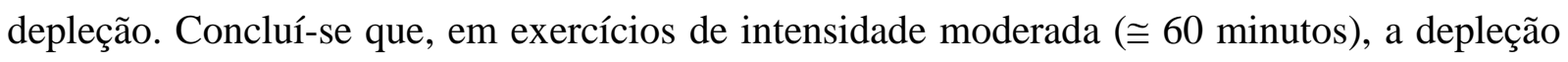
prévia de GM pode ter importância secundária, sendo que a regulação da temperatura corporal pode aumentar sua contribuição para a fadiga. Por outro lado, nos exercícios intensos $(\cong 20$ minutos), a aumentada taxa de utilização do GM torna esse substrato valioso e imprescindível, tornando mais importante até mesmo do que o acúmulo de metabólitos (lactato, por exemplo). 
Esses resultados são parcialmente divergentes com relação à literatura justamente por utilizar uma metodologia diferenciada na determinação do esforço, que é o uso de limiares de lactato em vez de porcentagens do $\mathrm{VO}_{2 \max }$ para determinação da intensidade de esforço. Estudos utilizando outros domínios fisiológicos seriam interessantes para melhor compreender os mecanismos de fadiga envolvendo o metabolismo de GM.

Evidências mostram que o exercício realizado acima do $\mathrm{VO}_{2 \max }$ (supra-máximo) parece ter uma dependência menor da disponibilidade inicial de GM. Em estudo de Vanderbergue et al. (1995) a $125 \% \mathrm{VO}_{2 \max }$, a supercompensação de glicogênio levou a um aumento de $56 \%$ na concentração muscular inicial desse composto, sem, no entanto aumentar a tolerância ao esforço ( $\cong 175$ s), ou modificar o acúmulo de lactato e de pH sanguíneos. Resultados similares foram encontrados por Hargreaves et al. (1997) que não identificaram nenhum efeito da supercompensação de GM sobre a potência de pico, potência média e máximo déficit acumulado de oxigênio em exercício máximo de 75 segundos. Entretanto, em atividades com exigência mista ou participação efetiva da capacidade lática (aeróbio-anaeróbio com duração entre 3 a 10 minutos, próximo ao $\mathrm{VO}_{2 \max }$ ), a depleção de $\mathrm{GM}$ pode interferir significativamente no desempenho. Newsholme, Blomstrand e Ekblom (1992) estimaram a

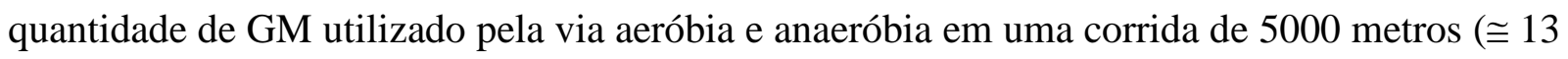
min) e demonstraram que, ambas, podem consumir quase todo glicogênio armazenado no músculo. Assumindo que essa estimativa esteja correta, a fadiga por depleção de glicogênio poderia acontecer antes do acúmulo excessivo de prótons no músculo. Estudos com o objetivo de determinar a intensidade a partir da qual as reservas de GM deixam de ser importante para o desempenho devem ser conduzidos, principalmente comparando esforços abaixo e acima do $\mathrm{VO}_{2 \max }$.

Digno de nota, nem todo glicogênio intracelular exerce função de regenerar ATP para contração muscular. Uma importante e significativa parcela destina-se a manter o funcionamento da bomba de cálcio e interfere apenas indiretamente no processo de contração relaxamento (FRIDÉN; SEGER; EKBLOM, 1989; CHIN; ALLEN, 1997). Alguns autores sugerem que, mesmo com glicogênio total intracelular suficiente para manter a atividade muscular, a depleção dos depósitos próximos à bomba de cálcio pode ocorrer precocemente, impossibilitando a continuidade do exercício (FEBBRAIO;. DANCEY, 1999). Apesar de 
evidências indiretas sugerirem a existência desse mecanismo em humanos (BOOTH et al., 1997), mas infelizmente não existem estudos que possam comprovar essa hipótese.

\subsubsection{Metabolismo do glicogênio hepático}

Até aqui, discutimos principalmente a alternância entre AGL e glicose no suprimento de energia, quando o GM encontra-se em estágios de depleção. Dentre as inúmeras possibilidades apresentadas, o transporte de glicose através da membrana plasmática constitui um fator importante que limita o uso desse substrato como fonte energética. Apesar de não ser totalmente conhecido, o organismo humano preferencialmente utiliza AGL plasmático e poupa glicose, provavelmente para manter a glicemia e garantir a sua oferta para o SNC. Entretanto, o principal órgão envolvido na manutenção da glicemia é o fígado, e sua reserva de glicose na forma de glicogênio é de suma importância para a continuidade de exercícios de longa duração, i.e. > 60 minutos (MAYES, 1994).

Apesar de não discutido anteriormente, é de grande aceitação que a principal técnica empregada para mensuração do glicogênio no músculo, a biópsia, apresenta uma série de limitações, das quais se destaca a mensuração de apenas uma pequena porção muscular. A dificuldade em mensurar o glicogênio hepático é ainda mais eminente, sendo a quantificação direta com o uso de biópsia inviável em humanos. Nós destinaremos essa sessão para discutir alguns poucos estudos que verificaram o metabolismo de glicogênio hepático, principalmente os artigos clássicos que foram publicados na década de 1970; e complementar a discussão com estudos que usaram glicose exógena na manutenção da glicemia.

Historicamente, os dois primeiros estudos que merecem atenção especial foram publicados na década de 1970. Ahlborg et al. (1974) estudaram seis indivíduos saudáveis durante a realização de quatro horas de exercício em um ciclo ergômetro, mantendo uma intensidade correspondente a $30 \% \mathrm{VO}_{2 \max }$. $\mathrm{O}$ metabolismo da região esplâncnica (devido à dificuldade em isolar as artérias e veias que circundam o fígado, o fluxo sanguíneo e a diferença arteriovenosa de determinado substrato era estimado dessa região) foi identificado utilizando um cateter que, após introdução pela veia antecúbital, era levado até o lado direito da veia hepática, utilizando a técnica de fluoroscopia. Pôde-se perceber que, a liberação de glicose pelo fígado aumentava aproximadamente em $100 \%$ em relação ao repouso, o que excedia a sua utilização pelo músculo ativo nos primeiros 40 minutos de exercício e considerado suficiente para manter a glicemia nesse período. Entretanto, até o final das quatro 
horas de exercício, acontecia um gradual declínio na concentração arterial de glicose, o qual foi associado com uma incapacidade do fígado em ofertar toda a glicose necessária para o metabolismo muscular. Gradativamente, ocorria um aumento no consumo de precursores gliconeogênicos (lactato, glicerol, piruvato e alanina), sendo esse mecanismo responsável por $45 \%$ da glicose liberada durante as 4 h de exercício e $20-25 \%$ mais alto do que no repouso.

Interessante que essa intensidade de exercício $\left(30 \% \mathrm{VO}_{2 \mathrm{max}}\right)$, é extremamente baixa, em comparação com os estudos de depleção de GM (Tabela 2). Estudos mais recentes de Romijn et al. (1993) e dados apresentados por Brooks e Trimmer (1996) demonstraram que a glicose sanguínea aumenta a sua participação como fonte energética apenas em intensidades acima de $65-80 \% \mathrm{VO}_{2 \max }$. Dessa forma, mesmo que exista uma diminuição significativa da glicose sanguínea no estudo de Ahlborg et al. (1974), as modificações poderiam ser mais expressivas se fossem utilizadas intensidades maiores. Além disso, como o tempo de exercício foi fixado em $4 \mathrm{~h}$ e a fadiga não foi utilizada como critério para interrupção do teste, não pode ser feita inferência quanto ao desempenho.

Em um estudo anterior, Wahren et al. (1971) observaram a liberação de glicose pelo fígado e o consumo pelo músculo em exercícios de intensidade leve, moderada e pesada (65, 130 e $196 \mathrm{~W}$, respectivamente). Todas as três formas de exercício foram realizadas por quarenta minutos. Importantes resultados foram obtidos a partir desse estudo. Nos exercícios de intensidade moderada e pesada ocorreu, em relação ao repouso, um aumento de 10 a 20 vezes no consumo de glicose sanguínea pelo músculo. Isso foi acompanhado por um aumento de três a cinco vezes na liberação de glicose pelo fígado. Quando calculado a contribuição percentual da gliconeogênese, essa ficou entre 6-11\%, o que é consideravelmente menor do que os $45 \%$ relatados por Ahlborg et al. (1974) em uma intensidade mais baixa. Esses resultados sugerem que, nas intensidades mais altas, a manutenção da glicemia depende da glicogenólise hepática, e consequentemente, do conteúdo prévio de glicogênio no fígado. Contudo, esses resultados devem ser vistos com cautela, pois a intensidade de esforço não foi determinada por nenhum marcador fisiológico e, possivelmente, representa intensidades relativas ao $\mathrm{VO}_{2 \max }$ ou limiares diferentes entre os sujeitos.

Explicitado a importância do conteúdo de glicogênio hepático na manutenção da glicemia, torna-se imprescindível correlacionar o desempenho com as diferentes manobras para poupar esse valioso substrato. Nós revisamos alguns estudos em que o desempenho era comparado em duas situações distintas; uma com uso de glicose durante a atividade (ingestão 
ou infusão), e outra com uso de placebo.

$\mathrm{O}$ uso de glicose durante o exercício atrasa consideravelmente o aparecimento de sintomas relacionados à fadiga (COYLE et al., 1986; NEUFER et al., 1987; COYLE, 1992; WAGENMAKERS et al., 1991; BOSCH; DENNIS; NOAKES, 1993; TSINTZAS et al., 1995; CHRYSSANTHOPOULOS; WILLIANS, 1997; DAVIS et al., 1999; SPENDIFF; CAMPBELL, 2002), embora alguns autores não observaram aumento da performance (RILEY et al., 1988; ANDREWS et al., 2003). Como os desenhos metodológicos entre os estudos são muitas vezes bem diferenciados, acaba sendo redundante atribuir os resultados conflitantes a essas diferenças. Torna-se mais produtivo, portanto, destacar apenas alguns estudos com melhor controle metodológico e objetivo mais abrangente. A seguir serão apresentados alguns desses estudos.

Coyle et al. (1986) estudaram sete ciclistas durante exercício até a fadiga em um ciclo ergômetro, com intensidade fixa referente a $70 \% \mathrm{VO}_{2 \max }$. O teste foi realizado duas vezes, uma com e outra sem o uso de glicose. Com o uso de glicose os indivíduos conseguiam pedalar por sessenta minutos adicionais, mas o metabolismo do GM foi basicamente o mesmo. Isso leva a crer que a manutenção da glicemia em níveis normais, observadas nessa condição experimental, estimula a uma maior oxidação de carboidrato exógeno e exerce um efeito poupador do glicogênio hepático (McCONELL et al., 1994). Entretanto a fadiga acontecia mesmo com a glicemia normal no exercício com uso de glicose, o que contestaria a hipótese de fadiga por hipoglicemia, levantada até aqui. Para esse fim, o estudo de Coyle et al. (1986) apresenta uma limitação porque a ordem dos testes não foi aleatória, sendo que, aquele com uso de glicose, foi realizado sempre por último. Isso pode levar os sujeitos a apresentar fadiga precocemente, uma vez que, percebendo que já haviam passado o tempo de exaustão apresentado no primeiro experimento, interromperiam a atividade. Outra possibilidade seria que, nessas condições, a fadiga poderia ocorrer por problemas termoregulatórios, e não por hipoglicemia.

Outro dado interessante é que o GM parece não ser poupado com o uso de glicose durante o exercício (COYLE et al., 1986). Comportamento muito similar foi observado por Neufer et al. (1987). Em sua revisão em 1992, Coyle baseia-se nos resultados de seu estudo de 1986 para afirmar que "a suplementação de carboidrato durante o exercício não exerce efeito poupador no GM". Atualmente, essa conclusão precisa ser vista com cautela porque existe um interessante estudo que não observou os mesmos resultados (TSINTZAS et al., 1995). Nesse 
estudo, Tsintzas et al. (1995) observaram que a ingestão de uma solução contendo $2 \mathrm{ml} / \mathrm{kg}$ de peso corporal de carboidratos a cada vinte minutos de corrida $\left(70 \% \mathrm{VO}_{2 \max }\right)$, aumenta significativamente o tempo de exaustão do exercício, com efeito poupador do GM. Não existe na literatura dados que possam explicar as possíveis causas das discrepâncias encontradas, merecendo ser mais bem investigado em trabalhos posteriores. Algumas observações referentes à metodologia desses estudos são importantes para elaboração de novos estudos. Abaixo são descritas algumas delas.

Analisando os dados de Coyle et al. (1986) percebe-se que a biópsia foi realizada no instante zero (repouso), na segunda, terceira e quarta hora após o início do exercício. Dados preliminares apresentados pelos autores, realizando a medida nos 105 minutos após o início do exercício, demonstravam a mesma tendência; um efeito não poupador de GM com o uso de glicose. Neufer et al. (1987) realizaram a medida no instante zero e 45 minutos após o inicio do exercício a $77 \% \quad \mathrm{VO}_{2 \max }$ e também não observaram mudanças significativas no metabolismo de GM. No estudo de Tsintzas et al. (1995), o espaço de tempo entre a primeira

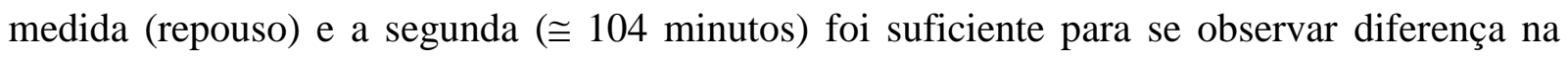
utilização do GM entre a situação experimental e placebo. Nesse último, o conteúdo de glicogênio foi poupado apenas nas fibras de contração lenta, com nenhum efeito sobre as fibras de contração rápida. Assim, o tempo/número de medidas e o tipo de fibra em que o glicogênio está sendo medido são importantes fatores metodológicos que necessitam ser controlados. A comparação entre diferentes ergômetros (ciclo ergômetro e esteira) também se torna necessária.

Como ainda é incerto o efeito poupador do GM com a suplementação de glicose durante o exercício, parece sensato pensar que uma importante parte dos mecanismos de fadiga estão ligados a processos centrais. Uma hipótese interessante é que com o uso de glicose exógena, a liberação de AGL pelo tecido adiposo seria menor e consequentemente, teria mais albumina na forma livre (DAVIS; BAILEY, 1997). Essa proteína realiza a função de carrear os AGL pelo plasma, mas exerce uma outra função importante; a de ligar-se ao triptofano, um aminoácido presente no sangue. Com o aumento acentuado na liberação de AGL, a albumina desliga-se do triptofano, dando preferência ao ácido graxo. Agora na sua forma livre, esse aminoácido é utilizado na região estriatal do SNC como precursor da serotonina (5-hidroxitriptamina; 5-HT), um neurotransmissor que pode causar indisposição, sonolência e falta de atenção (DAVIS; BAILEY, 1997; BERTUZZI; FRANCHINI; KISS, 
2004). Vale salientar que essa hipótese carece de comprovação experimental.

Como a mensuração de neurotransmissores centrais requer técnicas sofisticadas, a identificação da sensação de sonolência e indisposição mencionada acima poderia ser feita indiretamente através da escala de percepção de esforço, isto é, PSE (BORG et al., 1982). Riley et al. (1988) demonstraram que o uso de glicose durante uma corrida a $70 \% \mathrm{VO}_{2 \max }$ até a exaustão diminui significativamente a sensação de esforço percebido. Entretanto, o tempo de exaustão não foi significativamente diferente. Contrariamente, Timmons e Bar-Or (2003) não observaram diferenças na PSE entre a condição experimental e placebo em exercício realizado no ciclo ergômetro a $70 \% \mathrm{VO}_{2 \max }$ durante sessenta minutos. Utter et al. (2002) também não conseguiram encontrar diferenças na PSE entre um grupo experimental e outro placebo durante uma maratona, embora existisse uma tendência de menor tempo e PSE no grupo experimental. Em virtude das diferentes metodologias empregadas nos estudos, conclusões definitivas quanto aos benefícios da ingestão de carboidratos sob a PSE não podem ser realizadas, sendo necessários futuros estudos, principalmente com medida direta de neurotransmissores em conjunto com a PSE.

\subsection{Mecanismos de fadiga durante o exercício}

A fadiga induzida pelo exercício tem sido um dos temas mais estudados nas últimas décadas. Dentre as diversas definições existentes sobre fadiga, as mais comumente utilizadas são: uma incapacidade na manutenção de uma determinada força, causando uma redução no desempenho (FITTS, 1994); ou uma queda aguda no desempenho em determinado exercício, acompanhado por um aumento na sensação de esforço percebido (DAVIS; BAILEY, 1997).

Devido à complexidade do tópico, uma divisão didática e metodológica tem sido utilizada para delimitar os estudos sobre a fadiga induzida pelo exercício. Assim, podemos classificá-la em crônica ou aguda. A primeira caracteriza-se por um somatório de processos de recuperações incompletas, durante um período longo de treinamento intenso, que podem causar alterações prolongadas no humor, personalidade, sistema hormonal e imune, com consequente comprometimento da saúde. Os principais sintomas são: indisposição, cansaço, gripes e resfriados constantes (SHEPHARD, 2001). Por outro lado, fadiga aguda está relacionada com a incapacidade em realizar determinado esforço em uma única sessão de treinamento. 
Diversos modelos foram criados para explicar os mecanismos fisiológicos, bioquímicos e psicológicos que seriam responsáveis pela interrupção do exercício. Uma extensa revisão sobre cada um desses assuntos foge do propósito dessa revisão. Revisões específicas foram publicadas em estudos anteriores e para um maior aprofundamento sugerese a leitura dos estudos de Fitts (1994), Enoka e Stuart (1992), St Clair Gibson e Noakes (2004), Noakes, St Clair Gibson e Lambert (2004) e a série de mini-revisões recentes, enumeradas por Mckenna e Hargreaves (2008). Para o propósito desse estudo, serão apresentados primeiramente os possíveis "sítios" de alterações fisiológicas ou bioquímicas que levariam a interrupção do esforço. Na sequencia, serão discutidos os modelos recentes de biointegração e fadiga, tendo como base os modelos do grupo do Noakes (NOAKES; ST CLAIR GIBSON, 2004; ST CLAIR GIBSON; NOAKES, 2004; NOAKES; ST CLAIR GIBSON; LAMBERT, 2004; LAMBERT; ST CLAIR GIBSON; NOAKES, 2005), Marcora (2008) e Mckenna e Hargreaves (2008).

\subsubsection{Possíveis sítios de fadiga}

Os possíveis sítios de fadiga seriam: a) a amplitude e frequência do estímulo excitatório do sistema nervoso central para os motoneurônios; b) a excitabilidade do motoneurônio; c) a transmissão neuromuscular e a excitabilidade do sarcolema; d) a ligação entre excitação e mecanismos contráteis; e) o acúmulo de metabólicos e; f) a oferta de energia para a manutenção dos processos metabólicos (HARGREAVES, 2008).

No primeiro ponto, estudos com estimulação magnética transcraniana e twitch interpolação são as técnicas utilizadas para quantificar a participação da excitabilidade do córtex e dos motoneurônios nos processos de fadiga (MCKENNA; HARGREAVES, 2008). Basicamente, suspeita-se que uma forte estimulação cortical e fortes estímulos excitatórios descendentes, sejam necessários para manter a atividade do motoneurônio (TAYLOR; BUTLER; GANDEVIA, 2000). Consequentemente, uma incapacidade do córtex em aumentar sua atividade poderia ofertar estímulos insuficientes para a estimulação do motoneurônio. Entretanto, como discutido mais detalhadamente na sessão de modelos integrativos, é provável que uma estimulação cortical não resulte em aumento no desempenho da tarefa (GANDEVIA, 2008).

Em exercícios que exigem rápido recrutamento das fibras musculares, como ocorre naqueles com predominância anaeróbia, a incapacidade em manter potenciais de ação em alta 
frequência constitui um importante fator desencadeador da fadiga. A manutenção desse potencial depende da capacidade em recapturar os íons de $\mathrm{K}^{+}$para dentro da célula e em expelir os íons de sódio $\left(\mathrm{Na}^{+}\right)$, a fim de repolarizar a membrana sarcoplasmática e permitir a entrada de um novo impulso elétrico (GREEN, 1997). Se a amplitude ou a frequência do potencial de ação for reduzida, os receptores sensíveis à voltagem localizados nas membranas dos túbulos T, chamados dihidropiridinicos, diminuem a sua sensibilidade ao impulso elétrico, atenuando consequentemente, a liberação do $\mathrm{Ca}^{2+}$ das cisternas do retículo sarcoplasmático (FITTS, 1994; GREEN, 1997). Do ponto de vista experimental, os estudos nesse aspecto são, por natureza, realizados quase que em totalidade em fibras musculares isoladas. $\mathrm{O}$ fator chave é que contrações intensas causam um influxo de $\mathrm{Na}^{+}$para o meio intracelular que aumenta a concentração desse íon em quase duas vezes o valor de repouso, enquanto o efluxo de $\mathrm{K}^{+}$para o meio extracelular aumenta também em quase duas vezes (McKENNA; BANGSBO; RENAUD, 2008). Quando essas alterações ocorrem, por dedução lógica, a força tende a diminuir devido à menor excitabilidade da membrana. Logo, uma maior atividade da bomba de sódio-potássio poderia proteger da fadiga. Interessante que, quando se encontra apenas um pequeno distúrbio na relação iônica entre meio intra- e extra-celular, isso potencializa a contração.

Algumas linhas, ainda em fibras musculares isoladas, sugerem mecanismos próprios de fadiga devido à liberação de $\mathrm{Ca}^{2+}$ pelas cisternas do reticulo endoplasmático, que independem, até certo ponto, do potencial de membrana (ALLEN; LAMB; WESTERBLAD, 2008). Nesse sentido, a quantidade de cálcio livre e o sistema de liberação-reabsorção desse íon passam a ser considerados os principais sítios de fadiga. Referente ao mecanismo de liberaçãoreabsorção, a fadiga desenvolve-se principalmente pela diminuição nos níveis de ATP, o qual acaba prejudicando o funcionamento das bombas de $\mathrm{Ca}^{2+}$ do retículo sarcoplasmático (CHIN; ALLEN, 1997). Mesmo que dificilmente os níveis de ATP diminuam mais do que 30-50\% dos valores de repouso, na célula com um todo, as concentrações de glicogênio e ATP na região próximo ao retículo sarcoplasmático podem diminuir muito mais (CHIN; ALLEN, 1997). Isso pode ser evidenciado pela localização dos depósitos de glicogênio dentro da célula muscular. Esses depósitos ficam próximos à banda I, que por sua vez, localiza-se ao lado das cisternas do retículo sarcoplasmático (CHIN; ALLEN, 1997; GREEN, 1997). Durante o exercício intenso o glicogênio dessa região é preferencialmente depletado (FRIDÉN; SEGER; EKBLOM, 1989), diminuindo a ressíntese de ATP e consequentemente a liberação de $\mathrm{Ca}^{2+}$. 
Westerblad, Allen e Lannergren (2002) reestruturaram recentemente o modelo apresentado acima, baseado em um trabalho clássico desenvolvido por Fryer et al. (1995). Nesse estudo, Fryer et al (1995) sugerem que o decréscimo na liberação de $\mathrm{Ca}^{2+}$ pelo retículo sarcoplasmático deve-se não pela redução total desse íon, mas sim pela redução da sua forma livre. Isso ocorre porque, durante o exercício intenso com deficiência na reposição de ATP, uma grande quantidade de $\mathrm{P}_{\mathrm{i}}$ acumula-se nessa região, ocasionando um fenômeno chamado precipitação do cálcio, que ocorre dentro do lúmen do retículo sarcoplasmático. Assim, o $\mathrm{P}_{\mathrm{i}}$ liga-se ao $\mathrm{Ca}^{2+}$ formando fosfato de cálcio $\left(\mathrm{CaHPO}^{4}\right)$ e diminui a quantidade livre para ser utilizada no processo de contração muscular. Apesar disso, a precipitação de cálcio não é totalmente prejudicial para o mecanismo contrátil, porque estimula a reabsorção do cálcio para dentro do retículo sarcoplasmático, auxiliando as bombas dependentes de ATP. O aumento da quantidade livre de cálcio no lúmen do retículo sarcoplasmático, caso o $\mathrm{P}_{\mathrm{i}}$ estivesse ausente, poderia diminuir a reabsorção desse íon da zona de ligação entre actina e miosina, aumentando o risco de toxidade intracelular (FRYER et al., 1995).

As explanações descritas acima são insuficientes e explicam apenas parcialmente a fadiga em exercícios intensos. Outro ponto bastante discutido é o envolvimento das reações ligadas à fosfocreatina $(\mathrm{CP})$ no processo de fadiga. Sucintamente, alguns segundos após o início do exercício, o ATP começa a ser ressintetizado a partir da hidrólise da $\mathrm{CP}$, formando creatina + fosfato inorgânico $\left(\mathrm{CP} \rightarrow \mathrm{Cr}+\mathrm{P}_{\mathrm{i}}\right)$. Grande parte da ressíntese de ATP no início do exercício deve-se a esse processo, sendo constatado diminuição significativa da concentração muscular de CP em exercícios com duração entre 30 e 60 segundos, chegando a aproximar-se de $20 \%$ dos valores de repouso (CASEY; GREENHAFF, 2000). Uma concentração relativamente baixa de PC induziria a uma menor e mais lenta ressíntese de ATP, diminuindo inevitavelmente a intensidade do exercício realizado.

Alguns estudos, porém, sustentam apenas uma ligação indireta entre fadiga e à diminuição das concentrações de CP (KARLSSON; SALTIN, 1970). O mecanismo mais provável parece estar relacionado com o acúmulo de ADP durante o processo de contração muscular, ocasionado indiretamente pela depleção de CP e consequente diminuição na velocidade de ressíntese de ATP. O aumento das concentrações desse nucleotídeo dificulta o "desprendimento" da cabeça da miosina dos sítios ativos da actina e, consequentemente, diminui a velocidade de contração (McLESTER Jr., 1997). Na figura 5 pode-se observar que a liberação de ADP é um ponto crítico no processo de contração muscular. Conjuntamente, o 
aumento nas concentrações de íons $\mathrm{H}^{+}$e diminuição do $\mathrm{pH}$ dificultam a ressíntese de ATP, facilitando os mecanismos descritos acima (FITTS, 1994). O aumento acentuado nas concentrações de $\mathrm{H}^{+}$é devido, ao menos parcialmente, pela depleção de $\mathrm{CP}$, visto sua importante ação com agente tamponante na reação: $\mathrm{ADP}+\mathrm{CP}+\mathrm{H}^{+} \rightarrow \mathrm{ATP}+\mathrm{Cr}$.

Mecanismos fisiológicos alternativos são acionados a fim de evitar o acúmulo de ADP. Caso a velocidade de ressíntese de ATP seja inferior à demanda, duas moléculas de ADP podem auxiliar na reposição, a partir da seguinte reação: ADP + ADP $\rightarrow$ ATP + AMP. Posteriormente, AMP (adenosina monofosfato) pode sofrer deaminação e formar IMP e $\mathrm{NH}_{3}$, sendo considerado o principal sistema para o catabolismo de adenina nucleotídeo no músculo esquelético. Esse mecanismo pode retardar o aumento de ADP por alguns segundos, prolongando o tempo de exercício (McLESTER Jr., 1997).

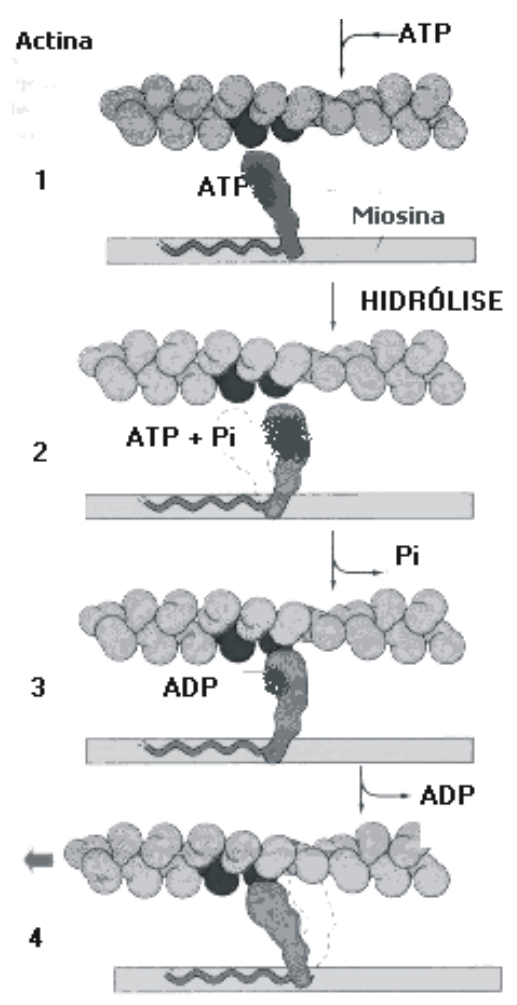

Figura 5. Modelo esquemático da ligação actina e miosina. Na primeira etapa, a molécula de ATP está ligada a cabeça da miosina, impedindo o contato com a actina. Na segunda etapa, $\underline{\text { ATP dissocia-se a ADP }+\mathrm{P}_{i} \text {, mudando a conformação da cabeça da miosina. Na terceira etapa, }}$ $\underline{P_{i}}$ é liberado e a união entre actina e miosina passa do estágio de baixa energia para o estágio de alta energia. Na quarta e última etapa, ADP é liberado causando o encurtamento do sarcômero (Esquema adaptado de FITTS, 1994). 
$\mathrm{O}$ acúmulo de $\mathrm{P}_{\mathrm{i}}$ também parece estar ligado à fadiga do mecanismo contrátil. Entretanto, a explicação fisiológica ainda não está completamente esclarecida. A hipótese mais sustentável é que o aumento nas concentrações de $\mathrm{P}_{\mathrm{i}}$ na região de contração muscular inibe a liberação do $\mathrm{P}_{\mathrm{i}}$ da reação $\mathrm{ATP} \rightarrow \mathrm{ADP}+\mathrm{P}_{\mathrm{i}}$, que é essencial para passar do estágio de ligação de baixa energia, para ligação de alta energia (figura 5). Consequentemente, a energia não é liberada e a ligação entre actina e miosina prejudicada (FITTS, 1994; WESTERBLAD; ALLEN; LANNERGREN, 2002). Um fator agravante é o aumento nas concentrações de íons $\mathrm{H}^{+}$. Isso porque o $\mathrm{P}_{\mathrm{i}}$ encontra-se na célula muscular na forma monoprotonada $\left(\mathrm{HPO}^{4--}\right)$ e/ou diprotonada $\left(\mathrm{H}_{2} \mathrm{PO}^{4-}\right)$. Em condições de baixo $\mathrm{pH}$, como as encontradas em situações de fadiga, a forma diprotonada aumenta significativamente e apresenta forte associação com a diminuição da força muscular (NOSEK; FENDER; GODT, 1987).

Até aqui, ficou evidente a relação entre o acúmulo de alguns derivados metabólicos $\left(\mathrm{ADP}, \mathrm{Pi}, \mathrm{H}^{+}\right.$) com a fadiga em exercícios de curta duração. Parte dessa relação é influenciada pelo sistema alático. Contudo, alguns dos derivados metabólicos acabam interferindo negativamente também no sistema glicolítico. Os parágrafos seguintes serão destinados à fadiga provocada pela falha nesse sistema, mas entendendo que as alterações que serão levantadas podem estar ocorrendo simultaneamente com as já mencionadas.

Uma importante enzima ativadora da glicogenólise, a glicogênio fosforilase (GF), parece sofrer influência de alguns dos derivados metabólicos citados acima. Em primeira instância, o aumento nas concentrações de $\mathrm{H}^{+}$com consequente diminuição do pH sanguíneo, pode inibir a transformação da GF tipo $b$ (não-fosfatada), para sua forma mais ativa $a$ (fosfatada) (CHASIOTIS; HULTMAN; SAHLIN, 1982). Em uma segunda situação, o acúmulo de íons $\mathrm{H}^{+}$atua como um potente inibidor da adenilato ciclase, impedindo consequentemente a formação de AMPc. A terceira possibilidade, considerada por alguns autores como a principal, seria a inibição da GF pela disponibilidade de $\mathrm{P}_{\mathrm{i}}$ como substrato (ROBERTS; SMITH, 1989). Isso porque, a GF pode ser fosfatada por $\mathrm{P}_{\mathrm{i}}$ apenas na sua forma monoprotonada, mas em situação de fadiga existe uma predominância da forma diprotonada, inibindo assim, a ação dessa enzima. O aumento na forma diprotonada é devido ao excesso de $\mathrm{H}^{+}$, conforme já descrito anteriormente.

Entretanto, algumas críticas quanto à dependência da glicogenólise à transformação da glicogênio fosforilase da forma $b$ para $a$, valem ser destacadas. Gollnick et al. (1978) observaram que, durante contrações voluntárias máximas estáticas ou dinâmicas, ou 
estimulação elétrica do músculo, existia pouca transformação da GF da forma $b$ para $a$, apesar de aumentar consideravelmente a taxa glicogenolítica. Os autores destacam que são necessárias apenas $5 \%$ da GF na forma ativa para atingir a produção glicogenolítica máxima, além de a ativação poder ser realizada tanto pela conversão da forma $b$ para $a$, quanto através de ativação alostérica da forma $b$, sendo esta última dependente das concentrações de AMP.

Um dos mecanismos mais conhecidos e tradicionais sobre fadiga muscular provêm da inibição da atividade da enzima PFK, causada pelo acúmulo de $\mathrm{H}^{+}$e diminuição do $\mathrm{pH}$ muscular (FITTS, 1994). A inibição dessa enzima impede a transformação de frutose-6-fosfato em frutose-1.6-difosfato, impossibilitando a degradação da glicose-6-fosfato até piruvato e consequente restauração de ATP. Grande parte dos íons de hidrogênio formados durante o exercício é derivada da dissociação do ácido lático em lactato (ROBERTS; SMITH, 1989). Existe uma tendência atual na literatura de rejeitar este modelo clássico, principalmente porque alguns autores não observaram relação de causa e efeito entre aumento das concentrações de lactato e fadiga muscular (KARLSSON; SALTIN, 1970; BANGSBO et al., 1996; WESTERBLAD; ALLEN; LANNERGREN, 2002). Bangsbo et al. (1996) reportaram que, após elevação das concentrações de lactato sanguíneo por meio de exercício prévio com membros superiores, a frequência de degradação do GM dos membros inferiores não foi afetada, impossibilitando, portanto, atribuir à fadiga muscular unicamente ao excesso de $\mathrm{H}^{+}$. A possível explicação para o desacordo entre os estudos nesta questão é que a PFK apenas pode ser inibida pelo acúmulo de $\mathrm{H}^{+}$de forma significativa em baixas temperaturas, mas em condições fisiológicas, isto parece pouco provável (WESTERBLAD; ALLEN; LANNERGREN, 2002; BERTUZZI; FRANCHINI; KISS, 2004).

Um ponto crucial refere-se à oferta de energia para a manutenção dos processos metabólicos. Oferta de energia de forma eficiente e prolongada depende da oferta de oxigênio - que envolve o processo de captação do oxigênio atmosférico, transporte até o músculo esquelético e utilização adequada por reações enzimáticas - e disponibilidade de substratos, sendo os mais importantes o GM e a glicose sanguínea. Por convenção, assume-se que a limitação da oferta de oxigênio ao músculo esquelético só poderia ocorrer durante esforços intensos e, portanto, estaria associado ao acúmulo de metabólitos, enquanto a depleção de substratos estaria associada ao exercício prolongado, sem ligação com a oferta de oxigênio. Uma visão segmentada desse aspecto será abordada nos parágrafos seguintes, explicando as 
bases teóricas para cada um dos modelos de fadiga por falta de aporte de oxigênio e por depleção de substratos.

Do ponto de vista bioquímico, a ligação entre oferta de oxigênio e acúmulo de metabólitos depende da intensidade do exercício. O destino da glicose 6-fosfato resultante da degradação do GM será a entrada na mitocôndria como piruvato, com consequente ressíntese de ATP por vias aeróbias se o esforço for de intensidade relativamente baixa. Como mecanismo alternativo, o próprio piruvato pode aceitar os elétrons de $\mathrm{NADH}+\mathrm{H}^{+}$ (nicotinamida adenina dinucleotídeo reduzida) sendo reduzido a ácido láctico e posteriormente a lactato em exercícios mais intensos.

Os mecanismos bioquímicos que controlam a entrada do piruvato na mitocôndria ou sua redução para ácido lático e lactato são controversos. Os modelos iniciais sugerem que o lactato é formado devido a uma deficiência no fornecimento de oxigênio ao músculo ativo, impossibilitando a re-oxidação de NADH pelas mitocôndrias (HILL; LUPTON, 1923; BASSET; HOWLEY, 1997). Modelos da década de 1980 sugerem mecanismos alternativos para explicar o acúmulo de lactato e o desenvolvimento da fadiga (BROOKS, 1985). A explicação seria de que, em exercício aeróbio de intensidade elevada, o mecanismo de transporte dos íons $\mathrm{H}^{+}$pelo NAD estaria sobrecarregado e doaria seus prótons para o piruvato, mesmo com a presença de oxigênio nas mitocôndrias. A deficiência pode estar localizada nos sistemas de lançadeiras de glicerol-fosfato, não atendendo a demanda ocasionada pela velocidade de fluxo da via glicolítica (STAINSBY, 1986), ou a uma possível inércia das enzimas e reações mitocondriais no início do exercício (GRASSI et al., 1998). O modelo de deficiência nos mecanismos de lançadeiras influenciando na formação de lactato foi desenvolvido em exercício submáximo, mas a extrapolação para exercícios próximos à potência aeróbia máxima parece razoável, uma vez que nessa situação a pressão de oxigênio intramitocondrial não atinge níveis críticos (vide abaixo).

As teorias que defendem uma deficiência na oferta de oxigênio com indutor de fadiga assumem uma limitação por parte do coração. O primeiro modelo foi elaborado por Archibald Vivian Hill e Hartley Lupton, ganhadores do premio Nobel em 1923. Hill e Lupton (1923) descreveram que, próximo a velocidades altas (aproximadamente $260 \mathrm{~m} \cdot \mathrm{min}^{-1}$ ) o coração atinge um platô de contratibilidade, limitando o fornecimento de oxigênio ao músculo ativo. Após essa intensidade, o exercício passa a ser sustentado com uma maior participação do sistema anaeróbio, aumentando as concentrações de lactato e levando o indivíduo rapidamente 
à fadiga. Esse modelo é intensamente defendido pelo grupo de pesquisadores compostos por Howley, Bassett e Welch (1995), que em um dos seus trabalhos concluíram: "Depois de cautelosa revisão das evidências de ambos os modelos até então propostos, nós concluímos que, o clássico paradigma do $\mathrm{VO}_{2 \max }$ de Hill e Lupton é o mais correto até o momento". O outro modelo ao qual Howley et al (1995) se referem, provém da África do Sul, e foi elaborado por Timothy David Noakes (NOAKES, 1997). O parágrafo seguinte será destinado à explicação do modelo de fadiga elaborado por Noakes na época. Entretanto, o mesmo grupo reformulou esse modelo e o apresentou a comunidade científica em quatro séries de trabalhos publicados em 2004 (NOAKES; ST CLAIR GIBSON, 2004; NOAKES; ST CLAIR GIBSON; NOAKES, 2004; ST CLAIR GIBSON; NOAKES, 2004; LAMBERT; ST CLAIR GIBSON; NOAKES, 2005).

Esse modelo sugere que, durante o exercício máximo, o coração não pode ser o responsável pela hipóxia muscular, visto que, seria o próprio coração o primeiro órgão a entrar em isquemia, aumentando o risco de lesão e infarto do miocárdio. A proposta é que um governador central (central govern) controle o término do exercício em intensidades máximas. Assim, "mensagens" via nervos aferentes provindos do coração são enviados ao sistema nervoso central, informando as condições de oxigenação do músculo cardíaco, antes que uma isquemia aguda desenvolva-se nesse órgão. Reciprocamente, pode ser observada uma queda na estimulação dos nervos eferentes responsáveis pela estimulação dos músculos esqueléticos ativos, diminuindo a sua contratilidade e limitando o tempo de exercício.

Até então esse modelo baseava-se em especulações, com poucas evidências experimentais. A base da teoria foi sustentada pelos trabalhos realizados em altitude. Nessas circunstâncias, em que a pressão de oxigênio é diminuída, poderia se esperar um maior fornecimento de energia pelo metabolismo anaeróbio, com maior acúmulo de lactato no sangue. Entretanto, isso não acontece. Em vez disso, uma menor [La] no sangue e uma menor frequência cardíaca máxima durante exercício em altitude, sugerem outras limitações, do que única e exclusivamente pela deficiência no fornecimento de $\mathrm{O}_{2}$ (NOAKES, 1997).

Algumas críticas podem ser destacadas. Comumente observa-se que, após o término de um teste com incrementos progressivos na carga de trabalho ou na velocidade de corrida, levando o indivíduo até a exaustão, os avaliados podem apresentar mal estar, enjôos e tonturas. A hipótese é que a interrupção abrupta do exercício ocasiona uma diminuição rápida da pressão arterial, limitando o fluxo de sangue e oxigênio para a região encefálica. Essa 
constatação sugere que a região encefálica apresenta uma grande sensibilidade a mudanças no fornecimento de oxigênio. Partindo desse pressuposto, qual o órgão que está sendo protegido, a musculatura esquelética, o coração ou o encéfalo? Obviamente não existe uma resposta simples e direta para tal questão, mas os resultados do estudo de Hochachka et al. (1999) permitem levantar uma hipótese. Nesse estudo, o metabolismo de 25 regiões cerebrais de seis marinheiros foi avaliado antes e depois de 63 dias de treinamento em altitude. Decréscimo significante no metabolismo de glicose foi observado em cinco regiões após exposição à altitude (três regiões frontais, lóbulo occipital esquerdo e tálamo direito). Em contrapartida, o cerebelo aumentou seu metabolismo. Esses resultados sugerem que o encéfalo responde precisamente aos baixos níveis de oxigênio e, durante o exercício máximo, mecanismos de feedback que poderiam estar localizados na própria região encefálica podem inibir a atividade cortical. Modelos matemáticos indicam que, em alguns capilares, o tempo requerido para liberar o oxigênio para os tecidos é maior do que o tempo de trânsito dos glóbulos vermelhos (HONIG et al., 1984). Isso pode ser importante para órgãos como o coração e o encéfalo que dependem quase que exclusivamente do metabolismo aeróbio, sendo menos destacável na musculatura esquelética. Em outra perspectiva Nybo (2008) sugere, em esforços realizados em climas quentes, um aumento de sinais inibitórios emitidos pelo hipotálamo ao córtex, reduzindo os sinais de recrutamento periférico.

Por fim, Wagner (2000) acrescenta que o nível de aptidão física dos indivíduos pode influenciar na identificação dos fenômenos fisiológicos responsáveis pelo $\mathrm{VO}_{2 \max }$. Segundo Wagner (2000), pessoas destreinadas apresentam pressão de $\mathrm{O}_{2}$ intracelular adequada (5 - 10 Torr), sugerindo que a limitação não é devido à oferta, mas sim na utilização de oxigênio pelo músculo ativo; por outro lado, pessoas treinadas apresentam pressão de $\mathrm{O}_{2}$ significativamente menor (inferior a 3 Torr), sugerindo uma deficiência no fornecimento de oxigênio. Essa teoria baseia-se no trabalho desenvolvido por Richardson et al (1998), os quais observaram que, nas situações com maior fornecimento de oxigênio ao músculo ativo (hiperoxia), ocorre um concomitante aumento no $\mathrm{VO}_{2 \max }$. Entretanto, os níveis críticos de pressão de oxigênio nas mitocôndrias, que poderiam comprometer o ciclo de Krebs e a cadeia respiratória, estão por volta de 0,1 e 0,5 Torr, bem abaixo dos encontrados nos trabalhos supracitados (BROOKS, 1985).

Para o exercício prolongado, a depleção de substrato é o foco. O interesse pelos mecanismos de fadiga por depleção de GM foi reacendido na década de sessenta, através de 
uma série de trabalhos clássicos publicados pelo grupo de Ahlborg, Bergstrom e Hultman (AHLBORG et al., 1967; BERGSTROM; HULTMAN, 1967). Um excelente trabalho feito por Robert K. Conlee em 1987 explicita bem a importância desses trabalhos sobre a luz do conhecimento atual no assunto. A fadiga por depleção de glicogênio parece ser mais evidente em atividades prolongadas, que estão mais relacionadas com a capacidade aeróbia.

Ahlborg et al. (1967) verificaram que o tempo para o aparecimento de fadiga durante o exercício prolongado era dependente das concentrações iniciais de GM e esses achados continuam sendo a base das investigações modernas (REN et al., 1990). Embora realmente exista uma nítida relação entre essas duas variáveis, a principal questão é: Quais são as alterações bioquímicas e fisiológicas que suportam tal teoria? A resposta para essa questão não é fácil e o conhecimento atual não permitiu uma resposta sustentável. Entretanto, algumas propostas da literatura serão discutidas nos parágrafos seguintes.

A primeira hipótese a ser levantada é que nas situações em que o GM atinge um nível muito baixo, a ação da glicogênio fosforilase pode ser inibida pela baixa concentração. Essa teoria pode ser questionada, visto que, a constante de Michaelis-Menten $\left(\mathrm{K}_{\mathrm{m}}\right)$, que expressa a quantidade de substrato necessário para ativar uma enzima, é relativamente baixa para essa enzima (REN et al., 1990). Normalmente as concentrações de GM em fadiga são superiores à $\mathrm{K}_{\mathrm{m}}$ dessa enzima. Vale ressaltar que alguns autores questionam a validade da extrapolação da $\mathrm{K}_{\mathrm{m}}$ medida in vitro para as situações in vivo (RICHTER; GALBO, 1986). Este pode ser considerado o primeiro ponto de dificuldade no entendimento do mecanismo descrito.

Ignorando o problema referenciado acima, e assumindo que a $\mathrm{K}_{\mathrm{m}}$ não é um fator limitante, mais uma vez cabe a pergunta: Quais são as alterações bioquímicas e fisiológicas que suportam tal teoria? Estudos conduzidos com indivíduos em estágio de depleção de GM (induzido previamente), fornecem subsídios adicionais para o problema (HEIGENHAUSER; SUTTON; JONES, 1983; PODOLIN et al., 1991). Nesses estudos existe aparentemente um consenso de que, com baixos estoques de GM, os ácidos graxos livres aumentam seu fornecimento de energia, acompanhados por uma diminuição na produção de lactato sanguíneo. Entretanto, a taxa de degradação do GM mantém-se ou diminui discretamente (REN et al., 1990). Se a taxa de degradação do glicogênio é mantida e a produção de lactato é diminuída, pode-se inferir que existe uma maior utilização de forma aeróbia da glicose-6fosfato, principalmente para manter os carbonos perdidos no ciclo de Krebs em forma de citrato e $\alpha$-cetoglutarato, durante a oxidação dos ácidos graxos (FITTS, 1994). A reposição 
desses carbonos é feita através da conversão de piruvato a oxalacetato, reação essa catalisada pela enzima piruvato carboxilase.

Para finalizar a proposta apresentada acima, em situação de depleção de GM a taxa de utilização do mesmo não é alterada, com o intuito de manter ativa a oxidação dos ácidos graxos. O indivíduo entraria em fadiga precocemente nesta situação porque a quantidade disponível de GM para manter ativa a beta-oxidação é limitada. Duas perguntas podem enfraquecer esse pensamento: Porque a beta-oxidação é interrompida pela deficiência no fornecimento de glicose para recompor o oxalacetato, visto que, alguns aminoácidos e corpos cetônicos também exercem essa função? Porque em situações de fadiga os estoques de glicogênio não são totalmente depletados? (CONLEE, 1987).

Ambas as questões são empecilhos para validar a hipótese levantada. Um estudo de Tsintzas et al. (1995) encoraja a busca por modelos alternativos. Nesse estudo os autores verificaram os efeitos da ingestão de uma solução com 5,5\% de carboidratos $(1,7 \%$ de glicose; $1,1 \%$ de frutose; $0,6 \%$ de maltose e $2,1 \%$ sacarídeos) sobre o tempo para o desenvolvimento de fadiga em exercícios realizados a $70 \%$ do consumo máximo de oxigênio. Os autores observaram que, a suplementação de carboidratos diminuía a taxa de degradação do GM, principalmente nas fibras de contração lenta, e prolongam o tempo para aparição da fadiga $(132,4 \pm 12,3$ vs 104,3 \pm 8,6 minutos). A concentração final de GM, porém, foi similar entre as situações $\left(31,6 \pm 10,3\right.$ vs $28,1 \pm 7,1 \mathrm{mmol} . \mathrm{kg}^{-1}$ de peso seco). Essa "reserva" preservada impede a confirmação do modelo apresentado anteriormente, que não consegue explicar a falta de depleção total do GM.

Uma explicação alternativa, mas pouco investigada até então, seria de que o exercício acaba sendo interrompido pela diminuição dos impulsos elétricos para contração muscular, vindo do sistema nervoso central, semelhante ao que ocorre em exercícios de potência aeróbia máxima (GANDEVIA, 1998; WESTERBLAD; ALLEN; LANNERGREN, 2002; NOAKES, 1997). Assim, o encéfalo, após ser informado das condições periféricas pelos nervos aferentes III e IV, diminui os impulsos elétricos eferentes a fim de evitar danos às estruturas musculares que poderiam ser ocasionadas pelo exercício prolongado. Esse mecanismo de feedback parece estar intimamente ligado ao mecanismo de ressíntese de ATP. Vissing et al. (1992) observaram que, pacientes com deficiência na enzima miofosforilase (Síndrome de McArdle) apresentam maiores níveis de glicose, glicerol e ácidos graxos livres circulantes do que seus congêneres que não possuem a doença. O aumento desses "combustíveis" extracelulares foi 
causado pelo decréscimo nos níveis de insulina e aumento nos níveis de norepinefrina, epinefrina, cortisol, hormônio do crescimento e adrenocorticotropina. Os autores atribuíram essas alterações ao feedback neural ocasionado pelo metabolismo do músculo ativo, demonstrando uma importante ligação entre mecanismos periféricos e centrais.

A glicose sanguínea aparentemente não abaixa além dos níveis seguros durante a fadiga ocasionada pelo exercício prolongado (CONLEE, 1987; TSINTZAS et al., 1995). Uma segunda possibilidade seria que o encéfalo limita a duração do exercício para evitar a queda acentuada da glicose sanguínea, seu principal combustível energético. Isto parece claro em atletas de alto rendimento que apresentam maior capacidade volitiva e, consequentemente, conseguem "enganar" o encéfalo, prolongando o exercício além dos limites de segurança. Nesse caso, uma diminuição da glicose sanguínea para níveis abaixo de 3 mmol. $\mathrm{l}^{-1}$, pode ser acompanhada por diminuição do metabolismo cerebral, com concomitante disfunção cognitiva (NYBO et al., 2003; NYBO, 2008).

\subsubsection{Modelo integrativo-complexo de fadiga}

O modelo integrativo-complexo de fadiga teve dois momentos cruciais no seu processo de estabelecimento. O primeiro foi demarcado pelos trabalhos publicados por Timothy Noakes na década de 1980 e 1990 (NOAKES, 1988; 1997; 1998), sugerindo que o esforço máximo obtido em teste incremental era limitado não pela oferta de oxigênio, como se pensava pelo modelo tradicional, mas sim pela redução no recrutamento de unidades motoras, tornando insuficiente a quantidade de massa muscular ativa para a execução do exercício. A sugestão do mecanismo pelo qual isso ocorria envolvia múltiplos sinais aferentes, sendo o músculo cardíaco e o esquelético os principais órgãos aferentes. A hipótese estabelecida foi que próximo ao ponto máximo de esforço, o coração e o músculo esquelético enviavam sinais via nervos aferentes sobre as condições metabólicas ao SNC, que por consequência reduzia a frequência e intensidade dos disparos dos motoneurônios. A esse controle central foi dado o nome de "Governador Central".

Inicialmente, o modelo apoiou-se nos estudos sobre platô de consumo de oxigênio e concentração de lactato sanguíneo durante esforços com simulação de altitude. Em muitos casos, indivíduos normais não apresentam platô no consumo de oxigênio durante um teste progressivo máximo e, paradoxalmente, as concentrações de lactato em altitude durante o esforço máximo são menores do que ao nível do mar, o que por dedução lógica inviabiliza 
assumir a existência do modelo tradicional de fadiga por acúmulo de metabólitos devido a hipóxia. Desse modo, o primeiro passo do modelo integrativo foi estabelecido por contestação e negação do modelo tradicional.

Em 2004, quatro estudos foram publicados no British Journal of Sports Medicine sobre o modelo integrativo (NOAKES; ST CLAIR GIBSON, 2004; ST CLAIR GIBSON; NOAKES, 2004; LAMBERT; NOAKES; ST CLAIR GIBSON; LAMBERT, 2004; ST CLAIR GIBSON; NOAKES, 2005). Nessa série foi elaborada apenas uma nova discussão provocativa referente às limitações do modelo tradicional (NOAKES; ST CLAIR GIBSON, 2004), mas uma proposta avançada de regulação integrada e complexa entre os sistemas que compõem o funcionamento humano. A sinalização por vias aferentes toma frente novamente na discussão, mas agora descentralizada do coração e provinda de vários órgãos e sistemas. $\mathrm{O}$ foco foi estabelecer que, múltiplos sinais aferentes são "interpretados" em diferentes regiões do SNC. Essas regiões então ficariam responsáveis em receber as informações aferentes, integrar essas informações e emitir um "parecer" ao córtex motor, que por sua vez reduziria ou não os impulsos ao motoneurônio, de acordo com a situação periférica. Como por definição o sistema funciona à base de retro-alimentação, ele passa a apresentar oscilações frequentes no tempo que, também por definição, não podem ser aleatórias. Como o modelo prevê a existência de "interpretação consciente", ou seja, o próprio indivíduo poderia regular sua intensidade de esforço ou o tempo que conseguiria suportar em uma intensidade pré-fixada. A representação quantitativa dessa "interpretação consciente" seria a PSE.

A partir desses dois pontos, o modelo foi sustentado, ao menos no seu caráter macro, por estudos com alterações no ritmo de corrida ou na variação de potência durante esforços com tarefa pré-determinada (fechada), como as estratégias adotadas pelos atletas durante as provas de corrida ou contra-relógio no ciclismo (ST CLAIR GIBSON; NOAKES, 2004; TUCKER et al., 2006; BILLAT et al., 2006; JOSEPH et al., 2008), além de estudos que estabeleceram relação entre PSE e tempo restante para cumprir a tarefa (JOSEPH et al., 2008) ou atingir à exaustão (NOAKES, 2004; ESTON et al., 2007; NOAKES, 2008; CREWE; TUCKER; NOAKES, 2008).

A confirmação da existência de integração entre múltiplos sistemas pode ser obtida se a resposta de alguma variável dependente desse suposto sistema integrado puder ser medida em uma frequência suficiente. Se o sistema apresenta características de variação aleatória, a inclinação $(\alpha)$ da função energia do espectro vs tempo do sinal seria próxima a zero. Mas, caso 
o sistema apresente oscilações não aleatórias, típicas de sistemas integrativos complexos, o valor de $\alpha$ seria entre 1 e 2 . Tucker et al. (2006) mensuraram a cada 200 metros a potência gerada durante um contra-relógio de $20 \mathrm{~km}$ no ciclismo. Os autores descobriram que a natureza do sinal não apresentava oscilações aleatórias, mas sim variações integrativas complexas, pelos valores de $\alpha$ estarem entre 1,5 e 1,9. Isso sugere que a potência "escolhida" pelo sujeito durante o teste não é ao acaso, mas faz parte de uma interpretação contínua dos múltiplos sinais de realimentação de um sistema complexo. Além disso, os autores observaram um aumento na potência ao final do evento em todos os indivíduos, sugerindo que a regulação da intensidade durante o transcorrer da prova é regulada para manter o organismo capaz de acelerar no final. Esse comportamento de aceleração ao final de uma competição parece ser um fenômeno global demonstrado em outros estudos (HANON et al., 2008; ATKINSON et al., 2007; JOSEPH et al., 2008).

O ponto crucial do modelo encontra-se agora na localização física desse "governador central" e da ação consciente do indivíduo no estabelecimento da fadiga. A pergunta chave seria: Um modelo integrativo-complexo, envolvendo múltiplos sinais aferentes endereçados ao SNC seria interpretado e a "interpretação" repassada a áreas cerebrais responsáveis pela consciência ou seria a consciência independente de sinais aferentes e a decisão em interromper o esforço dependeria apenas da incapacidade de manter o nível de recrutamento necessário para manter a intensidade de esforço estabelecida?

Essa questão acendeu uma discussão recente na literatura (MARCORA, 2008), mas de certa maneira, marca a substituição momentânea do modelo tradicional de fadiga e centraliza a discussão no modelo integrativo-complexo. A proposta do modelo estabelecido (NOAKES; ST CLAIR GIBSON, 2004; ST CLAIR GIBSON; NOAKES, 2004; NOAKES; ST CLAIR GIBSON; LAMBERT, 2004; LAMBERT; ST CLAIR GIBSON; NOAKES, 2005) coloca a PSE do indivíduo como uma ação consciente decorrente da interpretação subconsciente de sinais aferentes. O contraponto é que um aumento na PSE do indivíduo possa ser decorrente de um aumento no comando central para o motoneurônio e músculos respiratórios, para compensar a reduzida capacidade de resposta do córtex, motoneurônio e músculo esquelético durante o esforço prolongado (MARCORA, 2008; TAYLOR; GANDEVIA, 2008).

O modelo levantado por Marcora (2008) apresenta muitas semelhanças com o modelo integrativo-complexo, pois assume também que a fadiga está intrinsecamente ligada ao SNC e a maneira como o individuo percebe o esforço. Logo, a interrupção do exercício até a exaustão 
seria uma decisão consciente do indivíduo, baseado na sua percepção máxima de esforço naquele momento. $\mathrm{O}$ aumento da percepção de esforço ao longo do tempo seria, como comentado anteriormente, uma decorrência do progressivo aumento da atividade do córtex no envio de estímulos para o motoneurônio. Nesse modelo, a PSE aumenta paralelamente com a atividade cortical, pois a primeira seria o produto da segunda. Essa sugestão é um grande avanço e combina com a sugestão de St Clair Gibson (2003), onde talvez não exista um local especifico em que a PSE é gerada, mas sim seja o resultado da atividade cerebral total.

O primeiro ponto divergente é a afirmação de que vias aferentes não são importantes para esse constructo da PSE. Essa afirmação é bastante ousada e depõe contra evidencias experimentais de que vias aferentes funcionam como sinalizadores ao SNC. Entretanto, uma reflexão dessa afirmação talvez leve a imaginar que vias aferentes não sejam tão importantes para a construção global da PSE, mas seja importante para o refinamento da PSE, ou seja, fornecem informações que aumentam a precisão da sensação. Outro ponto, é que o modelo não adota o termo "inconsciente" e "consciente" para separar os fenômenos. Essa discussão talvez seja desnecessária se adotarmos os termos subcortical e cortical, uma definição anatômica e funcionalmente mais correta do que inconsciente e consciente.

O fato é que, independente do mecanismo correto, a PSE apresenta um modelo bem definido de resposta em função do tempo decorrido de exercício. Nesse sentido, Noakes (2003) observou a partir de dados de Baldwin et al. (2003) que a PSE aumenta proporcionalmente ao tempo de exercício, mas com uma maior taxa para uma situação de depleção prévia de GM do que em uma situação de reserva normal. Entretanto, independente da situação, a PSE final ficava próxima a 18 pontos, na escala de 6 a 20. Quando a PSE era plotada em função do tempo relativo ao tempo total, a taxa de incremento era exatamente a mesma nas duas situações. Alguns outros estudos confirmaram esse comportamento com a manipulação da intensidade (CREWE; TUCKER; NOAKES, 2008), temperatura ambiente (CREWE; TUCKER; NOAKES, 2008) e fadiga prévia (ESTON et al., 2008). Um comportamento similar ocorre durante esforços fechados, como provas de contra-relógio, nas quais foi observado que, quando a PSE é plotada em função da distancia relativa ao término da atividade, a taxa de incremento é a mesma independente da distância total do evento (JOSEPH et al., 2008).

Todos esses resultados sugerem que, uma ação "consciente" marca o tempo possível de ser sustentado ou ritmo a ser empregado para obter o melhor desempenho, sem comprometer 
estruturas corporais, como previsto no modelo de governador central. Mas, a ligação física entre interpretação subconsciente de vias aferentes e transmissão da informação para conversão em sensação consciente ainda não foi descrita, assim como, a ligação física entre a maior ativação cortical e a conversão em expressão consciente também não.

\subsection{Percepção Subjetiva de Esforço}

No modelo integrativo-complexo, a discussão sobre PSE transcende para consciência. Entretanto, antes de abordar esse fato, torna-se necessário apresentar a validade e a base teórica na qual a PSE foi criada.

A PSE foi construída com o objetivo de complementar as informações comportamentais e fisiológicas obtidas durante uma determinada atividade (BORG, 1982). O seu processo de validação foi relativamente simples, apesar do processo de criação, em especial das ancoragens, terem sido complexos. Na sua essência, a PSE representa a integração de múltiplos sinais aferentes centrais e periféricos, que por sua vez são diretamente influenciados pelo aumento da intensidade do esforço. A validação da escala historicamente consistiu de comparar o padrão de resposta da PSE durante teste incremental com o padrão de respostas de algumas variáveis fisiológicas centrais e periféricas, ou diretamente com a carga externa imposta pelo exercício.

Borg e Kaijser (2006) reforçaram a validade da escala de PSE de 15 pontos ao relacioná-la com a potência externa gerada em um teste incremental. Os autores observaram que a PSE aumenta linearmente com o aumento da intensidade do exercício, sugerindo que a escala tem validade para a percepção de alterações na carga externa. Nesse mesmo estudo, foi observado que a PSE aumenta de maneira proporcional à FC. Quando um modelo de regressão foi criado para estimativa da PSE, apenas a FC entrou como variável preditora, sugerindo que, mesmo que a carga externa seja associada à PSE, são os estímulos internos que determinam a sua construção. Estudos similares confirmam a validade das escalas de PSE, tanto de 15 quanto de 10 pontos (NOBLE et al., 1983; BORG, LJUNGGREN, CECI, 1985; BORG, HASSMÉN, LAGERSTRÖM, 1987).

Mesmo que na sua validação original a escala de PSE representasse a integração de diversos estímulos fisiológicos, foram mensurados experimentalmente apenas FC, lactato muscular e sanguíneo (NOBLE et al., 1983). No modelo integrativo-complexo ela toma proporções mais audaciosas. Por exemplo, a decisão tomada pelo indivíduo ao ser questionado 
sobre qual é a sua percepção em um dado exercício, representa a expressão da consciência referente ao momento. Inevitavelmente, no modelo integrativo-complexo a discussão sobre PSE deve passar pelo campo da consciência.

Consciência pode ser definida por duas teorias distintas, a do dualismo e a do monismo (ST CLAIR GIBSON et al., 2003). A primeira refere-se a um estado mental, que independe de estruturas físicas cerebrais para sua existência. Logo, esse tipo é bastante explorado no campo filosófico, mas impossível de ser explorado em um campo experimental. A segunda assume que a consciência é o produto da atividade de uma ou mais áreas cerebrais. No modelo integrativo-complexo, a consciência seria o produto final de todas as alterações metabólicas e funcionais provocadas pelo esforço e tem sua forma de expressão com a PSE.

As áreas cerebrais envolvidas nessa integração entre sinais fisiológicos e PSE não é conhecida. Esse é o ponto chave do modelo integrativo-complexo que requer confirmação experimental. Entretanto, existem evidências suficientes para suportar o envolvimento de algumas áreas cerebrais na geração da percepção da fadiga (ST CLAIR GIBSON et al., 2003). As próprias regiões cerebrais motoras poderiam ser as responsáveis pela sensação de fadiga, como o córtex motor e pré-motor, córtex motor suplementar, gânglios da base e cerebelo, pois estão diretamente ligadas ao movimento. Como a fadiga é diretamente relacionada à motivação e à emoção, as amígdalas, córtex pré-frontal, hipotálamo e núcleos da base também poderiam estar envolvidos. Experiências anteriores e conhecimento prévio da atividade também influenciam no modo como o indivíduo planeja e percebe o esforço (MAUGER, JONES, WILLIAMS, 2009) e regiões diretamente ligadas à memória como o hipocampo, para-hipocampo e outras áreas do lobo temporal poderiam estar envolvidas. Nesse último caso, a consolidação da memória (transferência de curta para longa duração) depende de certo modo de emoção, representada fisicamente pelo córtex pré-frontal. Outro ponto, mas apenas de modulação da intensidade da percepção de fadiga, seria o tronco cerebral e a medula espinal, pois nessas regiões são integradas diversas vias aferentes e estão envolvidas com a liberação de neurotransmissores dopaminérgicos e colinérgicos que podem atuar em outras áreas responsáveis pelo humor e pela memória.

Contudo, com tantas áreas possivelmente envolvidas, é difícil imaginar que apenas uma dessas áreas seja a principal. Ao contrário disso, especula-se que a sincronização da atividade elétrica cerebral geral seria interpretada de maneira integrada e geraria a percepção 
de fadiga (ST CLAIR GIBSON et al., 2003). Esse é o ponto chave que o modelo integrativocomplexo ainda não conseguiu transpor experimentalmente.

Contudo, capturando algumas informações chaves da proposta de St Clair Gibson et al. (2003) e Tucker (2009), o modelo de fadiga integrativo-complexo baseia-se em memória, antecipação ou projeção, feedback e retroalimentação. Um estereótipo é criado a partir desses elementos formando o que seria considerado a condição homeostática "ideal", chamado de "proto-self". Esse proto-self seria o parâmetro central tomado de base para futuras comparações de alguma alteração metabólica. Quando um exercício inicia-se, as alterações fisiológicas e ambientais geram um novo proto-self das condições atuais, chamado de protoself de segunda ordem. A comparação entre os dois, ou mais especificamente a diferença entre os dois, seria a base para gerar uma PSE daquele momento (figura 6A).

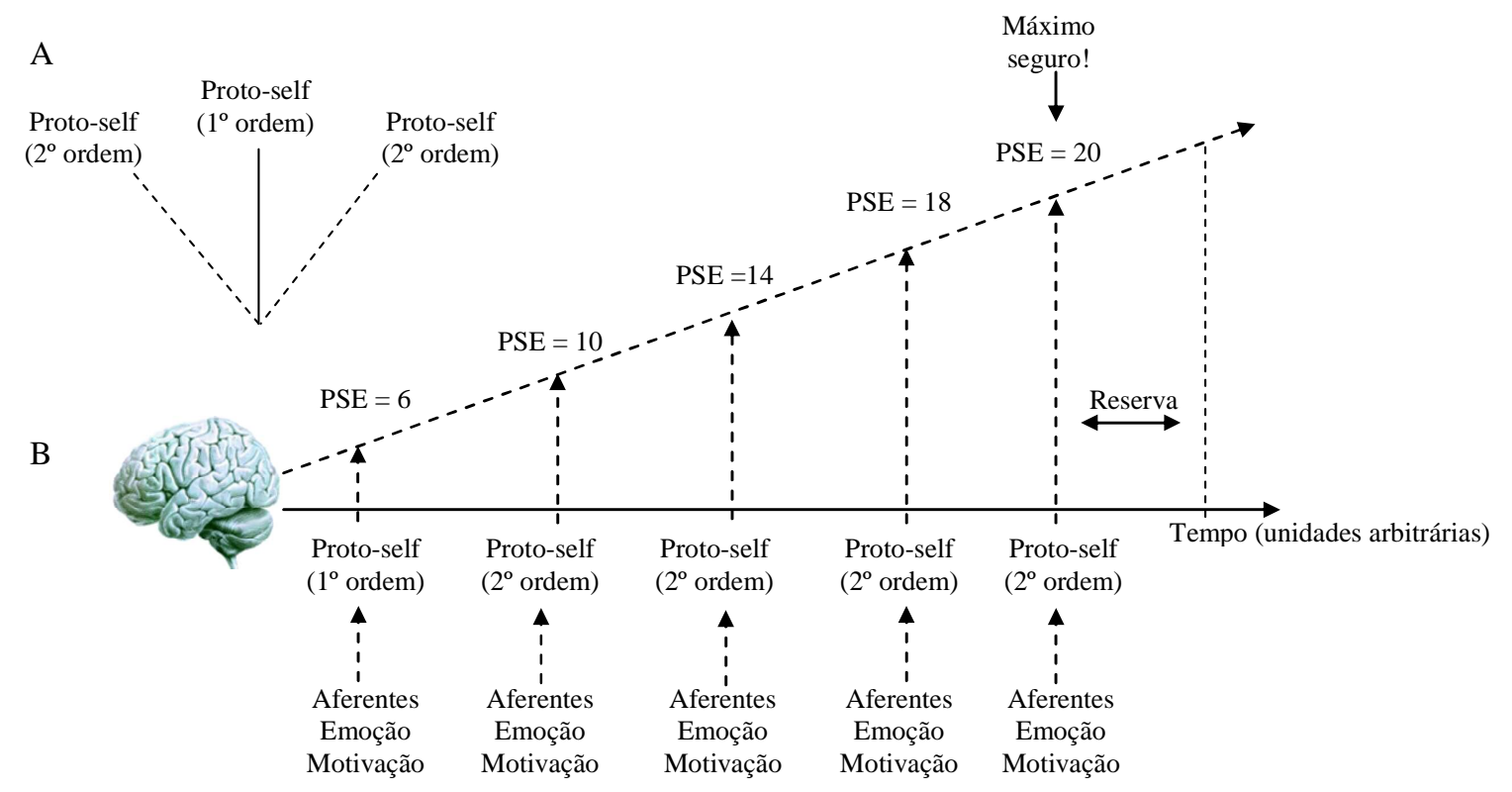

Figura 6. Modelo ilustrativo de como a PSE pode ser regulada a partir do modelo de protoself. A parte "A" demonstra como uma perturbação pode gerar um proto-self de segunda ordem. A diferença entre o proto-self de primeira e segunda ordem representa a magnitude do estímulo. Na parte "B" é ilustrado como múltiplos proto-self de segunda ordem podem ser gerados ao longo do exercício de carga constante e como a PSE responde a esses novos protoself. Cada proto-self de segunda ordem é influenciado pelas vias aferentes, estado emocional e motivacional naquele momento. O esforço máximo corresponde ao máximo seguro, onde acima dele existiria apenas uma reserva quase nunca utilizada em situações normais. 
$\mathrm{Na}$ figura 6B, a base para gerar um proto-self de segunda ordem em um dado momento é a integração de múltiplos sinais aferentes, de emoção e de motivação. Esse novo proto-self gerado é então comparado ao proto-self original de primeira ordem, construindo assim a PSE daquele momento. Como o exercício de carga constante não permite regular a intensidade de esforço, esses múltiplos proto-self de segunda ordem são cada vez mais distantes do original, o que faz com que a PSE aumente de maneira linear ao tempo de exercício. Por consequência, o modelo prevê ainda o tempo máximo seguro durante esse esforço. $\mathrm{O}$ máximo considerado seguro não representa o máximo real, pois o esgotamento total de reservas energéticas não está previsto em nossa base evolutiva. Um estudo recente sugere que a reserva do sistema poderia ser acessada através de drogas estimulantes, como anfetaminas (SWART et al., 2008). Entretanto, como essa droga, assim como o uso de música durante a atividade reduz a PSE (NETHERY, 2002), não se sabe até que ponto a reserva está sendo utilizada ou simplesmente os proto-self de segunda ordem estão sendo gerados de forma menos intensa. Como no modelo, motivação e emoção estão embutidas nos proto-self de segunda ordem, essa última explicação é mais provável. A reserva só seria utilizada em casos extremos, com consequência direta sobre a integridade dos sistemas. Evidências científicas sobre a utilização dessa reserva não são possíveis, mas observações práticas de atletas desmaiando ao final de competições longas demonstram a capacidade de atletas de elite em passar os limites considerados seguros.

\section{MATERIAIS E MÉTODOS}

\subsection{Amostra}

Doze homens saudáveis foram voluntários para participar do estudo. As características morfofuncionais dos indivíduos estão descritas na tabela 3. Cada um dos participantes foi informado sobre os riscos e procedimentos do estudo e assinaram um termo de consentimento concordando em participar voluntariamente do experimento. Os procedimentos adotados no presente estudo foram aprovados pelo Comitê de Ética para estudos com humanos da Escola de Educação Física e Esporte da Universidade de São Paulo (ANEXO 2). Apenas foram selecionados para amostra indivíduos que eram adaptados ao cicloergômetro, ou seja, que já haviam realizados testes em laboratórios nesse ergômetro, ou 
que praticavam ciclismo como atividade do dia-a-dia. Todos os sujeitos relataram terem realizados antes de iniciar o estudo algum exercício de alta intensidade nesse tipo de ergômetro e estarem familiarizados com as sensações provocadas por esse tipo de exercício. Além disso, os pesquisadores envolvidos foram orientados a não darem informações aos participantes referentes ao tipo de manipulação que estava sendo empregada e não revelarem os objetivos centrais do projeto, para evitar qual quer tipo de influência sobre os resultados.

\subsection{Desenho experimental}

Os 12 sujeitos selecionados foram encaminhados aleatoriamente para um de dois grupos: grupo $1=\Delta \operatorname{LW75\% }(\mathrm{n}=6)$ e grupo $2=115 \% \mathrm{VO}_{2 \max }(\mathrm{n}=6)$. A intensidade de $\Delta \mathrm{LW} 75 \%$ corresponde a $75 \%$ da diferença entre a carga máxima e o segundo limiar de lactato e representa o domínio MP. A intensidade de $115 \% \mathrm{VO}_{2 \max }$ corresponde a $115 \%$ do consumo máximo de oxigênio e representa o domínio SE. Cada indivíduo compareceu ao laboratório seis vezes até o término do estudo (Figura 7). Na primeira visita, foi realizada uma avaliação antropométrica para determinação da massa corporal, estatura e percentual de gordura, este último utilizando as dobras cutâneas do peitoral, abdômen e coxa (JACKSON; POLLOCK, 1978). Logo em seguida, os indivíduos realizaram um teste progressivo no cicloergômetro para determinação do $\mathrm{VO}_{2 \max }$ e do LL1 e LL2. Na segunda visita, um teste controle foi realizado na intensidade de $\Delta \mathrm{LW} 75 \%$ para o grupo 1 e à $115 \% \mathrm{VO}_{2 \max }$ para o grupo 2. Nas visitas quatro e seis foi realizado um teste experimental com carga constante ( $\triangle \mathrm{LW} 75 \%$ para o grupo 1 e à $115 \% V_{2}$ max para o grupo 2). Quarenta e oito horas antes desses dois testes (visitas três e cinco, respectivamente), os indivíduos compareceram ao laboratório para induzir a depleção dos estoques de CHO com exercício, seguindo por uma manipulação dietética até o dia do teste experimental (48 horas). As dietas foram elaboradas para manter a depleção ou restabelecer as reservas de $\mathrm{CHO}$. A ordem de aplicação das dietas foi determinada de forma contrabalançada. Um intervalo de uma semana entre um teste experimental e outro foi dado para wash-out. Foi solicitado aos sujeitos que mantivessem seu programa de exercícios físicos durante todo o período do estudo, exceto nos dias anteriores às avaliações e durante o período que separou a fase de depleção dos estoques de CHO e o teste experimental. Nesses períodos os sujeitos foram orientados a terem o menor nível possível de exercício físico. Nenhuma informação referente ao tempo de esforço foi dada ao sujeito até o término do estudo. 


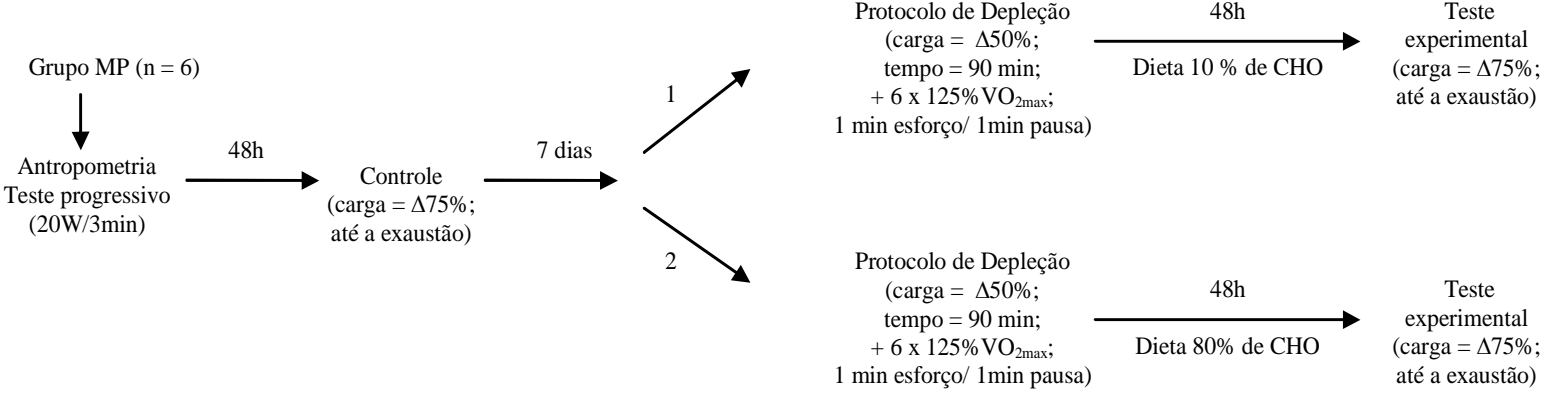

B
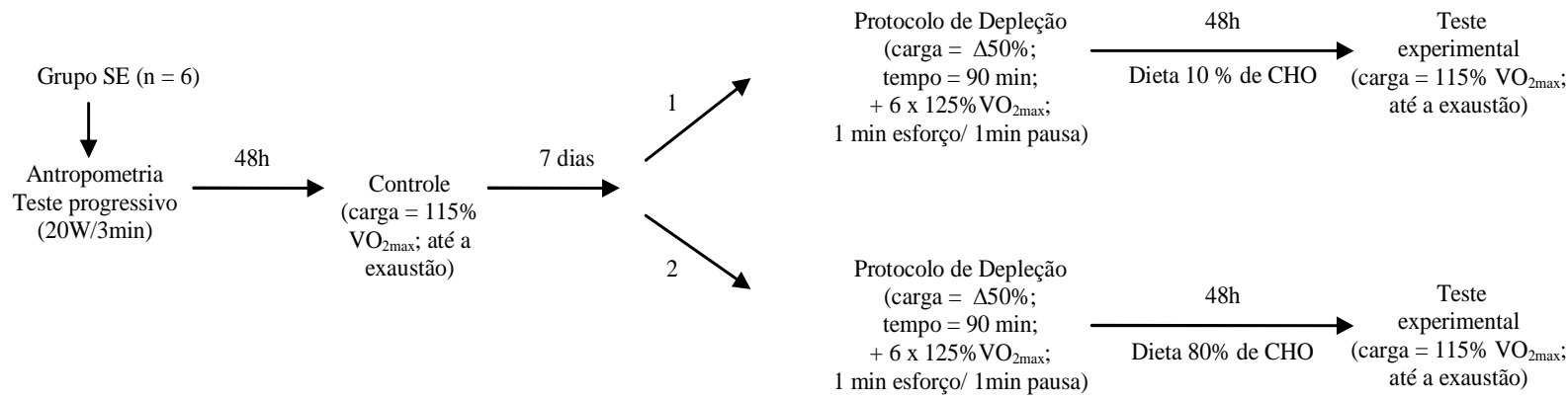

Figura 7. Painel A: desenho experimental para o grupo de esforço muito pesado (MP). Painel B: desenho experimental para o grupo de esforço severo (SE). $\Delta 75 \%$ : carga correspondente a $\underline{75 \%}$ da diferença entre o segundo limiar de lactato e a carga máxima. $\Delta 50 \%$ : carga correspondente a $50 \%$ da diferença entre o primeiro e o segundo limiar de lactato. $115 \% \mathrm{VO}_{2 \max }:$ carga correspondente a $115 \%$ do consumo máximo de oxigênio. CHO: carboidratos. Os números 1 e 2 indicam as duas situações experimentais possíveis para ambos os grupos. Essas duas sequências foram realizadas de forma contrabalanceada entre os sujeitos e separadas por sete dias para washout.

\subsection{Teste progressivo}

Os indivíduos iniciaram o teste progressivo pedalando em um cicloergômetro eletromagnético durante cinco minutos a $50 \mathrm{~W}$ para aquecimento. Posteriormente, foram acrescentados $20 \mathrm{~W}$ a cada três minutos, até a exaustão voluntária. Durante todo o teste, os indivíduos mantiveram a frequência de rotação do pedal entre 60 e $70 \mathrm{rev} \cdot \mathrm{min}^{-1}$. O teste foi interrompido quando os indivíduos não conseguiram manter a rotação dentro desse intervalo. A $\mathrm{VE}, \mathrm{VO}_{2}$ e $\mathrm{VCO}_{2}$ foram monitoradas respiração a respiração durante todo o teste 
progressivo. Antes de iniciar o teste, uma pomada vasodilatadora à base de nicotinato de butoxietileno e nonivamida foi aplicada no lóbulo da orelha direita do indivíduo, para obtenção de $25 \mu 1$ de amostra de sangue para posterior análise da concentração de lactato sanguíneo [La] (analisador automático YSI 1500 Sport, Yellow Springs Instruments, Yellow Springs, $\mathrm{OH}$ ). As [La] foram medidas no repouso e em cada estágio do teste progressivo.

\subsection{Teste controle}

Quarenta e oito horas após o teste incremental, os indivíduos realizaram um teste controle de carga constante na intensidade determinada para cada grupo. O teste foi realizado no período da manhã, nos períodos entre 7:00 e 9:00 horas, com o indivíduo em jejum de 8-12 horas e sem manipulação prévia da dieta ou depleção de CHO. Os testes foram realizados aproximadamente uma hora após o individuo ter acordado.

Antes de iniciar o teste, os indivíduos ficaram sentados durante vinte minutos em repouso para medida de base de variáveis fisiológicas e bioquímicas. Antes do início do aquecimento, foram coletados $10 \mathrm{ml}$ de sangue venoso. Após a coleta, os indivíduos pedalaram durante cinco minutos a $50 \mathrm{~W}$ para aquecimento. Ao término do aquecimento, a carga foi ajustada para a intensidade estipulada. $\mathrm{O}$ teste foi realizado até a exaustão voluntária ou até quando o indivíduo não conseguia mais manter uma rotação superior a $60 \mathrm{rpm}$. A validade dos testes de carga fixa realizados até a exaustão foi determinado previamente por Amann, Hopkins e Marcora (2008), que encontraram alta sensibilidade desse tipo de teste para identificação dos efeitos causados por uma intervenção (hipóxia e hiperóxia), o qual foi muito similar ao grau de sensibilidade de testes "contra-relógio" (distancia conhecida, potência variada de acordo com a vontade do sujeito). Amostras adicionais de sangue (10 ml) foram obtidas imediatamente após o final do esforço e nos minutos cinco e dez da recuperação.

Após o término da sessão controle, os indivíduos foram orientados a registrarem em forma de recordatório, todos os alimentos (tipo, quantidade e horário) consumidos em cada uma de suas refeições durante cinco dias consecutivos. Esses recordatórios foram utilizados posteriormente para escolher os alimentos que iriam compor as dietas com baixo ou alto conteúdo de $\mathrm{CHO}$.

\subsection{Protocolo para depleção das reservas de CHO}

Cada indivíduo compareceu ao laboratório dois dias antes do teste experimental para 
depleção dos estoques de CHO. Para isso, os indivíduos pedalaram em uma intensidade correspondente a $\Delta$ LL50\% (50\% da diferença entre LL1 e LL2) durante 90 minutos. Após cinco minutos de intervalo, seis séries de um minuto de exercício, intercaladas por um minuto de pausa, foram realizadas em uma intensidade correspondente à $125 \%$ do $\mathrm{VO}_{2 \max }$. $\mathrm{A}$ combinação de exercício prolongado com exercício intermitente intenso foi destinada a reduzir os estoques de GM das fibras do tipo I e II, respectivamente (GOLLNICK et al., 1974; VOLLESTAD et al., 1984).

\subsection{Controle dietético}

Após a realização do protocolo de depleção do GM, os indivíduos foram submetidos a um controle dietético até o dia do teste experimental (dois dias). As dietas foram aplicadas em ordem contrabalançada e compostas pela seguinte distribuição: uma dieta com baixo teor de $\mathrm{CHO}$ ( $10 \%$ de carboidrato, $35 \%$ de gordura e $55 \%$ de proteína) ou com alto teor de $\mathrm{CHO}$ (80\% de carboidrato, $10 \%$ de gordura e $10 \%$ de proteína). Apesar das diferenças na composição, ambas as dietas foram elaboradas para conter o mesmo conteúdo calórico. A necessidade energética de cada indivíduo foi estimada pela equação de Harris e Benedict (1918):

$\operatorname{TMB}(\mathrm{kcal})=66+(13,7 \cdot$ massa corporal $)+(5 \cdot$ estatura $)-(6,8 \cdot$ idade $) \cdot 1,2$

Onde: TMB é a taxa metabólica basal medida em kcal; a massa corporal medida em quilogramas, a estatura em centímetros e a idade em anos. Como foi orientado ao indivíduo que não praticassem exercício físico durante a manipulação dietética, a TMB foi corrigida pelo fator 1,2, que considera as atividades diárias como sedentárias.

A análise dos recordatórios e a elaboração das dietas foram realizadas por uma nutricionista. $\mathrm{O}$ intervalo de dois dias entre o protocolo para depleção das reservas de $\mathrm{CHO}$ e o protocolo experimental foi utilizado para minimizar o desgaste fisiológico provocado pelo exercício prévio (GRISDALE et al., 1990). Durante este período foi recomendado aos indivíduos que evitassem ao máximo a prática de exercício físico. Durante os dois dias de realização das dietas, os indivíduos foram orientados a registrarem em forma de recordatório, todos os alimentos (tipo, quantidade e horário) consumidos nesse período, para posterior comparação 
com o que foi prescrito. A validade desse tipo de instrumento foi descrita em estudos anteriores (STORLIE, 1991; BASSIT; MALVERDI, 1998; MAGKOS; YANNAKOULIA, 2003).

\subsection{Testes experimentais}

Similar à situação controle, os indivíduos compareceram ao laboratório na manhã do teste experimental, em jejum de 8-12 horas. Os testes foram realizados adotando os mesmos horários, procedimentos e técnicas de medidas utilizadas no teste controle. Um período de sete dias foi adotado para wash-out entre as duas situações experimentais (GRISDALE et al., 1990).

\subsection{Análises bioquímicas}

Antes do início dos testes controle e experimentais, um cateter foi fixado na veia braquial com infusão periódica de heparina diluída em cloreto de sódio $(\mathrm{NaCl}$ 0,9\%) estéril para evitar a coagulação e obstrução da passagem do sangue pelo cateter $(1 \mathrm{ml})$. As amostras de sangue foram transferidas para tubos contendo EDTA e imediatamente centrifugadas a $3.000 \mathrm{rpm}$ à $4^{\circ} \mathrm{C}$ durante dez minutos para separação do plasma. O plasma foi armazenado em freezer com temperatura de $-80^{\circ} \mathrm{C}$ para posterior análise bioquímica.

A mensuração das concentrações plasmáticas de glicose (kit Biotécnica, Varginha, Brasil) foi realizada através de reações colorimétricas medidas em espectrofotômetro. A concentração de lactato arterializado e venoso foi mensurada no sangue total, usando o mesmo analisador automático descrito para as medidas realizadas durante o teste progressivo (analisador automático YSI 1500 Sport, Yellow Springs Instruments, Yellow Springs, OH). A análise de epinefrina, norepinefrina e dopamina foi feita por cromatografia líquida de alta performance (HPLC), com detecção eletroquímica da fase cromatográfica dos pares de íons reversos (NAFFAH-MAZZACORATTI et al., 1992). A concentração de insulina e cortisol no plasma foi mensurada por radioimunoensaio. O potássio plasmático foi mensurado com determinação por análise seletiva de íons, por meio da medida do potencial de membrana e voltagem, em analisador AVLÒ 9180 (Roche, São Paulo, Brasil). O pH foi mensurado através de fitas especificas. 


\subsection{Mensuração de variáveis respiratórias, freqüência cardíaca e percepção subjetiva de esforço}

Durante todos os testes os indivíduos utilizaram uma máscara com respostas da ventilação e trocas gasosas mensuradas por um sistema computadorizado e com transmissão imediata, respiração a respiração, para um software especifico (Quark $b^{2}$; Cosmed, Itália). O volume de ar expirado foi mensurado através de um sensor de fluxo bidirecional, calibrado antes do início de cada teste com uma seringa contendo três litros de ar. A fração expirada de $\mathrm{O}_{2}$ foi analisada com sensor de zircônio e a fração expirada de $\mathrm{CO}_{2}$ por absorção de infravermelho. Ambos os sensores foram calibrados de forma automática antes do início de cada teste, utilizando cilindro com concentração conhecida de $\mathrm{O}_{2}(20,9 \%)$ e $\mathrm{CO}_{2}(5 \%)$.

$\mathrm{O} \mathrm{VO}_{2}, \mathrm{VCO}_{2}, \mathrm{VE}$ e FR foram medidos, respiração a respiração, durante todo o teste progressivo e nos testes controle e experimentais. A FC foi monitorada batimento-a-batimento (Polar S810i, Finlândia) durante o mesmo período.

Durante o teste progressivo, a PSE foi mensurada através da escala de Borg de 15 pontos (BORG, 1982) ao final de cada estágio. Durante o teste controle e experimentais, a PSE foi questionada a cada 30 segundos e no momento da exaustão. Os indivíduos indicaram quão intenso ou desconfortável estava o esforço naquele momento, levando em consideração dois aspectos: 1) a percepção relacionada ao desconforto no organismo como um todo, tendo como base a sensação geral de esforço e desconsiderando aspectos localizados em determinadas regiões ou órgãos $\left(\mathrm{PSE}_{\mathrm{Geral}}\right) ; 2$ ) a percepção relacionada ao grau de esforço e ao desconforto dos músculos ativos (coxas e pernas) durante o exercício ( $\left.\mathrm{PSE}_{\text {Local }}\right)$. Antes do primeiro teste (progressivo), a utilização correta da escala foi explicada a todos os indivíduos, destacando o sistema de ancoragem no ponto inicial seis (referente ao repouso) e final 20 (referente ao desconforto máximo possível de ser suportado).

\subsection{Análise dos dados}

\subsubsection{Teste progressivo}

No teste progressivo, as [La] foram plotadas em função da potência e o $L_{1}$ e $L_{2}$ identificado a partir de regressão linear múltipla de três segmentos (RIBEIRO et al., 1985; 1986a; 1986b). Os dados de $\mathrm{VO}_{2}$ (média dos 20 segundos finais de cada estágio) foram igualmente plotados em função da potência, sendo que o maior valor atingido no teste foi 
considerado o $\mathrm{VO}_{2 \max }$. Os seguintes critérios foram utilizados para verificar se o teste foi realmente máximo: 1) aumento inferior a $150 \mathrm{ml} \cdot \mathrm{min}^{-1}$ no $\mathrm{VO}_{2}$ após o incremento da carga; 2) razão de trocas respiratórias $(\mathrm{R}) \geq 1,10 ; 2$ ) frequência cardíaca $\geq$ a $90 \%$ da máxima predita pela idade $\left(\mathrm{FC}_{\max }=220\right.$ - idade $)($ HOWLEY et al. 1995).

A carga máxima obtida $\left(\mathrm{W}_{\max }\right)$ no teste foi considerada a maior intensidade, medida em Watts, alcançada e sustentada durante os três minutos de estágio. Nos casos em que o estágio não foi completado, a carga máxima foi calculada a partir da seguinte equação:

$$
\mathrm{W}_{\max }=\mathrm{W}_{\mathrm{UEC}}+\left(\mathrm{T}_{\mathrm{UEI}} / 180 \cdot 20\right)
$$

Onde: $\mathrm{W}_{\mathrm{UEC}}$ corresponde a carga do último estágio completo e $\mathrm{T}_{\mathrm{UEI}} \mathrm{O}$ tempo do último estágio incompleto. As constantes 180 e 20 correspondem à duração dos estágios (180 segundos) e a amplitude de incremento na carga $(20 \mathrm{~W})$, respectivamente.

A intensidade correspondente ao domínio MP foi obtida a partir da carga correspondente a $75 \%$ da diferença entre a $\mathrm{W}_{\text {MÁx }}$ e o $\mathrm{LL}_{2}(\Delta \mathrm{LW} 75 \%)$, utilizando a seguinte equação:

$$
\Delta \mathrm{LW} 75 \%=\mathrm{LL}_{2}+\left[\left(\mathrm{W}_{\mathrm{MÁX}}-\mathrm{LL}_{2}\right) \cdot 0,75\right]
$$

A intensidade correspondente ao domínio SE foi representada pela intensidade correspondente a $115 \%$ do $\mathrm{VO}_{2 \text { máx }}$, que foi obtida a partir da extrapolação linear da curva $\mathrm{VO}_{2}$-intensidade obtida no teste progressivo.

\subsubsection{Testes controle e experimentais}

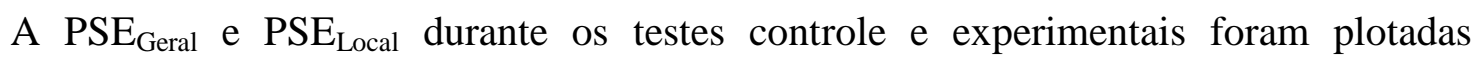
individualmente em função do tempo absoluto (minutos) e relativo (porcentagem em relação ao tempo de exaustão) para o cálculo do coeficiente angular (inclinação).

Para VE, FR, $\mathrm{VO}_{2}$ e FC foram calculadas as médias dos valores das respirações contidas em intervalos de dez segundos, mas usados apenas os valores correspondentes a cada intervalo de 30 segundos, para equiparar com o tempo de mensuração da PSE.

Para o cálculo de parâmetros cinéticos das variáveis cardiorrespiratórias (FR, VE, $\mathrm{VO}_{2}$, $\mathrm{VCO}_{2}$ e FC) durante os testes controle e experimentais, os dados foram interpolados no tempo a cada um segundo e, posteriormente, calculado a média móvel a cada cinco segundos. Isso foi feito para reduzir os ruídos na distribuição dos dados (SLAWINSKI et al., 2001). 
No caso especifico da FR, optou-se por ajustá-la com uma função linear para o cálculo do coeficiente angular da função (inclinação), com o intuito de obter a sua taxa de incremento em função do tempo.

As demais variáveis foram ajustadas por funções exponenciais. Inicialmente, as curvas foram ajustadas por uma equação biexponencial para o domínio MP, e monoexponencial para o domínio SE (ÖZYENER et al., 2001):

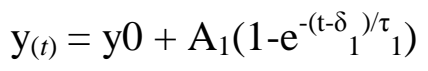

$$
\begin{aligned}
& \text { ou }
\end{aligned}
$$

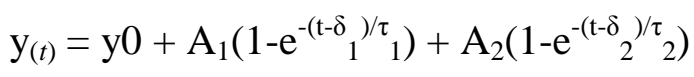

Onde y é a variável dependente $\left(\mathrm{VE}, \mathrm{VO}_{2}\right.$ ou $\left.\mathrm{VCO}_{2}\right)$ e ${ }_{1}$ e 2 denotam, respectivamente, o componente rápido e lento; $\mathrm{y} 0=$ linha de base; $\mathrm{A}, \tau$ e $\delta$ são referentes à amplitude, à constante de tempo (s) e ao tempo de atraso (s), respectivamente.

A partir da comparação individual da qualidade dos dois ajustes $\left(\mathrm{R}^{2}\right.$ e somatório de resíduos ao quadrado) e baseando-se no princípio da parcimônia, optou-se por utilizar o ajuste monoexponencial também para o domínio MP, pois é um modelo mais simples e utiliza menos parâmetros. Contudo, no caso especifico do domínio MP, a possível presença de um componente lento para alguma das variáveis foi investigada calculando o coeficiente angular da variável em questão do minuto três até a exaustão.

O total de oxigênio consumido durante o esforço foi calculado a partir da integral da equação monoexponencial ajustada e convertida em quilojoules $(\mathrm{kJ})$ usando um equivalente energético correspondente a $20,9 \mathrm{~kJ}$ por litro de oxigênio consumido $(20,9 \mathrm{~kJ} / \mathrm{L})$.

\subsection{Análise estatística}

Primeiramente foi verificada a normalidade na distribuição dos dados utilizando o teste de Shapiro-Wilk. A comparação das variáveis antropométricas, fisiológicas obtidas no teste incremental e referentes ao protocolo de depleção entre os dois grupos (MP e SE) foi realizada através do teste $t$ de Student para medidas independentes. O tempo de exaustão, o trabalho total realizado, a inclinação da $\mathrm{PSE}_{\mathrm{Geral}}$ ou $\mathrm{PSE}_{\mathrm{Local}}$, os parâmetros cinéticos, as variáveis dietéticas, os valores finais das variáveis de PSE e cardiorrespiratórios foram 
comparados entre as condições utilizando ANOVA com mensuração repetida, tendo a situação de $\mathrm{CHO}$ como fator independente. As alterações dos valores de PSE, cardiorrespiratórios, metabólicos e hormonais ao longo do tempo foram comparadas com ANOVA de dois caminhos com mensurações repetidas nos dois fatores (fatores: situação = controle, alto e baixo $\mathrm{CHO} ;$ tempo $=$ repouso, $30 \mathrm{~s}, 60 \mathrm{~s}, . .$. exaustão ou só repouso e exaustão, no caso das metabólicas e hormonais), com modelagem de matriz de co-variância e ajuste de Bonferroni para comparações múltiplas. A correlação linear de Pearson foi utilizada para identificar o grau de associação entre variáveis, utilizando os dados agrupados das situações $(n=18)$. Para todos os tratamentos foi adotado um nível de significância inferior a 5\%.

\section{RESULTADOS}

\subsection{Características dos sujeitos}

Na tabela 3 estão descritas as principais características dos indivíduos de cada um dos grupos estudados. Não foram encontradas diferenças significativas entre os grupos em nenhuma das variáveis morfológicas ou fisiológicas listadas na tabela 3. 
Tabela 3 - Características morfofisiológicas dos indivíduos do grupo de esforço muito pesado (MP) e severo (SE).

\begin{tabular}{lcc}
\hline & $\mathrm{MP}$ & $\mathrm{SE}$ \\
\hline Idade (anos) & $27,3 \pm 6,4$ & $29,7 \pm 7,6$ \\
Massa corporal $(\mathrm{kg})$ & $73,8 \pm 8,1$ & $75,8 \pm 10,0$ \\
Estatura (cm) & $178,0 \pm 4,5$ & $179,3 \pm 4,4$ \\
Percentual de gordura (\%) & $12,9 \pm 3,8$ & $13,0 \pm 2,7$ \\
$\mathrm{~W}_{\text {máx }}(\mathrm{W})$ & $235 \pm 43$ & $241 \pm 41$ \\
$\mathrm{VO}_{2 \max }\left(\mathrm{L} \cdot \mathrm{min}^{-1}\right)$ & $3,40 \pm 0,55$ & $3,50 \pm 0,69$ \\
$\mathrm{VO}_{2 \max }\left(\mathrm{ml} \cdot \mathrm{kg}^{-1} \cdot \mathrm{min}^{-1}\right)$ & $47,1 \pm 8,5$ & $46,7 \pm 10,9$ \\
$\mathrm{FC}_{\text {máx }}(\mathrm{bpm})$ & $176 \pm 19$ & $174 \pm 25$ \\
$\mathrm{LL}_{1}(\mathrm{~W})$ & $133 \pm 61$ & $132 \pm 29$ \\
$\mathrm{LL}_{2}(\mathrm{~W})$ & $195 \pm 55$ & $203 \pm 27$ \\
$\mathrm{LL}_{1}\left(\mathrm{ml} \cdot \mathrm{kg}^{-1} \cdot \mathrm{min}^{-1}\right)$ & $28,7 \pm 8,8$ & $28,2 \pm 8,5$ \\
$\mathrm{LL}_{2}\left(\mathrm{ml} \cdot \mathrm{kg}^{-1} \cdot \mathrm{min}^{-1}\right)$ & $40,2 \pm 8,2$ & $39,9 \pm 9,9$ \\
\hline
\end{tabular}

$\mathrm{VO}_{2 \text { máx }}$ : consumo máximo de oxigênio, $\mathrm{W}_{\text {máx }}$ : carga máxima obtida no teste progressivo máximo; $\mathrm{LL}_{1}$ : primeiro limiar de lactato; $\mathrm{LL}_{2}$ : segundo limiar de lactato.

\subsection{Protocolo de depleção de glicogênio muscular}

Todos os sujeitos, de ambos os grupos e em todas as situações, conseguiram cumprir integralmente os 90 minutos estipulados no protocolo para depleção de GM, sem a necessidade de alterar a carga de trabalho. A carga utilizada para MP foi de 163,8 $\pm 57,5 \mathrm{~W}$ $\left(72,7 \pm 8,5 \% \mathrm{VO}_{2 \max }\right)$ e para SE foi de $168,0 \pm 27,8 \mathrm{~W}\left(72,9 \pm 6,0 \% \mathrm{VO}_{2 \max }\right)$, não havendo diferenças estatisticamente significantes entre os grupos $(\mathrm{P}>0,05)$.

A carga correspondente a $125 \%$ do $\mathrm{VO}_{2 \max }$, utilizada na fase seguinte do protocolo de depleção de GM, foi de $285,8 \pm 59,0 \mathrm{~W}$ e $301,5 \pm 50,9 \mathrm{~W}$ para os grupos MP e SE, respectivamente. O número de séries realizadas foi 5,8 \pm 0,4 para o grupo MP (mínimo de 5 e máximo de 6) e 5,4 \pm 1,0 para o grupo SE (mínimo de 4 e máximo de 6). Tanto para a carga, quanto para o número de séries, não foram encontradas diferenças significantes entre os grupos $(\mathrm{P}>0,05)$. 


\subsection{Controle dietético}

Os valores absolutos (kcal) e relativos $(\%)$ dos macronutrientes contidos na dieta consumida nos dois dias anteriores às situações controle, alto e baixo $\mathrm{CHO}$ estão descritos na tabela 4.

Tabela 4 - Conteúdo dietético das dietas consumidas nos dois dias anteriores as situações $\underline{\text { controle, alto e baixo carboidrato. }}$

\begin{tabular}{|c|c|c|c|c|c|c|c|c|}
\hline \multicolumn{9}{|c|}{ Conteúdo dietético } \\
\hline & \multicolumn{8}{|c|}{ MP } \\
\hline & \multirow{2}{*}{\multicolumn{4}{|c|}{ Absoluto (kcal) }} & & & & \\
\hline & & & & & \multicolumn{4}{|c|}{ Relativo (\%) } \\
\hline & $\mathrm{CHO}$ & PRO & LIP & Total & $\mathrm{CHO}$ & PRO & LIP & Total \\
\hline Controle & $1280,1 \pm 257,7$ & $357,5 \pm 110,4$ & $653,8 \pm 103,6$ & $2291,5 \pm 183,0$ & $55,8 \pm 8,9$ & $15,7 \pm 4,8$ & $28,6 \pm 4,1$ & $100,0 \pm 0,0$ \\
\hline Alto $\mathrm{CHO}$ & $1069,5 \pm 299,7$ & $178,9 \pm 98,4$ & $255,6 \pm 29,5$ & $1504,0 \pm 369,7$ & $70,7 \pm 2,3$ & $11,4 \pm 3,3$ & $17,9 \pm 5,6$ & $100,0 \pm 0,0$ \\
\hline \multirow[t]{5}{*}{ Baixo $\mathrm{CHO}$} & $521,2 \pm 137,1^{a}$ & $517,1 \pm 213,9^{b}$ & $643,4 \pm 240,0$ & $1679,7 \pm 564,0$ & $31,7 \pm 3,5^{a, b}$ & $30,1 \pm 3,9^{a, b}$ & $38,3 \pm 4,4^{b}$ & $100,0 \pm 0,0$ \\
\hline & \multicolumn{8}{|c|}{ SE } \\
\hline & \multirow{2}{*}{\multicolumn{4}{|c|}{ Absoluto (kcal) }} & \multirow{2}{*}{\multicolumn{4}{|c|}{ Relativo (\%) }} \\
\hline & & & & & & & & \\
\hline & $\mathrm{CHO}$ & PRO & LIP & Total & $\mathrm{CHO}$ & PRO & LIP & Total \\
\hline Controle & $1095,0 \pm 131,4$ & $389,5 \pm 57,0^{b}$ & $764,8 \pm 109,8^{b}$ & $2249,1 \pm 193,6$ & $48,8 \pm 4,8^{b}$ & $17,3 \pm 2,0$ & $33,9 \pm 2,9^{b}$ & $100,0 \pm 0,0$ \\
\hline Alto $\mathrm{CHO}$ & $1411,6 \pm 375,9$ & $229,1 \pm 56,1^{a}$ & $353,0 \pm 94,6^{a}$ & $1993,9 \pm 352,1$ & $70,1 \pm 9,3^{\mathrm{a}}$ & $11,9 \pm 4,2$ & $18,0 \pm 5,4^{\mathrm{a}}$ & $100,0 \pm 0,0$ \\
\hline Baixo $\mathrm{CHO}$ & $434,3 \pm 152,8^{a, b}$ & $491,7 \pm 63,0^{b}$ & $704,1 \pm 235,5$ & $1678,2 \pm 346,4$ & $25,3 \pm 4,7^{a, b}$ & $29,8 \pm 4,2^{\mathrm{a}, \mathrm{b}}$ & $41,1 \pm 5,7^{b}$ & $100,0 \pm 0,0$ \\
\hline
\end{tabular}

CHO: carboidratos; PRO: proteínas; LIP: lipídios. ${ }^{a}$ Significativamente diferente da situação controle; ${ }^{\mathrm{b}}$ Significativamente diferente da situação de alto $\mathrm{CHO}(\mathrm{P}<0,05)$.

Para o grupo MP, a porcentagem de $\mathrm{CHO}$ da dieta na situação controle e alto $\mathrm{CHO}$ foram significativamente maiores do que na situação de baixo $\mathrm{CHO}(\mathrm{P}<0,05)$. Quando expresso em valores absolutos (kcal), apenas na situação controle a quantidade de CHO consumida foi maior do que a de baixo $\mathrm{CHO}(\mathrm{P}<0,05)$, apesar do conteúdo médio da situação de alto $\mathrm{CHO}$ ter sido duas vezes maior do que na de baixo $\mathrm{CHO}$. A porcentagem de proteína na dieta foi maior na situação de baixo $\mathrm{CHO}$ do que na situação controle ou alto $\mathrm{CHO}(\mathrm{P}<$ 0,05). Quando expresso em valores absolutos, a condição de baixo CHO foi maior do que na situação de alto CHO ( $<$ < 0,05). A porcentagem de lipídios consumidos na situação de alto $\mathrm{CHO}$ foi significativamente menor apenas quando comparado à situação de baixo $\mathrm{CHO}(\mathrm{P}<$ 0,05). Quando expresso em valores absolutos, não houve diferenças significantes, apesar dos valores na situação de alto $\mathrm{CHO}$ ser menos do que a metade para as demais situações.

Para o grupo SE, a porcentagem de $\mathrm{CHO}$ da dieta na situação de alto $\mathrm{CHO}$ foi maior 
do que nas duas outras situações, ao passo que os valores na situação controle foram maiores do que na situação de baixo CHO $(\mathrm{P}<0,05)$. Quando expresso em valores absolutos, as situações controle e alto $\mathrm{CHO}$ foram maiores do que a de baixo $\mathrm{CHO}(\mathrm{P}<0,05)$. A porcentagem de proteína na dieta foi maior na situação de baixo $\mathrm{CHO}$ do que na situação controle ou alto CHO (P < 0,05). Quando expresso em valores absolutos, a condição de alto $\mathrm{CHO}$ foi menor do que nas demais situações $(\mathrm{P}<0,05)$. A porcentagem de lipídios consumidos na situação de alto $\mathrm{CHO}$ foi menor do que na situação controle e baixo $\mathrm{CHO}$ (P < 0,05). Quando expresso em valores absolutos, a situação de alto CHO foi menor apenas quando comparado a situação controle, apesar dos valores terem sido a metade do encontrado para a situação de baixo CHO.

\subsection{Grupo MP}

\subsubsection{Tempo de exaustão}

A carga utilizada na situação experimental para o grupo MP foi de 217,8 $\pm 51,5 \mathrm{~W}$, o que correspondeu a aproximadamente $94,3 \pm 2,4 \% \mathrm{VO}_{2 \max }$.

O tempo de exaustão médio em cada uma das situações para o grupo MP está descrito na figura 8, painel superior. Para o grupo MP, não foram encontradas diferenças significantes no tempo de exaustão entre as três situações (controle: 9,54 \pm 4,12 min; alto CHO: 10,72 \pm 5,08 min e; baixo CHO: 8,12 $\pm 2,49 \mathrm{~min} ; \mathrm{P}=0,19)$. De maneira similar, o trabalho total realizado também não foi diferente entre as três situações (controle: 121,0 \pm 45,6 kJ; alto CHO: 141,4 \pm 73,0 kJ e; baixo CHO: 109,8 \pm 53,7 kJ; P = 0,29).

Uma análise individual do grupo MP revelou que três indivíduos aumentaram seu tempo de exaustão na situação de alto $\mathrm{CHO}$ em relação a situação controle, enquanto três reduziram (figura 8, painel inferior). Quando a situação de baixo $\mathrm{CHO}$ foi comparada ao controle, quatro indivíduos reduziram e dois aumentaram o seu tempo de exaustão. Comparando a situação de alto com baixo CHO, apenas um indivíduo teve seu maior tempo de exaustão na situação de baixo $\mathrm{CHO}$, sendo que os demais tiveram maiores tempo na situação de alto CHO. Por fim, dos seis sujeitos, três obtiveram seu maior tempo de exaustão na situação controle, enquanto os outros três na situação de alto CHO. Nenhum sujeito obteve seu maior tempo de exaustão na situação de baixo CHO. 

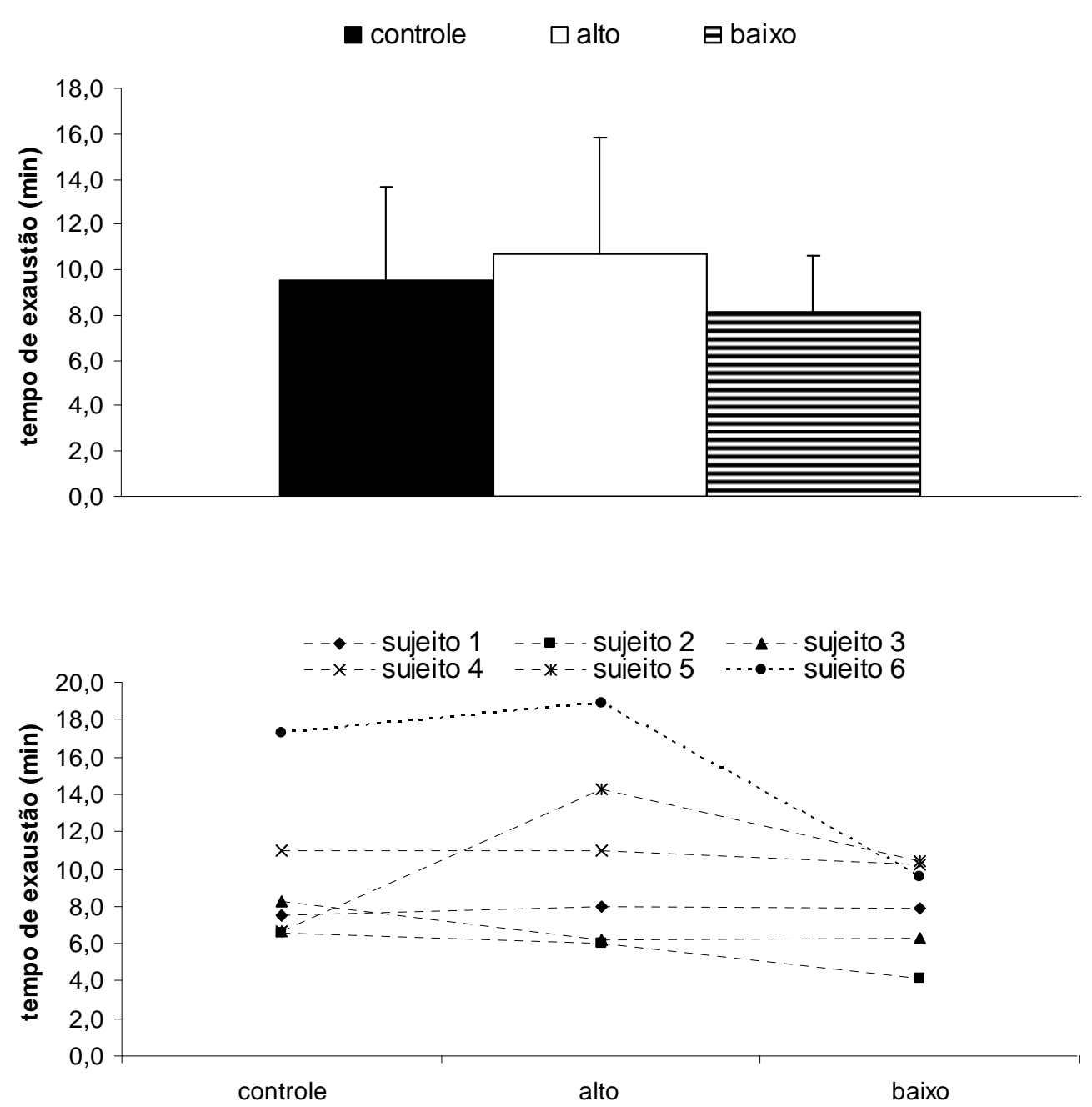

Figura 8. Tempo de exaustão do grupo que realizou esforço no domínio muito pesado (MP) em três situações distintas (controle, alto ou baixo carboidrato na dieta). O painel superior representa os valores médios e o desvio padrão do tempo de exaustão do grupo em cada situação. O painel inferior representa os valores individuais do tempo de exaustão para cada individuo avaliado em cada uma das situações.

\subsubsection{Resposta da percepção subjetiva de esforço}

Um exemplo de resposta da $\mathrm{PSE}_{\text {Geral }}$ e $\mathrm{PSE}_{\mathrm{Local}}$ de um sujeito do grupo MP está presente na figura 9. O apêndice 1 e 2 contém as curvas individuais de cada sujeito do grupo MP. Para evitar descrição excessiva de resultados, as diferenças entre pontos no fator tempo não foi explorado porque já era esperado um efeito nesse fator. De particular interesse nesse estudo foi o fator condição e a interação entre fatores. 

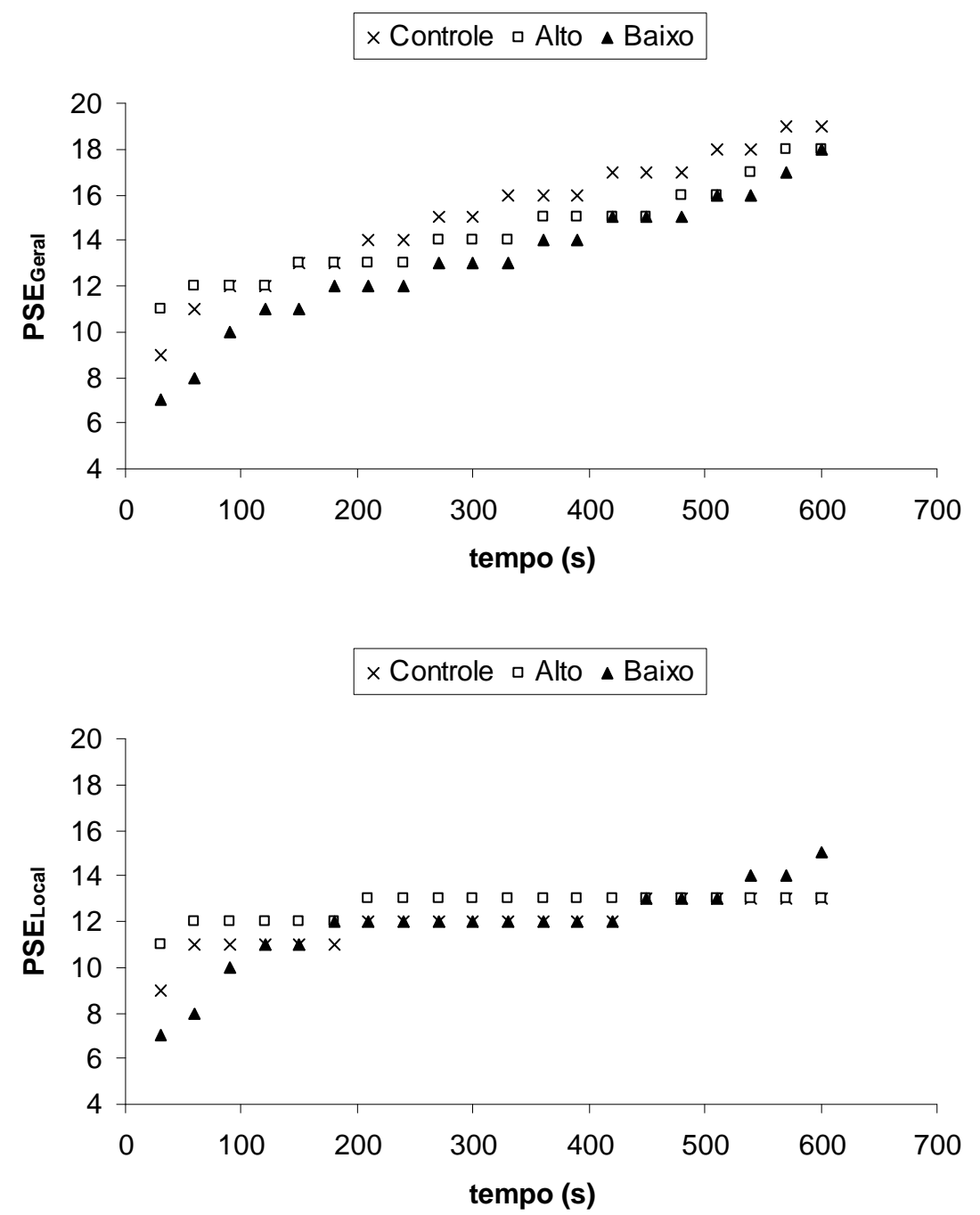

Figura 9. Percepção subjetiva de esforço (PSE) de um sujeito do grupo de esforço muito pesado (MP) nas três situações (controle, alto ou baixo carboidrato na dieta). Os dados do painel superior são referentes a PSE geral. O painel inferior representa os valores da PSE $\underline{\text { local. }}$

A resposta da $\mathrm{PSE}_{\mathrm{Geral}}$ no grupo MP foi afetada por ambos, situação $(\mathrm{P}<0,001)$ e tempo ( $P<0,001)$, mas não houve efeito de interação entre esses dois fatores $(P=0,99)$. Para

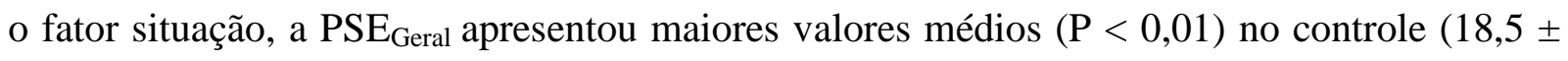
0,6 pontos) do que em alto $\mathrm{CHO}(17,8 \pm 0,6$ pontos) ou baixo $\mathrm{CHO}(15,6 \pm 0,6$ pontos $)$. As diferenças na $\mathrm{PSE}_{\mathrm{Geral}}$ entre a situação alto e baixo $\mathrm{CHO}$ também foram significantes $(\mathrm{P}<$ $0,001)$.

Apesar dos valores médios da $\mathrm{PSE}_{\mathrm{Geral}}$ durante o exercício com baixo $\mathrm{CHO}$ terem sido 
menores do que nas demais situações, a taxa de aumento em função do tempo absoluto de

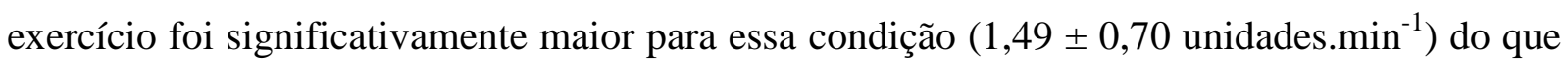
para a situação controle $\left(1,00 \pm 0,42\right.$ unidades. $\left.\min ^{-1} ; \mathrm{P}=0,018\right)$. A taxa de aumento na situação de alto $\mathrm{CHO}\left(1,23 \pm 0,74\right.$ unidades. $\left.\min ^{-1}\right)$ não foi diferente de nenhuma das outras situações. Quando a taxa de aumento da $\mathrm{PSE}_{\text {Geral }}$ foi calculada em função do tempo relativo, não foram identificadas diferenças significantes entre as situações (controle: 0,08 \pm 0,02 unidades. $\%^{-1}$; alto $\mathrm{CHO}: 0,10 \pm 0,03$ unidades. $\%^{-1}$ e; baixo $\mathrm{CHO}: 0,10 \pm 0,03$ unidades. $\%^{-1}$; $\mathrm{P}>0,05)$.

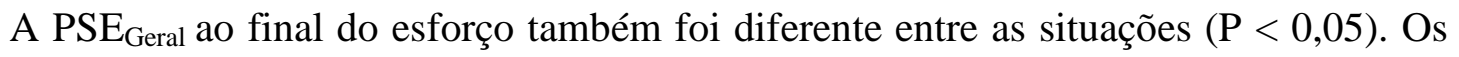
valores ao final do exercício para a situação de baixo $\mathrm{CHO}(18,8 \pm 1,3$ pontos $)$ foram significativamente menores $(\mathrm{P}<0,05)$ do que na situação controle $(20 \pm 0,0$ pontos $)$, mas não foi diferente da situação de alto $\mathrm{CHO}$ (19,5 \pm 0,8 pontos). Também não foram encontradas diferenças significantes entre a situação de alto $\mathrm{CHO}$ e controle $(\mathrm{P}>0,05)$.

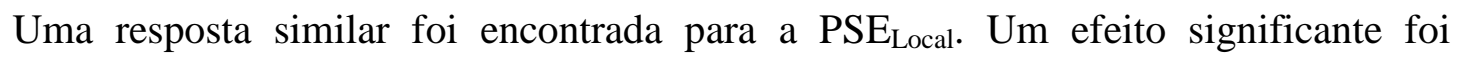
encontrado para os fatores situação $(\mathrm{P}<0,001)$ e tempo $(\mathrm{P}<0,001)$, mas sem efeito de interação $(\mathrm{P}=0,99)$. Para o fator situação, a PSE $\mathrm{Local}_{\text {da }}$ situação de baixo $\mathrm{CHO}(13,4 \pm 1,0$ pontos) foi significantemente menor $(\mathrm{P}<0,001)$ do que na situação controle $(16,0 \pm 1,0$ pontos) ou alto $\mathrm{CHO}(16,7 \pm 1,0$ pontos $)$. As diferenças na $\mathrm{PSE}_{\text {Local }}$ entre a situação alto $\mathrm{CHO}$ e controle não foram significantes $(P>0,05)$.

Do mesmo modo ao encontrada para $\mathrm{PSE}_{\mathrm{Geral}}$, a taxa de aumento da $\mathrm{PSE}_{\mathrm{Local}} \mathrm{em}$ função do tempo absoluto de exercício foi significativamente maior para a condição de baixo CHO $\left(1,13 \pm 0,79\right.$ unidades. min $\left.^{-1}\right)$ do que para a situação controle $\left(0,80 \pm 0,36\right.$ unidades. min $^{-1}$;

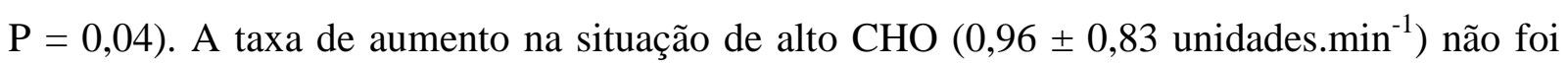
estatisticamente diferente de nenhuma das outras situações. Quando a taxa de aumento da PSE $_{\text {Local }}$ foi calculada em função do tempo relativo, não foram identificadas diferenças significantes entre as situações (controle: $0,07 \pm 0,03$ unidades. $\%^{-1}$; alto CHO: $0,09 \pm 0,06$ unidades. $\%^{-1}$ e; baixo CHO: 0,09 $\pm 0,05$ unidades. $\%^{-1}$; P > 0,05).

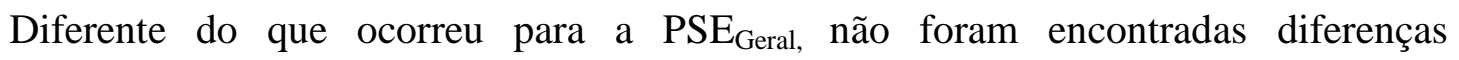

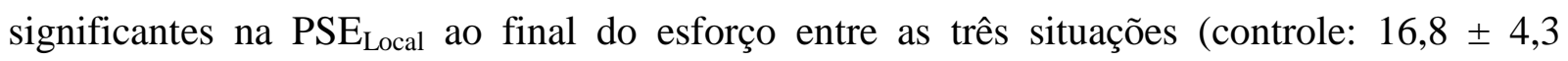
pontos; alto CHO: 17,2 \pm 3,8 pontos e; baixo $\mathrm{CHO}$ : 15,8 \pm 4,3 pontos; $\mathrm{P}>0,05$ ). 


\subsubsection{Respostas cardiorrespiratórias}

A resposta do $\mathrm{VO}_{2}$ e $\mathrm{VCO}_{2}$ no grupo MP até o tempo de 330 segundos está ilustrada na figura 10. Esse tempo foi escolhido devido a ser o último ponto em que todos os indivíduos apresentavam a medida $(n=6)$.

Para $\mathrm{O}_{2}$ foi encontrado um efeito significativo em ambos os fatores $(\mathrm{P}<0,001)$, mas sem interação entre eles $(\mathrm{P}=0,95)$. Em todas as situações, o $\mathrm{VO}_{2}$ aumenta em função do tempo de exercício $(\mathrm{P}<0,001)$. A comparação de Bonferroni mostrou que tanto na situação de baixo, quanto de alto $\mathrm{CHO}$, os valores foram significativamente menores do que na situação controle $(\mathrm{P}<0,05)$, mas não houve diferenças entre os dois primeiros.

Para o $\mathrm{VCO}_{2}$ foi encontrado apenas um efeito significativo no fator tempo ( $\left.\mathrm{P}<0,05\right)$, sem efeito para situação $(\mathrm{P}=0,48)$ ou interação entre fatores $(\mathrm{P}=0,76)$. Similar ao $\mathrm{VO}_{2}$, $\mathrm{VCO}_{2}$ também aumenta em função do tempo de exercício $(\mathrm{P}<0,001)$. 

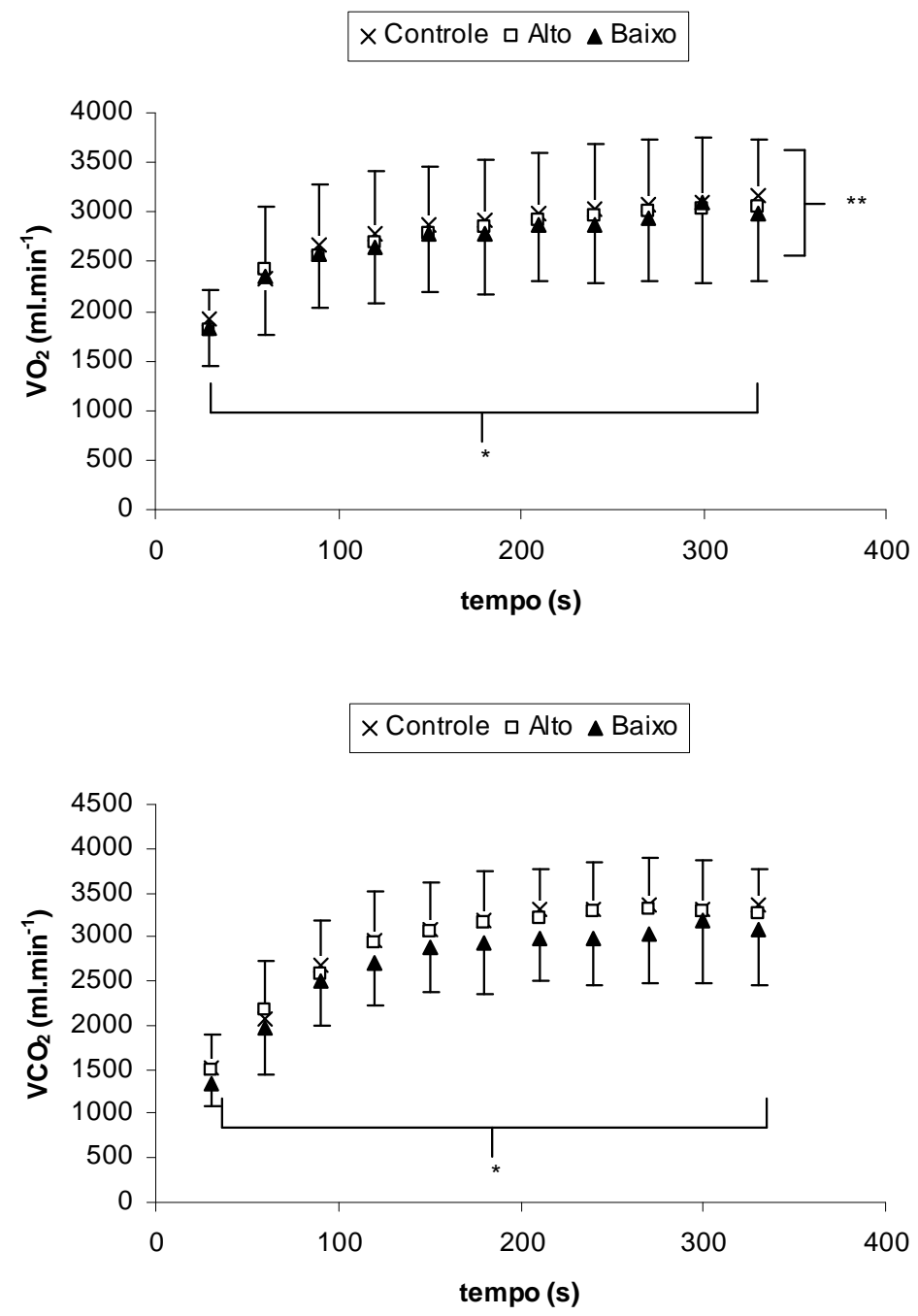

Figura 10. Consumo de oxigênio (painel superior) e produção de dióxido de carbono (painel inferior) no grupo de esforço muito pesado (MP) nas três situações (controle, alto ou baixo carboidrato na dieta). Os dados são expressos como média e desvio padrão. O desvio padrão da situação controle foi omitido para melhor visualização do gráfico. * Efeito significativo do tempo de exercício $(\mathrm{P}<0,05)$; ** Efeito significativo da situação $(\mathrm{P}<0,05)$.

A resposta da razão de trocas respiratórias $(\mathrm{R})$ está descrita na figura 11. Os valores de $\mathrm{R}$ também foram afetados por ambos os fatores $(\mathrm{P}<0,05)$, mas sem efeito de interação entre eles $(\mathrm{P}>0,05)$. Em todas as situações, os valores de $\mathrm{R}$ aumentam com o transcorrer do exercício $(\mathrm{P}<0,001)$. Uma análise individual mostrou que os valores da situação de baixo CHO foram significativamente menores do que na situação de alto $\mathrm{CHO}$ ( $\mathrm{P}<0,05)$, mas não foi diferente da situação controle $(\mathrm{P}>0,05)$. Também não houve diferença nos valores de $\mathrm{R}$ 
entre a situação controle e de alto $\mathrm{CHO}(\mathrm{P}>0,05)$.

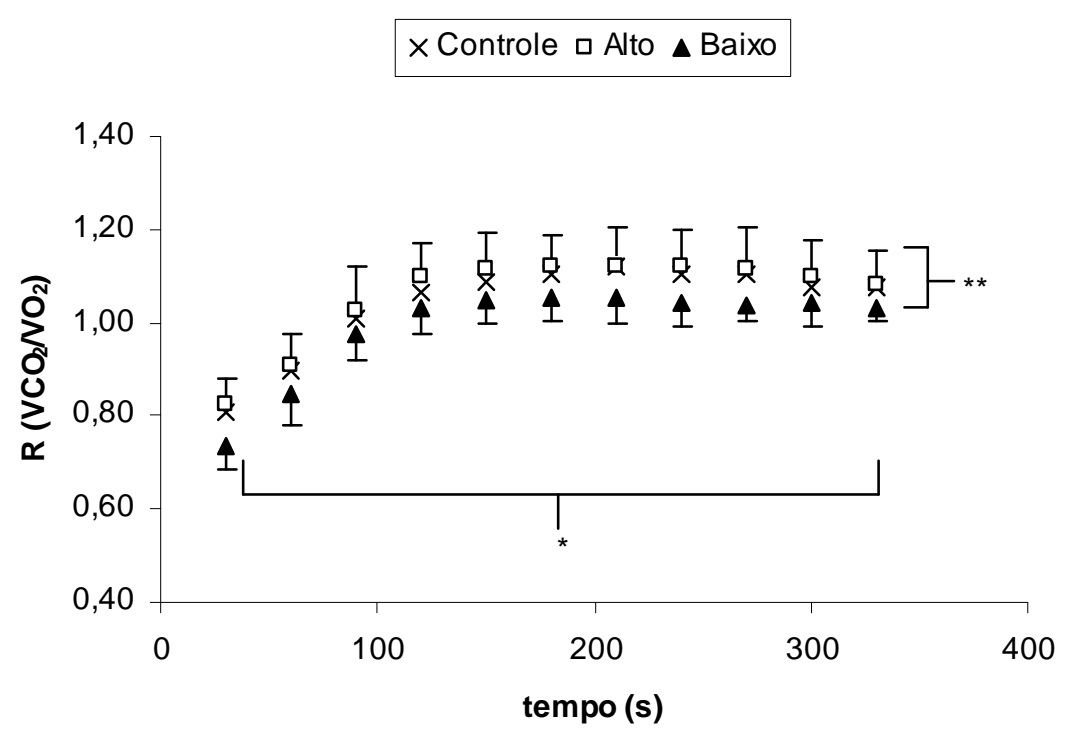

Figura 11. Razão de trocas respiratórias (R) no grupo de esforço muito pesado (MP) nas três situações (controle, alto ou baixo carboidrato na dieta). Os dados são expressos como média e desvio padrão. O desvio padrão da situação controle foi omitido para melhor visualização do gráfico. * Efeito significativo do tempo de exercício $(\mathrm{P}<0,05)$; ** Efeito significativo da situação $(\mathrm{P}<0,05)$.

As respostas da frequência respiratória (FR) e da ventilação (VE) estão descritas na figura 12.

A FR também foi influenciada pelos fatores tempo $(\mathrm{P}<0,001)$ e situação $(\mathrm{P}<0,02)$, mas não houve interação entre os dois $(\mathrm{P}=0,98)$. No fator tempo, a FR aumentou com o tempo de exercício para as três situações $(\mathrm{P}<0,001)$. Na comparação entre as situações, a FR na situação de baixo $\mathrm{CHO}$ foi significativamente menor do que na situação de alto $\mathrm{CHO}$ (P < 0,05), mas não houve diferenças significantes entre baixo $\mathrm{CHO}$ e controle, ou alto $\mathrm{CHO}$ e controle $(\mathrm{P}>0,05)$.

De maneira similar a FR, a VE foi influenciada pelos fatores tempo $(\mathrm{P}<0,001)$ e situação $(\mathrm{P}<0,001)$, mas não houve interação entre os dois $(\mathrm{P}=0,91)$. No fator tempo, a VE aumentou com o tempo de exercício para as três situações $(\mathrm{P}<0,001)$. Na comparação entre as situações, a VE na situação de baixo CHO foi significativamente menor do que na situação 
de alto $\mathrm{CHO}$ e controle $(\mathrm{P}<0,001)$. Não foram encontradas diferenças significantes entre a situação de alto $\mathrm{CHO}$ e controle $(\mathrm{P}>0,05)$.
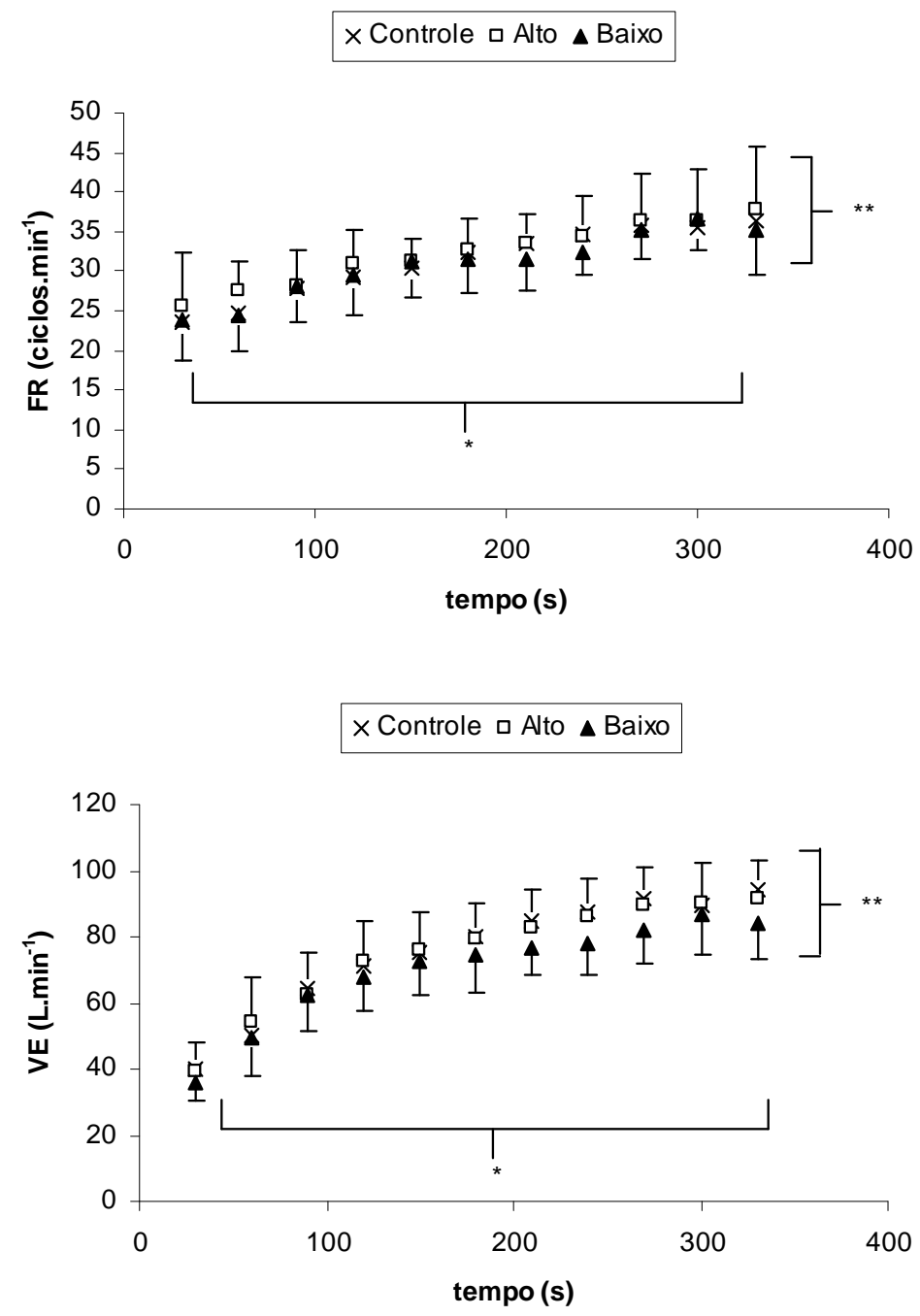

Figura 12. Frequência respiratória (painel superior) e ventilação (painel inferior) no grupo de esforço muito pesado (MP) nas três situações (controle, alto ou baixo carboidrato na dieta). Os dados são expressos como média e desvio padrão. O desvio padrão da situação controle foi omitido para melhor visualização do gráfico. * Efeito significativo do tempo de exercício $(\mathrm{P}<$

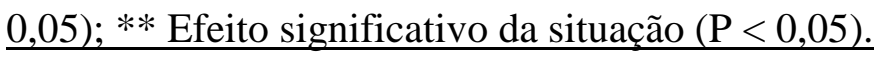

A resposta da frequência cardíaca (FC) está descrita na figura 13. A FC foi influenciada pelo tempo e pela situação do exercício $(\mathrm{P}<0,01)$, mas sem efeito de interação ( $\mathrm{P}$ = 0,99). Em todas as situações, a FC aumentou com o transcorrer do tempo de exercício. Os valores de FC foram significativamente menores para a situação de baixo $\mathrm{CHO}$ quando 
comparado à situação controle $(\mathrm{P}<0,01)$, mas não foi diferente da situação de alto CHO. Do mesmo modo, os valores de FC não foram diferentes entre a situação controle e alto $\mathrm{CHO}$ (P > $0,05)$.

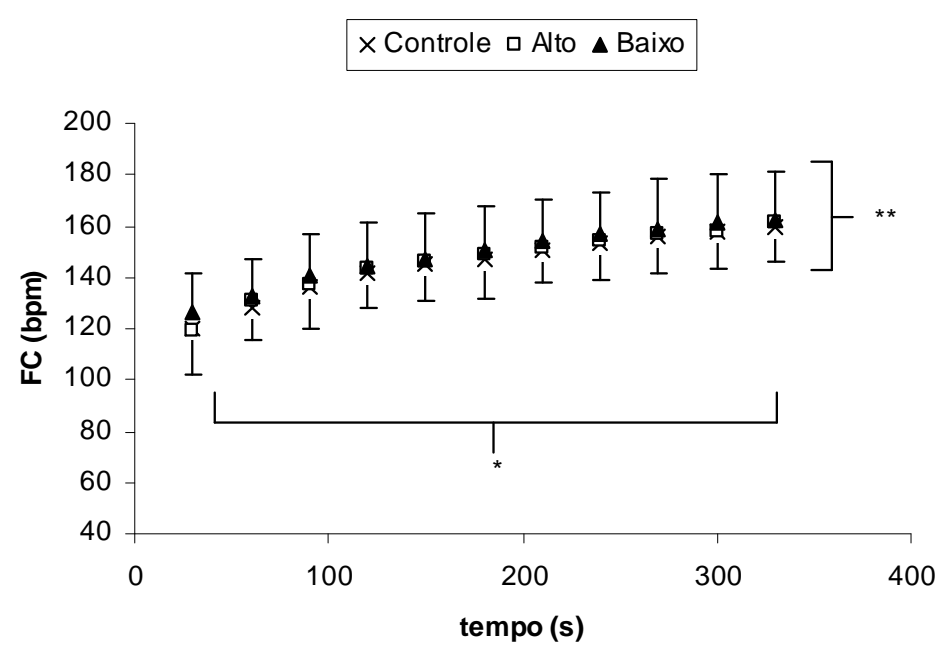

Figura 13. Frequência cardíaca (FC) no grupo de esforço muito pesado (MP) nas três situações (controle, alto ou baixo carboidrato na dieta). Os dados são expressos como média e desvio padrão. O desvio padrão da situação controle foi omitido para melhor visualização do gráfico. * Efeito significativo do tempo de exercício $(\mathrm{P}<0,05)$; ** Efeito significativo da situação $(\mathrm{P}<$ $\underline{0,05)}$.

Os valores de $\mathrm{VO}_{2}$ ao final do esforço na situação de baixo $\mathrm{CHO}\left(2,94 \pm 0,58 \mathrm{~L} \cdot \mathrm{min}^{-}\right.$ $\left.{ }^{1}\right)$ foram significativamente menores $(\mathrm{P}<0,05)$ do que na situação controle $(3,21 \pm 0,67$ L. $\left.\min ^{-1}\right)$ (tabela 4), mas não foi significativamente $(\mathrm{P}>0,05)$ diferente da situação de alto CHO (3,10 \pm 0,79 L.min $\left.{ }^{-1}\right)$. As diferenças entre a situação de alto e controle não foram estatisticamente significantes $(\mathrm{P}>0,05)$. $\mathrm{O}$ mesmo ocorreu quando os valores foram expressos como porcentagem do $\mathrm{VO}_{2 \max }$, sendo os valores menores para a situação de baixo $\mathrm{CHO}(86,4$ $\left.\pm 9,3 \% \mathrm{VO}_{2 \max }\right)$ do que para situação controle $\left(94,2 \pm 11,0 \% \mathrm{VO}_{2 \max }\right)$, mas ambos não foram significativamente diferentes $(\mathrm{P}>0,05)$ da situação de alto $\mathrm{CHO}\left(90,5 \pm 13,4 \% \mathrm{VO}_{2 \max }\right)$. Os valores de $\mathrm{VO}_{2}$ ao final do esforço não foram significativamente diferentes $(\mathrm{P}>0,05)$ dos valores de $\mathrm{VO}_{2 \max }$ para a situação controle e alto $\mathrm{CHO}$, mas foi significativamente menor $(\mathrm{P}<$ $0,02)$ para a situação de baixo $\mathrm{CHO}$.

Os valores de $\mathrm{VCO}_{2}, \mathrm{R}, \mathrm{FR}, \mathrm{VE}$ e $\mathrm{FC}$ ao final do exercício não foram significativamente diferentes $(\mathrm{P}>0,05)$ entre as três situações (tabela 5). 
Tabela 5. Valores (média \pm desvio padrão) das variáveis cardiorrespiratórias ao final do exercício muito pesado (média dos últimos $30 \mathrm{~s}$ ) nas três situações (controle, alto e baixo $\underline{\mathrm{CHO}}$.

\begin{tabular}{lccc}
\hline & Controle & Alto CHO & Baixo CHO \\
\hline $\mathrm{VO}_{2}\left(\mathrm{~L} \cdot \mathrm{min}^{-1}\right)$ & $3,21 \pm 0,67$ & $3,10 \pm 0,79$ & $2,94 \pm 0,58^{*}$ \\
$\mathrm{VCO}_{2}\left(\mathrm{~L} \cdot \mathrm{min}^{-1}\right)$ & $3,32 \pm 0,65$ & $3,27 \pm 0,69$ & $3,12 \pm 0,53$ \\
$\mathrm{R}\left(\mathrm{VCO}_{2} / \mathrm{VO}_{2}\right)$ & $1,04 \pm 0,08$ & $1,07 \pm 0,06$ & $1,07 \pm 0,06$ \\
$\mathrm{FR}($ ciclos.min & -1 & $42 \pm 8$ & $41 \pm 8$ \\
$\mathrm{VE}\left(\mathrm{L} \cdot \mathrm{min}^{-1}\right)$ & $44 \pm 5$ & $100,9 \pm 20,7$ & $93,2 \pm 15,6$ \\
$\mathrm{FC}(\mathrm{bpm})$ & $104,5 \pm 18,3$ & $168 \pm 15$ & $168 \pm 18$ \\
\hline
\end{tabular}

CHO: carboidratos; $\mathrm{VO}_{2}$ : consumo de oxigênio; $\mathrm{VCO}_{2}$ : dióxido de carbono; $\mathrm{R}$ : razão de trocas respiratórias; FR: frequiência respiratória; VE: ventilação; FC: freqüência cardíaca. * Significativamente menor do que na situação controle $(\mathrm{P}<0,05)$.

Os parâmetros cinéticos da $\mathrm{FR}, \mathrm{VE}, \mathrm{VO}_{2}, \mathrm{VCO}_{2}$ e $\mathrm{FC}$ para o grupo MP nas três situações estão descritas na tabela 6. 
Tabela 6. Valores (média \pm desvio padrão) dos parâmetros cinéticos da frequência respiratória (FR), ventilação (VE), consumo de oxigênio $\left(\mathrm{VO}_{2} 2\right.$, dióxido de carbono produzido $\left(\mathrm{VCO}_{2}\right)$ e frequência cardíaca (FC) durante o exercício muito pesado (MP), nas três situações (controle, alto e baixo $\mathrm{CHO}$ ).

\begin{tabular}{|c|c|c|c|}
\hline \multicolumn{4}{|c|}{ Parametros cinéticos } \\
\hline FR & Controle & Alto & Baixo \\
\hline inclinaçẫo $\left(\operatorname{ciclos} \cdot \mathrm{min}^{-1} \cdot \mathrm{s}^{-1}\right)$ & $0,33 \pm 0,28$ & $0,34 \pm 0,30$ & $0,17 \pm 0,28$ \\
\hline \multicolumn{4}{|l|}{ VE } \\
\hline Linha de base (L. $\left.\min ^{-1}\right)$ & $11,8 \pm 7,9$ & $10,9 \pm 6,4$ & $9,2 \pm 6,2$ \\
\hline Amplitude (L. $\left.\min ^{-1}\right)$ & $97,2 \pm 20,3$ & $93,7 \pm 14,9$ & $84,7 \pm 7,5^{*}+$ \\
\hline$\tau 1(s)$ & $158,3 \pm 70,8$ & $182,1 \pm 89,5$ & $128,5 \pm 46,2^{*}$ \\
\hline inclinaçẫo $3^{\prime}-\operatorname{exh}\left(L \cdot \min ^{-1} \cdot s^{-1}\right)$ & $0,07 \pm 0,06$ & $0,07 \pm 0,05$ & $0,02 \pm 0,06$ \\
\hline \multicolumn{4}{|l|}{$\mathrm{VO}_{2}$} \\
\hline Linha de base (L. $\left.\min ^{-1}\right)$ & $0,67 \pm 0,28$ & $0,65 \pm 0,31$ & $0,56 \pm 0,30^{*} \dagger$ \\
\hline Amplitude (L. $\left.\min ^{-1}\right)$ & $2,53 \pm 0,32$ & $2,48 \pm 0,40$ & $2,38 \pm 0,35^{*} \dagger$ \\
\hline$\tau 1(s)$ & $78,9 \pm 24,9$ & $88,8 \pm 26,1$ & $56,6 \pm 8,9^{*}$ \\
\hline inclinaçẫo $3^{\prime}-\operatorname{exh}\left(\mathrm{ml}^{\prime} \mathrm{min}^{-1} \cdot \mathrm{s}^{-1}\right)$ & $1,05 \pm 0,64$ & $0,99 \pm 0,69$ & $0,12 \pm 0,36^{*} \dagger$ \\
\hline \multicolumn{4}{|l|}{$\mathbf{V C O}_{2}$} \\
\hline Linha de base (L. $\left.\min ^{-1}\right)$ & $0,75 \pm 0,28$ & $0,73 \pm 0,27$ & $0,62 \pm 0,29^{*}$ \\
\hline Amplitude (L. $\left.\mathrm{min}^{-1}\right)$ & $2,67 \pm 0,33$ & $2,62 \pm 0,34$ & $2,51 \pm 0,31 \dagger$ \\
\hline$\tau 1(s)$ & $75,1 \pm 23,2$ & $73,3 \pm 21,6$ & $70,3 \pm 25,5$ \\
\hline inclinaçẫo $3^{\prime}-\operatorname{exh}\left(\mathrm{ml}^{\prime} \mathrm{min}^{-1} \cdot \mathrm{s}^{-1}\right)$ & $0,41 \pm 0,73$ & $0,58 \pm 0,71$ & $-0,29 \pm 1,06$ \\
\hline \multicolumn{4}{|l|}{ FC } \\
\hline Linha de base (bpm) & $90 \pm 7$ & $91 \pm 6$ & $90 \pm 11$ \\
\hline Amplitude (bpm) & $78 \pm 11$ & $79 \pm 9$ & $77 \pm 8$ \\
\hline$\tau 1(s)$ & $152,5 \pm 71,8$ & $153,1 \pm 44,6$ & $161,3 \pm 45,4$ \\
\hline inclinaçẫo $3^{\prime}-\operatorname{exh}\left(\mathrm{bpm} \cdot \mathrm{s}^{-1}\right)$ & $0,06 \pm 0,04$ & $0,06 \pm 0,03$ & $0,09 \pm 0,08$ \\
\hline
\end{tabular}

$†$ Baixo CHO é significativamente menor do que controle $(\mathrm{P}<0,05)$; * Baixo CHO é significativamente menor do que alto $\mathrm{CHO}(\mathrm{P}<0,05) . \tau 1$ : constante de tempo; exh: exaustão.

A inclinação da FR não foi significativamente afetada pela disponibilidade de $\mathrm{CHO}$ $(\mathrm{P}>$ 0,05). A amplitude e a constante de tempo de resposta da VE foram reduzidas na situação de baixo $\mathrm{CHO}$ em relação à situação controle e alto $\mathrm{CHO}$ no primeiro caso, e em relação ao alto $\mathrm{CHO}$ no segundo caso (tabela 6).

A cinética do $\mathrm{VO}_{2}$ também foi afetada pela disponibilidade de $\mathrm{CHO}$, sendo que os 
valores de linha de base, amplitude e constante de tempo foram todos reduzidos em comparação a situação controle ou alto $\mathrm{CHO}$ (exceto a constante de tempo quando comparado à situação de alto $\mathrm{CHO}$ ). A taxa de aumento do $\mathrm{VO}_{2}$ do minuto 3 até a exaustão também foi reduzida na situação de baixo $\mathrm{CHO}$, quando comparada às outras duas situações.

A linha de base e a amplitude de resposta do $\mathrm{VCO}_{2}$ foram reduzidas quando comparados ao alto $\mathrm{CHO}$ e controle, respectivamente $(\mathrm{P}<0,05)$. Entretanto, nem a constante de tempo, nem a taxa de aumento do $\mathrm{VCO}_{2}$ do minuto 3 até a exaustão foi afetado pela condição do exercício $(\mathrm{P}>0,05)$.

Nenhum dos parâmetros cinéticos da FC foi afetado pela condição do exercício ( $\mathrm{P}>$ $0,05)$.

\subsubsection{Respostas metabólicas e hormonais}

As respostas metabólicas e hormonais para grupo que realizou o exercício MP estão descritas na tabela 7 . 
Tabela 7. Valores (média \pm desvio padrão) das variáveis bioquímicas e hormonais no repouso e ao final do exercício muito pesado nas três situações (controle, alto e baixo $\mathrm{CHO}$ ).

\begin{tabular}{|c|c|c|c|c|c|c|}
\hline \multicolumn{7}{|c|}{ Condiçäo } \\
\hline & & & & & & \\
\hline & \multicolumn{2}{|c|}{ Controle } & \multicolumn{2}{|c|}{ Alto $\mathrm{CHO}$} & \multicolumn{2}{|c|}{ Baixo $\mathrm{CHO}$} \\
\hline & repouso & exaustẫo/pico & repouso & exaustẫo/pico & repouso & exaustẫo/pico \\
\hline Lactato art $\left(m m o l . L^{-1}\right) b$ & $0,54 \pm 0,22$ & $8,22 \pm 2,65$ & $0,55 \pm 0,53$ & $7,28 \pm 2,77$ & $0,51 \pm 0,19$ & $6,79 \pm 1,26$ \\
\hline Lactato ven $\left(\right.$ mmol. $\left.L^{-1}\right) b$ & $0,50 \pm 0,32$ & $7,93 \pm 2,11$ & $0,57 \pm 0,37$ & $6,71 \pm 3,07$ & $0,61 \pm 0,18$ & $6,03 \pm 1,43$ \\
\hline $\mathrm{pH}$ (unidades) b & $7,50 \pm 0,42$ & $7,01 \pm 0,26$ & $7,30 \pm 0,25$ & $6,81 \pm 0,38$ & $7,40 \pm 0,71$ & $7,25 \pm 0,27$ \\
\hline $\mathrm{K}^{+}\left(\mathrm{mmol} \cdot \mathrm{L}^{-1}\right)$ & $3,80 \pm 0,53$ & $4,18 \pm 0,59$ & $4,10 \pm 0,32$ & $4,37 \pm 0,42$ & $3,80 \pm 0,33$ & $4,17 \pm 0,85$ \\
\hline Insulina (uU. $\left.\mathrm{mL}^{-1}\right)$ a,c & $1,90 \pm 0,60$ & $2,58 \pm 0,62$ & $3,20 \pm 0,60$ & $3,53 \pm 0,63$ & $3,58 \pm 0,62$ & $3,22 \pm 1,34$ \\
\hline Glicose $\left(m m o l . L^{-1}\right)$ & $4,20 \pm 1,33$ & $4,44 \pm 1,52$ & $4,03 \pm 0,98$ & $4,64 \pm 0,73$ & $4,58 \pm 0,61$ & $4,48 \pm 0,80$ \\
\hline Epinefrina $\left(\mathrm{pg} \cdot \mathrm{mL}^{-1}\right)$ & $62,12 \pm 23,78$ & $67,80 \pm 20,72$ & $52,30 \pm 21,62$ & $66,95 \pm 44,07$ & $49,08 \pm 27,09$ & $77,87 \pm 34,26$ \\
\hline Norepinefrina $\left(\mathrm{pg} \cdot \mathrm{mL}^{-1}\right) \mathrm{b}$ & $476,11 \pm 240,81$ & $712,39 \pm 293,18$ & $354,24 \pm 125,51$ & $1108,45 \pm 680,14$ & $480,15 \pm 106,46$ & $1285,89 \pm 714,41$ \\
\hline Dopamina $\left(\mathrm{pg} \cdot \mathrm{mL}^{-1}\right)$ & $24,33 \pm 13,67$ & $26,68 \pm 17,35$ & $33,14 \pm 23,55$ & $26,66 \pm 6,69$ & $36,35 \pm 25,99$ & $29,43 \pm 9,12$ \\
\hline Cortisol (nmol. $\left.\mathrm{L}^{-1}\right)$ & $346,1 \pm 34,2$ & $356,3 \pm 66,5$ & $431,4 \pm 97,9$ & $519,4 \pm 218,1$ & $497,5 \pm 307,4$ & $354,4 \pm 151,5$ \\
\hline
\end{tabular}

${ }^{\mathrm{a}}$ Efeito significativo do fator condição (controle $\neq$ alto e baixo $\mathrm{CHO}, \mathrm{P}<0,05$ ); ${ }^{\mathrm{b}}$ Efeito significativo do fator tempo (exaustão $\neq$ repouso, $\mathrm{P}<0,05$ ); ${ }^{\mathrm{c}}$ Interação significativa entre o fator tempo e condição $(\mathrm{P}<0,05)$. Os dados na coluna exaustão/pico correspondem aos valores obtidos no momento da exaustão do exercício, exceto para o lactato arterializado (lactato art) e venoso (lactato ven), que se refere aos valores máximos obtidos após o término do teste.

Tanto a concentração de lactato medido no sangue arterializado, quanto o medido no sangue venoso, aumentaram significativamente em função do tempo $(\mathrm{P}<0,05)$, mas sem efeito da condição ou interação entre os fatores $(P>0,05)$. Entretanto, uma análise cinética da resposta do lactato do repouso até 10 minutos pós-esforço revela um efeito significativo da condição de $\mathrm{CHO}$, com menores valores para a condição de baixo $\mathrm{CHO}$ quando comparado a situação controle (figura 14). 

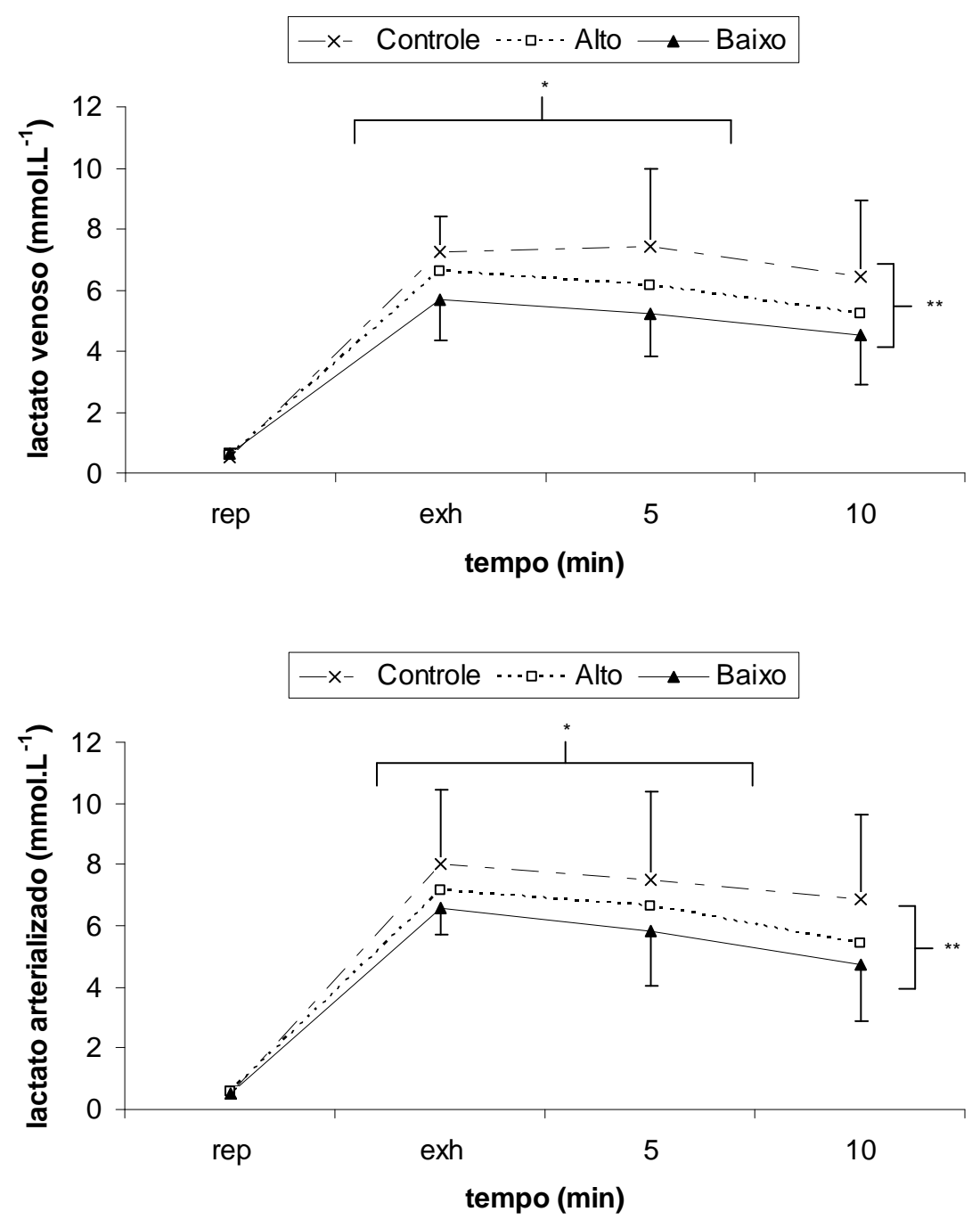

Figura 14. Concentração de lactato no sangue venoso (painel superior) e arterializado (painel inferior) no grupo de esforço muito pesado (MP) nas três situações (controle, alto ou baixo carboidrato na dieta). Os dados são expressos como média e desvio padrão. O desvio padrão da situação de alto CHO foi omitido para melhor visualização do gráfico. * Efeito significativo do tempo de exercício $(\mathrm{P}<0,05)$; ** Efeito significativo da situação $(\mathrm{P}<0,05)$.

$\mathrm{O}$ pH plasmático diminuiu significativamente $(\mathrm{P}<0,05)$ no momento da exaustão, quando comparado ao repouso, mas não houve efeito da situação ou interação entre os fatores (tabela 7). Para o potássio plasmático, não foi observado efeito significativo nem para o tempo, e nem para a situação de CHO (P > 0,05).

A glicose plasmática não se alterou com o exercício e também não foi afetada pela 
condição de $\mathrm{CHO}(\mathrm{P}>0,05)$. A concentração de insulina no plasma não se modifica com o exercício, mas foi encontrado um efeito significativo do fator situação, com menores valores para a condição controle do que na situação alto ou baixo CHO (tabela 7). Do mesmo modo, as alterações no tempo foram dependentes da situação (interação entre os fatores), com tendência a aumento da insulina na situação controle e alto $\mathrm{CHO}$ e redução na situação de baixo $\mathrm{CHO}$.

A concentração de epinefrina, dopamina e cortisol no plasma não se altera com o tempo de exercício e não foi influenciada pela situação de exercício (P > 0,05). Entretanto, a concentração de norepinefrina aumenta significativamente com o exercício nas três situações $(\mathrm{P}<0,05)$.

\subsubsection{Relações entre taxa de aumento na PSE e respostas metabólicas, hormonais e cardiorrespiratórias}

Poucas variáveis metabólicas, hormonais e cardiorrespiratórias foram associadas com

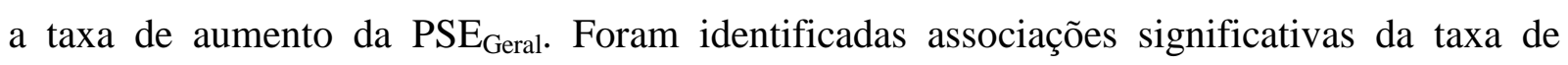
aumento da $\mathrm{PSE}_{\mathrm{Geral}}$ com a taxa de aumento da $\mathrm{PSE}_{\text {Local }}(\mathrm{r}=0,54 ; \mathrm{P}<0,05)$, amplitude do $\mathrm{VO}_{2}$ $(\mathrm{r}=-0,54 ; \mathrm{P}<0,05)$, a constante de tempo de $\mathrm{VCO}_{2}(\mathrm{r}=0,54 ; \mathrm{P}<0,05)$, a constante de tempo da FC ( $\mathrm{r}=0,49 ; \mathrm{P}<0,05)$ e com a inclinação da curva FC vs tempo do minuto 3 até a exaustão $(\mathrm{r}=0,69 ; \mathrm{P}<0,05)$. Das variáveis metabólicas e hormonais, apenas o delta de alteração da insulina com o exercício foi associado com a taxa de aumento da $\operatorname{PSE}_{\mathrm{Geral}}(\mathrm{r}=0,60 ; \mathrm{P}<0,05)$.

As variáveis significativamente associadas a taxa de incremento na PSE $_{\text {Local }}$ foram a amplitude do $\mathrm{VCO}_{2}(\mathrm{r}=-0,50 ; \mathrm{P}<0,05)$, a linha de base da $\mathrm{FC}(\mathrm{r}=0,64 ; \mathrm{P}<0,05)$ e a constante de tempo da FC ( $\mathrm{r}=0,75 ; \mathrm{P}<0,001)$.

O tempo de exaustão foi significativamente associado a taxa de aumento da PSE Geral $(\mathrm{r}=-0,78 ; \mathrm{P}<0,001)$, constante de tempo para o $\mathrm{VO}_{2}(\mathrm{r}=-0,57 ; \mathrm{P}<0,05)$, taxa de aumento da FR ( $\mathrm{r}=-0,57 ; \mathrm{P}<0,05)$, a inclinação da curva FC $v s$ tempo do minuto 3 até a exaustão $(\mathrm{r}=-$ 0,64; $\mathrm{P}<0,01)$ e delta de modificação na concentração de epinefrina $(\mathrm{r}=-0,57 ; \mathrm{P}<0,05)$.

\subsection{Grupo SE}

\subsubsection{Tempo de exaustão}

Para o grupo SE a carga utilizada foi de $277,3 \pm 46,7 \mathrm{~W}\left(115 \% \mathrm{VO}_{2 \max }\right)$. O tempo de 
exaustão (figura 15, painel superior) foi significativamente diferente entre as três situações (controle: 3,59 \pm 0,72 min; alto CHO: 4,26 $\pm 0,69$ min e; baixo CHO: 2,91 $\pm 0,56 \mathrm{~min}$; $\mathrm{P}=$ 0,002). A comparação múltipla de Bonferroni indicou que o tempo de exaustão na situação de baixo $\mathrm{CHO}$ foi significativamente menor do que na situação controle e de alto $\mathrm{CHO}$ (P < 0,05). Os valores da situação de alto $\mathrm{CHO}$ tendiam a serem maiores do que na situação controle, mas essa diferença não atingiu nível de significância estatística $(P=0,09)$. $O$ trabalho total realizado também foi diferente entre as três situações (controle: 59,1 $\pm 10,6 \mathrm{~kJ}$; alto CHO: 71,6 \pm 19,7 kJ e; baixo CHO: 48,1 $\pm 10,8$ kJ; P = 0,007). Similar ao encontrado para o tempo de exaustão, o trabalho total realizado foi menor na situação de baixo CHO do que na situação controle ou alto $\mathrm{CHO}(\mathrm{P}<0,05)$. Não foram encontradas diferenças significantes no trabalho entre a situação alto $\mathrm{CHO}$ e controle $(\mathrm{P}=0,18)$.

Uma análise individual do grupo SE revelou que cinco dos seis indivíduos aumentaram seu tempo de exaustão na situação de alto $\mathrm{CHO}$ em relação a situação controle (figura 15, painel inferior). Quando a situação de baixo CHO foi comparada ao controle, cinco sujeitos reduziram seu tempo de exaustão na primeira situação, enquanto para um sujeito o tempo de esforço foi exatamente o mesmo em ambas as situações. Comparando a situação de alto com baixo $\mathrm{CHO}$, todos os indivíduos tiveram seu maior tempo de esforço na situação de alto CHO. Por fim, dos seis sujeitos, cinco obtiveram seu maior tempo de exaustão na situação de alto $\mathrm{CHO}$, enquanto apenas um na situação controle. Nenhum sujeito obteve seu maior tempo de exaustão na situação de baixo CHO. 

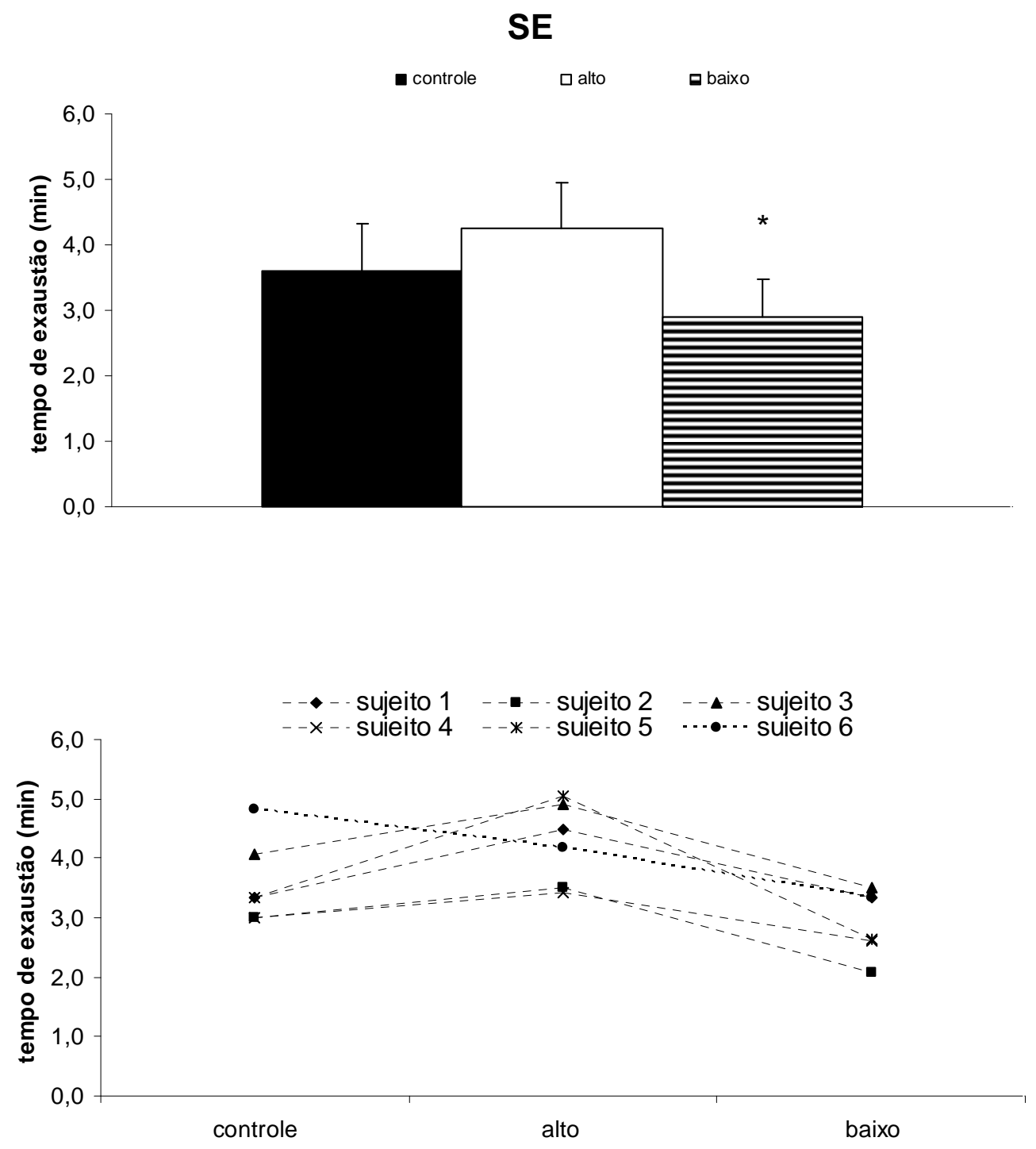

Figura 15. Tempo de exaustão do grupo que realizou esforço no domínio severo (SE) em três $\underline{\text { situações distintas (controle, alto ou baixo carboidrato na dieta). O painel superior representa }}$ os valores médios e o desvio padrão do tempo de exaustão do grupo em cada situação. $\mathrm{O}$ painel inferior representa os valores individuais do tempo de exaustão para cada individuo avaliado em cada uma das situações. * Significativamente menor do que a situação controle e de alto carboidrato $(\mathrm{P}<0,05)$.

\subsubsection{Resposta da percepção subjetiva de esforço}

A resposta da $\mathrm{PSE}_{\text {Geral }}$ e PSE $\mathrm{PScal}_{\text {Le }}$ de sujeito representativo da amostra do grupo SE está descrita na figura 16. As repostas individuais estão ilustradas no apêndice 3 e 4. 

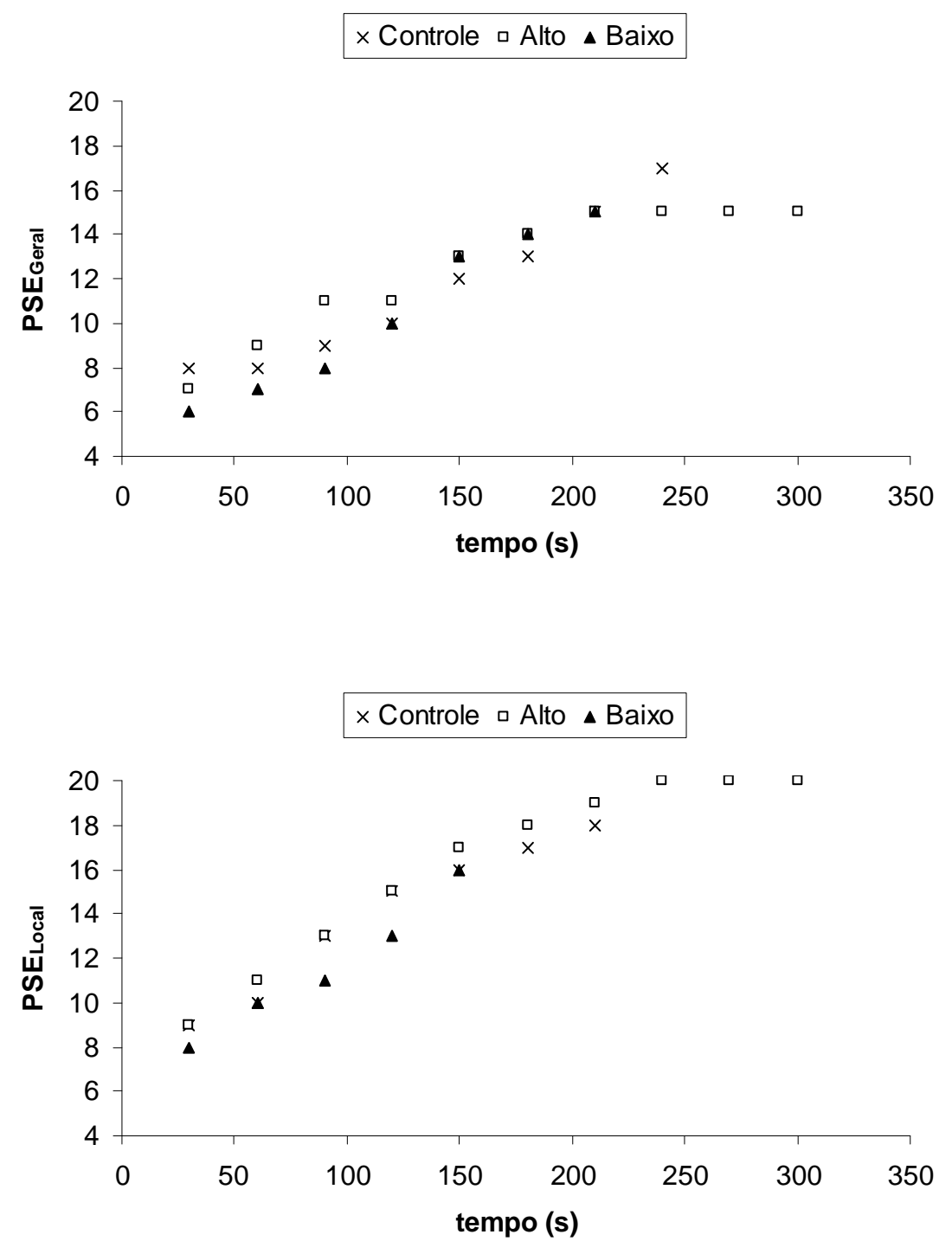

Figura 16. Percepção subjetiva de esforço (PSE) de um sujeito do grupo de esforço severo (SE) nas três situações (controle, alto ou baixo carboidrato na dieta). Os dados do painel superior são referentes a PSE geral. O painel inferior representa os valores da PSE local.

A resposta da $\mathrm{PSE}_{\mathrm{Geral}}$ no grupo $\mathrm{SE}$ também foi afetada por ambos, situação $(\mathrm{P}<$ $0,02)$ e tempo $(P<0,001)$, mas sem efeito de interação entre os fatores $(P=0,99)$. Para o fator

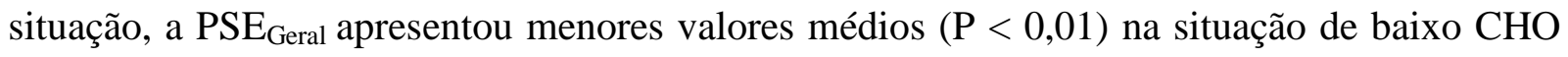
$(14,7 \pm 1,0$ pontos $)$ do que na situação controle $(15,6 \pm 1,1$ pontos $)$, mas não foi significativamente $(\mathrm{P}>0,05)$ diferente da situação de alto $\mathrm{CHO}(15,2 \pm 1,1$ pontos $)$. As diferenças na $\mathrm{PSE}_{\mathrm{Geral}}$ entre a situação controle e alto também não foram significantes $(\mathrm{P}>$ $0,05)$. 
A taxa de aumento da $\mathrm{PSE}_{\text {Geral }}$ em função do tempo absoluto de exercício não foi significativamente diferente entre as situações, apesar de existir uma tendência dos valores

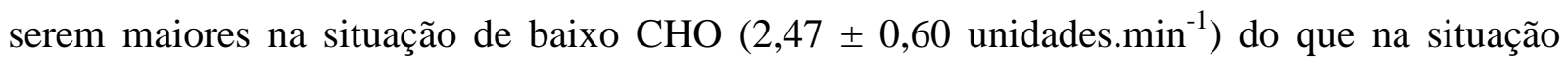
controle $\left(1,95 \pm 0,84\right.$ unidades. min $\left.^{-1} ; \mathrm{P}=0,07\right)$ e alto $\mathrm{CHO}\left(1,77 \pm 0,95\right.$ unidades.min $^{-1} ; \mathrm{P}=$ 0,09). Quando a taxa de aumento da $P S E_{\text {Geral }}$ foi calculada em função do tempo relativo, não foram identificadas diferenças significantes entre as situações (controle: 0,07 $\pm 0,03$ unidades. $\%^{-1}$; alto CHO: 0,08 $\pm 0,04$ unidades. $\%^{-1}$ e; baixo CHO: $0,07 \pm 0,01$ unidades. $\%^{-1} ; \mathrm{P}>0,05$ ). Do mesmo modo, a $\mathrm{PSE}_{\mathrm{Geral}}$ ao final do esforço não foi diferente entre as situações (controle: 17,5 $\pm 2,1$ pontos; alto $\mathrm{CHO}: 17,3 \pm 2,8$ pontos e; baixo $\mathrm{CHO}: 16,6 \pm 1,8$ pontos; $\mathrm{P}>0,05$ ).

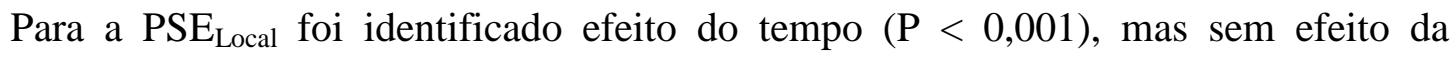
situação $(P=0,37)$ ou interação $(P=0,99)$. Entretanto, quando a taxa de aumento da $P_{S E} E_{\text {Local }}$ em função do tempo foi comparada entre as situações, foi descoberto maiores valores para a situação de baixo CHO $\left(2,89 \pm 0,69\right.$ unidades. $\left.\min ^{-1}\right)$ do que para a situação controle $(2,14 \pm$ 0,75 unidades.min $\left.{ }^{-1} ; \mathrm{P}=0,04\right)$ ou alto $\mathrm{CHO}\left(2,18 \pm 0,34\right.$ unidades. $\left.\mathrm{min}^{-1} ; \mathrm{P}=0,03\right)$. Não foram encontradas diferenças significantes PSE $_{\text {Local }}$ entre as situações controle e alto CHO. Quando a taxa de aumento da $\mathrm{PSE}_{\text {Local }}$ foi calculada em função do tempo relativo, não foram identificadas diferenças significantes entre as situações (controle: $0,08 \pm 0,03$ unidades. $\%^{-1}$; alto CHO: 0,09 \pm 0,02 unidades. $\%^{-1}$ e; baixo CHO: 0,08 $\pm 0,04$ unidades. $\%^{-1} ; \mathrm{P}>0,05$ ).

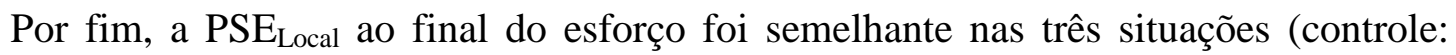
19,3 \pm 0,8 pontos; alto CHO: $20,0 \pm 0,0$ pontos e; baixo CHO: $19,5 \pm 0,8$ pontos; $\mathrm{P}>0,05$ ).

\subsubsection{Respostas cardiorrespiratórias}

A resposta do $\mathrm{VO}_{2}$ e $\mathrm{VCO}_{2}$ no grupo $\mathrm{SE}$ até o tempo de 180 segundos $(\mathrm{n}=6)$ está ilustrada na figura 17.

Para $\mathrm{o} \mathrm{VO}_{2}$ foi encontrado um efeito significativo apenas no fator tempo ( $\mathrm{P}<0,001$ ), mas sem efeito da situação ou interação entre eles $(\mathrm{P}>0,05)$. Em todas as três situações, o $\mathrm{VO}_{2}$ aumenta com o passar do tempo de exercício $(\mathrm{P}<0,001)$. De maneira similar, o $\mathrm{VCO}_{2}$ apresenta um efeito significativo apenas no fator tempo $(\mathrm{P}<0,001)$. 

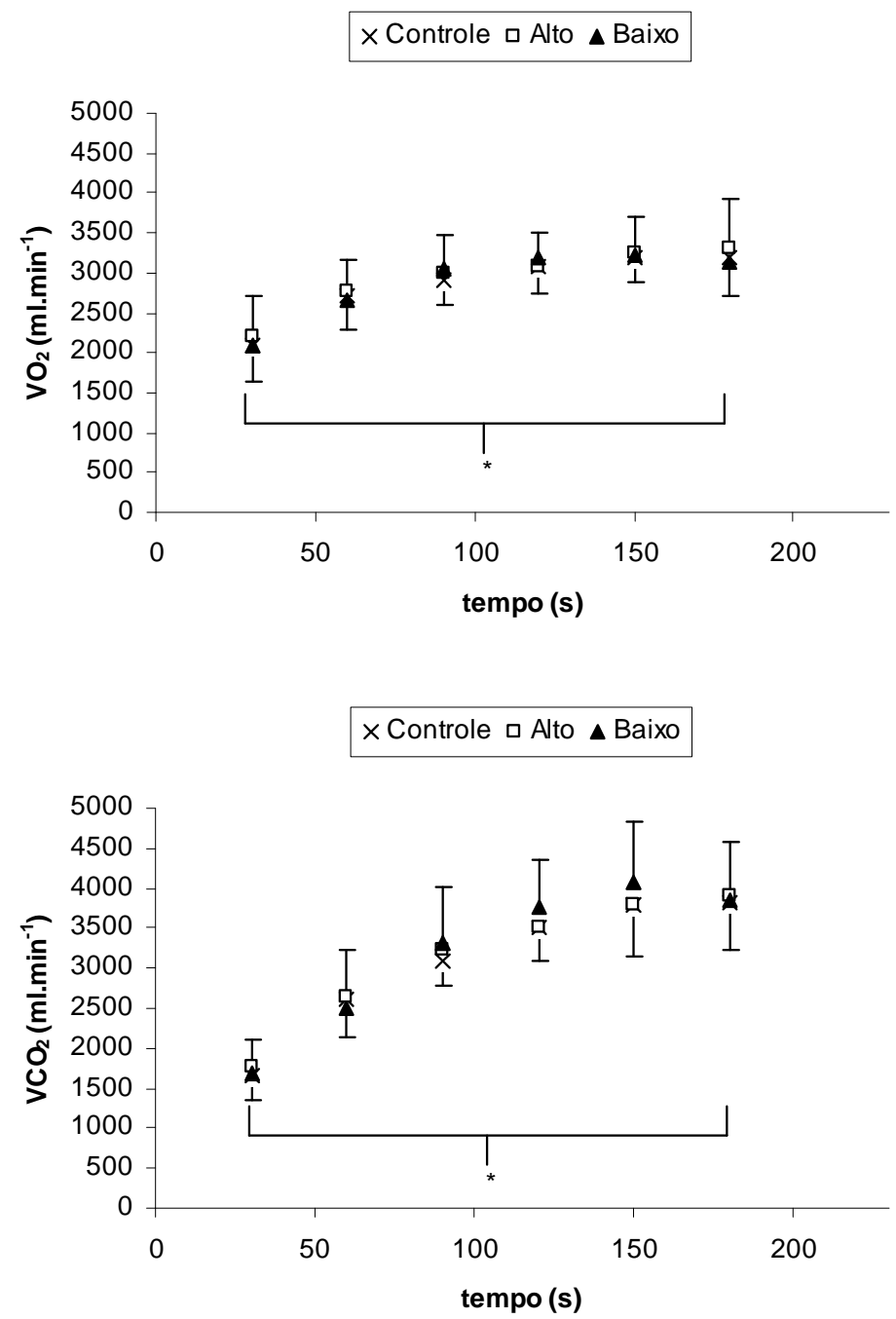

Figura 17. Consumo de oxigênio (painel superior) e produção de dióxido de carbono (painel inferior) no grupo de esforço severo (SE) nas três situações (controle, alto ou baixo carboidrato na dieta). Os dados são expressos como média e desvio padrão. O desvio padrão da situação controle foi omitido para melhor visualização do gráfico. * Efeito significativo do tempo de exercício $(\mathrm{P}<0,05)$.

A resposta da razão de trocas respiratórias $(\mathrm{R})$ está descrita na figura 18. Os valores de $\mathrm{R}$ foram afetados apenas pelo fator tempo ( $\mathrm{P}<0,001)$, mas sem efeito no fator situação ou de interação entre os dois ( $\mathrm{P}>0,05)$. Em todas as situações, os valores de $\mathrm{R}$ aumentam com o transcorrer do exercício $(\mathrm{P}<0,001)$. 


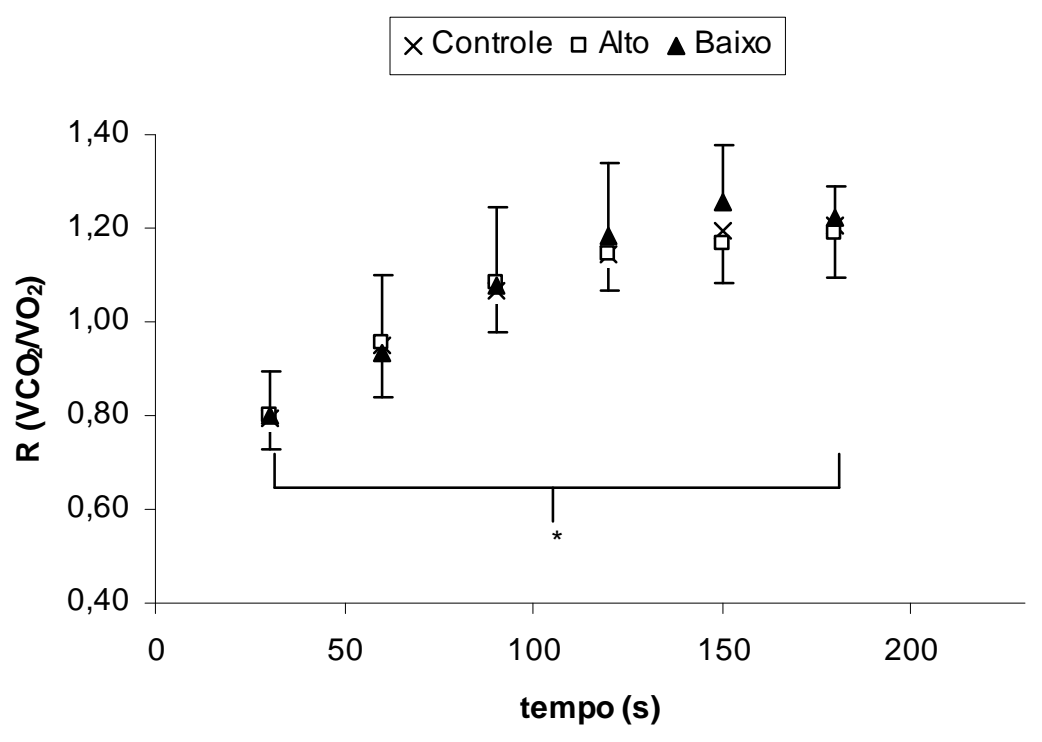

Figura 18. Razão de trocas respiratórias $(\mathrm{R})$ no grupo de esforço severo (SE) nas três situações (controle, alto ou baixo carboidrato na dieta). Os dados são expressos como média e desvio padrão. O desvio padrão da situação controle foi omitido para melhor visualização do gráfico. * Efeito significativo do tempo de exercício $(\mathrm{P}<0,05)$.

As respostas da freqüência respiratória (FR) e da ventilação (VE) estão descritas na figura 19.

A FR foi influenciada pelos fatores tempo $(\mathrm{P}<0,001)$ e situação $(\mathrm{P}<0,03)$, mas não houve interação entre os dois $(\mathrm{P}=0,44)$. A FR aumentou com o tempo de exercício para as três situações $(\mathrm{P}<0,001)$. Na situação de baixo $\mathrm{CHO}$, a FR foi significativamente maior do que na situação de alto $\mathrm{CHO}(\mathrm{P}<0,05)$, mas não houve diferenças significantes entre baixo $\mathrm{CHO}$ e controle, ou alto $\mathrm{CHO}$ e controle $(\mathrm{P}>0,05)$.

A VE foi influenciada pelos fatores tempo $(\mathrm{P}<0,001)$ e situação $(\mathrm{P}<0,001)$, e foi encontrado uma significativa interação entre os fatores $(P=0,04)$. No fator tempo, a VE aumenta com o tempo de exercício para as três situações $(\mathrm{P}<0,001)$. Na comparação entre as situações, a VE na situação de baixo CHO foi significativamente maior do que na situação de alto $\mathrm{CHO}$ e controle $(\mathrm{P}<0,001)$. Não houve diferenças significantes entre a situação de alto CHO e controle $(\mathrm{P}>0,05)$. 

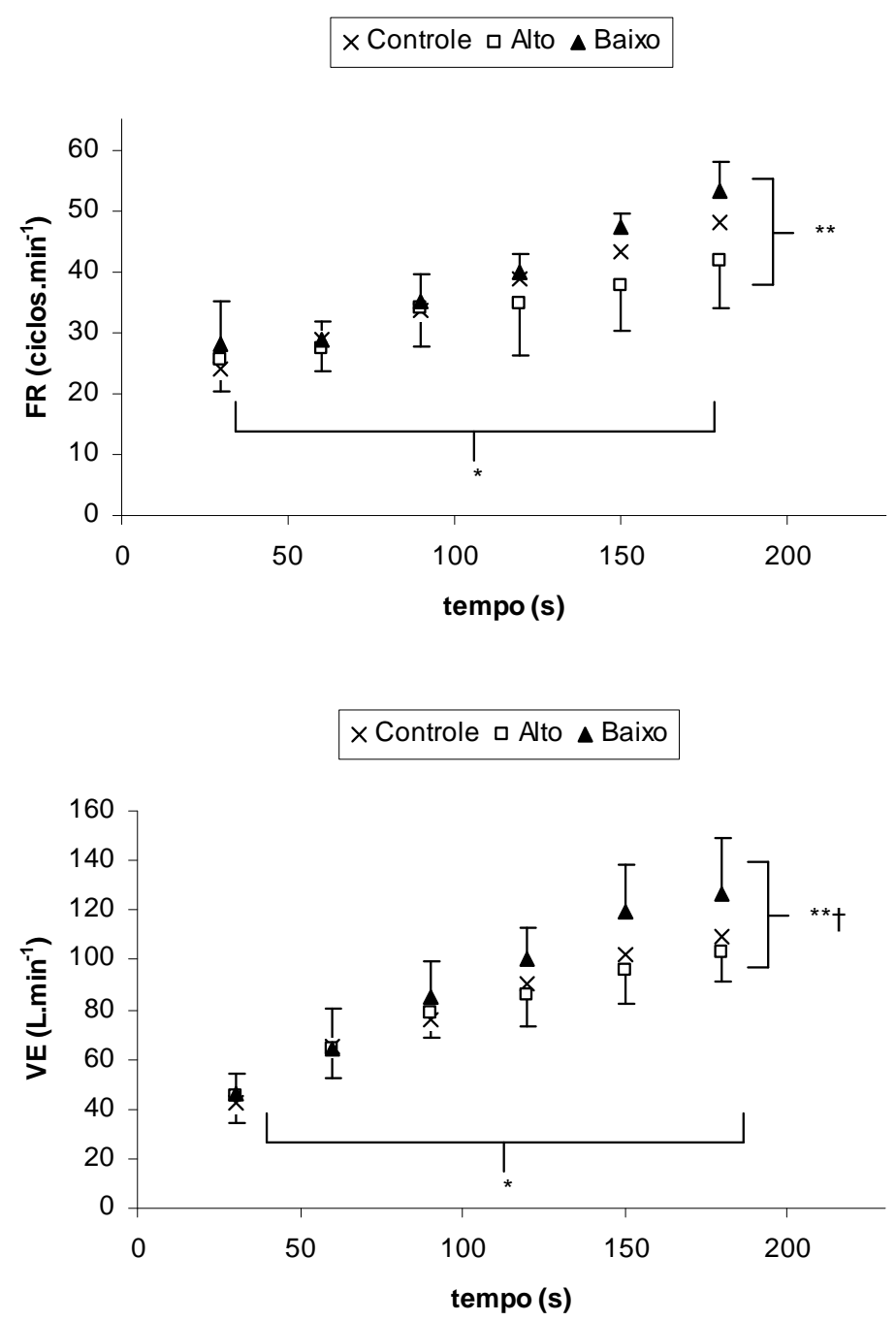

Figura 19. Freqüência respiratória (painel superior) e ventilação (painel inferior) no grupo de esforço severo (SE) nas três situações (controle, alto ou baixo carboidrato na dieta). Os dados $\underline{\text { são expressos como média e desvio padrão. O desvio padrão da situação controle foi omitido }}$ para melhor visualização do gráfico. * Efeito significativo do tempo de exercício $(\mathrm{P}<0,05)$; ** Efeito significativo da situação $(\mathrm{P}<0,05) ; \dagger$ Interação entre os fatores tempo de exercício e situação $(\mathrm{P}<0,05)$.

A resposta da frequência cardíaca (FC) está descrita na figura 20. A FC foi influenciada pelo tempo e pela situação do exercício $(\mathrm{P}<0,05)$, mas sem efeito de interação ( $\mathrm{P}$ $=0,91)$. Em todas as situações, a FC aumentou com o transcorrer do tempo de exercício. Os valores de FC foram significativamente menores para a situação de baixo $\mathrm{CHO}$ quando comparado à situação de alto $\mathrm{CHO}(\mathrm{P}<0,05)$, mas não foi diferente da situação controle $(\mathrm{P}>$ 
0,05). Do mesmo modo, os valores de FC não foram diferentes entre a situação controle e alto $\mathrm{CHO}(\mathrm{P}>0,05)$.

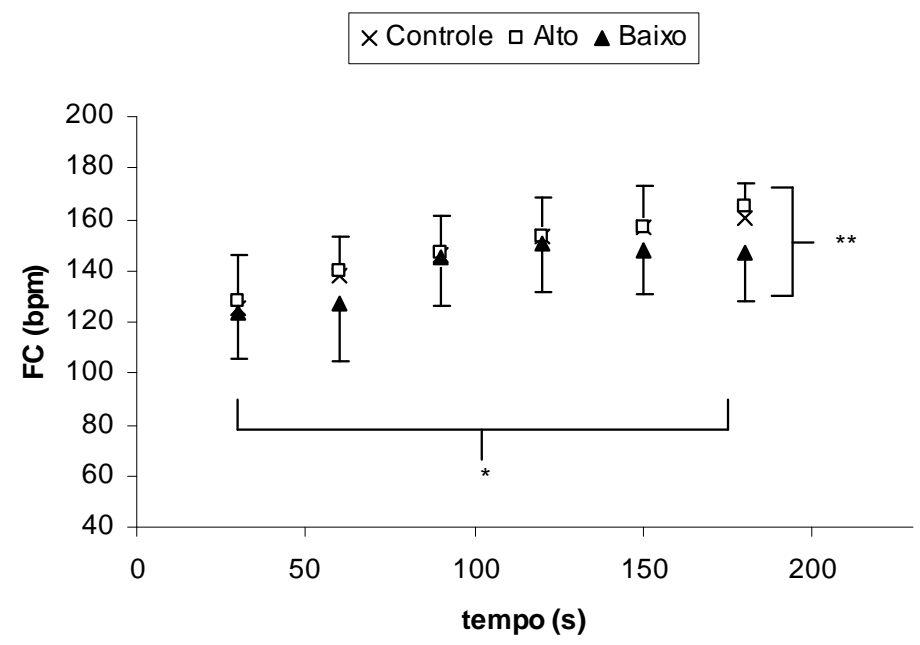

Figura 20. Frequência cardíaca (FC) no grupo de esforço severo (SE) nas três situações (controle, alto ou baixo carboidrato na dieta). Os dados são expressos como média e desvio padrão. O desvio padrão da situação controle foi omitido para melhor visualização do gráfico. * Efeito significativo do tempo de exercício $(\mathrm{P}<0,05)$; ** Efeito significativo da situação $(\mathrm{P}<$ $\underline{0,05)}$.

Os valores de $\mathrm{VO}_{2}$ ao final do esforço não foi diferente entre as situações $(\mathrm{P}>0,05)$ (tabela 8). O mesmo ocorreu quando os valores foram expressos como porcentagem do $\mathrm{VO}_{2 \max }$ (controle: 91,5 \pm 11,3 \% $\mathrm{VO}_{2 \max }$; alto $\mathrm{CHO}$ : 97,7 \pm 8,5 \% $\mathrm{VO}_{2 \max }$ e; baixo CHO: 91,6 \pm 8,7 \% $\left.\mathrm{VO}_{2 \max } ; \mathrm{P}>0,05\right)$. Os valores de $\mathrm{VO}_{2}$ ao final do esforço também não foram significativamente diferentes dos valores de $\mathrm{VO}_{2 \max }$ em nenhuma das situações $(\mathrm{P}>0,05)$.

Os valores de $\mathrm{VCO}_{2}, \mathrm{R}$, FR e VE ao final do exercício não foram significativamente diferentes $(\mathrm{P}>0,05)$ entre as três situações (tabela 8). A FC na situação de alto CHO foi significativamente maior do que na situação controle ou de baixo $\mathrm{CHO}(\mathrm{P}<0,05)$. 
Tabela 8. Valores (média \pm desvio padrão) das variáveis cardiorrespiratórias ao final do exercício severo (média dos últimos $30 \mathrm{~s}$ ) nas três situações (controle, alto e baixo CHO).

\begin{tabular}{|c|c|c|c|}
\hline & Controle & Alto $\mathrm{CHO}$ & Baixo CHO \\
\hline $\mathrm{VO}_{2}\left(\mathrm{~L} \cdot \mathrm{min}^{-1}\right)$ & $3,19 \pm 0,69$ & $3,37 \pm 0,48$ & $3,35 \pm 0,45$ \\
\hline $\mathrm{VCO}_{2}\left(\mathrm{~L} \cdot \mathrm{min}^{-1}\right)$ & $3,83 \pm 0,69$ & $3,98 \pm 0,64$ & $3,98 \pm 0,64$ \\
\hline $\mathrm{R}\left(\mathrm{VCO}_{2} / \mathrm{VO}_{2}\right)$ & $1,21 \pm 0,12$ & $1,18 \pm 0,08$ & $1,19 \pm 0,15$ \\
\hline FR $\left(\right.$ ciclos.min $\left.{ }^{-1}\right)$ & $52 \pm 3$ & $50 \pm 7$ & $50 \pm 9$ \\
\hline $\mathrm{VE}\left(\mathrm{L} \cdot \mathrm{min}^{-1}\right)$ & $115,2 \pm 17,2$ & $121,0 \pm 16,6$ & $120,1 \pm 24,4$ \\
\hline $\mathrm{FC}(\mathrm{bpm})$ & $161 \pm 13$ & $166 \pm 16 \dagger$ & $155 \pm 17$ \\
\hline
\end{tabular}

CHO: carboidratos; $\mathrm{VO}_{2}$ : consumo de oxigênio; $\mathrm{VCO}_{2}$ : dióxido de carbono; R: razão de trocas respiratórias; FR: frequêencia respiratória; VE: ventilação; FC: freqüência cardíaca. † Significativamente maior do que na situação controle e baixo CHO $(\mathrm{P}<0,05)$.

Os parâmetros cinéticos da $\mathrm{FR}, \mathrm{VE}, \mathrm{VO}_{2}, \mathrm{VCO}_{2}$ e $\mathrm{FC}$ para o grupo SE nas três situações estão descritas na tabela 9 . 
Tabela 9. Valores (média \pm desvio padrão) dos parâmetros cinéticos da frequência respiratória

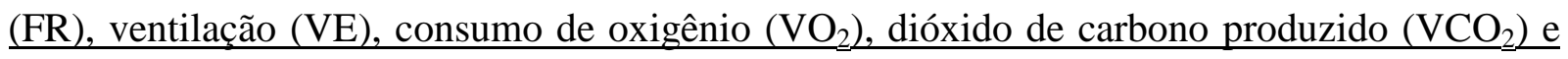
frequência cardíaca (FC) durante o exercício severo (SE), nas três situações (controle, alto e baixo $\mathrm{CHO}$ ).

\begin{tabular}{|c|c|c|c|}
\hline \multicolumn{4}{|c|}{ Parametros cinéticos } \\
\hline FR & Controle & Alto & Baixo \\
\hline inclinaçẫo (ciclos. $\left.\min ^{-1} \cdot s^{-1}\right)$ & $0,14 \pm 0,02$ & $0,12 \pm 0,04$ & $0,17 \pm 0,04^{*}$ \\
\hline \multicolumn{4}{|l|}{ VE } \\
\hline Linha de base (L. $\left.\min ^{-1}\right)$ & $23,6 \pm 7,7$ & $14,2 \pm 15,4$ & $17,4 \pm 5,3$ \\
\hline Amplitude (L. $\left.\mathrm{min}^{-1}\right)$ & $109,4 \pm 19,4$ & $116,4 \pm 5,9$ & $111,8 \pm 16,1$ \\
\hline$\tau 1(\mathrm{~s})$ & $110,6 \pm 44,0$ & $119,6 \pm 24,4$ & $111,8 \pm 24,1$ \\
\hline \multicolumn{4}{|l|}{$\mathrm{VO}_{2}$} \\
\hline Linha de base (L. $\left.\min ^{-1}\right)$ & $0,71 \pm 0,35$ & $0,85 \pm 0,48$ & $0,90 \pm 0,33$ \\
\hline Amplitude (L. $\left.\min ^{-1}\right)$ & $2,56 \pm 0,30$ & $2,51 \pm 0,48$ & $2,49 \pm 0,44$ \\
\hline$\tau 1(s)$ & $40,6 \pm 4,9$ & $43,6 \pm 7,6$ & $39,7 \pm 5,7$ \\
\hline \multicolumn{4}{|l|}{$\mathbf{V C O}_{2}$} \\
\hline Linha de base (L. $\left.\min ^{-1}\right)$ & $0,99 \pm 0,32$ & $1,14 \pm 0,56$ & $1,27 \pm 0,42$ \\
\hline Amplitude (L. $\left.\mathrm{min}^{-1}\right)$ & $3,12 \pm 0,29$ & $3,26 \pm 0,65$ & $3,38 \pm 0,69$ \\
\hline$\tau 1(s)$ & $71,7 \pm 19,1$ & $82,2 \pm 28,9$ & $93,2 \pm 23,3$ \\
\hline \multicolumn{4}{|l|}{ FC } \\
\hline Linha de base (bpm) & $84 \pm 24$ & $85 \pm 17$ & $86 \pm 17$ \\
\hline Amplitude (bpm) & $81 \pm 25$ & $82 \pm 12$ & $78 \pm 4$ \\
\hline$\tau 1(\mathrm{~s})$ & $61,6 \pm 31,0$ & $69,2 \pm 31,8$ & $44,3 \pm 20,3^{*}$ \\
\hline
\end{tabular}

* Baixo CHO é significativamente diferente do que alto $\mathrm{CHO}(\mathrm{P}<0,05) . \tau 1$ : constante de tempo; exh: exaustão.

Diferente do ocorrido no exercício MP, os parâmetros cinéticos das variáveis cardiorrespiratórias foram menos afetados pela condição de $\mathrm{CHO}$ no exercício. A inclinação da FR foi significativamente aumentada na situação de baixo $\mathrm{CHO}$, quando comparado à situação de alto $\mathrm{CHO}(\mathrm{P}<0,05)$. Contudo, os parâmetros de $\mathrm{VE}, \mathrm{VO}_{2}$ e $\mathrm{VCO}_{2}$ não foram afetados pela condição $(\mathrm{P}>0,05)$. O mesmo ocorreu para a FC, exceto que a constante de tempo foi significativamente reduzida na situação de baixo $\mathrm{CHO}$ em relação a de alto $\mathrm{CHO}(\mathrm{P}$ $<0,05)$. 


\subsubsection{Respostas metabólicas e hormonais}

As respostas metabólicas e hormonais para grupo que realizou o exercício SE estão descritas na tabela 10 .

Tabela 10. Valores (média \pm desvio padrão) das variáveis bioquímicas e hormonais no repouso e ao final do exercício severo nas três situações (controle, alto e baixo $\mathrm{CHO}$ ).

\begin{tabular}{|c|c|c|c|c|c|c|}
\hline \multicolumn{7}{|c|}{ Condição } \\
\hline & & & & & & \\
\hline & \multicolumn{2}{|c|}{ Controle } & \multicolumn{2}{|c|}{ Alto $\mathrm{CHO}$} & \multicolumn{2}{|c|}{ Baixo $\mathrm{CHO}$} \\
\hline & repouso & exaustäo/pico & repouso & exaustão/pico & repouso & exaustâo/pico \\
\hline Lactato art $\left(\mathrm{mmol}^{-1} \mathrm{~L}^{-1}\right) \mathrm{a}, \mathrm{b}, \mathrm{c}$ & $0,57 \pm 0,17$ & $7,38 \pm 2,13$ & $0,48 \pm 0,12$ & $9,38 \pm 3,12$ & $0,43 \pm 0,19$ & $7,08 \pm 1,86$ \\
\hline Lactato ven $\left(\right.$ mmol. $\left.L^{-1}\right) a, b, c$ & $0,73 \pm 0,37$ & $5,56 \pm 1,38$ & $0,56 \pm 0,24$ & $7,34 \pm 2,48$ & $0,48 \pm 0,23$ & $4,91 \pm 2,15$ \\
\hline $\mathrm{pH}$ (unidades) b & $7,60 \pm 0,27$ & $6,98 \pm 0,38$ & $7,48 \pm 0,38$ & $6,98 \pm 0,38$ & $7,31 \pm 0,38$ & $7,06 \pm 0,26$ \\
\hline $\mathrm{K}^{+}\left(\mathrm{mmol} \mathrm{L}^{-1}\right) \mathrm{b}$ & $4,05 \pm 0,71$ & $4,48 \pm 0,33$ & $3,92 \pm 0,36$ & $4,48 \pm 0,22$ & $4,07 \pm 0,22$ & $4,30 \pm 0,33$ \\
\hline Insulina (uU. $\left.\mathrm{mL}^{-1}\right)$ & $3,89 \pm 1,28$ & $4,58 \pm 0,54$ & $4,26 \pm 1,07$ & $3,89 \pm 0,52$ & $4,19 \pm 0,08$ & $3,82 \pm 1,25$ \\
\hline Glicose $\left(m m o l . L^{-1}\right)$ & $4,44 \pm 1,77$ & $4,65 \pm 1,10$ & $4,56 \pm 1,30$ & $4,57 \pm 1,35$ & $4,49 \pm 0,66$ & $4,51 \pm 0,49$ \\
\hline Epinefrina $\left(\mathrm{pg} \cdot \mathrm{mL}^{-1}\right)$ & $57,48 \pm 27,60$ & $59,64 \pm 32,09$ & $49,23 \pm 26,42$ & $66,77 \pm 38,10$ & $38,65 \pm 14,58$ & $52,82 \pm 32,23$ \\
\hline Norepinefrina $\left(p g \cdot \mathrm{mL}^{-1}\right) \mathrm{a}, \mathrm{b}$ & $1180,93 \pm 499,88$ & $3185,28 \pm 1667,29$ & $756,16 \pm 485,95$ & $1773,82 \pm 711,97$ & $610,43 \pm 507,47$ & $1213,32 \pm 542,65$ \\
\hline Dopamina $\left(\mathrm{pg} \cdot \mathrm{mL}^{-1}\right)$ & $31,95 \pm 16,85$ & $50,16 \pm 24,24$ & $21,13 \pm 9,78$ & $36,61 \pm 20,40$ & $38,03 \pm 15,96$ & $35,78 \pm 19,29$ \\
\hline Cortisol $\left(n m o l . L^{-1}\right)$ a & $568,8 \pm 240,8$ & $531,8 \pm 213,5$ & $357,1 \pm 116,1$ & $337,1 \pm 95,6$ & $529,8 \pm 169,9$ & $332,5 \pm 100,9$ \\
\hline
\end{tabular}

a Efeito significativo do fator condição (lactato art e ven: baixo $\mathrm{CHO} \neq$ alto $\mathrm{CHO}$, norepinefrina e cortisol: controle $\neq$ alto e baixo $\mathrm{CHO}, \mathrm{P}<0,05) ;{ }^{b}$ Efeito significativo do fator tempo (exaustão $\neq$ repouso, $\mathrm{P}<0,05$ ); ${ }^{\mathrm{c}}$ Interação significativa entre o fator tempo e condição ( $\mathrm{P}<0,05)$. Os dados na coluna exaustão/pico correspondem aos valores obtidos no momento da exaustão do exercício, exceto para o lactato arterializado (lactato art) e venoso (lactato ven), que se refere aos valores máximos obtidos após o término do teste.

Tanto a concentração de lactato medido no sangue arterializado, quanto o medido no sangue venoso, aumentaram significativamente em função do tempo $(\mathrm{P}<0,05)$, e foram influenciadas pela situação $(\mathrm{P}<0,05)$. $\mathrm{O}$ aumento foi consideravelmente mais acentuado para a situação de alto $\mathrm{CHO}$ do que para a situação controle ou baixo $\mathrm{CHO}$ (interação entre os fatores situação e tempo). Uma análise cinética da resposta do lactato do repouso até 10 minutos pós-esforço confirma um efeito significativo da condição de $\mathrm{CHO}$, com maiores 
valores para a condição de alto $\mathrm{CHO}$ quando comparado à situação controle ou baixo $\mathrm{CHO}$ (figura 21).
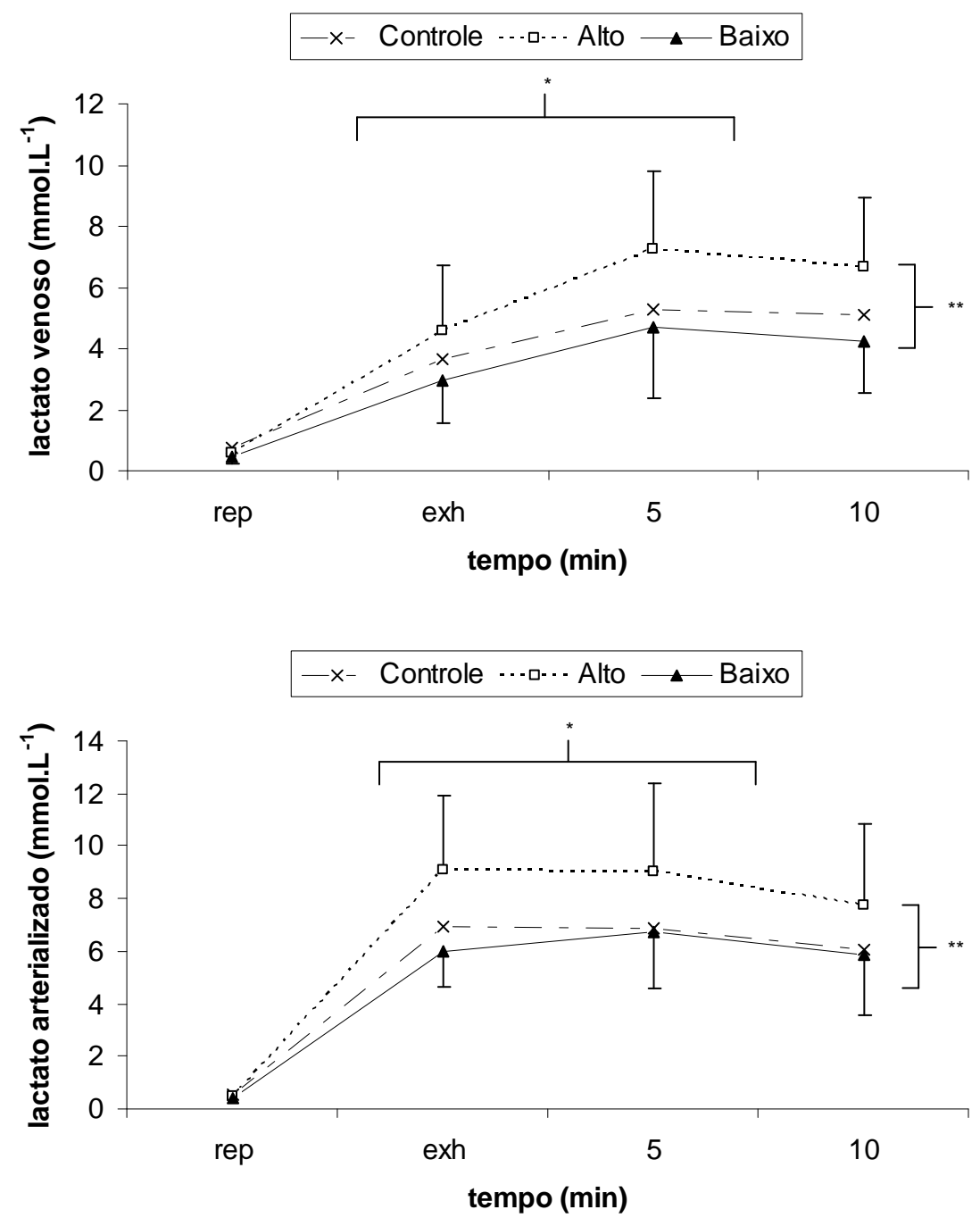

Figura 21. Concentração de lactato no sangue venoso (painel superior) e arterializado (painel inferior) no grupo de esforço severo (SE) nas três situações (controle, alto ou baixo carboidrato na dieta). Os dados são expressos como média e desvio padrão. O desvio padrão da situação controle foi omitido para melhor visualização do gráfico. * Efeito significativo do tempo de exercício $(\mathrm{P}<0,05)$; ** Efeito significativo da situação $(\mathrm{P}<0,05)$.

$\mathrm{O}$ pH plasmático diminuiu significativamente $(\mathrm{P}<0,05)$ no momento da exaustão, quando comparado ao repouso, mas não houve efeito da situação ou interação entre os fatores (tabela 10). Para o potássio plasmático, houve um aumento significativo com o exercício, mas 
o aumento foi similar entre as situações $(\mathrm{P}<0,05)$.

A glicose plasmática não se alterou com o exercício e também não foi afetada pela condição de $\mathrm{CHO}(\mathrm{P}>$ 0,05). O mesmo resultado foi encontrado para a concentração de insulina no plasma, que não se modifica com o exercício e nem sofre efeito da situação (P > $0,05)$.

As concentrações de epinefrina e dopamina no plasma não se alteraram com o tempo de exercício e também não foram influenciadas pela situação de exercício $(P>0,05)$. Entretanto, a concentração de norepinefrina aumentou significativamente com o exercício nas três situações $(\mathrm{P}<0,05)$. Um efeito da situação também foi encontrado, com maiores valores para a situação controle do que para a situação de alto ou baixo $\mathrm{CHO}(\mathrm{P}<0,05)$. O cortisol não se alterou com a realização do exercício $(\mathrm{P}>0,05)$, mas os valores foram maiores para a situação controle do que para a situação de alto ou baixo $\mathrm{CHO}(\mathrm{P}<0,05)$.

\subsubsection{Relações entre taxa de aumento na PSE e respostas metabólicas, hormonais e cardiorrespiratórias}

Para o grupo SE, a taxa de aumento da PSE Geral $_{\text {foi significativamente associada com }}$ a taxa de aumento da $\mathrm{PSE}_{\mathrm{Local}}(\mathrm{r}=0,73 ; \mathrm{P}<0,001)$ e a constante de tempo da VE $(\mathrm{r}=0,54$; $\mathrm{P}$ $<0,05)$.

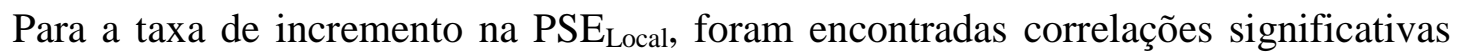
com linha de base da VE $(r=0,60 ; \mathrm{P}<0,05)$, a constante de tempo da VE $(r=0,80 ; \mathrm{P}<$ $0,001)$ e a constante de tempo da $\mathrm{VCO}_{2}(\mathrm{r}=0,50 ; \mathrm{P}<0,05)$.

O tempo de exaustão não foi significativamente associado a nenhuma das variáveis estudadas.

\section{DISCUSSÃO}

Antes de iniciar a discussão referente aos principais significados dos achados encontrados no presente estudo, algumas limitações serão apontadas e discutidas.

A validade dos resultados encontrados aqui depende, até certo ponto, da eficácia na manipulação exercício-dieta proposta para alterar as reservas de CHO. Infelizmente, não foi possível mensurar diretamente as reservas de GM, que é a principal reserva de CHO no organismo. Contudo, alguns indicativos sugerem que a redução nas reservas endógenas de 
CHO foi obtida com sucesso no presente estudo.

Primeiramente, todos os indivíduos conseguiram realizar o protocolo de exercício para redução nas reservas de CHO. Em alguns estudos com proposta similar, foram obtidas evidências diretas (GOLLNICK et al., 1973; GOLLNICK; PIEHL; SALTIN, 1974; COSTILL et al., 1973; HEIGENHAUSER; SUTTON; JONES, 1983) e indiretas (HUGHES et al., 1982; GLASS et al., 1997; BALDWIN et al., 2003) de que esse protocolo é efetivo para a redução das reservas de GM. A referência de tempo (90 minutos) e intensidade ( 70\% do $\mathrm{VO}_{2 \max }$ ) utilizada na primeira etapa do protocolo para depleção dos estoques de $\mathrm{CHO}$ se enquadra na descrita na literatura, em que a utilização de valores de tempo entre 75 - 100 minutos e de intensidade entre $55-75 \%$ do $\mathrm{VO}_{2 \max }$ seriam suficientes para reduzir as reservas endógenas de CHO (HUGHES et al., 1982; HEIGENHAUSER; SUTTON; JONES, 1983; GRISDALE et al., 1990; SPENCER; KATZ, 1991; PRUSACZYK et al., 1992; GLASS et al., 1997; HARGREAVES et al., 1997; BALSOM et al., 1999; MIURA et al., 2000; BALDWIN et al., 2003). Referente à segunda etapa do protocolo, esses mesmos autores utilizaram a aplicação de séries múltiplas (de cinco repetições à exaustão), com cargas que variam entre 110 - 150\% do $\mathrm{VO}_{2 \max }$ e intervalos de esforço e pausa entre 1 e 2 minutos. A combinação de exercício prolongado (etapa 1) com exercício intermitente intenso (etapa 2) é capaz de reduzir os estoques de GM tanto das fibras do tipo I quanto do tipo II, conforme descrito em estudos anteriores que realizaram a medida direta da concentração de GM logo após o término do protocolo (GOLLNICK; PIEHL; SALTIN, 1974; VOLLESTAD; VAAGE; HERMANSEN, 1984). A confirmação prévia da validade desse protocolo justifica, do ponto de vista prático e ético, a não utilização de técnicas invasivas como a biópsia para a quantificação direta das reservas de GM.

O ponto crucial para o sucesso do protocolo é a correta execução da fase subseqüente, isto é, garantir que os sujeitos realmente consumiriam o que estava prescrito em suas dietas. Para investigar se essa meta seria alcançada, os sujeitos foram orientados a registrarem todos os alimentos (quantidade, tipo, horário) consumidos nos dois dias de manipulação dietética. Quando os registros alimentares dos dois dias de dieta foram comparados entre si, foi encontrado que a porcentagem de $\mathrm{CHO}$ na dieta pobre em $\mathrm{CHO}$ era significativamente menor do que na situação controle e alto CHO. Quando comparado em termos absolutos, no grupo $\mathrm{SE}$, a quantidade de $\mathrm{CHO}$ em quilocalorias foi significativamente menor na situação de baixo $\mathrm{CHO}$ do que no controle ou alto CHO. Para MP, uma tendência similar foi observada, mas os 
valores na situação de baixo $\mathrm{CHO}$, mesmo sendo a metade do encontrado na situação de alto $\mathrm{CHO}$, não atingiu nível de significância. Em conjunto, esses resultados sugerem que todos os indivíduos seguiram as recomendações dietéticas e, provavelmente, foi obtido sucesso na manipulação das reservas de CHO.

A ingestão de uma dieta pobre em CHO durante as 48 horas seguintes ao protocolo de depleção provavelmente deve ter mantido as reservas de CHO baixas (BALSOM et al., 1999; ARKINSTALL et al., 2004), enquanto uma dieta rica em CHO deve ter restabelecido essas reservas (PIEHL et al., 1974; CASEY et al., 1996; BALSOM et al., 1999; ARKINSTALL et al., 2004), criando assim, duas condições distintas, que foi o objetivo proposto dessa metodologia. Vale ressaltar que, mesmo não sendo significante, o conteúdo calórico total das dietas tendeu a ser menor na situação de baixo CHO do que nas demais situações, o que de certo modo pode ter algum efeito sobre os resultados encontrados.

Outras evidências de que o objetivo de manipulação das reservas de $\mathrm{CHO}$ foi alcançado são: 1) uma cinética alterada de lactato na situação de baixo $\mathrm{CHO}$; 2) uma menor razão de trocas respiratórias na situação de baixo $\mathrm{CHO}$. Essa última observação não foi encontrada no grupo SE, mas é pouco provável que o protocolo de depleção tenha sido eficaz apenas em um dos grupos, uma vez que os procedimentos e resultados dietéticos foram semelhantes entre os grupos.

Por fim, o número de sujeitos avaliados em cada um dos grupos foi baixo, o que certamente reduz a potência dos testes estatísticos. O Power effect calculado para tempo de exaustão, taxa de incremento da $\mathrm{PSE}_{\mathrm{Geral}}$ e PSE $\mathrm{L}_{\text {Local }}$ do grupo MP, que são as principais variáveis estudadas nesse trabalho, foram 0,$19 ; 0,25$ e 0,13 , respectivamente. Esses valores são relativamente baixos para localizar diferenças significantes. Contudo, o número de sujeitos necessários para gerar um Power effect igual a 0,80 seria entre 22 à 53 sujeitos, o que constitui um tamanho de amostra impraticável do ponto de vista operacional, para estudos experimentais que envolvem procedimentos invasivos, múltiplos testes, inúmeras visitas ao laboratório. Mesmo assim, foram encontradas diferenças significantes para a taxa de

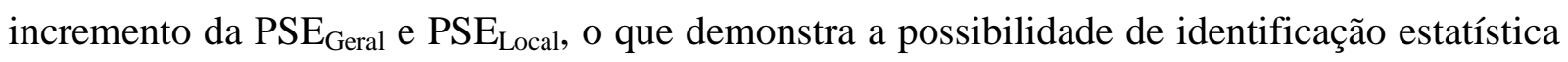
de efeito do tratamento, mesmo com um número reduzido de sujeitos na amostra.

O Power effect calculado para tempo de exaustão, taxa de incremento da $\operatorname{PSE}_{\mathrm{Geral}} \mathrm{e}$ PSE $_{\text {Local }}$ do grupo SE foram 0,95; 0,32 e 0,69, respectivamente. Com exceção do Power effect para a taxa de incremento da $\mathrm{PSE}_{\mathrm{Geral}}$, os valores foram relativamente altos. Essas variáveis 
foram significativamente diferentes entre as condições, sugerindo que o tamanho da amostra foi adequado para identificar as diferenças provocadas pelo tratamento. Entretanto, não foi encontrado diferenças significantes na taxa de incremento da $\mathrm{PSE}_{\mathrm{Geral}}$, mas foi identificado um valor relativamente alto de effect size $(0,58)$, sugerindo que possivelmente não foram encontradas diferenças significantes entre as condições devido ao tamanho da amostra. Dessa forma, os resultados desse estudo, principalmente dessa variável, devem ser visto com cautela devido ao número reduzido de indivíduos avaliados.

\subsection{Grupo MP}

De um modo geral, a disponibilidade de CHO não afetou o desempenho no exercício de domínio MP. De forma individualizada, foi observada uma grande variação do efeito da disponibilidade de $\mathrm{CHO}$ entre os sujeitos, mas de maneira consistente, nenhum dos indivíduos teve seu maior tempo de exaustão na situação de baixo CHO. Essa condição induziu a menores valores de $\mathrm{PSE}_{\mathrm{Geral}}$ ao longo e ao final do esforço, mas com maiores taxas de

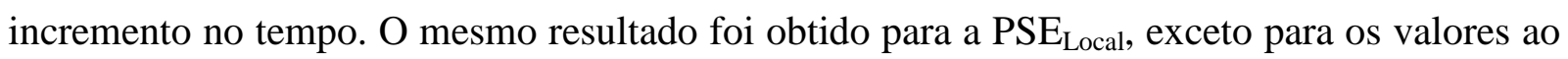
final do esforço, que foram iguais entre as situações. Essas alterações na PSE foram acompanhadas por uma redução na amplitude e constante de tempo do $\mathrm{VO}_{2}$ e da $\mathrm{VE}$, e redução nos valores de FR e FC. Do ponto de vista metabólico, a condição de baixo CHO induziu a menores valores de lactato pós-esforço e maiores concentrações de insulina. A taxa de incremento da $\mathrm{PSE}_{\mathrm{Geral}}$ foi negativamente associada à amplitude de $\mathrm{VO}_{2}$ e positivamente

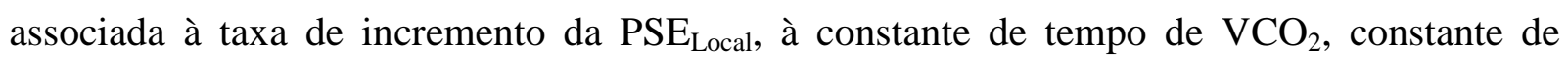
tempo da FC, à inclinação da FC do terceiro minuto até a exaustão e com o delta de modificação da insulina com o exercício. Para o tempo de exaustão, a taxa de incremento na $\mathrm{PSE}_{\text {Geral }}$ foi a variável mais importante.

Apenas alguns estudos verificaram o efeito da disponibilidade de $\mathrm{CHO}$ sobre o tempo de exaustão em exercício de intensidade do domínio MP. Lima-Silva et al. (2009) observaram uma redução significativa no tempo de exaustão durante um exercício em cicloergômetro no domínio MP (25\% da diferença entre a carga máxima e o $\mathrm{LL}_{2}$ ) com baixa disponibilidade de $\mathrm{CHO}$, quando comparado a uma situação de disponibilidade normal de CHO. Greenhaff et al. (1987a, 1987b, 1988) observaram uma redução no tempo de exaustão realizado a 100\% do $\mathrm{VO}_{2 \max }$ quando os indivíduos pedalavam com as reservas endógenas de $\mathrm{CHO}$ reduzidas. Entretanto, o aumento na disponibilidade de $\mathrm{CHO}$ não resultou em aumento no tempo de 
exaustão nesses últimos estudos, sugerindo que, para esforços realizados no domínio MP o fator crucial para o desempenho seria a redução nas reservas de CHO. No presente estudo, não foram encontradas diferenças significantes entre as situações, apesar de individualmente existir uma tendência à redução no tempo de exaustão com baixa disponibilidade de $\mathrm{CHO}$ em relação à situação controle e alto $\mathrm{CHO}$. Por outro lado, o efeito da alta disponibilidade de CHO não foi muito evidente, com três indivíduos aumentando o seu tempo de exaustão em relação à situação controle, enquanto três reduziram. Esses resultados sugerem que, a melhora ou piora do desempenho com a manipulação das reservas de CHO são altamente dependentes da individualidade biológica. Essa hipótese está de acordo com os resultados obtidos por Claassen et al. (2005) em que observaram uma alta variabilidade inter-indivíduo na melhora do desempenho em um exercício prolongado ( 150 minutos a 70\% do $\mathrm{VO}_{2 \max }$ ) com infusão periódica de glicose, quando comparado à uma situação placebo.

A condição de baixo $\mathrm{CHO}$ gerou menores valores finais de $\mathrm{PSE}_{\mathrm{Geral}}$, quando comparado a situação controle ou alto CHO. Não existe aparentemente uma explicação clara para esse fenômeno, mas algumas inferências podem ser feitas a partir de resultados de estudos anteriores. Noakes (2004) demonstrou que a PSE ao final de exercício prolongado a $70 \%$ do $\mathrm{VO}_{2 \max }$ é a mesma na condição de baixo ou normal disponibilidade de GM, mas que a taxa na qual ela aumenta é reduzida na situação normal. Noakes (2004) sugeriu que um "programador" central calcula antecipadamente a taxa de aumento na PSE de modo a atingir seu valor máximo apenas ao final do exercício. Como o final do exercício não é conhecido, a PSE final seria então a representação do máximo possível considerado seguro pelo programador. No presente estudo a $\mathrm{PSE}_{\mathrm{Geral}}$ foi considerada a representação da percepção de esforço de todos os sistemas fisiológicos envolvidos com o exercício (respiração, freqüência cardíaca e contração muscular). A partir disso, poderia ser inferido que a PSE $\mathrm{Geral}_{\mathrm{a} a}$ atingiu o máximo porque algum outro fator, ou fatores, tenham limitado a continuidade do exercício. Provavelmente, esse fator seja específico do músculo ativo, pois nenhuma das variáveis ventilatórias ao final do exercício foi influenciada pela baixa disponibilidade de CHO. Realmente, $\mathrm{o} \mathrm{VO}_{2}$ final foi reduzido na situação controle, enquanto a $\mathrm{PSE}_{\text {Local }}$ final não foi diferente entre as condições. Um menor $\mathrm{VO}_{2}$ implicou provavelmente em menor velocidade no fornecimento energético, que poderia aumentar a percepção do indivíduo referente ao desconforto muscular, tornando impossível continuar o exercício. Como a intensidade utilizada no presente estudo foi superior a aquela utilizada por Noakes (2004) $(94,3 \pm 2,4$ vs 70 
$\% \mathrm{VO}_{2 \max }$ ), essas diferenças entre os estudos também podem ser atribuídas a esse fato, pois os fatores podem se alterar à medida que a intensidade do esforço aumenta.

Como dito anteriormente, a baixa disponibilidade de $\mathrm{CHO}$ reduziu o consumo de oxigênio durante o exercício e, consequentemente, a amplitude de incremento em relação ao repouso. Além disso, esse efeito se estendeu para uma redução na constante de tempo e redução na inclinação da função $\mathrm{VO}_{2}$-tempo a partir do terceiro minuto. Assumindo que o consumo de oxigênio mensurado a nível pulmonar representa o $\mathrm{VO}_{2}$ do músculo em atividade (WHIPP, 1994; POOLE et al., 1994), existem duas possibilidades para explicar esse fato. Ou cada fibra muscular individualmente passou a consumir menos oxigênio e suportar o esforço com maior dependência do metabolismo anaeróbio, ou o número de unidades motoras ativas passou a ser menor em um dado instante do exercício, principalmente as fibras menos eficientes, como as fibras rápidas. A primeira possibilidade parece pouco provável porque a concentração de lactato tanto no sangue venoso, quanto arterializado foi reduzido na situação de baixo CHO. Desse modo, a explicação provável é de alteração no padrão de recrutamento das unidades motoras. Durante exercício dinâmico, apenas uma pequena parcela das fibras são utilizadas ao mesmo tempo (ST CLAIR GIBSON; SCHABORT; NOAKES, 2001; HETTINGA et al., 2006), sendo que a rotação e alternância entre as unidades motoras podem influenciar o tempo total possível de ser sustentado. Se uma parcela das unidades motoras já começarem sem reserva apropriada de GM, parece razoável imaginar que, ou essas unidades motoras não serão ativadas, ou deixarão de ser recrutadas muito precocemente. Uma menor amplitude de incremento no $\mathrm{VO}_{2}$ talvez represente uma redução no recrutamento e possivelmente justifique uma redução no tempo de exaustão.

A ideia de que, no presente estudo, o menor $\mathrm{VO}_{2}$ na situação de baixo $\mathrm{CHO}$ represente uma alteração no padrão de recrutamento das unidades motoras é suportado por estudos que realizaram depleção seletiva do GM das fibras de contração rápida e lenta (KRUSTRUP et al., 2004; CARTER et al., 2004; BOUCKAERT; JONES; KOPPO, 2004; OSBORNE; SCHNEIDER, 2005). Carter et al. (2004) observaram que a depleção seletiva das fibras de contração rápida induz a um aumento na amplitude e na velocidade de resposta do $\mathrm{VO}_{2}$ do componente primário, mas causa uma redução significativa no componente lento do $\mathrm{VO}_{2}$ durante exercício no domínio pesado. No presente estudo, não foi identificado a presença de componente lento, porque a equação monoexponencial ajustou melhor os dados (segundo o principio de parcimônia) do que a equação biexponencial e os valores tenderam a atingir o 
$\mathrm{VO}_{2 \max }$. Contudo, a baixa disponibilidade de $\mathrm{CHO}$ reduziu a constante de tempo do $\mathrm{VO}_{2}$, sugerindo que o tempo de resposta foi mais rápido nessa situação, mas reduziu também a amplitude total da resposta e a taxa de incremento na função $\mathrm{VO}_{2}$-tempo a partir do terceiro minuto, impossibilitando que os valores de $\mathrm{VO}_{2 \max }$ fossem atingidos ao final do esforço. Alguns estudos têm demonstrado que a resposta "atrasada" do $\mathrm{VO}_{2}$ (componente lento) está diretamente associada ao recrutamento das fibras de contração rápida (WHIPP, 1994; BARSTOW et al., 1996). Apesar da concentração de GM não ter sido mensurada, no presente estudo o protocolo de depleção de GM foi desenhado para induzir depleção em ambos os tipos de fibras. Uma redução das reservas de GM das fibras de contração rápida pode ter impossibilitado seu recrutamento nos instantes finais do exercício, o que pode ter influenciado na redução no tempo de exaustão em alguns casos.

A baixa disponibilidade de $\mathrm{CHO}$ também alterou outras importantes variáveis fisiológicas. A FR e a VE foram significativamente reduzidas na situação de baixo CHO, do que na situação controle ou alto CHO. No caso da VE, a amplitude e a constante de tempo também foram reduzidas. O mecanismo pelo qual a baixa disponibilidade reduz os parâmetros ventilatórios no exercício MP não é bem claro. Alguns estudos demonstraram um efeito oposto, com um aumento na VE com depleção prévia de GM (HEIGENHAUSER; SUTTON; JONES, 1983; BUSSE et al., 1991), possivelmente devido ao aumento no extravasamento de potássio (BUSSE et al., 1991) ou aumento na acidez do sangue devido ao aumento na circulação de AGLs (MAUGHAN et al., 1997). No presente estudo, nem as concentrações de potássio, nem o $\mathrm{pH}$ plasmático foram afetados pela disponibilidade de $\mathrm{CHO}$. Como a concentração de lactato de pico (medido durante a recuperação) foi menor na situação de baixo $\mathrm{CHO}$, sugerindo que a produção durante o exercício tenha sido menor, isso talvez explique os baixos níveis de FR e VE.

Curiosamente, tanto a baixa quanto a alta disponibilidade de $\mathrm{CHO}$ aumentaram os níveis de insulina em relação a situação controle. Entretanto, a concentração de glicose plasmática foi semelhante entre as situações. Esses resultados sugerem que, durante o exercício MP, a alteração na disponibilidade de $\mathrm{CHO}$ talvez induza uma resistência à insulina. Apesar de no presente estudo o consumo de glicose pelas células não ter sido mensurado, é possível especular que nas duas condições ele tenha diminuído, justificando os altos níveis de insulina. Aparentemente não é claro porque nessas situações o consumo seja diminuído, mas talvez com alta disponibilidade de $\mathrm{CHO}$ o conteúdo de GM esteja aumentado, tornando 
desnecessário um aumento no consumo de glicose. Isso pode ser fisiologicamente suportado pelo estudo de Shearer e Graham (2004), que sugerem uma ligação física da enzima PKA com a molécula de GM. Assim, na medida em que a molécula de GM vai reduzindo o seu tamanho, o consumo de glicose e AGL vão aumentando, devido à redução do efeito inibitório da molécula sobre a PKA. O oposto também é verdadeiro, ou seja, um aumento na molécula de GM pode aumentar o efeito inibitório sobre a PKA, reduzindo o consumo de glicose pela célula. Na situação de baixo $\mathrm{CHO}$, o consumo reduzido poderia representar um efeito "poupador" do substrato que está escasso, o reservando para o consumo pelo SNC. Talvez, nessa situação o consumo de AGL seja priorizado em relação ao consumo de glicose. Isso pode ser suportado pelos achados de Weltan et al. (1998) em exercício de menor intensidade, que demonstraram que o consumo normal de glicose em situação de depleção de GM somente pode ser mantido ou com hiperinsulinemia ou com hiperglicemia induzida. No caso, a redução dos níveis plasmática de glicose para valores abaixo do considerado seguro poderia ser acompanhada por diminuição do metabolismo cerebral, com concomitante disfunção cognitiva (NYBO et al., 2003; NYBO, 2008). Entretanto, futuros estudos com medidas diretas do consumo de glicose pela célula poderiam confirmar essa hipótese.

A taxa de incremento da PSE $_{\text {Geral }}$ foi negativamente associada com a amplitude de $\mathrm{VO}_{2}$ e positivamente associada à constante de $\mathrm{VCO}_{2}$, constante da $\mathrm{FC}$, inclinação da $\mathrm{FC}$ do minuto três à exaustão e delta de insulina. Como discutido anteriormente, uma redução na amplitude do $\mathrm{VO}_{2}$ talvez represente uma redução no recrutamento das fibras rápidas. Um aumento na constante de tempo para $\mathrm{VCO}_{2}$ representaria um "atraso" na transformação aeróbia de energia ou no tamponamento. Um aumento na constante de tempo da FC representa um "atraso" na adaptação do ritmo cardíaco frente ao esforço, ao passo que o aumento na inclinação da FC significa um aumento progressivo no ritmo cardíaco ao final do esforço, provavelmente para compensar à redução no $\mathrm{VO}_{2}$. Por fim, um aumento no delta de insulina representaria uma adaptação fisiológica para tentar aumentar o consumo de glicose pela célula. Em conjunto, esses resultados sugerem que, uma redução momentânea no estado energético da célula, devido a redução no $\mathrm{VO}_{2}$ e provavelmente menor consumo de glicose, sem compensação satisfatória pelos sistemas centrais, induziriam um aumento progressivo na forma como o indivíduo percebe o esforço. Esses resultados sugerem que as condições metabólicas funcionariam como vias de sinalização para um centro de controle e que podem ser utilizadas para gerar a percepção do esforço pelo indivíduo (NOAKES; ST CLAIR 
GIBSON, 2004; ST CLAIR GIBSON; NOAKES, 2004; NOAKES; ST CLAIR GIBSON; LAMBERT, 2004; LAMBERT; ST CLAIR GIBSON; NOAKES, 2005) e contrapõe o modelo sugerido de que a PSE seria gerada de maneira independente de sinais aferentes (MARCORA, 2008).

Alguns estudos têm sugerido que a PSE $\mathrm{Geral}_{\mathrm{s}}$ seria ajustada de maneira antecipatória, ou seja, a taxa na qual ela iria aumentar seria calculada antecipadamente no SNC (ESTON et al., 2007; CREWE, TUCKER, NOAKES, 2008; JOSEPH et al., 2008; FALKNER, PARFITT, ESTON, 2008). Entretanto, com o passar do exercício, múltiplos sinais aferentes informam ao SNC a condição fisiológica do organismo, os quais, integrados no cérebro, são comparados com uma PSE "esperada". A diferença entre o "esperado" e o "interpretado no momento" pelo SNC seria a base para a construção da PSE (ST CLAIR GIBSON et al., 2003; TUCKER, 2009). Essa teoria explica como o indivíduo consegue perceber condições fisiológicas adversas como aumento na temperatura corporal (CREWE, TUCKER, NOAKES, 2008), intensidade do exercício (CREWE, TUCKER, NOAKES, 2008), fadiga (ESTON et al., 2007) e depleção de substratos (NOAKES, 2004; LIMA-SILVA et al., 2009). Os dados do presente estudo reforçam essa teoria, pois a taxa de incremento da PSE $_{\text {Geral }}$ foi associada a diversos indicadores fisiológicos e perceptivos, em especial ao $\mathrm{VO}_{2}, \mathrm{FC}$, alteração na insulina e percepção local de desconforto com o exercício. Isso sugere que esses fatores fisiológicos podem ter alguma influência na geração da taxa de incremento da PSE.

A variável que obteve maior relação com o tempo de exaustão foi a taxa de incremento na $\mathrm{PSE}_{\mathrm{Geral}}$. Esses resultados sugerem que a forma como o indivíduo percebe o esforço e, mais especificamente, como essa percepção aumenta ao longo do tempo, são os fatores determinantes do tempo de esforço que será sustentado. Esses resultados estão de acordo com os obtidos por Crewe, Tucker e Noakes (2008), que descobriram uma relação inversa entre taxa de aumento da $\mathrm{PSE}_{\text {Geral }}$ e tempo de exaustão $(r=-0,83)$ durante exercícios de carga constante em diferentes condições ambientais (calor $v s$ frio); e com os obtidos por Horstman et al. (1979) que demonstraram a possibilidade de predizer o tempo total de um esforço $\left(80 \%\right.$ do $\mathrm{VO}_{2 \max }$ ) a partir da extrapolação dos valores de PSE a 25 e $50 \%$ do tempo total de exercício para o ponto de exaustão. Além disso, evidências adicionais foram obtidas de estudos que demonstraram a possibilidade de estimar o $\mathrm{VO}_{2 \max }$ a partir da extrapolação linear da PSE submáxima para valores máximos (ESTON et al., 2006; 2008). Assim, a relação entre tempo de exaustão e $\mathrm{PSE}_{\text {Geral }}$ emitem evidências adicionais ao modelo de antecipação da 
fadiga, baseado na ação de um programador que começa a agir precocemente, logo no início do exercício e é capaz de predizer o tempo possível de ser realizado em um dado esforço (NOAKES et al., 2008).

\subsection{Grupo SE}

No grupo SE, a baixa disponibilidade de $\mathrm{CHO}$ afetou significativamente o desempenho, quando comparado à situação controle ou alto CHO. Entretanto, o aumento na disponibilidade de $\mathrm{CHO}$ não se traduziu em melhora no desempenho, apesar de individualmente cinco indivíduos terem aumentado seu tempo de exaustão na situação de alto

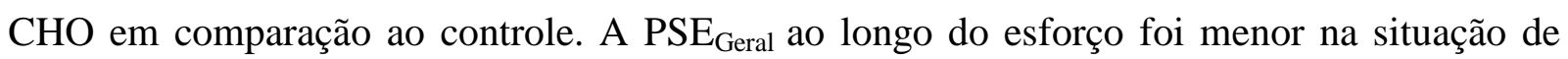
baixo $\mathrm{CHO}$, mas a taxa de incremento não foi alterada pela manipulação, apesar de existir uma tendência a maiores valores para a situação de baixo $\mathrm{CHO}$ do que controle ou alto $\mathrm{CHO}$. Já

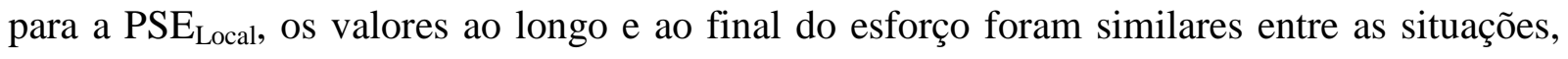
mas a taxa de incremento foi significativamente maior para a condição de baixo CHO do que para controle ou alto $\mathrm{CHO}$. Diferente do encontrado para o domínio $\mathrm{MP}$, o $\mathrm{VO}_{2}$ não foi afetado pela manipulação de $\mathrm{CHO}$. Contudo, a situação de baixo $\mathrm{CHO}$ gerou maiores valores de FR e VE, e menores valores de FC, do que as demais situações. Do mesmo modo, a taxa de incremento da FR e a constante de tempo da FC foram maiores e menores, respectivamente, nessa situação do que nas demais. A situação de alto $\mathrm{CHO}$ foi eficiente para gerar maiores valores de FC ao final do exercício do que as demais situações. Do ponto de vista metabólico, a condição de baixo $\mathrm{CHO}$ induziu a menores valores de lactato pós-esforço do que a situação de alto $\mathrm{CHO}$ e essas diferenças foram dependentes do tempo. A taxa de incremento da PSE $\mathrm{Local}_{\mathrm{L}}$ e constante de tempo da VE foram associadas à taxa de aumento da PSE Geral $_{\text {. Nenhuma das }}$ variáveis foi associada ao tempo de exaustão.

No presente estudo, o tempo de exaustão no esforço SE foi significativamente reduzido com a baixa disponibilidade de $\mathrm{CHO}$ em comparação à situação controle ou alto CHO. Apesar de individualmente existir uma tendência aos maiores tempos serem encontrados na situação de alto $\mathrm{CHO}$ do que no controle, na média não foram observadas diferenças entre essas duas situações. Apenas poucos estudos utilizaram cargas supramáximas (SE) para investigar o efeito da disponibilidade de CHO sobre o tempo de exaustão (MAUGHAN; POOLE, 1981; VANDERBERGUE et al., 1995). Maughan e Poole (1981) demonstraram que o tempo de exaustão durante um exercício realizado a aproximadamente 
$104 \%$ do $\mathrm{VO}_{2 \max }$ era reduzido de 4,87 $\pm 1,07$ minutos na situação controle para 3,32 $\pm 0,93$ minutos na situação de baixo $\mathrm{CHO}$, mas aumentava significantemente para 6,65 $\pm 1,39$ minutos na situação de alto CHO. Por outro lado, Vanderbergue et al. (1995) não encontraram diferenças entre o tempo de exaustão durante um exercício realizado a $125 \% \mathrm{VO}_{2 \max }(\cong 2,92$ minutos) entre a condição de alto $\mathrm{CHO}$ e controle, mas uma condição de baixo CHO não foi incluída nessa investigada. No presente estudo, o tempo médio de esforço na situação controle foi 3,59 \pm 0,72 minutos, o que devido à intensidade de esforço, é consideravelmente menor do que no estudo de Maughan e Poole (1981) e maior do que no estudo de Vanderbergue et al. (1995). Então, as diferenças no efeito da manipulação talvez possam ser explicadas pela hipótese levantada por Newsholme, Blomstrand e Ekblom (1992), na qual a disponibilidade de CHO poderia interferir no desempenho do exercício de alta intensidade apenas em atividades com duração entre três e 10 minutos. Nesse sentido, o tempo total de esforço do presente estudo e do estudo de Maughan e Poole (1981) talvez tenha sido alto o suficiente para a manipulação das reservas terem algum efeito sobre o desempenho, enquanto talvez não tenha sido no estudo de Vanderbergue et al. (1995).

Diferente do obtido no exercício do domínio MP, no esforço SE não foram encontradas diferenças significantes na taxa de incremento na $\mathrm{PSE}_{\text {Geral }}$ entre as situações, apesar de existir uma tendência a maiores valores para a situação de baixo CHO. A taxa de

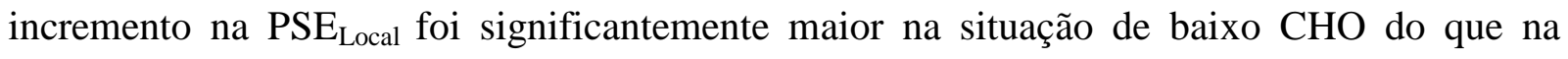
situação controle ou alto $\mathrm{CHO}$. Esses resultados sugerem que, a manipulação de CHO no domínio SE tenha maior efeito sobre a percepção referente ao desconforto específico da musculatura ativa, ao invés de um efeito sobre a percepção geral do indivíduo referente ao esforço realizado. Suporte para essa suposição pode ser obtido no estudo de Johnson et al. (2006) em que os indivíduos, mesmo sem serem capazes de identificar o conteúdo de CHO em suas dietas, reportaram maior sensação de "cansaço", "fraqueza" e "dor nos membros inferiores" após dois dias de uma dieta pobre em CHO. Interessante que a PSE não foi alterada durante um esforço prolongado a $70 \%$ do $\mathrm{VO}_{2 \max }$. Isso sugere que talvez seja necessária uma intensidade mínima de exercício para que essas sensações interfiram no modo como o indivíduo percebe o esforço (HOLLANDER et al., 2008). Nesse sentido, os resultados do presente estudo sugerem que essa intensidade sejam aquelas contidas no domínio SE, uma vez que os mesmos resultados não foram obtidos para o domínio MP.

Também de modo diferente do exercício MP, a baixa disponibilidade de $\mathrm{CHO}$ não 
interferiu na amplitude e tempo de resposta do $\mathrm{VO}_{2}$, mas aumentou substancialmente a taxa de aumento da FR e os valores de FR e VE. Apesar de no presente estudo a explicação fisiológica para esses resultados não serem tão claros, uma vez que os principais componentes que poderiam interferir no padrão respiratório não foram diferentes entre as situações (potássio e $\mathrm{pH}$ ), eles corroboram os achados de estudos anteriores em que a ventilação foi significativamente aumentada devido à baixa disponibilidade de CHO (HEIGENHAUSER; SUTTON; JONES, 1983; BUSSE et al., 1991).

A FC foi menor e teve um maior atraso no tempo de reposta na situação de baixo $\mathrm{CHO}$ em comparação à situação de alto $\mathrm{CHO}$. Além disso, a situação de alto $\mathrm{CHO}$ gerou maiores valores ao final do exercício do que na situação controle ou baixo CHO. Os menores valores de FC durante a situação de baixo $\mathrm{CHO}$ podem ser explicados por um possível efeito mecânico da respiração sobre o nódulo sinusal (PICHON et al., 2004; COTTIN et al., 2004). Realmente, esses estudos (PICHON et al., 2004; COTTIN et al., 2004) demonstraram que um aumento na VE induzida pelo exercício intenso poderia alterar o ritmo cardíaco, aumentando o componente de alta frequência (HF) da variabilidade da FC. Em um estudo posterior (LIMASILVA et al., dados não publicados), foi observado em exercício intenso uma redução na FC com uma baixa disponibilidade de CHO, acompanhada de aumento do componente HF e VE. No presente estudo, ambos FR e VE, aumentaram na condição de baixo CHO, sugerindo que possivelmente, um efeito mecânico da respiração sobre o nódulo sinusal possa ter alterado o ritmo cardíaco.

Uma importante influência da alteração na disponibilidade de $\mathrm{CHO}$ sobre os hormônios norepinefrina e cortisol foram encontrados para esse domínio. Basicamente, tanto à situação de baixo $\mathrm{CHO}$, quanto à de alto $\mathrm{CHO}$, reduzem a concentração desses hormônios em relação à situação controle. A explicação para esses resultados não é muito clara, pois seria esperado um aumento na concentração desses hormônios na situação de baixo CHO (WELTAN et al., 1998). Além disso, os valores de cortisol não foram afetados pelo exercício. Vale ressaltar que, como as medidas foram realizadas no período da manhã e com os indivíduos em jejum, talvez os valores já estivessem próximos ao máximo, não sendo possível algum aumento adicional com o exercício. Como o exercício no domínio SE é relativamente curto, talvez isso também explique porque os valores de cortisol não aumentaram com o exercício. Estudos com desenho experimental similar, mas realizando o exercício à tarde ou à noite talvez esclareçam se esses resultados são decorrentes do período em que foram feitas as 
mensurações.

A taxa de incremento na $\mathrm{PSE}_{\mathrm{Geral}}$ foi significantemente associada à PSE $\mathrm{Local}_{\mathrm{e}}$ ao

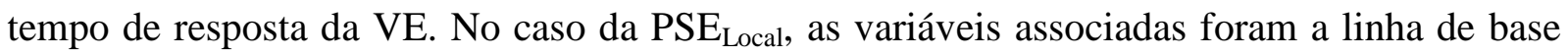
da $\mathrm{VE}$ e as constantes de tempo de $\mathrm{VE}$ e $\mathrm{VCO}_{2}$. O maior coeficiente de correlação da $\mathrm{PSE}_{\text {Geral }}$

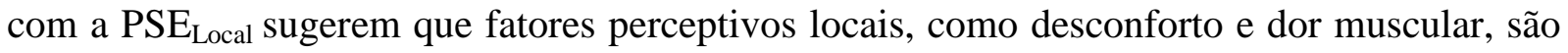

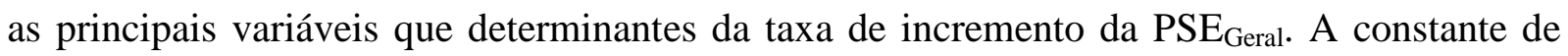
tempo para VE também apresentou relação com ambas as formas de PSE, sugerindo que um atraso no tempo de resposta da mecânica ventilatória talvez interfira na resposta perceptiva. Interessante que a $\mathrm{VE}$ responde a fatores locais, como $\mathrm{pH}$, potássio e $\mathrm{VCO}_{2}$. Desses, apenas a constante de tempo do $\mathrm{VCO}_{2}$ foi associado a $\mathrm{PSE}_{\mathrm{Local}}$, sugerindo que um atraso na produção de dióxido de carbono pode aumentar a taxa de percepção de esforço. Esse atraso pode estar associado à reduzida disponibilidade de $\mathrm{CHO}$ endógeno, o que aumenta a oxidação de ácidos graxos pelas mitocôndrias. Como a oxidação de ácidos graxos é muito mais lenta do que a da glicose, a produção de dióxido de carbono pode ser atrasada, aumentando assim a constante de tempo para o $\mathrm{VCO}_{2}$. Com a produção de ATP mais lenta em cada fibra, provavelmente o número de unidades motoras recrutadas tenham aumentado, o que poderia explicar o aumento

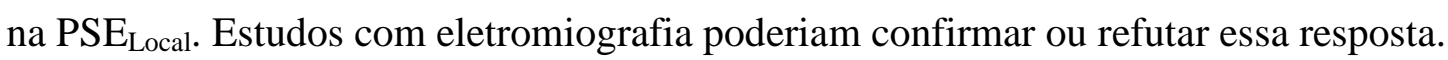

O tempo de exaustão não foi associado a nenhuma das variáveis estudadas. A correlação entre $\mathrm{PSE}_{\mathrm{Geral}}$ e tempo de exaustão não atingiu nível de significância $(\mathrm{r}=-0,37 ; \mathrm{P}=$ 0,12). Como o tempo de exaustão foi menor na situação de baixo $\mathrm{CHO}$, provavelmente ele seja dependente das reservas iniciais de GM, as quais infelizmente não puderam ser medidas no presente estudo. Outros fatores como a atividade de enzimas de degradação de GM e a taxa glicolítica talvez também sejam afetadas pela manipulação e interferiram no tempo de exaustão. Assim, aparentemente, a resposta da $\mathrm{PSE}_{\mathrm{Geral}}$ talvez tenha alguma influência sobre o tempo de exaustão, mas essa influência não parece ser suficiente e outros fatores não mensurados aqui talvez contribuam para a interrupção do exercício.

\subsection{Comparação entre os domínios metabólicos}

No presente estudo a comparação entre os grupos não foi feita de maneira estatística porque a potencia dos testes estatísticos aplicados poderia diminuir em virtude do número reduzido de sujeitos em cada grupo. Assim, optou-se por analisar separadamente a resposta em cada um dos grupos e verificar se a manipulação de CHO teve o mesmo efeito nas duas 
intensidades e se as alterações cardiorrespiratórias, metabólicas e hormonais derivadas da manipulação estavam relacionadas da mesma maneira com a PSE. Entretanto, quando apropriado, uma comparação estatística comparando algumas variáveis entre os dois grupos será apresentada nessa etapa do trabalho.

A primeira grande diferença entre os grupos está no tempo total de exaustão e, consequentemente, no trabalho total realizado (integral potência-tempo). O trabalho total realizado foi significativamente superior (teste $\mathrm{t}$ independente, $\mathrm{P}<0,05$ ) no grupo MP do que no grupo SE para todas as situações (controle: $121,0 \pm 45,6$ vs 59,1 $\pm 10,6$; alto CHO: 141,4 \pm 73,0 vs 71,6 \pm 19,7; baixo CHO: 109,8 \pm 53,7 vs 48,1 $\pm 10,8 \mathrm{~kJ}$, respectivamente). Consequentemente, o total de oxigênio consumido (integral da equação 4 e 5), foi maior em MP do que SE em todas as situações (controle: $496,0 \pm 224,8$ vs 181,4 $\pm 47,0$; alto CHO: $594,5 \pm 365,4$ vs 229,8 \pm 54,4; baixo CHO: 407,9 $\pm 226,6$ vs 149,2 $\pm 17,3 \mathrm{~kJ}$, respectivamente).

Essas diferenças no tempo de exaustão e no trabalho total realizado (físico e fisiológico) podem explicar porque a manipulação de $\mathrm{CHO}$ afetou algumas variáveis no domínio MP, mas não afetou as mesmas variáveis no domínio SE. Por exemplo, a amplitude do $\mathrm{VO}_{2}$ foi reduzida apenas no domínio MP, mas não no SE. Provavelmente, um possível componente lento possa estar presente apenas no domínio MP devido ao tempo de duração do esforço, que é longo o suficiente para que ele apareça (ÖZYENER et al., 2001). Mesmo que no presente estudo a equação biexponencial não tenha ajustado bem os dados, o menor coeficiente angular do minuto 3 até a exaustão na situação de baixo CHO do que nas demais situações demonstra que o componente lento foi reduzido nessa situação. Outro fator interessante é que o domínio MP é alto o suficiente para que se atinja o $\mathrm{VO}_{2 \max }$ e, devido a duração, longo o suficiente para manter um tempo relativamente alto sustentando o $\mathrm{VO}_{2 \max }$. Por outro lado, no domínio SE, a intensidade de esforço é alta o suficiente para atingir rapidamente o $\mathrm{VO}_{2 \max }$, mas o indivíduo entra em exaustão também rapidamente, sem ter tido tempo suficiente para o aparecimento do componente lento, com um tempo de permanência mais curto em valores de $\mathrm{VO}_{2 \max }$. Isso sugere que o aparecimento ou não do componente lento pode ser um fator decisivo no desempenho no domínio MP, mas não é no domínio SE. Como o componente lento está associado ao recrutamento das fibras rápidas (WHIPP, 1994), esses resultados sugerem que a capacidade em prolongar o exercício no domínio MP depende da capacidade das fibras rápidas em prolongar seu período de atuação, não tem a mesma 
importância no exercício SE.

A ligação entre os dados de $\mathrm{VO}_{2}$ com a PSE no domínio MP reforça a idéia de que esses parâmetros metabólicos estão associados ao SNC. Por exemplo, a $\mathrm{PSE}_{\mathrm{Geral}}$ ao final do esforço foi significativamente menor na situação de baixo CHO do que na controle, similar ao

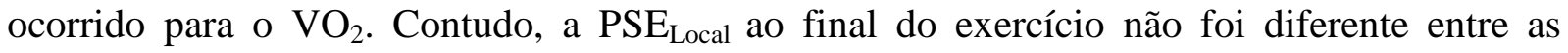
situações. Esses resultados sugerem que, uma incapacidade em aumentar o $\mathrm{VO}_{2}$ nos momentos finais, principalmente das fibras rápidas (CARTER et al., 2004), implica em perceber o esforço exercido pelo músculo ativo como mais intenso, impossibilitando a continuidade do exercício. Por outro lado, o $\mathrm{VO}_{2}$ no domínio SE não foi diferente entre as situações e talvez não seja tão importante para a elaboração da PSE nesse domínio.

Interessante que aspectos centrais respiratórios parecem ser afetados pela manipulação do $\mathrm{CHO}$, mas com resultados opostos entre os domínios. Por exemplo, a resposta da FR e VE do domínio MP foi reduzida na situação de baixo CHO (hipoventilação), enquanto foi aumentada no domínio SE (hiperventilação). Como o protocolo de manipulação foi o mesmo e as características físicas e fisiológicas semelhantes entre os grupos, o único fator que parece explicar esses achados é a intensidade do esforço, mas não há uma explicação fisiológica plausível desses resultados a partir das medidas feitas no presente estudo, pois não foram encontradas diferenças significantes entre as situações para as variáveis que poderiam influenciar a resposta ventilatória, como o $\mathrm{pH}$ e o potássio plasmático, em nenhum dos domínios. Nas outras variáveis, como lactato e norepinefrina, as diferenças encontradas apontariam em um sentido oposto ao identificado no padrão respiratório, como por exemplo, no domínio SE, a concentração de lactato e a concentração de norepinefrina na situação de baixo CHO foram menores, o que deveria causar hipoventilação em vez de hiperventilação. Estudos com medidas adicionais, principalmente intramusculares e/ou potássio intersticial em vez de plasmático, poderiam esclarecer melhor esses achados.

Esses diferentes resultados também implicaram em modificação das variáveis que se associavam com a taxa de incremento da PSE geral, de maneira dependente do domínio. No

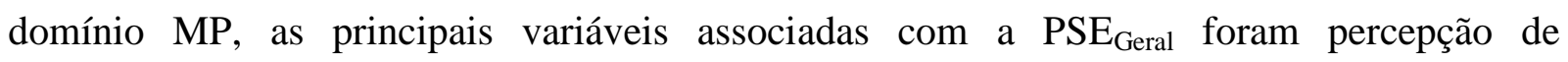
desconforto local, amplitude de $\mathrm{VO}_{2}$, constante de tempo para $\mathrm{VCO}_{2}$ e $\mathrm{FC}$, inclinação da $\mathrm{FC}$ do terceiro minuto à exaustão e delta de insulina. Esses resultados sugerem que, para o domínio MP, variáveis representativas de percepção de dor, metabólicas e centrais interferem na maneira com o indivíduo percebe o esforço como um todo. Interessante que para esse 
domínio, essas variáveis não foram associadas ao tempo de exaustão, com exceção da inclinação da FC do terceiro minuto à exaustão. A maior correlação foi obtida entre tempo de exaustão e PSE $\mathrm{Geral}_{\text {, }}$ sugerindo que as alterações fisiológicas são primeiramente integradas em um construto de percepção global, para posteriormente, interferir na interrupção do exercício.

Essa mesma diversidade de variáveis perceptivas, fisiológicas e centrais interferindo na $\mathrm{PSE}_{\mathrm{Geral}}$ não foi obtida para o domínio SE. Nesse domínio, apenas a percepção local e a

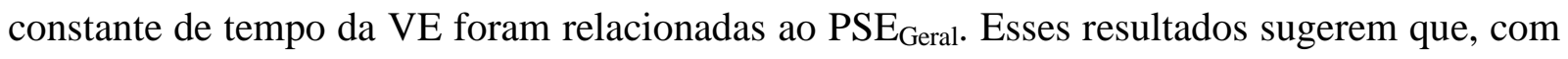
o aumento da intensidade do domínio MP para SE, os fatores que influenciam a PSE $\mathrm{Beral}_{\mathrm{a}}$ mudam, diminuindo a importância dos fatores metabólicos e centrais, e aumentando a participação dos perceptivos da dor local. Essa maior percepção de dor pode ser decorrente da elevada carga externa que os indivíduos que pedalaram nesse domínio tiveram que enfrentar, o que foi muito maior do que a utilizada no domínio MP (HOLLANDER et al., 2008). No final, o tempo de exaustão não foi associado a nenhuma das variáveis, o que torna a explicação da exaustão nesse domínio muito mais complexa do que no domínio MP, ao menos a partir dos presentes resultados.

\section{CONCLUSÕES}

De um modo geral, os resultados do presente estudo sugerem que a manipulação de CHO não interfere no desempenho em exercícios de domínio MP, apesar de ser altamente dependente da individualidade biológica. Por outro lado, o desempenho parece ser prejudicado no domínio SE quando os indivíduos iniciam o esforço com baixas reservas de $\mathrm{CHO}$. A taxa de incremento da PSE, tanto geral quanto local, é sensível a disponibilidade de CHO, sendo maior quando o individuo começa o esforço com baixa reserva desse substrato. A manipulação das reservas de $\mathrm{CHO}$ reduz a amplitude de aumento do $\mathrm{VO}_{2}$ e a taxa de aumento do componente lento do $\mathrm{VO}_{2}$ no domínio $\mathrm{MP}$, além de provocar uma hiperventilação durante o exercício no domínio SE. A manipulação da disponibilidade de CHO também interfere no comportamento da insulina frente ao esforço no domínio MP, enquanto atenua a resposta de norepinefrina e cortisol no domínio SE, sugerindo que a resposta hormonal é afetada pela manipulação de $\mathrm{CHO}$ de maneira distinta entre os domínios. Variáveis perceptivas de desconforto muscular local, metabólicas e centrais parecem influenciar na taxa em que PSE geral aumenta com o tempo de exercício no domínio MP e, provavelmente, a integração dessas variáveis na construção da PSE determine o ponto de interrupção do esforço. No 
domínio SE, a percepção de desconforto muscular e a hiperventilação parecem influenciar a taxa de incremento na PSE em função do tempo, mas a exaustão não pode ser explicada por nenhuma dessas variáveis. A relação entre variáveis metabólicas, hormonais e cardiorespiratórias com a PSE sugere que a construção da percepção referente ao esforço é construída com algum nível de influência de vias aferentes periféricas.

\section{REFERÊNCIAS}

ACHTEN, J.; JEUKENDRUP, A.E. Relation between plasma lactate concentration and fat oxidation rates over a wide range of exercise intensities. International Journal of Sports Medicine, Stuttgart, v. 25, p. 32-37, 2004.

ADAMO, K.B.; TARNOPOLSKY, M.A.; GRAHAM, T.E. Dietary carbohydrate and postexercise synthesis of proglycogen and macroglycogen in human skeletal muscle. American Journal Physiology (Endocrinol. Metab.), Bethesda, v. 275, p. E229-E234, 1998. AHLBORG, B.; BERGSTROM, J.; EKELUND, L-G.; HULTMAN, E. Muscle glycogen and muscle electrolytes during prolonged physical exercise. Acta Physiologica Scandinavica, Stockholm, v. 70, p 129-142, 1967.

AHLBORG, G.; FELIG, P.; HAGENFELDT, L.; HENDLER, R.; WAHREN, J. Substrate turnover during prolonged exercise in man. Splanchnic and leg metabolism of glucose, free fatty acids, and amino acids. The Journal of Clinical Investigation, New Haven, v. 53, p. 1080-1090, 1974.

ALLEN, D.G.; LAMB, G.D.; WESTERBLAD, H. Impaired calcium release during fatigue. Journal of Applied Physiology, Bethesda, v.104, p. 296-305, 2008.

AMANN, M.; HOPKINS, W.G.; MARCORA, S.M. Similar sensitivity of time to exhaustion and time-trial time to changes in endurance. Medicine and Science in Sports and Exercise, Madison, v. 40, p. $574-578,2008$.

AMENT, W.; VERKERKE, G.J. Exercise and fatigue. Sports Medicine, Auckland, v.39, p. 389-422, 2009.

ANDREWS, J.L.; SEDLOCK, D.A.; FLYNN, M.G.; NAVALTA, J.W.; JI, H. Carbohydrate loading and supplementation in endurance-trained women runners. Journal of Applied Physiology, Bethesda, v. 95, p. 584-590, 2003. 
ARKINSTALL, M.J.; BRUCE, C.R.; CLARK, S.A.; RICKARDS, C.A.; BURKE, L.M.; HAWLEY, J.A. Regulation of fuel metabolism by preexercise muscle glycogen content and exercise intensity. Journal of Applied Physiology, Bethesda, v. 97, p. 2275-2283, 2004.

ATKINSON, G.; PEACOCK, O.; GIBSON, A.S.; TUCKER, R. Distribution of power output during cycling: impact and mechanisms. Sports Medicine, Auckland, v.37, p. 647-667, 2007. BALDWIN, J.; SNOW, R.J.; GIBALA, M.J.; GARNHAM, A.; HOWARTH, K.; FEBBRAIO, M.A. Glycogen availability does not affect the TCA cycle or TAN pools during prolonged, fatiguing exercise. Journal of Applied Physiology, Bethesda, v. 94, p. 2181-2187, 2003.

BALSOM, P.D.; GAITANOS, G.C.; SODERLUND, K.; EKBLOM, B. High-intensity exercise and muscle glycogen availability in humans. Acta Physiologica Scandinavica, Stockholm, v. 165, p. 337-345, 1999.

BANGSBO, J.; MADSEN, K.; KIENS, B.; RICHTER, E.A. Effect of muscle acidity on muscle metabolism and fatigue during intense in man. Journal of Physiology, London, v. 495, p. 587-596, 1996.

BARSTOW, T.J.; JONES, A.M.; NGUYEN, P.H.; CASABURI, R. Influence of muscle fiber type and pedal frequency on oxygen uptake kinetics of heavy exercise. Journal of Applied Physiology, Bethesda, v. 81, p. 1642-1650, 1996.

BARSTOW, T.J.; MOLÉ, P.A. Linear and nonlinear characteristics of oxygen uptake kinetics during heavy exercise. Journal of Applied Physiology, Bethesda, v. 71, p. 2099-2106, 1991.

BASSETT, D.R.; HOWLEY, E.T. Maximal oxygen uptake: "classical” versus “contemporary" viewpoints. Medicine and Science in Sports and Exercise, Madison, v. 29, p. $591-603,1997$.

BASSIT, R.A.; MALVERDI, M. Avaliação nutricional de triatletas. Revista Paulista de Educação Física, São Paulo, v.12, p. 42-53, 1998.

BERGSTROM, J.; HULTMAN, E. A study of the glycogen metabolism during exercise in man. Scandinavian Journal of Clinical and Laboratory Investigation, Oslo, v. 19, p. 218228, 1967.

BERGSTROM, J.; HERMANSEN, L.; HULTMAN, E.; SALTIN, B. Diet, muscle glycogen and physical performance. Acta Physiologica Scandinavica, Stockholm, v. 71, p. 140-150, 1967. 
BERTUZZI, R.M.C.; FRANCHINI, E.; KISS, M.A.P.D.M. Possíveis fatores participantes na fadiga aguda em exercícios físicos de longa duração: uma breve revisão. Motriz, Rio Claro, v. 10, p. 45-54, 2004.

BILLAT, V.L.; WESFREID, E.; KAPFER, C.; KORALSZTEIN, J.P.; MEYER, Y. Nonlinear dynamics of heart rate and oxygen uptake in exhaustive 10,000 m runs: influence of constant vs. freely paced. The Journal of Physiological Sciences, Tokyo, v.56, p. 103-111, 2006.

BLOMSTRAND, E; SALTIN, B. Effect of muscle glycogen on glucose, lactate and amino acid metabolism during exercise and recovery in human subjects. Journal of Physiology, London, v. 514, p.293-302, 1999.

BOOTH, J.; McKENNA, M.J.; RUELI, P.A.; GWINN, T.H.; DAVIS, G.M.; THOMPSON, M.W.; HARMER, A.R.; HUNTER, S.K.; SUTTON, J.R. Impaired calcium pump function does not slow relaxation in human skeletal muscle after prolonged exercise. Journal of Applied Physiology, Bethesda, v. 83, p. 511-521, 1997.

BORG, G.A. Psychophysical bases of perceived exertion. Medicine and Science in Sports and Exercise, Madison, v. 14, p. 377-381, 1982.

BORG, G.; HASSMÉN, P.; LAGERSTRÖM, M. Perceived exertion related to heart rate and blood lactate during arm and leg exercise. European Journal of Applied Physiology and Occupational Physiology, Berlin, v.56, p. 679-685, 1987.

BORG, E.; KAIJSER, L. A comparison between three rating scales for perceived exertion and two different work tests. Scandinavian Journal of Medicine and Science in Sports, Copenhagen, v.16, p. 57-69, 2006.

BORG, G.; LJUNGGREN, G.; CECI, R. The increase of perceived exertion, aches and pain in the legs, heart rate and blood lactate during exercise on a bicycle ergometer. European Journal of Applied Physiology and Occupational Physiology, Berlin, v.54, p. 343-349, 1985.

BOSCH, A.N.; DENNIS, S.C.; NOAKES, T.D. Influence of carbohydrate loading on fuel substrate turnover and oxidation during prolonged exercise. Journal of Applied Physiology, Bethesda, v. 74, p. 1921-1927, 1993.

BOUCKAERT, J.; JONES, A.M.; KOPPO, K. Effect of glycogen depletion on the oxygen uptake slow component in humans. International Journal of Sports Medicine, Stuttgart, v. 25, p. 351-356, 2004.

BROBERG, S.; SAHLIN, K. Hyperammoniemia during prolonged exercise: an effect of 
glycogen depletion? Journal of Applied Physiology, Bethesda, v. 65, p. 2475-2477, 1988.

BROOKS, G.A. Anaerobic threshold: review of the concept and directions for future research. Medicine and Science in Sports and Exercise, Madison, v. 17, p. 22-31, 1985.

BROOKS, G.A.; MERCIER, J. Balance of carbohydrate and lipid utilization during exercise: the "crossover" concept. Journal of Applied Physiology, Bethesda, v. 76, p. 2253-2261, 1994.

BROOKS, G.A..; TRIMMER, J.K. Glucose kinetics during high-intensity exercise and the crossover concept. Journal of Applied Physiology, Bethesda, v. 80, p. 1073-1074, 1996.

BUSSE, M.W.; MAASSEN, N.; KONRAD, H. Relation between plasma $\mathrm{K}^{+}$and ventilation during incremental exercise after glycogen depletion and repletion in man. Journal of Physiology, London, v. 443, p. 469-476, 1991.

CARTER, H.; PRINGLE, J.S.; BOOBIS, L.; JONES, A.M.; DOUST, J.H. Muscle glycogen depletion alters oxygen uptake kinetics during heavy exercise. Medicine and Science in Sports and Exercise, Madison, v. 36, p. 965-972, 2004.

CASEY, A.; GREENHAFF, P.L. Does dietary creatine supplementation play a role in skeletal muscle metabolism and performance. The American Journal of Clinical Nutrition, Bethesda, v. 72 (suppl), p. 607s - 617s, 2000.

CASEY, A.; SHORT, A.H.; CURTIS, S.; GREENHAFF, P.L. The effect of glycogen availability on power output and the metabolic response to repeated bouts of maximal, isokinetic exercise in man. European Journal of Applied Physiology, Berlin, v. 72 (3), p. 249-255, 1996.

CHASIOTIS, D.; HULTMAN, E.; SAHLIN, K. Acidotic depression of cyclic AMP accumulation and phosphorylase $b$ to a transformation in skeletal muscle of man. Journal of Physiology, London, v. 335, p. 197 - 204, 1982.

CHIN, E.R.; ALLEN, D.G. Effects of reduced muscle glycogen concentration on force, $\mathrm{Ca}^{+2}$ release and contractile protein function in intact mouse skeletal muscle. Journal of Physiology, London, v. 498 (1), p. 17-29, 1997.

CHRIST-ROBERTS, C.Y.; PRATIPANAWATR, T.; PRATIPANAWATR, W.; BERRIA, R.; BELFORT, R.; MANDARINO, L.J. Increased insulin receptor signaling and glycogen synthase activity contribute to the synergistic effect of exercise on insulin action. Journal of Applied Physiology, Bethesda, v. 95, p. 2519-2529, 2003.

CHRYSSANTHOPOULOS, C.; WILLIAMS, C. Pre-exercise carbohydrate meal and 
endurance running capacity when carbohydrates are ingested during exercise. International Journal of Sports Medicine, Stuttgart, v. 18, p. 543-548, 1997.

CLAASSEN, A.; LAMBERT, E.V.; BOSCH, A.N.; RODGER, M.; ST CLAIR GIBSON, A.; NOAKES, T.D. Variability in exercise capacity and metabolic response during endurance exercise after a low carbohydrate diet. International Journal of Sports Nutrition and Exercise Metabolism, Florida, v. 15, p. 97 - 116, 2005.

COOGAN, A.R. Plasma glucose metabolism during exercise in humans. Sports Medicine, Auckland, v. 11, p. 102-131, 1991.

COOGAN, A. R.; RAGUSO, C. A.; WILlIAMS, B. D.; SIDOSSIS, L. S.; GASTALDELLI, A. Glucose kinetics during high-intensity exercise in endurance-trained and untrained humans. Journal of Applied Physiology, Bethesda, v. 78(3), p. 1203-1207, 1995.

CONLEE, R.K. Muscle glycogen and exercise endurance: A twenty-year perspective. Exercise and Sports Science Reviews, Baltimore, v. 15, p. 1-28, 1987.

COSTILL, D. L.; BOWERS, R.; BRANAM, G.; SPARKS, K. Muscle glycogen utilization during prolonged exercise on successive days. Journal of Applied Physiology, Bethesda, v. 31(6), p. 834-838, 1971.

COSTILL, D.L.; GOLLNICK, P.D.; JANSSON. E.D.; SALTIN, B.; STEIN, E.M. Glycogen depletion pattern in human muscle fibres during distance running. Acta Physiologica Scandinavica, Stockholm, v. 89, p. 374-383, 1973.

COTTIN, F.; MEDIGUE, C.; LEPRETRE, P.M.; PAPELIER, Y.; KORALSZTEIN, J.P.; BILLAT, V. Heart rate variability during exercise performed below and above ventilatory threshold. Medicine and Science in Sports and Exercise, Madison, v. 36, p. 594-600, 2004.

COYLE, E.F.; COGGAN, A.R.; HEMMERT, M.K.; IVY, J.L. Muscle glycogen utilization during prolonged strenuous exercise when fed carbohydrate. Journal of Applied Physiology, Bethesda, v. 61, p.165-172, 1986.

COYLE, E.F. Carbohydrate feeding during exercise. International Journal of Sports Medicine, Stuttgart, v. 13, suppl 1., pp. S126-S128, 1992.

CREWE, H.; TUCKER, R.; NOAKES, T.D. The rate of increase in rating of perceived exertion predicts the duration of exercise to fatigue at a fixed power output in different environmental conditions. European Journal of Applied Physiology, Berlin, v. 103, p. 569$577,2008$.

DAVIS, J.M., BAILEY, S.P. Possible mechanisms of central nervous system fatigue during 
exercise. Medicine and Science in Sports and Exercise, Madison, v. 29, p. 45-57, 1997.

DAVIS, J.M.; WELSH, R.S.; DE VOLVE, K.L.; ALDERSON, N.A. Effects of branchedchain amino acids and carbohydrate on fatigue during intermittent, high-intensity running. International Journal of Sports Medicine, Stuttgart, v. 20, p. 309-314, 1999.

EDWARDS, R. H. T. Biochemical bases of fatigue in exercise performance: catastrophe theory of muscular fatigue. In: edited by H. G. KUNUTTGEN. Biochemistry of exercise. Champion, IL: Human Kinetics1983. p.3-28.

ENOKA, R.M.; STUART, D.G. Neurobiology of muscle fatigue. Journal of Applied Physiology, Bethesda, v. 72, p. 1631-1648, 1992.

ESTON, R.; FAULKNER, J.A.; MASON, E.A.; PARFITT, G. The validity of predicting maximal oxygen uptake from perceptually regulated graded exercise tests of different durations. European Journal of Applied Physiology, Berlin, v. 97, p. 535-541, 2006.

ESTON, R.; FAULKNER, J.; ST CLAIR GIBSON, A.; NOAKES, T.D.; PARFITT, G. The effect of antecedent fatiguing activity on the relationship between perceived exertion and physiological activity during a constant load exercise task. Psychophysiology, Baltimore, v. 44, p. 779-786, 2007.

ESTON, R.; LAMBRICK, D.; SHEPPARD, K.; PARFITT, G. Prediction of maximal oxygen uptake in sedentary males from a perceptually regulated, sub-maximal graded exercise test. Journal of Sports Sciences, London, v. 26, p. 131-139, 2008.

FAULKNER, J.; PARFITT, G.; ESTON, R. The rating of perceived exertion during competitive running scales with time. Psychophysiology, Baltimore, v. 45, p. 977-985, 2008.

FEBBRAIO, M.A.; DANCEY, J. Skeletal muscle energy metabolism during prolonged, fatigue exercise. Journal of Applied Physiology, Bethesda, v. 87, p. 2341-2347, 1999.

FITTS, R.H. Cellular mechanisms of fatigue muscle. Physiological Reviews, Baltimore, v. 74, p. 49-93, 1994.

FRIDÉN, J.; SEGER, J.; EKBLOM, B. Topographical localization of muscle glycogen: An ultrahistochemical study in human vastus lateralis. Acta Physiologica Scandinavica, Stockholm, v. 135, p.381-391, 1989.

FRYER, M.W.; OWEN, V.J.; LAMB, G.D.; STEPHENSON, D.G. Effects of creatine phosphate and $\mathrm{P}_{\mathrm{i}}$ on $\mathrm{Ca}^{+2}$ movements and tension development in rat skinned skeletal muscle fibres. Journal of Physiology, London, v. 482, p. 123 - 140, 1995.

GAESSER; G,A.; POOLE, D.C. The slow component of oxygen uptake kinetics in humans. . 
Exercise and Sports Science Reviews, Baltimore, v. 24, p. 35-71, 1996.

GANDEVIA, S.C. Neural control in human muscle fatigue: changes in muscle afferents, moto neurones and moto cortical drive. Acta Physiologica Scandinavica, Stockholm, v. 162, p. 275 $-283,1998$.

GANDEVIA, S.C.; BUTLER, J.E.; TAYLOR, J.L. Viewpoint: Fatigue mechanisms determining exercise performance: integrative physiology is systems physiology. Journal of Applied Physiology, Bethesda, v. 104, p. 1546, 2008.

GLASS, C.; KNOWLTON, R. G.; SANJABI, P. B.; SULLIVAN, J. J. The effect of exercise induced glycogen depletion on the lactate, ventilatory and electromyographic thresholds. The Journal of Sports Medicine and Physical Fitness, Turin, v. 37, p. 32-40, 1997.

GOLLNICK, P.D.; ARMSTRONG, R.B.; SEMBROWICH, W.L.; SHEPHERD, R.E.; SALTIN, B. Glycogen depletion pattern in human skeletal muscle fibers after heavy exercise. Journal of Applied Physiology, Bethesda, v. 34, p. 615-618, 1973.

GOLLNICK, P.D.; KARLSSON, J.; PIEHL, K.; SALTIN, B. Phosphorylase a in human skeletal muscle during exercise and electrical stimulation. Journal of Applied Physiology: Respiratory, Environmental and Exercise Physiology, Bethesda, v. 45, p. 852 - 857, 1978.

GOLLNICK, P.D.; PIEHL, K.; SALTIN, B. Selective glycogen depletion pattern in human muscle fibres after exercise of varying intensity and at varying pedalling rates. Journal of Physiology, London, v. 241, p. 45-57, 1974.

GOLLNICK, P.D.; PIEHL, K.; SAUBERT IV, C.W.; ARMSTRONG, R.B.; SALTIN, B. Diet, exercise, and glycogen changes in human muscle fibers. Journal of Applied Physiology, Bethesda, v. 33, p. 421-425, 1972.

GRAHAM, T. E.; ADAMO, K. B.; SHEARE, J.; MARCHAND, I.; SALTIN, B. Pro-and macroglycogenolysis: relationship with exercise intensity and duration. Journal of Applied Physiology, Bethesda, v. 90, p. 873-879, 2001.

GRASSI, B.; GLADDEN, L.B.; SAMAJA, M.; STARY, C.M.; HOGAN, M.C. Faster adjustment of $\mathrm{O}_{2}$ delivery does not affect $\mathrm{VO}_{2}$ on-kinetics in isolated in situ canine muscle. Journal of Applied Physiology, Bethesda, v. 85, p. 1394-1403, 1998.

GREEN, H.J. Mechanisms of muscle fatigue in intense exercise. Journal of Sports Sciences, London, v. 15, p. 247 - 256, 1997.

GREEN, H.J.; DUHAMEL, T.A.; FOLEY, K.P.; OUYANG, J.; SMITH, I.C.; STEWART, 
R.D. Glucose supplements increase human muscle in vitro $\mathrm{Na}^{+}-\mathrm{K}^{+}$-ATPase activity during prolonged exercise. American Journal of Physiology: Regulatory, Integrative and Comparative Physiology, Bethesda, v. 293, p. R354-R362, 2007.

GREENHAFF, P.L.; GLEESON, M.; MAUGHAN, R.J. The effects of dietary manipulation on blood acid-base status and the performance of high intensity exercise. European Journal of Applied Physiology and Occupational Physiology, Berlin, v.56, p. 331-337, 1987a.

GREENHAFF, P.L.; GLEESON, M.; WHITING, P.H.; MAUGHAN, R.J. Dietary composition and acid-base status: limiting factors in the performance of maximal exercise in man? European Journal of Applied Physiology and Occupational Physiology, Berlin, v.56, p. 444-450, $1987 b$.

GREENHAFF, P.L.; GLEESON, M.; MAUGHAN, R.J. Diet-induced metabolic acidosis and the performance of high intensity exercise in man. European Journal of Applied Physiology and Occupational Physiology, Berlin, v. 57, p. 583-590, 1988.

GRISDALE, R.K.; JACOBS, I.; CAFARELLI, E. Relative effects of glycogen depletion and previous exercise on muscle force and endurance capacity. Journal of Applied Physiology, Bethesda, v. 69, p. 1276-1282, 1990.

HAMPSON, D.B.; ST CLAIR GIBSON, A.; LAMBERT, M.I.; NOAKES, T.D. The influence of sensory cues on the perception of exertion during exercise and central regulation of exercise performance. Sports Medicine, Auckland, v. 31, p. 935-952, 2001.

HANON, C.; LEVEQUE, J.M.; THOMAS, C.; VIVIER, L. Pacing strategy and $\mathrm{VO}_{2}$ kinetics during a 1500-m race. International Journal of Sports Medicine, Stuttgart, v. 29, p. 206$211,2008$.

HARGREAVES M, FINN JP, WITHERS RT, HALBERT JA, SCROOP GC, MACKAY M, SNOW RJ, CAREY MF. Effect of muscle glycogen availability on maximal exercise performance. European Journal of Applied Physiology and Occupation Physiology, Berlin, v.75(2), p.188-92, 1997.

HARGREAVES, M. Fatigue mechanisms determining exercise performance: integrative physiology is systems biology. Journal of Applied Physiology, Bethesda, v. 104, p.1541$1542,2008$.

HARRIS, J.A.; BENEDICT, F.G. A biometric study of human basal metabolism. The Carnegie Institute of Washington, Washington, v.4, p. 370-373, 1918.

HAVEMANN, L.; WEST, S.J.; GOEDECKE, J.H.; MACDONALD, I.A.; ST CLAIR 
GIBSON A.; NOAKES T.D.; LAMBERT, E.V. Fat adaptation followed by carbohydrate loading compromises high-intensity sprint performance. Journal of Applied Physiology, Bethesda, v. 100, p.194-202, 2006.

HEIGENHAUSER, G. J. F.; SUTTON, J. R.; JONES, N. L. Effet of glycogen depletion on the ventilatory response to exercise. Journal of Applied Physiology, Bethesda, v. 54(2), p. 470474, 1983.

HESPEL, P.; RICHTER, E.A. Glucose uptake and transport in contracting, perfused rat muscle with different pre-contraction glycogen concentration. Journal of Physiology, London, v. 427, p.347-359, 1990.

HETTINGA, F.J.; DE KONING, J.J.; BROERSEN, F.T.; VAN GEFFEN, P.; FOSTER, C. Pacing strategy and the occurrence of fatigue in 4000-m cycling time trials. Medicine and Science in Sports and Exercise, Madison, v. 38, p. 1484 - 1491, 2006.

HILL, A.V.; LUPTON, H. Muscular exercise, lactic acid, and the supply and utilization of oxygen. Quarterly Journal of Medicine, Oxford, v.16, p. 135 - 171, 1923.

HILL, D.W.; POOLE, D.C.; SMITH, J.C. The relationship between power and the time to achieve $\mathrm{VO}_{2 \max }$. Medicine and Science in Sports and Exercise, Madison, v. 34, p. 709 $714,2002$.

HOCHACHKA, P.W.; CLARK, C.M.; MATHESON, G.O.; BROWN, W.D.; STONE, C.K.; NICKLES, R.J.; HOLDEN, J.E. Effects on regional brain metabolism of high-altitude hypoxia: a study of six US marines. American Journal of Physiology: Regulatory, Integrative and Comparative Physiology, Bethesda, v. 46, p. R314 - R319, 1999.

HOLLANDER, D.B.; KILPATRICK, M.W.; RAMADAN, Z.G.; REEVES, G.V.; FRANCOIS, M.; BLAKENEY, A.; CASTRACANE, V.D.; KRAEMER, R.R. Load rather than contraction type influences rate of perceived exertion and pain. Journal of Strength and Conditional Research. Champaign, v.22, p. 1184-1193, 2008.

HONIG, C.R.; GAYESKI, T.E.J.; FEDERSPIEL, W.; CLARK-Jr., A.; CLARK, P. Muscle $\mathrm{O}_{2}$ gradients from hemoglobin to cytochrome: New concepts, new complexities. Advance in Experimental Medicine and Biology, New York, v. 169, p. 23 - 28, 1984.

HORSTMAN, D.H.; MORGAN, W.P.; CYMERMAN, A.; STOKES, J. Perception of effort during constant work to self-imposed exhaustion. Perceptual and Motor Skills, Missoula, v. 48, p. $1111-1126,1979$.

HOWLEY, E.T.; BASSETT JR, D.R; WELCH, H.G. Criteria for maximal oxygen uptake: 
review and commentary. Medicine and Science in Sports and Exercise, Madison, v. 27, p. 1292 - 1301, 1995.

HUGHES, E. F.; TURNER, S. C.; BROOKS, G. A. Effects of glycogen depletion and pedaling speed on "anaerobic threshold". Journal of Applied Physiology, Bethesda, v. 52(6), p. $1598-1607,1982$.

JACKSON, A.S.; POLLOCK, M.L. Generalized equations for predicting body density of men. British Journal of Nutrition, Cambridge, v. 40, p. 497-504, 1978.

JESSEN, N.; POLD, R.; BUHL, E.S.; JENSEN, L.S.; SCHIMITZ, O.; LUND, S. Effects of AICAR and exercise on insulin-stimulated glucose uptake, signaling, and GLUT-4 content in rat muscles. Journal of Applied Physiology, Bethesda, v. 94, p. 1373-1379, 2003.

JOHNSON, N.A.; STANNARD, S.R.; CHAPMAN, P.G.; THOMPSON, M.W. Effect of altered pre-exercise carbohydrate availability on selection and perception of effort during prolonged cycling. European Journal of Applied Physiology, Berlin, v.98, p. 62-70, 2006.

JOSEPH, T.; JOHNSON, B.; BATTISTA, R.A.; WRIGHT, G.; DODGE, C.; PORCARI, J.P.; DE KONING, J.J.; FOSTER C. Perception of fatigue during simulated competition. Medicine and Science in Sports Exercise, Madison, v. 40, p. 381-386, 2008.

KARLSSON, J.; SALTIN, B. Lactate ATP, and CP in working muscles during exhaustive in man. Journal of Applied Physiology, Bethesda, v. 29, p. 598 - 602, 1970.

KRUSTRUP, P.; SODERLUND, K.; MOHR, M.; BANGSBO, J. Slow-twitch fiber glycogen depletion elevates moderate-exercise fast-twitch fiber activity and $0_{2}$ uptake. Medicine and Science in Sports and Exercise, Madison, v. 36, p. 973-982, 2004.

LAMBERT, E.V.; ST CLAIR GIBSON, A.; NOAKES, T.D. Complex systems model of fatigue: integrative homoeostatic control of peripheral physiological systems during exercise in humans. British Journal of Sports Medicine, London, v.39, p. 52-62, 2005.

LIMA-SILVA, A.E.; DE-OLIVEIRA, F.R.; NAKAMURA, F.Y.; GEVAERD, M.S. Effect of carbohydrate availability on time to exhaustion in exercise performed at two different intensities. Brazilian Journal of Medical and Biological Research, Ribeirão Preto, v.42, p. 404-412, 2009.

LOY, S.F.; CONLEE, R.K.; WINDER, W.W.; NELSON, A.G.; ARNALL, D.A.; FISHER, A.G. Effects of 24-hour fast on cycling endurance time at two different intensities. Journal of Applied Physiology, Bethesda, v. 61, p.654-659, 1986. 
MAGKOS, F.; YANNAKOULIA, M. Methodology of dietary assessment in athletes: concepts and pitfalls. Current opinion in Clinical Nutrition and Metabolic Care, Hagerstown, v.6, p.539-549, 2003.

MANETTA, E.; BRUN, J.F.; PEREZ-MARTIN, A.; CALLIS, A.; PREFAUT, C.; MERCIER, J. Fuel oxidation during exercise in middle-aged men: role of training and glucose disposal. Medicine and Science in Sports and Exercise, Madison, v. 33, p. 423-429, 2002.

MARCORA, S.M. Do we really need a central governor to explain brain regulation of exercise performance? European Journal of Applied Physiology, Berlin, v. 104, p. 929-931, 2008.

MAUGER, A.R.; JONES, A.M.; WILLIAMS, C.A. Influence of feedback and prior experience on pacing during a 4-km cycle time trial. Medicine and Science in Sports and Exercise, Madison, v. 41, p. 451-458, 2009.

MAUGHAN, R.J.; GREENHAFF, P.L.; LEIPER, J.B.; BALL, D.; LAMBERT, C.P.; GLEESON, M. Diet composition and the performance of high-intensity exercise. Journal of Sports Sciences, London, v. 15, p. 265-275, 1997.

MAUGHAN, R.J.; POOLE, D.C. The effects of a glycogen-loading regimen on the capacity to perform anaerobic exercise. European Journal of Applied Physiology and Occupational and Physiology, Berlin, v. 46, p. 211-219, 1981.

MAYES, P.A. Carboidratos de significado fisiológico. In: MURRAY, R.K.; GRANNER, D.K.; MAYES, P.A.; RODWELL, V.W, editores. Harper: Bioquímica. São Paulo: Atheneu editora; 1994.

MCCONELL, G.; FABRIS, S.; PROIETTO, J.; HARGREAVES, M. Effect of carbohydrate ingestion on glucose kinetics during exercise. Journal of Applied Physiology, Bethesda, v. 77, p.1537-1541, 1994.

MCKENNA, M.J.; BANGSBO, J.; RENAUD, J.M. Muscle $\mathrm{K}+, \mathrm{Na}+$, and Cl disturbances and $\mathrm{Na}+\mathrm{K}+$ pump inactivation: implications for fatigue. Journal of Applied Physiology, Bethesda, v. 104, p.288-295, 2008.

MCKENNA, M.J.; HARGREAVES, M. Resolving fatigue mechanisms determining exercise performance: integrative physiology at its finest! Journal of Applied Physiology, Bethesda, v. 104, p.286-287, 2008.

McLESTER Jr., J.R. Muscle contraction and fatigue: The role of adenosine 5'-Diphosphate and inorganic phosphate. Sports Medicine, Auckland, v. 23, p. 287-305, 1997.

MIURA, A.; SATO, H.; SATO, H.; WHIPP, B.J.; FUKUBA, Y. The effect of glycogen 
depletion on the constant parameter of the power-duration curve for cycle ergometry. Ergonomics, London, v.43, p. 133-141, 2000.

NAFFAH-MAZZACORATTI, M. G; CASARINI, D. E; FERNANDES, M. J. S; CAVALHEIRO, E. A. Serum catecholamine levels determined by performance liquid chromatrography coupled with electrochemical detection. Arquivos Brasileiros de Endocrinologia e Metabologia, Rio de Janeiro, v. 36, n. 4, p. 119 - 122. 1992.

NETHERY, V.M. Competition between internal and external sources of information during exercise: influence on RPE and the impact of the exercise load. The Journal of Sports Medicine and Physical Fitness, Turin, v. 42, p. 172-178, 2002.

NEUFER, P.D.; COSTILL, D.L.; FLYNN, M.G.; KIRWAN, J.P.; MITCHELL, J.B.; HOUMARD, J. Improvements in exercise performance: effects of carbohydrate feedings and diet. Journal of Applied Physiology, Bethesda, v. 62, p.983-988, 1987.

NEWSHOLME, E.A.; BLOMSTRAND, E.; EKBLOM, B. Physical and mental fatigue: Metabolic mechanisms and importance of plasma amino acids. British Medical Bulletin, London, v. 48, p.477-495, 1992.

NIELSEN, J.N.; MUSTARD, K.J.W.; GRAHAM, D.A.; YU, H.; MACDONALD, C.S.; PILEGAARD, H.; GOODYEAR, L.J.; HARDIE, D.G.; RICHTER, E.A.; WOJTASZEWSKY, J.F.P. 5'-AMP-activeted protein kinase activity and subunit expression in exercise-trained human skeletal muscle. Journal of Applied Physiology, Bethesda, v. 94, p.631-641, 2003.

NOAKES, T.D. Implications of exercise testing for prediction of athletic performance: a contemporary perspective. Medicine and Science in Sports and Exercise, Madison, v. 20, p. $319-330,1988$.

NOAKES, T.D. Challenging beliefs: ex Africa semper aliquid novi. Medicine and Science in Sports and Exercise, Madison, v. 29, p. 571 - 590, 1997.

NOAKES, T.D. Maximal oxygen uptake: "classical" versus "contemporary" viewpoints: a rebuttal. Medicine and Science in Sports and Exercise, Madison, v. 30, p. 1381 - 1398, 1998.

NOAKES, T.D. Physiological models to understand exercise fatigue and the adaptations that predict or enhance athletic performance. Medicine and Science in Sports and Exercise, Madison, v. 10, p. 123 - 145, 2000.

NOAKES, T.D. Linear relationship between the perception of effort and the duration of 
constant load exercise that remains. Journal of Applied Physiology, Bethesda, v. 96, p.15711572, 2004.

NOAKES, T.D. Rating of perceived exertion as a predictor of the duration of exercise that remains until exhaustion. British Journal of Sports and Medicine, London, v. 42, p. 623624, 2008.

NOAKES, T.D.; PELTONEN, J.E.; RUSKO, H.K. Evidence that a central governor regulates exercise performance during acute hypoxia and hyperoxia. The Journal of Experimental Biology, Cambridge, v. 204, p. 3225-3234, 2001.

NOAKES, T.D.; ST CLAIR GIBSON, A. Logical limitations to the "catastrophe" models of fatigue during exercise in humans. British Journal of Sports Medicine, London, v.38, p. 648-649, 2004.

NOAKES, T.D.; ST CLAIR GIBSON, A.; LAMBERT, E.V. From catastrophe to complexity: a novel model of integrative central neural regulation of effort and fatigue during exercise in humans. British Journal of Sports Medicine, London, v.38, p. 511-504, 2004.

NOBLE, B.J.; BORG, G.A.; JACOBS, I.; CECI, R.; KAISER, P. A category-ratio perceived exertion scale: relationship to blood and muscle lactates and heart rate. Medicine and Science in Sports and Exercise, Madison, v. 15, p. 523-528, 1983.

NOSEK, T.M.; FENDER, K.Y.; GODT, R.E. It is disprotonated inorganic phosphate that depresses force in skinned skeletal muscle fibers. Science, Washington, v.236, p. 191-193, 1987.

NYBO, L. Hyperthermia and fatigue. Journal of Applied Physiology, Bethesda, v.104, p. 871-878, 2008.

NYBO, L.; MOLLER, K.; PEDERSEN, B.K.; NIELSEN, B.; SECHER, N.H. Association between fatigue and failure to preserve cerebral energy turnover during prolonged exercise. Acta Physiologica Scandinavica, Stockholm, v. 179, p. 67 - 74, 2003.

OSBORNE, M.A.; SCHNEIDER, D.A. Muscle glycogen reduction in man: relationship between surface EMG activity and oxygen uptake kinetics during heavy exercise. Experimental Physiology, Cambridge, v. 91, p. 179-189, 2006.

ÖZYENER, F.; ROSSITER, H.B.; WARD, S.A.; WHIPP, B.J. Influence of exercise intensity on the on- and off-transient kinetics of pulmonary oxygen uptake in humans. Journal of Physiology, London, v. 533, p. 891-902, 2001.

PERREY, S.; CANDAU, R.; ROUILLON, J.D.; HUGHSON, R.L. The effect of prolonged 
submaximal exercise on gas exchange kinetics and ventilation during heavy exercise in humans. European Journal of Applied Physiology, Berlin, v. 89, p. 587-594, 2003.

PIEHL, K. Time course for refilling of glycogen stores in human muscle fibres following exercise-induced glycogen depletion. Acta Physiologica Scandinavica, Stockholm, v. 90, p. 297-302, 1974.

PICHON, A.P.; DE BISSCHOP, C.; ROULAUD, M.; DENJEAN, A.; PAPELIER, Y. Spectral analysis of heart rate variability during exercise in trained subjects. Medicine and Science in Sports and Exercise, Madison, v. 36, p. 1702-1708, 2004.

PODOLIN, D. A.; MUNGER, P. A.; MAZZEO, R. S. Plasma catecholamine and lactate response during graded exercise with varied glycogen conditions. Journal of Applied Physiology, Bethesda, v. 71(4), p. 1427-1433, 1991.

POOLE, D.C.; BARSTOW, T.J.; GAESSER, G.A.; WILLIS, W.T.; WHIPP. B.J. VO $\mathrm{VO}_{2}$ slow component: physiological and functional significance. Medicine and Science in Sports and Exercise, Madison, v. 26, p. 1354-1358, 1994.

PRUSACZYK, W. K.; CURETON, K. J.; GRAHAM, R. E.; RAY, C. A. Differential effects of dietary carbohydrate on RPE at the lactate and ventilatory thresholds. Medicine and Science in Sports and Exercise, Madison, v. 24, p. 568-575, 1992.

REN, J.M.; BROBERG, S.; SAHLIN, K.; HULTMAN, E. Influence of reduced glycogen level on glycogenolysis during short-term stimulation in man. Acta Physiologica Scandinavica, Stockholm, v. 139, p. 467-474, 1990.

RIBEIRO, J.P. Metabolic and ventilatory thresholds during exercise. Physiological and methodological aspects. Arquivos Brasileiro de Cardiologia, São Paulo, v.64, p. 171-181, 1995.

RIBEIRO, J.P.; FIELDING, R.A.; HUGHES, V.; BLACK, A.; BOCHESE, M.A.; KNUTTGEN, H.G. Heart rate break point may coincide with the anaerobic threshold and not the aerobic threshold. International Journal of Sports Medicine, Stuttgart, v.6, p. 220-224, 1985.

RIBEIRO, J.P.; HUGHES, V.; FIELDING, R.A.; HOLDEN, W.; EVANS, W.; KNUTTGEN. Metabolic and ventilatory responses to steady state exercise relative lactate thresholds. European Journal of Applied Physiology, Berlin, v.55, p. 215-221, 1986a.

RIBEIRO, J.P.; YANG, J.; ADAMS, R.P.; KUCA, B.; KNUTTEN, H.G. Effect of different incremental exercise protocols on the determination of lactate and ventilatory thresholds. 
Brazilian Journal of Medical Biological Research, Ribeirão Preto, v. 19, p. 109-117, 1986b. RICHARDSON, R.S.; TAGORE, K.; HASELER, L.J.; JORDAN, M.; WAGNER, P.D. Increased $\mathrm{VO}_{2 \max }$ with right-shifted $\mathrm{Hb}-\mathrm{O}_{2}$ dissociation curve at a constant $\mathrm{O}_{2}$ delivery in $\operatorname{dog}$ muscle in situ. Journal of Applied Physiology, Bethesda, v. 84, p. 995 - 1002, 1998.

RICHTER, E.A.; GALBO, H. High glycogen levels enhance glycogen breakdown in isolated contracting skeletal muscle. Journal of Applied Physiology, Bethesda, v. 61, p. 827 - 831, 1986.

RILEY, M.L.; ISRAEL, R.G.; HOLBERT, D.; TAPSCOTT, E.B.; DOHM, G.L. Effect of carbohydrate ingestion on exercise endurance and metabolism after a 1-day fast. . International Journal of Sports Medicine, Stuttgart, v. 9, p. 320-324, 1988.

ROBERTS, D.; SMITH, D.J. Biochemical aspects of peripheral muscle fatigue: A review. Sports Medicine, Auckland, v. 7, p. 125-138, 1989.

ROMIJN, J.A.; COYLE, E.F.; SIDOSSIS, L.S.; GASTALDELLI, A.; HOROWITZ, J.F.; ENDERT, E.; et al. Regulation of endogenous fat and carbohydrate metabolism in relation to exercise intensity and duration. American Journal Physiology (Endocrinol. Metab.), Bethesda, v. 265, p. E380-391, 1993.

SHEARER, J.; GRAHAM, T.E. Novel aspects of skeletal muscle glycogen and its regulation during rest and exercise. Exercise and Sports Science Reviews, Baltimore, v. 32, p. 120-126, 2004.

SLAWINSKI, J.; DEMARLE1, A.; KORALSZTEIN, J.-P.; BILLAT, V. Effect of supralactate threshold training on the relationship between mechanical stride descriptors and aerobic energy cost in trained runners. Archives of Physiology and Biochemistry, Lisse, v. 109, p. 110-116, 2001.

SPENCER, M.K.; KATZ, A. Role of glycogen in control of glycolysis and IMP formation in human muscle during exercise. American Journal of Physiology (Endocrinol. Metab.), Bethesda, v. 260, p. E859-E864, 1991.

SPENDIFF, O.; CAMPBELL, I.G. The effect of glucose ingestion on endurance upper-body exercise and performance. International Journal of Sports Medicine, Stuttgart, v. 23, p. 142-147, 2002.

SHEPHARD, R.J. Chronic fatigue syndrome. Sports Medicine, Auckland, v. 31, p. 167-194, 2001. 
STAINSBY, W.N. Biochemical and physiological bases for lactate production. Medicine and Science in Sports and Exercise, Madison, v.18, p.341-343, 1986.

ST CLAIR GIBSON, A.; BADEN, D.A.; LAMBERT, M.I.; LAMBERT, E.V.; HARLEY, Y.X.; HAMPSON, D.; RUSSELL, V.A.; NOAKES, T.D. The conscious perception of the sensation of fatigue. Sports Medicine, Auckland, v. 33, p. 167-176, 2003.

ST CLAIR GIBSON, A.; NOAKES, T.D. Evidence for complex system integration and dynamic neural regulation of skeletal muscle recruitment during exercise in humans. British Journal of Sports Medicine, London, v. 38, p.797-806, 2004.

ST CLAIR GIBSON, A.; SCHABORT, E.J.; NOAKES, T.D. Reduced neuromuscular activity and force generation during prolonged cycling. American Journal of Physiology: Regulatory, Integrative and comparative physiology, Bethesda, v. 281, p. R187 - R196, 2001.

STEWART, R.D.; DUHAMEL, T.A.; FOLEY, K.P.; OUYANG, J.; SMITH, I.C.; GREEN, H.J. Protection of muscle membrane excitability during prolonged cycle exercise with glucose supplementation. Journal of Applied Physiology, Bethesda, v. 103, p. 331-339, 2007.

STORLIE, J. Nutrition assessment of athletes: a model for integrating nutrition and physical performance indicators. International Journal of Sport Nutrition, Champaign, v.1, p.192209, 1991.

SWART, J.; LAMBERTS, R.P.; LAMBERT, M.I.; ST CLAIR GIBSON, A.; LAMBERT, E.V.; SKOWNO, J.; NOAKES, T.D. Exercising with reserve: Evidence that the CNS regulates prolonged exercise performance. British Journal of Sports Medicine, London, 2008 Dec 3. [Epub ahead of print].

TAYLOR, J.L.; BUTLER, J.E.; GANDEVIA, S.C. Changes in muscle afferents, motoneurons and motor drive during muscle fatigue. European Journal of Applied Physiology, Berlin, v. 83, p. 106-115, 2000.

TAYLOR, J.L.; GANDEVIA, S.C. A comparison of central aspects of fatigue in submaximal and maximal voluntary contractions. Journal of Applied Physiology, Bethesda, v. 104, p.542-550, 2008.

TIMMONS, B.W.; BAR-OR, O. RPE during prolonged cycling with and without carbohydrate ingestion in boys and men. Medicine and Science in Sports and Exercise, 
Madison, v. 35, p. 1901-1907, 2003.

TSINTZAS, O.K.; WILLIAMS, C.; BOOBIS, L.; GREENHAFF, P. Carbohydrate ingestion and single muscle fiber glycogen metabolism during prolonged running in man. Journal of Applied Physiology, Bethesda, v. 81, p.801-809, 1995.

TUCKER, R.; BESTER, A.; LAMBERT, E.V.; NOAKES, T.D.; VAUGHAN, C.L.; ST CLAIR GIBSON, A. Non-random fluctuations in power output during self-paced exercise. British Journal of Sports Medicine, London, v. 40, p. 912-917, 2006.

TUCKER, R. The anticipatory regulation of performance: The physiological basis for pacing strategies and the development of a perception-based model for exercise performance. British Journal of Sports Medicine, London, 2009 Feb 17. [Epub ahead of print].

UTTER, A.C.; KANG, J.; ROBERTSON, R.J.; NIEMAN, D.C.; CHALOUPKA, E.C.; SUMINSKI, R.R.; PICCINNI, C.R. Effect of carbohydrate ingestion on ratings of perceived exertion during a marathon. Medicine and Science in Sports and Exercise, Madison, v. 34, p. 1779-1784, 2002.

VANDENBERGHE K, HESPEL P, EYNDE BV, LYSENS R, RICHTER EA. No effect of glycogen level on glycogen metabolism during high intensity exercise. Medicine and Science in Sports and Exercise, Madison, v. 27, p. 1278-83, 1995.

VISSING, J.; LEWIS, S.F.; GALBO, H.; HALLER, R.G. Effect of deficient muscular glycogenolysis on extramuscular fuel production in exercise. Journal of Applied Physiology, Bethesda, v. 72, p.1773-1779, 1992.

VOLLESTAD, N.K.; VAAGE, O.; HERMANSEN, L. Muscle glycogen depletion patterns in type I and subgroups of type II fibres during prolonged severe exercise in man. Acta Physiologica Scandinavica, Stockholm, v. 122, p. 433-441, 1984.

WAGENMAKERS, A.J.; BECKERS, ED.J.; BROUNS, F.; KUIPERS, H.; SOETERS, P.B.; VUSSE, G.J.V.D.; SARIS, W.H.M. Carbohydrate supplementation, glycogen depletion, and amino acid metabolism during exercise. American Journal of Physiology (Endocrinol. Metab.), Bethesda, v. 260, p. E883-E890, 1991.

WAGNER, P.D. New ideas on limitations to $\mathrm{VO}_{2 \max }$. Exercise and Sports Science Reviews, Baltimore, v. 28, p. $10-14,2000$.

WAHREN, J.; FELIC, P.; AHLBORG, G.; JORFELDT, L. Glucose Metabolism during Leg 
Exercise in Man. The Journal of Clinical Investigation, New Haven, v. 50, p. 2715-2725, 1971.

WELTAN, S.M.; BOSCH, A.N.; DENNIS, S.C.; NOAKES, T.D. Influence of muscle glycogen content on metabolic regulation. American Journal of Physiology (Endocrinol. Metab.), Bethesda, v. 274, p. E72-E82, 1998.

WELTMAN, A.; WELTMAN, J.; RUTT, R.; SEIP, R.; LEVINE, S.; SNEAD, D.; KAISER, D.; ROGOL, A. Percentages of maximal heart rate, heart rate reserve, and $\mathrm{VO}_{2 \text { peak }}$ for determining endurance training intensity in sedentary women. International Journal of Sports Medicine, Stuttgart, v. 10, p. 212-216, 1989.

WESTERBLAD, H.; ALLEN, D.G.; LANNERGREN, J. Muscle fatigue: lactic acid or inorganic phosphate the major cause? News in Physiological Sciences, Baltimore, v. 17, p. 17- 21, 2002.

WHIPP, B.J. The component of $\mathrm{O}_{2}$ uptake kinetics during heavy exercise. Medicine and Science in Sports and Exercise, Madison, v. 26, p. 1319-1326, 1994.

WHIPP, B.J.; WASSERMAN, K. Oxygen uptake kinetics for various intensities of constantload work. Journal of Applied Physiology, Bethesda, v. 33, p.351-356, 1972. 


\section{ANEXOS}

ANEXO 1 - Permissão de reimpressão da figura 4.

$\begin{array}{ll}\text { From: } & \text { "Adriano Eduardo Lima Silva" <limasilvaae@hotmail.com> } \\ \text { To: } & \text { <pripka@the-aps.org> } \\ \text { Date: } & \text { 2/3/2006 1:26:13 PM } \\ \text { Subject: } & \text { request for print figure }\end{array}$

Hello. My name is Adriano and I am from Brazil. I need copy the figure 1 in Graham's articles ( Graham TE, Adamo KB, Sheare J, Marchand I, Saltin B.

Pro-and macroglycogenolysis: relationship with exercise intensity and

duration. J Appl Physiol 2001; 90: 873-879) for print in local journals.

How can I to get the permission?

Thanks

Adriano

THE AMERICAN PHYSIOLOGICAL SOCIETY 9650 Rocktille Pike-Bethesda, MD 20814-3991

Permission is granted for use of the material specified above provided the publication is credited as the source, including the words "used with permission."

$$
\text { Margaer Reich }
$$

Publications Manager \& Executive Editor 
ANEXO 2 - Termo de consentimento informado.

ESCOLA DE EDUCAÇÃO FÍSICA E ESPORTE

DA

UNIVERSIDADE DE SÃO PAULO

Formulário $\mathrm{E}$

TERMO DE CONSENTIMENTO LIVRE E ESCLARECIDO

(Instruções para preenchimento no verso)

\section{I - DADOS DE IDENTIFICAÇÃO DO SUJEITO DA PESQUISA OU RESPONSÁVEL LEGAL

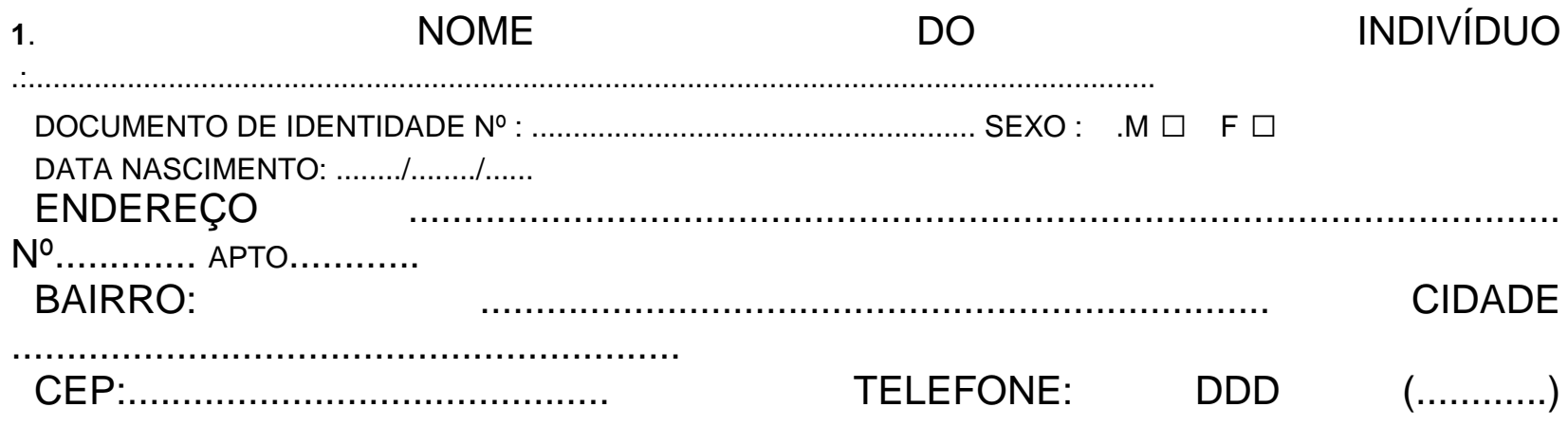

\section{RESPONSÁVEL}

LEGAL:

NATUREZA (grau de parentesco, tutor, curador, etc.)

DOCUMENTO DE IDENTIDADE :....................................XXO: M $\square \quad F$

DATA NASCIMENTO.: ....................

ENDEREÇO:

BAIRRO:

№

APTO:

CEP:

TELEFONE: DDD

CIDADE:

\section{II - DADOS SOBRE A PESQUISA CIENTÍFICA}

1. TÍTULO DO PROJETO DE PESQUISA Efeitos da depleção do glicogênio muscular sobre o desempenho em exercícios de alta intensidade

2. PESQUISADOR RESPONSÁVEL Maria Augusta Peduti Dal' Molin Kiss

3. CARGO/FUNÇÃO Professora Titular

4. AVALIAÇÃO DO RISCO DA PESQUISA:

$\begin{array}{ll}\text { RISCO MÍNIMO } & \text { RISCO MÉDIO } \\ \text { RISCO BAIXO } \square & \text { RISCO MAIOR }\end{array}$


(probabilidade de que o indivíduo sofra algum dano como consequência imediata ou tardia do estudo)

5. DURAÇÃO DA PESQUISA: 24 MESES (01/07/2007 a 01/07/2009).

\section{III - EXPLICAÇÕES DO PESQUISADOR AO INDIVÍDUO OU SEU REPRESENTANTE LEGAL SOBRE A PESQUISA, DE FORMA CLARA E SIMPLES, CONSIGNANDO:}

\section{Justificativa e os objetivos da pesquisa;}

O objetivo deste estudo será avaliar o efeito da depleção das reservas de carboidratos do músculo esquelético sobre o tempo de exaustão em exercícios supramáximos. O estudo se justifica, principalmente, para o conhecimento do comportamento do metabolismo durante exercícios físicos intensos, pois este tipo de exercício é freqüentemente utilizado por indivíduos com objetivos de melhora do rendimento esportivo. Este conhecimento é necessário para uma melhor orientação e prescrição do treinamento, além de fornencer conhecimento adicional sobre as estratégias dietéticas a serem adotadas pelos atletas no período pré-competitivo.

\section{Procedimentos que serão utilizados e propósitos, incluindo a identificação dos procedimentos que são experimentais.}

Você será submetido, inicialmente, a uma avaliação antropométrica para determinação do percentual de gordura e a um teste de incremento progressivo até a exaustão (esforço máximo), para determinação da sua capacidade e potência aeróbia. Durante esse teste você estará sendo assistido pelo pesquisador gerente prof Ms Adriano Eduardo Lima da Silva e por um médico cardiologista, que irá acompanhar o comportamento elétrico do seu coração através do eletrocardiograma. $O$ acompanhamento do eletrocardiograma durante o esforço aumenta a segurança do teste que você irá realizar. Após no minímo 48 horas, você irá realizar dois testes de carga constante até a exaustão. Um teste será realizado com as reservas de carboidratos no músculo abaixo do normal, enquanto o outro com as reservas normais. A ordem desses testes será determinada aleatoriamente. Para induzir as condições experimentais você deverá comparecer ao laboratório 48 horas antes do teste e pedalar durante 90 minutos em uma carga constante, seguido por cinco minutos de repouso e séries até exaustão de um minuto de esforço intercalado por um minuto de pausa. Nas 48 horas subsequentes você irá consumir um dieta pobre em carboidrato (10\%) ou rica em carboidrato (65\%), ambas prescrita por uma nutricionista. A professora Dra. Maria Augusta, médica, fará coletas de sangue (microamostras de $25 \mu \mathrm{l}$ ) após perfuração no lóbulo da orelha com uma agulha descartável, para determinação das concentrações de lactato no sangue apenas durante o teste progressivo. Nos testes de carga constante, serão coletados $10 \mathrm{ml}$ de sangue da veia localizada no braço, sendo as coletas feitas imediatamente antes, após o término e durante os minutos três, cinco, sete e dez da recuperação. A amostra de sangue será obtida através de um cateter butterfly, inserido na veia braquial, semelhante ao procedimento utilizado em análises clinicas (clínica médicas, laboratórios e hospitais). O cateter também será fixado pela professora Dra. Maria Augusta. Vale ressaltar que todo o material utilizado para coleta de sangue é descartável. 


\section{Desconfortos e riscos esperados}

Os principais riscos envolvidos neste estudo estão relacionados ao teste progressivo até exaustão (máximo) e à coleta de sangue. Dentre os possíveis desconfortos do teste máximo estão náuseas, vômitos e enjôos. Entretanto, menos de $1 \%$ da população americana apresenta desconforto extremo durante este tipo de teste (American College of Sports Medicine). O desconforto da coleta se refere à inserção da agulha. Entretanto, as análises descritas acima são rotineiras em laboratórios clínicos, com poucos casos de desconforto excessivo por parte dos pacientes. Antes da perfuração com a agulha, o local será umedecido com álcool para antissepsia, para evitar riscos de contaminação. Todos os procedimentos serão realizados com o responsável pelas coletas utilizando luvas cirurgicas.

\section{Benefícios que poderão ser obtidos}

Os benefícios do estudo estão, principalmente, em se conhecer o comportamento metabólico durante exercícios físicos intensos supramáximos e a importância das reservas de glicogênio muscular sobre o desempenho nesse tipo de exercício. Este conhecimento torna-se necessário para uma melhor orientação e prescrição do treinamento. Além disto, você receberá as informações sobre seu estado de saúde atual (cardiorrespiratória), percentual de gordura e a prescrição de exercícios (se desejar).

\section{Procedimentos alternativos que possam ser vantajosos para o indivíduo}

O teste progressivo máximo deverá ser feito com jejum de aproximadamente 2 horas, para diminuir os riscos de desconforto. Esse teste será acompanhado pro um médico. Na coleta de sangue dos testes de carga constante, além da antissepsia local, serão utilizados materiais cirurgicos descartáveis, e a inserção do cateter será realizado com o indivíduo deitado confortavelmente. Ao sinal de qualquer sintoma de desconforto, durante qualquer fase do estudo, os procedimentos serão interrompidos.

\section{IV - ESCLARECIMENTOS DADOS PELO PESQUISADOR SOBRE GARANTIAS DO SUJEITO DA PESQUISA:}

1. Acesso, a qualquer tempo, às informações sobre procedimentos, riscos e

benefícios relacionados à pesquisa, inclusive para dirimir eventuais dúvidas.

Os resultados obtidos durante este estudo serão mantidos em sigilo e apenas serão divulgados em publicações científicas, não sendo mencionados dados pessoais. Caso desejar, poderá pessoalmente tomar conhecimento dos resultados ao final das etapas do estudo, e/ou eventuais esclarecimentos sobre todos os procedimentos em qualquer fase do estudo. 
2. Liberdade de retirar seu consentimento a qualquer momento e de deixar de participar do estudo, sem que isto traga prejuízo à continuidade da assistência;

Há a liberdade de desistir ou de interromper a colaboração neste estudo no momento em que desejar, sem necessidade de qualquer explicação. A desistência não causará nenhum prejuízo à saúde ou bem estar físico, e ficamos à disposição para eventuais dúvidas, mesmo após o término do estudo ou da sua retirada dele.

\section{Salvaguarda da confidencialidade, sigilo e privacidade;}

Os resultados obtidos durante este estudo serão mantidos em sigilo, e apenas serão divulgados em publicações científicas, através de média e desvio padrão (ou outras medidas de tendência central), sem que os dados pessoais sejam mencionados.

4. Disponibilidade de assistência no HU ou HCFMUSP, por eventuais danos à saúde, decorrentes da pesquisa

Qualquer possível desconforto provocado pelos procedimentos desta pesquisa será prontamente atendido no próprio local (por pessoal capacitado), e/ou em casos mais cuidadosos, terá assistência médica no HU ou na HCFMUSP, sem qualquer ônus.

V - INFORMAÇÕES DE NOMES, ENDEREÇOS E TELEFONES DOS RESPONSÁVEIS PELO ACOMPA-NHAMENTO DA PESQUISA, PARA CONTATO EM CASO DE INTERCORRÊNCIAS CLÍNICAS E REAÇÕES ADVERSAS.

Maria Augusta Peduti Dal' Molin Kiss

Endereço: Rua Itajaçu, no 106, Pacaembu

Cep: 01247-030

Fone: $3672-4336$

Adriano Eduardo Lima da Silva

Endereço: Rua Humberto de Campos, 41, Vila Guarani

Cep: $04311-080$

Fone: $5071-4735$

\section{OBSERV AÇÕES COMPLEMENTARES:}

\section{VII - CONSENTIMENTO PÓS-ESCLARECIDO}

Declaro que, após convenientemente esclarecido pelo pesquisador e ter entendido o que me foi explicado, consinto em participar do presente Projeto de Pesquisa
São Paulo,
de
de 20 


\section{APENDICES}

APENDICE 1 - Percepção subjetiva de esforço (PSE) geral de cada sujeito do grupo que realizou o esforço no domínio muito pesado (MP) nas três situações (controle, alto e baixo carboidrato na dieta).
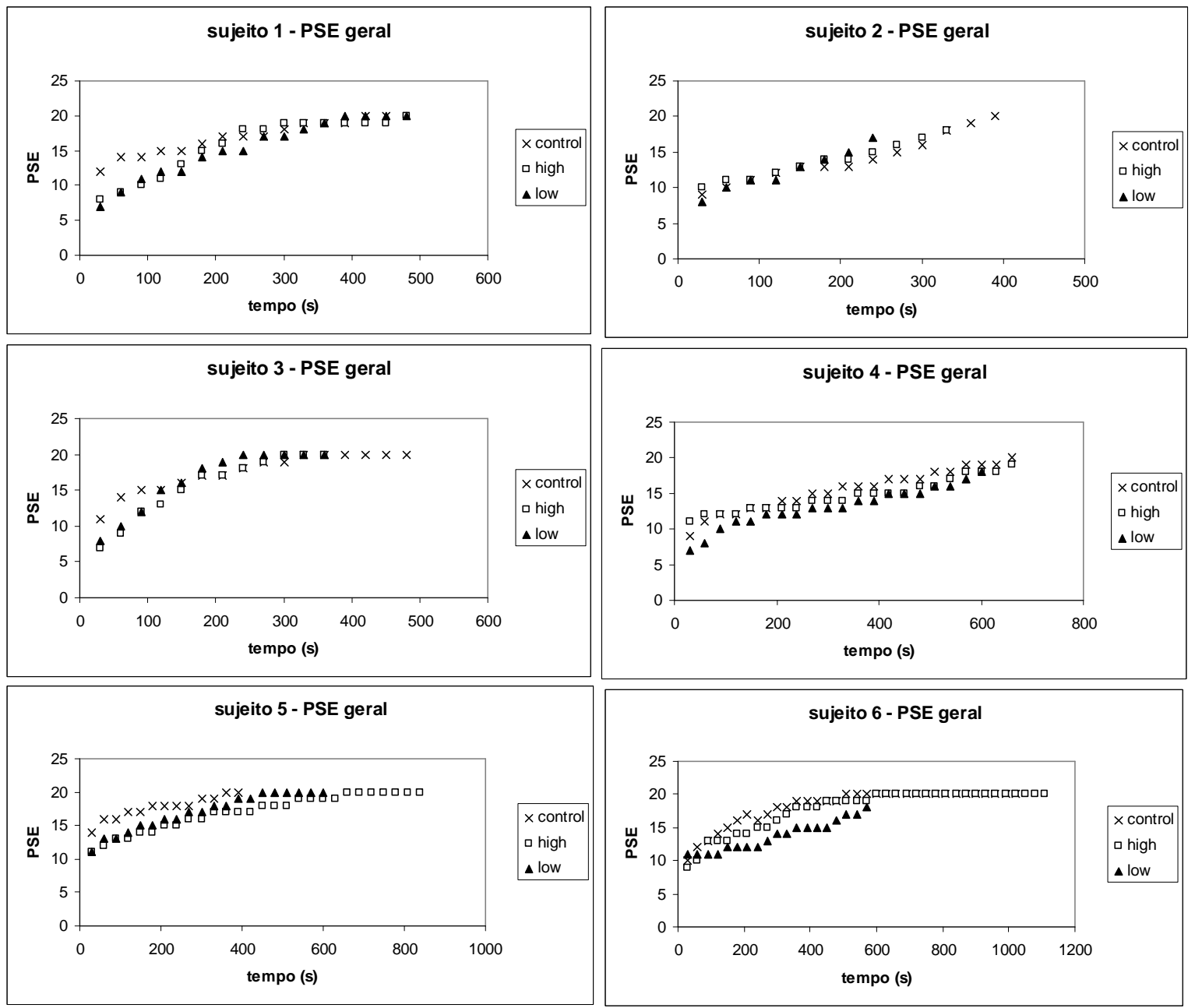
APENDICE 2 - Percepção subjetiva de esforço (PSE) local de cada sujeito do grupo que realizou o esforço no domínio muito pesado (MP) nas três situações (controle, alto e baixo carboidrato na dieta).
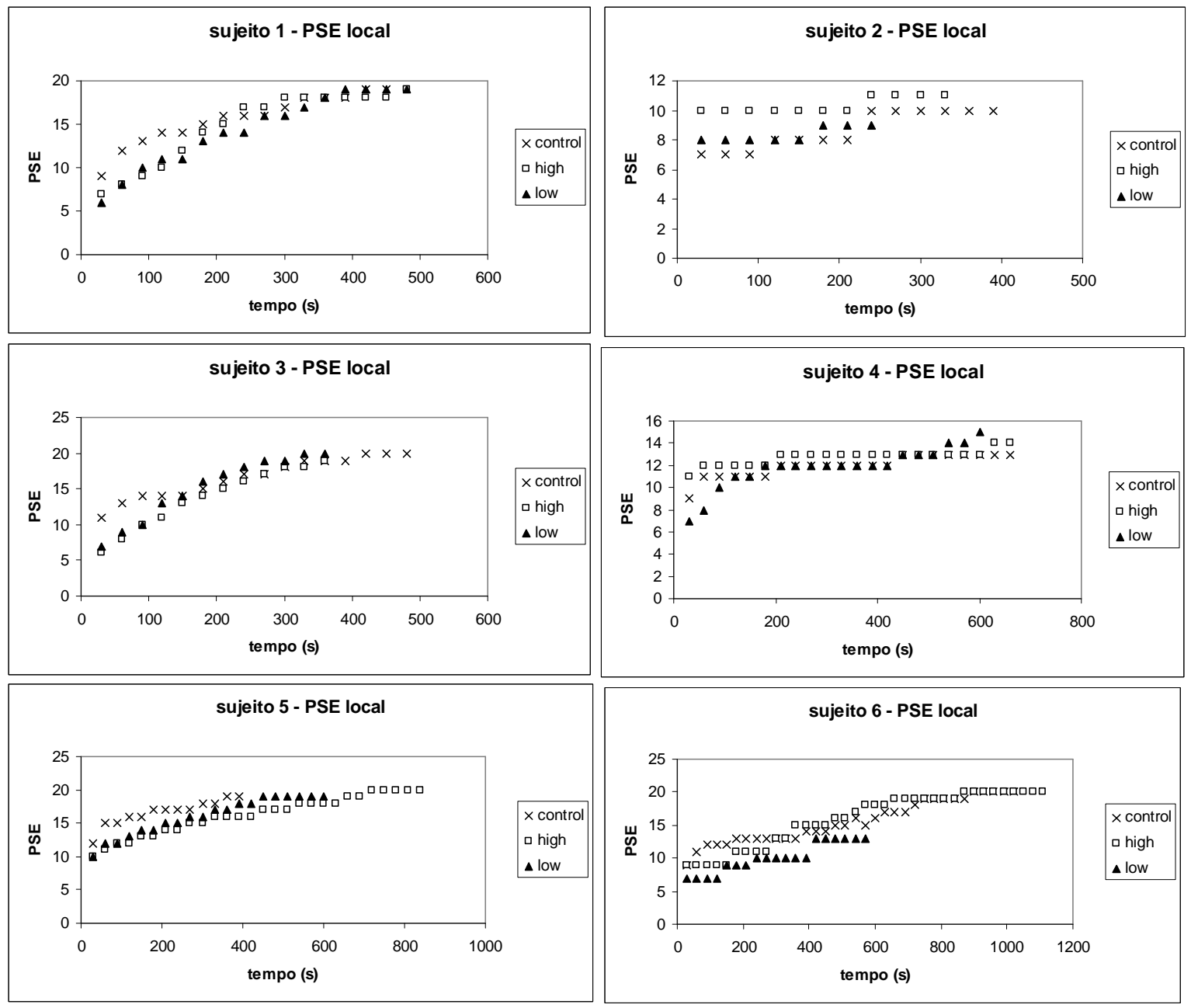
APENDICE 3 - Percepção subjetiva de esforço (PSE) geral de cada sujeito do grupo que realizou o esforço no domínio severo (SE) nas três situações (controle, alto e baixo carboidrato na dieta).
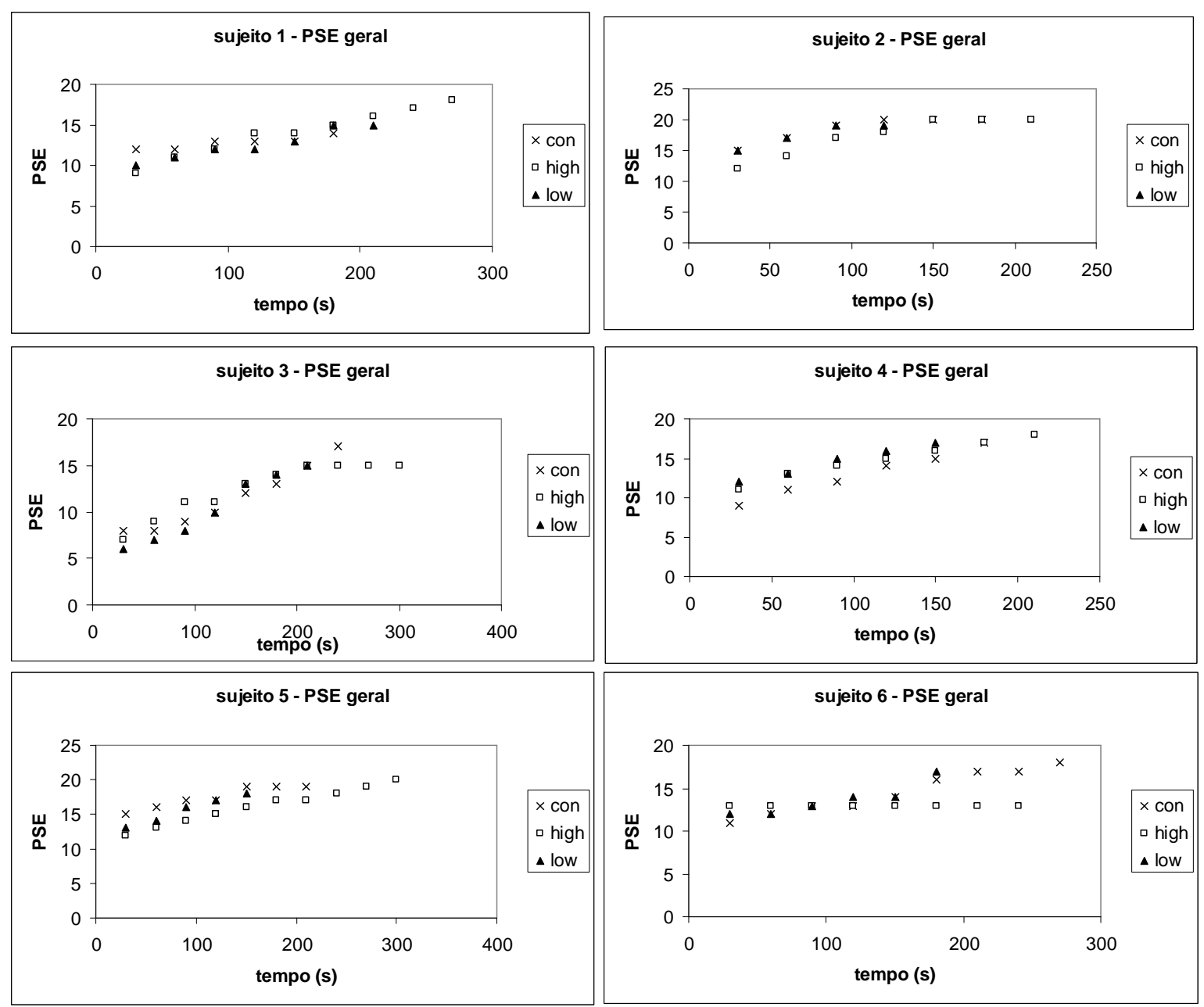
APENDICE 4 - Percepção subjetiva de esforço (PSE) local de cada sujeito do grupo que realizou o esforço no domínio severo (SE) nas três situações (controle, alto e baixo carboidrato na dieta).
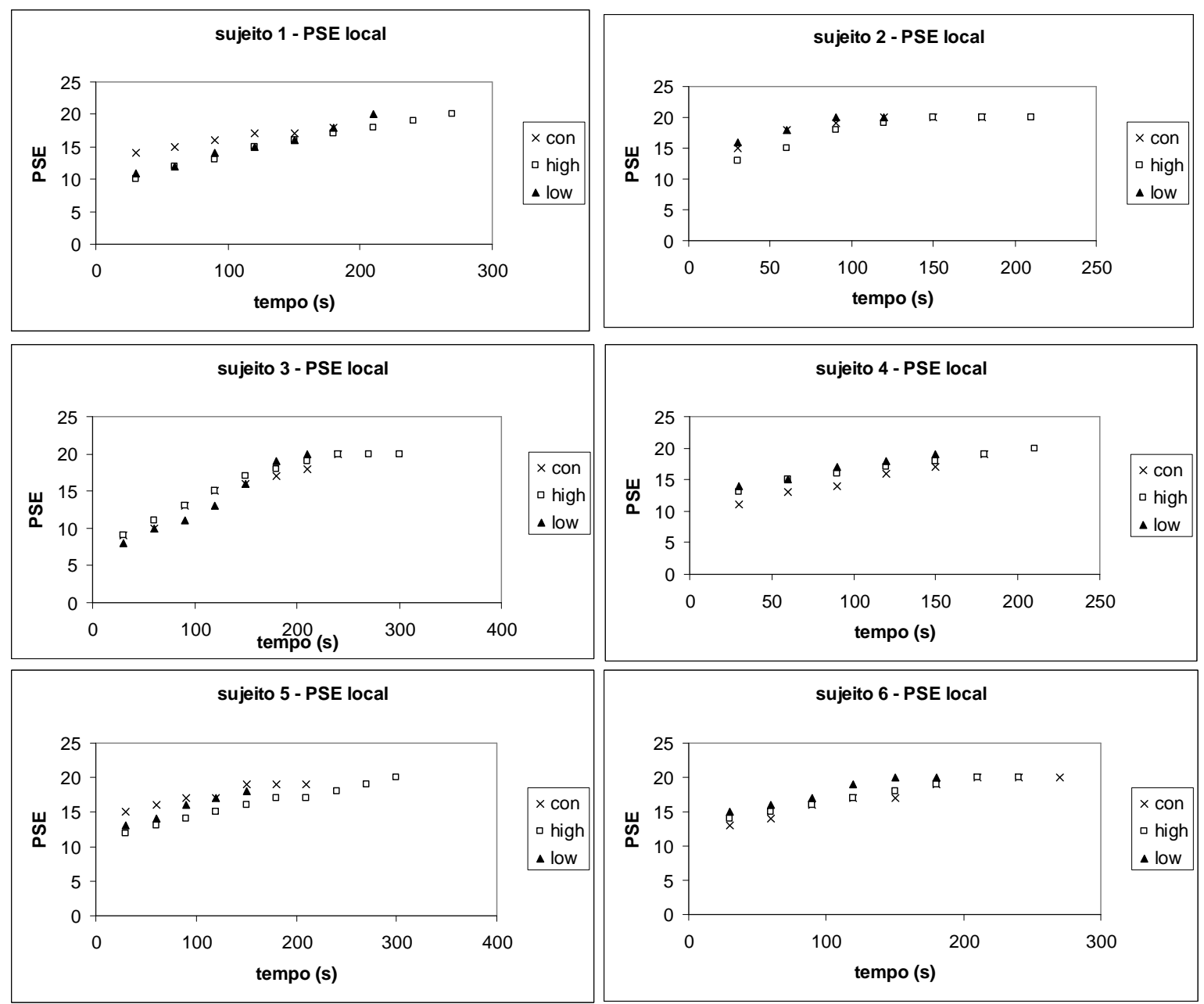